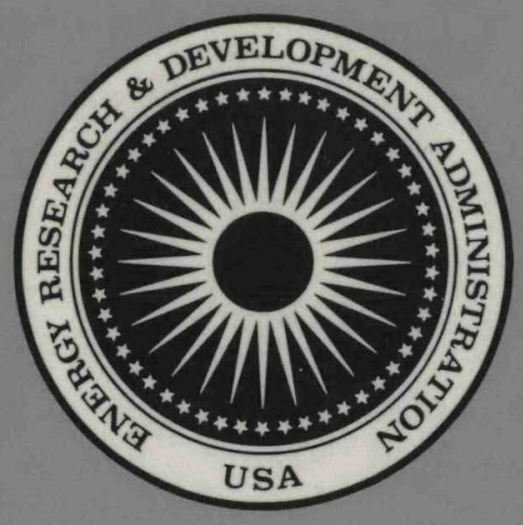

COO-2245-21TR

DEVELOPMENT OF INPUT DATA TO ENERGY CODE FOR ANALYSIS OF REACTOR FUEL BUNDLES

By

F. O. Carre

N. E. Todreas

Date Published-May 1975

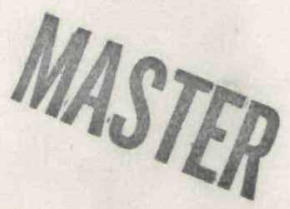

of

Department of Nuclear Engineering

Massachusetts Institute of Technology

Cambridge, Massachusetts (USA) 


\section{DISCLAIMER}

This report was prepared as an account of work sponsored by an agency of the United States Government. Neither the United States Government nor any agency Thereof, nor any of their employees, makes any warranty, express or implied, or assumes any legal liability or responsibility for the accuracy, completeness, or usefulness of any information, apparatus, product, or process disclosed, or represents that its use would not infringe privately owned rights. Reference herein to any specific commercial product, process, or service by trade name, trademark, manufacturer, or otherwise does not necessarily constitute or imply its endorsement, recommendation, or favoring by the United States Government or any agency thereof. The views and opinions of authors expressed herein do not necessarily state or reflect those of the United States Government or any agency thereof. 


\section{DISCLAIMER}

Portions of this document may be illegible in electronic image products. Images are produced from the best available original document. 


\section{NOTICE}

This report was prepared as an account of work sponsored by the United States Government. Neither the United States nor the United States Energy Research and Development Administration, nor any of their employees, nor any of their contractors, subcontractors, or their employees, makes any warranty, express or implied, or assumes any legal liability or responsibility for the accuracy, completeness or usefulness of any information, apparatus, product or process disclosed, or represents that its use would not infringe privately owned rights.

This report has been reproduced directly from the best available copy.

Available from the National Technical Information Service, U. S. Department of Commerce, Springfield, Virginia 22161

Price: Paper Copy $\$ 7.60$

Microfiche $\$ 2.25$ (domestic)

$\$ 3.75$ (foreign) 


\title{
DEVELOPMENT OF INPUT DATA TO \\ ENERGY CODE FOR ANALYSIS OF \\ REACTOR FUEL BUNDLES
}

\author{
by
}

\section{Frank Olivier CARRE}

Neil E. Todreas

NOTICE

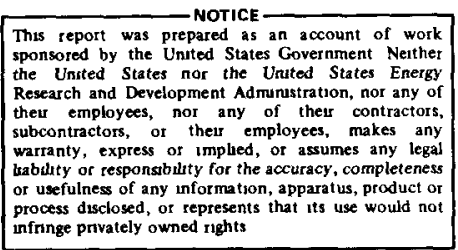

PORTIONS OF THTS PTPCTT ARE IITEETPTE. has been ranod". an reatho! st availab copy to permit the bruadest possible avai. ability.

\section{May, 1975}

\section{DEPARTMENT OF NUCLEAR ENGINEERING}

MASSACHUSETTS INSTITUTE OF TECHNOLOGY

Cambridge, Massachusetts

02139

ERDA Research and Development

Contract $\operatorname{AT}(11-1)-2245$

U.S. Energy Research and Development Administration 

TABLE OF CONTENTS

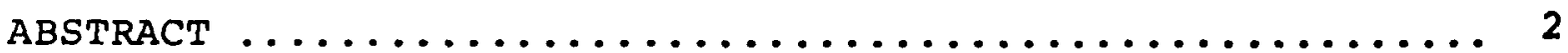

TABLE OF CONTENTS .......................... 3

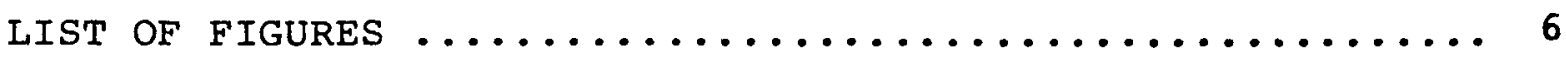

LIST OF TABLES ........................... 9

ACKNOWLEDGEMENTS $\ldots \ldots \ldots \ldots \ldots \ldots \ldots \ldots \ldots \ldots \ldots \ldots \ldots \ldots \ldots$

NOMENCLATURE $\ldots \ldots \ldots \ldots \ldots \ldots \ldots \ldots \ldots \ldots \ldots \ldots \ldots \ldots \ldots \ldots \ldots$

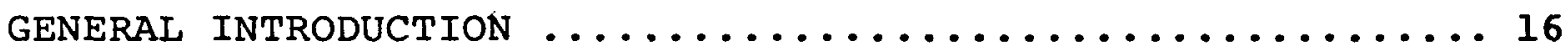

CHAPTER 1 Comparison MISTRAL II - ENERGY I .......... 19

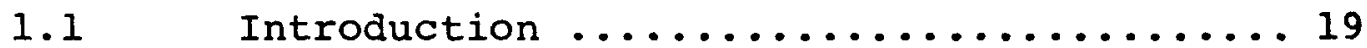

1.2 Presentation of the Two Programs

and Derivation of Their Finite

Differences Equations............... 19

1.2.1 ENERGY I (with the mesh size taken

equal to a subchannel) ............. 20

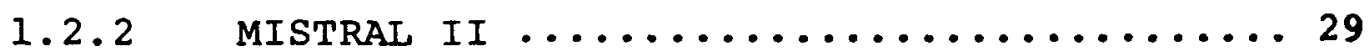

1.2.3 Comparison of the Schemes Used for Solving the Equations ................. 34

1.3 Comparison of the Finite Differences Equations Applied to all Types of subchannels ..................... 35

1.3.1 Subchannels of Type I .............. 36

1.3.2 Subchannels of Type II .............. 38

1.3.3 Subchannels of Type III ............ 40

1.3.4 Subchannels of Type IV ..............44

1.3 .5 summary $\ldots \ldots \ldots \ldots \ldots \ldots \ldots \ldots \ldots \ldots \ldots \ldots \ldots \ldots \ldots \ldots$

1.4 Relationship Between the Two Sets

of Input Parameters $\left(\varepsilon^{\star}, C\right)$ and

$(\mu, \mathrm{EF}) \quad \ldots \ldots \ldots \ldots \ldots \ldots \ldots \ldots \ldots \ldots \ldots \ldots \ldots . \ldots 46$ 
TABLE OF CONTENTS (Cont.)

1.4.1 Relation $\varepsilon^{*}=f(P, D, \mu) \ldots \ldots \ldots \ldots \ldots$

1.4.2 Relation $C=g(P, D, H, E F) \ldots \ldots \ldots \ldots \ldots$

1.4.3 Validity of the Two Correlations for an Arbitrary set of Input

data .......................... 59

$1.5 \quad$ Conclusion $\ldots \ldots \ldots \ldots \ldots \ldots \ldots \ldots \ldots \ldots \ldots \ldots \ldots$

CHAPTER 2 Gridded Bundles ....................... 69

$2.1 \quad$ Model of flow ................... 69

2.2 Predictions of ENERGY I ........... 71

2.2.1 Karlsruhe Data (Honeycomb Grids) ....... 71

2.2.2 11:1 Scale Rod Bundle Flow Test ....... 75

$2.3 \quad$ Conclusion $\ldots \ldots \ldots \ldots \ldots \ldots \ldots \ldots \ldots \ldots \ldots . \ldots . \ldots . \ldots$

CHAPTER 3 Oak Ridge National Laboratory Bundle 5C ...... 81

3.1 Introduction $\ldots \ldots \ldots \ldots \ldots \ldots \ldots \ldots \ldots \ldots$

3.2 Analysis of the Data ............... 83

3.2.1 Procedure Adopted ................ 83

3.2.2 Description of the Data ............ 86

3.2.3 Analysis of the Results ............ 87

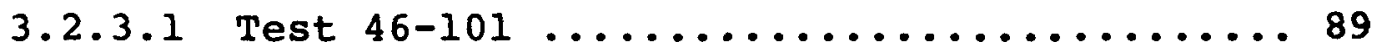

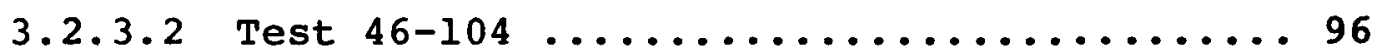

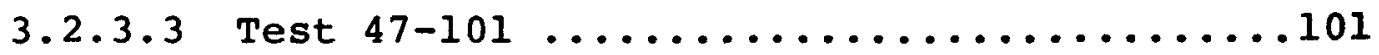

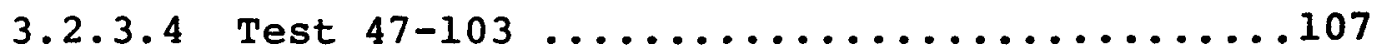

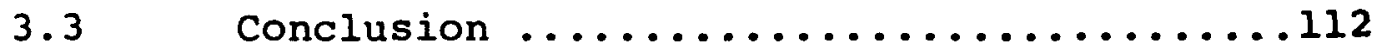

CHAPTER 4 11:1 Scale Model Clinch River Breeder

Subassembly ........................116

4.1 Introduction $\ldots \ldots \ldots \ldots \ldots \ldots \ldots \ldots \ldots \ldots \ldots \ldots$

4.2 Analysis of the Data ...............116 
TABLE OF CONTENTS (Cont.)

4.2.1 Integration Procedure ...............119

4.2.2 Analysis of the Integration

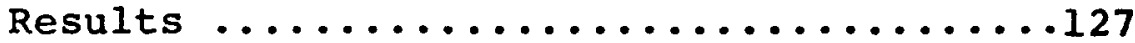

4.2.3 Special Version of ENERGY I Used

for this study ...................

4.2.4 Results of the Comparison ............

4.3 Conclusion $\ldots \ldots \ldots \ldots \ldots \ldots \ldots \ldots \ldots \ldots \ldots$

GENERAL CONCLUSION ........................136

REFERENCES .................................

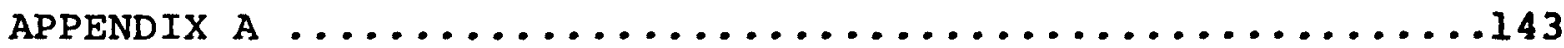

APPENDIX B ................................ 
LIST OF FIGURES

Figure Number

Title

Number

1-1 Numbering of the Rods and Subchannels

for a 217 Pins Bundle ..............

1-2 Simplified Model of Flow Assumed by

ENERGY I .......................

1-3 ENERGY I Parameters

$\left(\varepsilon_{1}^{*}, \varepsilon_{2}^{\star}, \varepsilon_{3}^{*}, \varepsilon_{4}^{*}\right.$, and $\left.C\right) \ldots \ldots \ldots \ldots \ldots \ldots$

MISTRAL II Parameters

$\left(\mu, \mu_{W}(E F), \mu_{e}(E F) \ldots \ldots \ldots \ldots \ldots \ldots \ldots \ldots \ldots \ldots \ldots\right.$

$1-5$

Mixing Parameter $\mu$ versus the Reynolds Number for Different Values of the Helical Pitch $\mathrm{H}$ in a 61 Pins Wire Wrapped Bundle $(P / D=1.32) \ldots \ldots \ldots \ldots \ldots \ldots \ldots$

Predictions of ENERGY I for the 61 Pins Karlsruhe Bundle .................

1-7 Correlations Expressing $\varepsilon^{*}$ and $C$ in Terms of the Geometrical Parameters (KHAN's Thesis)

1-8 Comparison of $\varepsilon^{*}(\mu)$ given by the correlation (23) with the General Recommendations for this Parameter ............

1-9 Temperature Profile Across the Bundle Comparison MISTRAL II - Experiment .....

1-10 Comparison of ENERGY I and MISTRAL II Predictions for a 37 Pins Bundle .......

1-11 Comparison of ENERGY I and MISTRAI II Predictions for a 37 Pins Bundle .......

1-12 Comparison of ENERGY I and MISTRAL II Predictions for a 217 Pins Bundle .......

1-13 Comparison of ENERGY I and MISTRAL II Predictions for a 217 Pins Bundle .......

2-1 Exponential Decrease of $\varepsilon *$ Behind a Grid 
LIST OF FIGURES (cont.)

Figure

Number

$\underline{\text { Title }}$

Page

Number

2-2 Spacer Honecomb Grid $\ldots \ldots \ldots \ldots \ldots \ldots$

2-3 Spacer Honecomb Grid $\ldots \ldots \ldots \ldots \ldots \ldots \ldots$

2-4 Cross-Section of Test Section

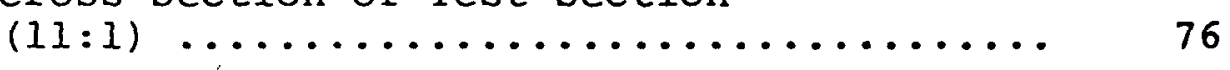

$2-5$

11:1 Scale Rod Bundle Flow Test .........

$3-1$

LMFBR-FFM Bundle 5B Instrumentation ......

82

3-2

Ratio of Side Subchannel Axial

Average Velocity to Bundle Axial

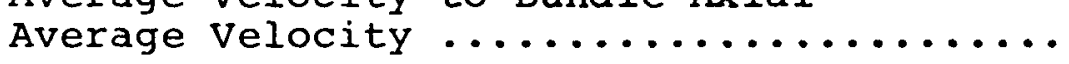

3-3 Test 46 Run 101 - ENERGY I Run 101

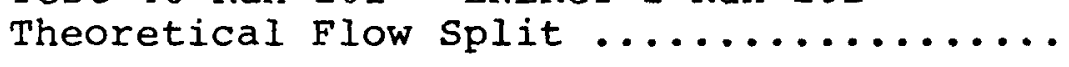

3-4 Test 46 Run 101 - ENERGY I with

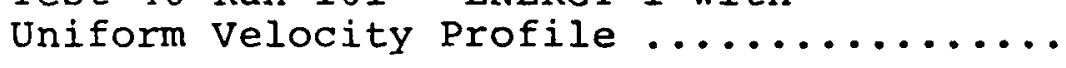

3-5 Test 46 Run 101 - SUPERENERGY with

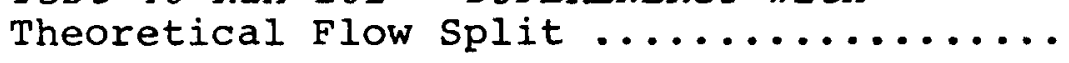

3-6 Test 46 Run 101 - Adjustment of the

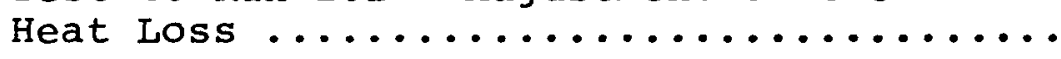

3-7 Test 46 Run 104 - ENERGY I with

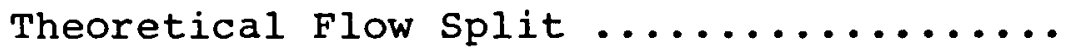

3-8 Test 46 Run 104 - ENERGY I with

Uniform Velocity Profile ..............

3-9 Test 46 Run 104 - SUPERENERGY with

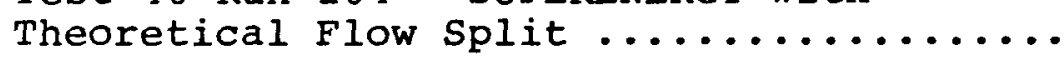

3-10 Test 47 Run 101 - ENERGY I with

Theoretical flow split ............... 102

3-11 Test 47 Run 101 - ENERGY I with

Uniform Velocity Profile ............. 104

3-12 Test 47 Run 101 - SUPERENERGY with

Theoretical Flow split ............... 
LIST OF FIGURES (Cont.)

Figure

Number

Title

Page

Number

3-13 Test 47 Run 101 - Adjustment of the

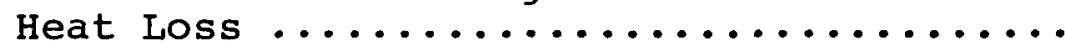

3-14 Test 47 Run 103 - ENERGY I with

Theoretical Flow split .............

3-15 Test 47 Run 103 - ENERGY I with

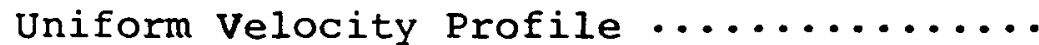

3-16 Test 47 Run 103 - SUPERENERGY with

Theoretical Flow split .............

3-17 Transverse Exit - Temperature

Profiles of Subassembly .............

4-1 Cross Section of Test - Section

(11:1)

$4-2$

Concentration Profiles 32 inches

Downstream of Injector .............

4-3 Average Concentration Profile

(Experiment A) $\ldots \ldots \ldots \ldots \ldots \ldots \ldots \ldots \ldots \ldots$

4-4 Map of the Mesh Used by the

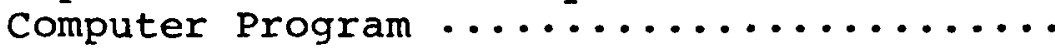

4-5 11:1 Scale Model Clinch River

Breeder Subassembly (Axial Concen-

tration Profile)

$4-6$

11:1 Scale Model Clinch River

Breeder Reactor Subassembly (Axial

Concentration Profile)

$4-7$

11:1 Scale Model Clinch River

Breeder Reactor Subassembly (Axial

Concentration Profile

$4-8$

Axial Variation of ENERGY I's

Parameter $\varepsilon^{*}$

A-1 Complete Map of the Mesh with its

Numbering Scheme (for the Version of ENERGY I calculating the concen-

tration Profiles) 


\section{LIST OF TABLES}

Table

Number

\section{Title}

Page

Number

1-I Relations Between the Two Sets of

Input Parameters $(\varepsilon, C)$ and $(\mu, E F)$

Corresponding to the Best Fit ..........

1-II Values of $\mu$ and $\varepsilon$ * for the Karlsruhe

61 Pins Bundle ....................

1-III Calculation of $\varepsilon^{*}(\mu)$ with the Corre-

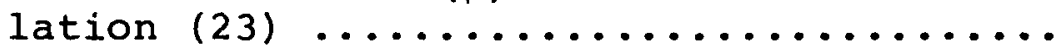

2-I Concentration Measurements in the

11: I Scale Rod Bundle Flow Test

Equipped with Grids ................

2-II ENERGY I's Prediction of the con-

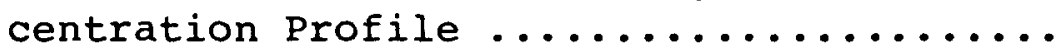

3-I Comparison of the Flow split for

Bundles $2 \mathrm{~A}$ and $5 \mathrm{C} \ldots \ldots \ldots \ldots \ldots \ldots \ldots$ 


\section{ACKNOWLEDGEMENTS}

I am extremely grateful to Professor N.E. TODREAS for giving me the opportunity to work on this problem, for his patience and help during the course of this research.

I would like to thank Dr. L. WOLF for giving his time for several useful discussions and for bringing to my notice reports from Karlsruhe.

In addition, I am thankful to E.U. KHAN for several interesting discussions.

Finally, I would like to express a deep gratitude to Ms P. Batchelder for her excellent work in typing.

I do not forget the helpful comments on my work and the efficient participation in our joint modification of the computer program ENERGY I, of my friend B.J. CHEN. 


\section{NOMENCLATURE}

$\Delta \mathrm{x}$

$\Delta \mathrm{y}_{i j}$

$\Delta Y_{I}$

$\Delta y_{I I}$

$\Delta \mathrm{Y}_{\text {I I I }}$

$\Delta \mathrm{Y}_{\mathrm{IV}}$

$\mathbf{s}_{i j}$

w

$F_{\mathbf{S}}$

$\mathrm{F}_{\text {I }}$

$\mathrm{F}_{\text {II }}$

FII

$\psi_{\mathrm{m}}$
Increment of axial distance

Average distance between the subchannels $i$ and $j$

Average distance between two triangular subchannels

Average distance between a triangular and a wall subchannel

Average distance between two wall subchannels

Average distance between a wall and a corner subchannel

Distance between the edges of the two rods located at the interface of the subchannels $i$ and $j$

Distance separating the outside diameter of the last row of rods from the wall

Surface of the subchannel number $\mathbf{s}$

Surface of a triangular subchannel

Surface of a wall subchannel

Surface of a corner subchannel

Linear power transmitted to the subchannel $m$ by the neighboring rods
$\Delta \mathbf{z}$

$n_{i j}$

$n_{I}$

$n_{I I}$

NIII

${ }^{n}$ IV

(P-D)

g

$A_{\mathbf{s}}$

$\mathrm{A}_{\mathrm{I}}$

${ }^{A_{I I}}$

$\mathrm{A}_{\text {III }}$

$Q_{m}^{\prime}=A_{m} Q_{m}^{\prime \prime \prime}$ 
NOMENCLATURE (Cont.)

MISTRAL II

ENERGY I

$\dot{\mathrm{M}}_{\mathrm{s}}, \overline{\mathrm{V}}_{\mathrm{S}}$

Mass flow rate through the subchannel number $s$; axial velocity

$\dot{\mathrm{M}}_{\mathbf{s}^{\prime}} \overline{\mathrm{V}}_{\mathbf{s}}$

$\dot{\mathrm{M}}_{I}, \overline{\mathrm{V}}_{\mathrm{I}}$

Mass flow rate and average velocity of the coolant through a tri-

$\dot{\mathrm{M}}_{I}, \overline{\mathrm{V}}_{\mathrm{I}}$ angular subchannel

$\dot{\mathrm{M}}_{I I}, \overline{\mathrm{v}}_{\mathrm{II}}$

Mass flow rate and average velocity of the coolant through a wall subchannel

$\dot{\mathrm{M}}_{I I I}, \overline{\mathrm{v}}_{I I I}$

Mass flow rate and average velocity of the coolant through a corner subchannel

$\dot{\mathrm{M}}, \overline{\mathrm{V}}$

Mass flow rate and average velocity of the coolant through the bundle

$\dot{\mathrm{M}}_{I I}, \overline{\mathrm{v}}_{\text {II }}$

$\dot{\mathrm{M}}_{\text {III }}, \overline{\mathrm{v}}_{\text {III }}$

$\dot{\mathrm{M}}, \overline{\mathrm{V}}$

$Q_{i j}$

Heat transferred per unit of time from the subchannel $i$ to the subchannel $j$

$\rho, C p$

Density, calorific capacity of the coolant

Heat conductivity k

Efficiency factor for heat $\mathrm{K}$ conduction

$\rho, C p$

$\lambda$

f*

Ratio $\frac{\lambda}{\rho C p}=\frac{k}{\rho C p}$

$\alpha$

$\mathrm{X}_{I}, \mathrm{X}_{\text {II }}, \mathrm{X}_{\text {III }} \quad$ Ratios $\frac{\overline{\mathrm{v}}_{I}}{\overline{\mathrm{v}}}, \frac{\overline{\mathrm{v}}_{\text {II }}}{\overline{\bar{v}}}, \frac{\overline{\mathrm{v}}_{\text {III }}}{\overline{\mathrm{v}}}$

$\mathrm{X}_{I}, \mathrm{x}_{\mathrm{II}}, \mathrm{x}_{\mathrm{III}}$

$w p_{I}, D_{e I}$

Wetted parameter, hydraulic diameter of a triangular chan$w p_{I}, D_{e I}$ nel 
NOMENCLATURE (Cont.)

MISTRAL II

$H_{S}(x), T_{S}(x)$

$\mathrm{H}$

$\mathrm{De}_{\mathrm{I}}$
Average enthalpy of the coolant at the distance $(x)$ downstream from the inlet, in the subchannel(s). Average temperature

Helical pitch

Hydraulic diameter of a triangular subchannel $4 \mathrm{~A}_{I} / \mathrm{wp}_{\mathrm{I}}$
ENERGY I

$H_{S}(x), T_{S}(x)$

H

$\mathrm{De}_{\mathrm{I}}$ 
Mixing Parameters

- $\bar{V}_{\theta}$ Peripheral velocity in the gap region

- $\varepsilon$ Describes the eddy diffusivity at a boundary between two adjacent subchannels

$\varepsilon_{1}$ Value of $\varepsilon$ between two triangular subchannels

$\varepsilon_{2}$ Value of $\varepsilon$ between a triangular and a rectangular subchannel

$\varepsilon_{3}$ Value of $\varepsilon$ between two rectangular subchannels

$\varepsilon_{4}$ Value of $\varepsilon$ between a rectangular subchannel and a corner

The code ENERGY I uses a single value for these 4 parameters. The reports [4] and [5] use two different sets of parameters $\left(\varepsilon^{l^{*}},(C l)\right)$ and $\left(\varepsilon^{*}, C\right)$.

Appendix 3 of KHAN's thesis [5] gives the relation between these two sets of parameters

$$
\begin{array}{ll}
\varepsilon^{*}=\frac{\lambda_{L I}}{\bar{\lambda}_{a}} \varepsilon^{I^{*}} & \text { and } \quad \mathrm{C}=\frac{\lambda_{s}}{\bar{\lambda}_{a}} \mathrm{Cl} \\
\lambda_{L l}=1-\frac{\mathrm{D}}{\mathrm{P}} & \text { lateral porosity for region } \mathrm{I} \\
\lambda_{\mathrm{s}}=\frac{\mathrm{g}}{\mathrm{g}+\frac{\mathrm{D}}{2}} & \text { lateral porosity for region II } \\
\bar{\lambda}_{\mathrm{a}}=\frac{\text { void area }}{\text { total area }} & \text { total porosity }
\end{array}
$$

The parameters $\varepsilon^{*}$ and $C$ are used in the porous body model analysis. The parameters $\varepsilon^{1 *}$ and $C l$ are used in subchannel 
analysis; their expression in terms of $\varepsilon$ and $\bar{v}_{\theta}$ is:
$\varepsilon^{1 *}=\frac{\varepsilon}{\bar{V} D_{\text {eI }}}$
and
$C 1=\frac{\bar{v}_{\theta}}{\bar{v}}$

Combining these equations yields:

$$
\begin{aligned}
& \varepsilon^{*}=\frac{\lambda_{L l}}{\bar{\lambda}_{a}} \frac{\varepsilon}{\bar{V} D_{e I}} \\
& c=\frac{\lambda_{s}}{\bar{\lambda}_{a}} \frac{\bar{V}_{\theta}}{\bar{V}}
\end{aligned}
$$

The parameters $\varepsilon_{1}^{*}, \varepsilon_{2}^{*}, \varepsilon_{3}^{*}$ and $\varepsilon_{4}^{*}$ used in the text refer to the value $\varepsilon^{*}$ when $\varepsilon$ takes the values $\varepsilon_{1}, \varepsilon_{2}, \varepsilon_{3}$ and $\varepsilon_{4}$ at the different boundaries.

$\mu$

$\mu_{W} \equiv \frac{\pi D W}{F_{I I} H} E F$

$\mu_{e} \equiv \frac{\pi \text { D W }}{F_{\text {III }}}$ EF
Percentage of flow of a triangular subchannel deviated per unit length (cm) towards its three neighbors

Percentage of flow exchanged in the swirl flow direction per unit length (cm) at a boundary between two rectangular subchannels

Percentage of flow exchanged in the swirl flow direction per unit length (cm) at a boundary between a rectangular subchannel and a corner 
General Introduction

The ENERGY I code is a semi-empirical method for predicting temperature distributions in wire wrapped rod bundles of a Liquid Metal Fast Breeder Reactor.

In calculating the temperature, the bundle is divided into two adjacent regions:

- In the inner region, a fluctuating transverse flow modelled by an effective eddy diffusivity is superimposed on a predominantly axial flow

- In the outer region (wall), the flow is assumed to have a circumferentially uniform swirl component and an axial velocity.

This state of flow is described by two dimensionless parameters and the flow split is calculated by the method developed by NOVENDSTERN [3] assuming that the pressure is radially uniform across the bundle.

Some input parameters have already been developed [5] for the case of bundles having a constant wire wrap diameter and their dependence on various geometrical parameters has been quantitatively investigated.

This thesis consists of four separate studies about ENERGY I undertaken to investigate more accurately the limits of the domain within which the simplified flow model assumed in the code leads to correct predictions. 
- The first part is a comparison of ENERGY I with its German alternate MISTRAL II. Although the two programs use different flow models and different schemes to solve their finite difference equations, it is possible to relate their input parameters in a very simple way involving only geometrical parameters.

The three other parts analyze the predictions of ENERGY I for special sets of data taken under geometric conditions at the limits of those the code was originally intended to accommodate.

- An attempt is made to predict the temperature distribution where the wire wrap is replaced by grid spacers. The study takes into account an axial variation of the eddy diffusivity enhanced by the grids. The usual input parameters are replaced by another set and the results are checked against data.

- For tracer injection experiments, the simplified flow model assumed by ENERGY $I$ is not able to predict well the concentration profile immediately behind the injector. A set of data reporting the results obtained with the 11:1 Scale Model Clinch River Subassembly Test permits the determination of whether or not the distance at which the predictions become reliable is smaller than one fourth of the helical pitch. 
- The last part analyses the validity of ENERGY I's results, when the size of the gap, at the periphery of the bundle is reduced to its half. A set of parameters corresponding to the best fit with the ORNL 5C Bundle Data, is determined. An attempt is made to account for the heat loss occuring in the tests and to explain the discrepancy between the found set of parameters and the set recommended to yield the best fit with a bundle having a full sized gap.

These four apparently separate parts, are only different approaches of the same problem; ENERGY I code is based on simplifying assumptions and all the following studies aim to determine more accurately, the domain in which its predictions are reliable. 


\author{
CHAPTER 1 \\ COMPARISON MISTRAL II - ENERGY I
}

\title{
1.1 Introduction
}

Since 1960, numerous methods of thermal analysis of a wire wrapped rod bundle of a Liquid Metal Fast Breeder Reactor, have been developed.

The goal of this chapter is to compare the input parameters needed by two such programs based on different models of flow. Relations expressing a set of input parameters in terms of the other set, will be developed.

Bundles of several geometries have been calculated by the Karlsruhle code MISTRAL II and the values of the input parameters leading to the best fit with the experimental tests are reported in the literature.

The aim of this study is to:

1. determine the relationships between MISTRAL and ENERGY input parameters

2. determine if the recommended MISTRAL set of parameters, when converted, falls within the recommended correlation for ENERGY input parameters

1.2 Presentation of the Two Programs and Derivation of Their Finite Differences Equations

In both codes, conduction through the individual fuel rods and through the contact of the wire with two adjacent rods 
has been neglected compared to the energy transport due to the radial conduction inside the coolant and the turbulent exchange at the boundary of two adjacent subchannels. The axial conduction is also neglected.

Both codes are based on a lumped parameter approach. The rods are virtually removed and the rod equivalent heat source is replaced by equivalent volumetric heat generation inside the coolant streaming through each subchannel.

MISTRAL uses and ENERGY can use a subchannel size mesh to describe the cross section of the bundle [fig. 1-1]:

- The inner region consists of triangular subchannels (one node per subchannel)

- The wall region consists of rectangular subchannels (one node per subchannel).

(It can be noticed that MISTRAL II splits the corner channels into two symmetric parts, while the mesh size of ENERGY can be varied.)

In both codes, the flow split is determined from the hydraulic diameter flow analysis of NOVENDSTERN [3]; the flow split is fixed by the condition of a vanishing radial pressure gradient.

1.2.1 ENERGY I (with the mesh size taken equal to a subchannel)

1.2.1.1 Simplified Model of Flow

The rod array in a LMFBR fuel assembly is divided into two predominant regions: the central and the wall regions; both 


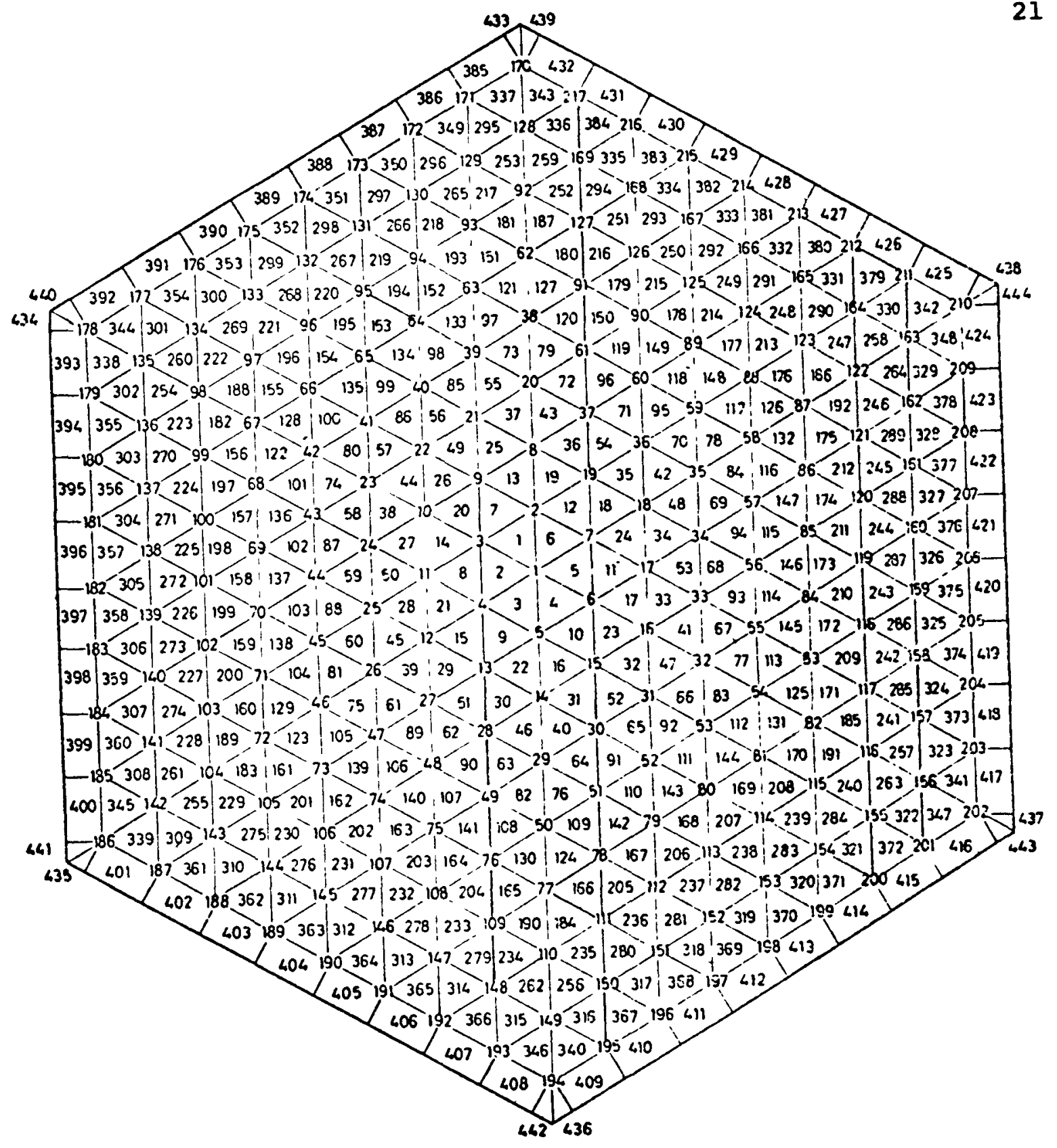

NUMBERING OF THE RODS AND SUBCHANNEIS

FOR A 217 PINS BUNDIE.

\section{FIGURE 1-1}


these regions are treated as a continuum. The basis of ENERGY's model is the existence of an axial flow having a uniform lateral eddy diffusivity $\varepsilon$ for the heat transfer in the inner region and the existence of a flow progressing with an axial component and a constant tangential component parallel to the wall [fig. 1-2], in the gap region.

\subsubsection{Formulation of the Finite Difference Equations for Both Regions}

These equations represent the energy balance of a subchannel $i$ and its three neighbors $(j, k, l)$ [fig. 1-3] written in a finite difference form. To solve them a forward difference scheme is used in the axial direction.

\subsection{Region I}

Using the notation defined in the nomenclature, the expression for the heat $Q_{i j}$ transferred per unit of time from the subchannel $j$, takes the following form in terms of finite differences of adjacent subchannel temperatures

$$
Q_{i j}=\Delta z \text { (P-D) }\left(\frac{\left(T_{i}-T_{j}\right)}{\eta_{i j}}\left(\rho C p \varepsilon_{i j}+K k\right)\right)
$$

The first term of the sum accounts for the energy transferred by exchange of flow; the second term accounts for the energy transferred by conduction.

$\varepsilon_{i j}$ is the lumped eddy diffusivity responsible for the heat transfer due to flow exchange in region $I$. 


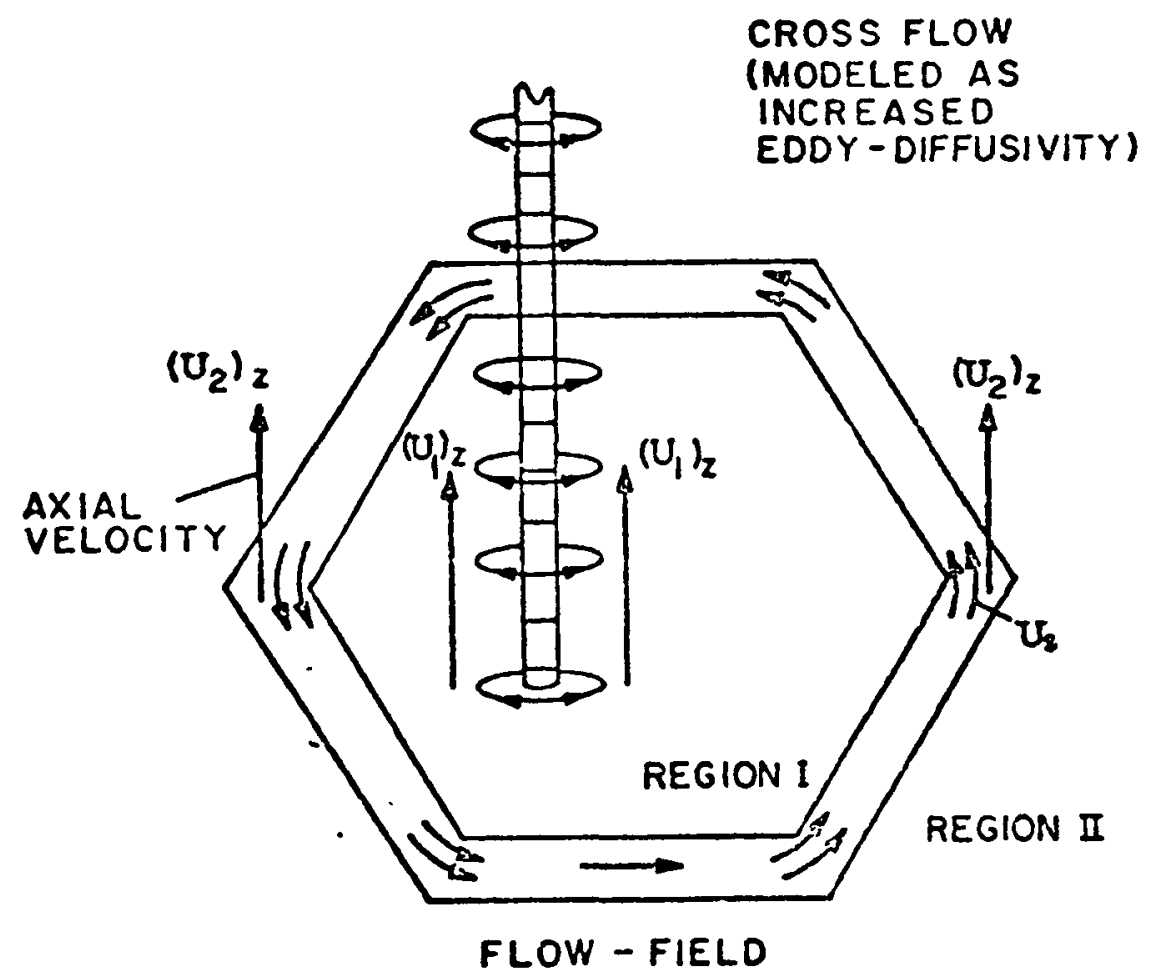

SIMPLIFIED MODEL OF FLOW ASSUMED BY ENERGY I.

FIGURE 1-2 


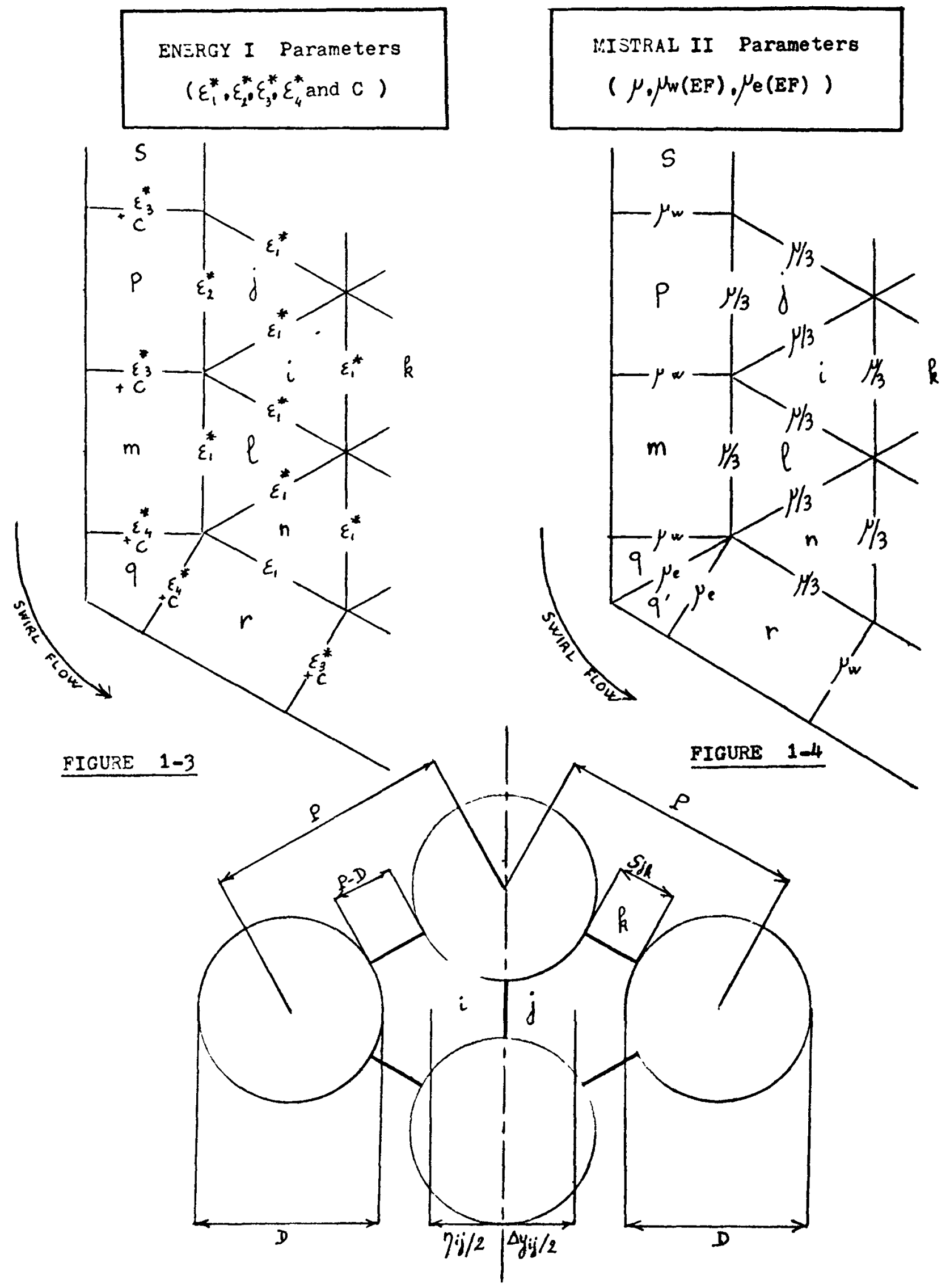


$K$, the coefficient of the thermal conductivity $k$ in Equation (la), is included to take into account the distortion of heat flow lines as they curve around the rods.

The heat balance of subchannel i can be written as

$$
\dot{M}_{i} C p \Delta T_{i}=Q_{i}^{\prime \prime} A_{i} \Delta z-Q_{i j}-Q_{i k}-Q_{i \ell}
$$

where the first term on the right hand side represents the virtual heat generation inside the subchannel i. Replacing (Cp $\Delta \mathrm{T}$ ) by $\Delta H$ and $\left(\frac{k}{\rho C p}\right)$ by $\alpha$, and combining Equations (la) and (2a) yields :

$$
\left(\frac{\Delta \mathrm{H}_{i}}{\Delta z}\right)=\frac{Q_{i}^{\prime \prime} \mathrm{A}_{i}}{\dot{\mathrm{M}}_{i}}-\frac{1}{\dot{\mathrm{M}}_{i}} \sum_{\gamma=j, k, l} \rho(P-D) \frac{\left(\mathrm{H}_{i}-\mathrm{H}_{j}\right)}{\eta_{i \gamma}}\left(\varepsilon_{i \gamma}+K \alpha\right)
$$

In fact, the program allows the choice of four different eddy diffusivities: one for each type of boundary. To keep the character of generality of this study, the calculation has been carried out with the four different parameters.

In Region I: $\varepsilon_{i \gamma}=\varepsilon_{1}$ if both subchannels $i$ and $\gamma$ are triangular

$$
\begin{aligned}
\varepsilon_{i \gamma}=\varepsilon_{2} & \text { if } i \text { and } \gamma \text { are respectively tri- } \\
& \text { angular and rectangular subchan- } \\
& \text { nels. }
\end{aligned}
$$


Equation (3a) expresses the axial variation of the enthalpy $\left(\Delta \mathrm{H}_{i}=\mathrm{H}_{i}(z+\Delta z)-\mathrm{H}_{i}(z)\right)$ in terms of the enthalpies $\left(\mathrm{H}_{i}(z)\right.$ and $\mathrm{H}_{\gamma}(z)$ ) evaluated at the level $z$. This scheme is then fully explicit and the enthalpy of each subchannel can be calculated independently, in terms of the forward differences.

\section{2 .1 .2 .2 Region II}

In the wall region, the uniform swirl flow has a peripheral velocity $\bar{v}_{\theta}$. This swirl flow causes a supplementary heat transport in its own direction, in addition to the heat transport due to the turbulent flow.

The energy balance of a wall subchannel (m), adjacent to two subchannels ( $p$ and $q$ ) region II and one subchannel ( $l$ ) of region $I$, takes the following form.

$$
\dot{\mathrm{i}}_{\mathrm{m}} \mathrm{Cp} \Delta \mathrm{T}_{\mathrm{m}}=Q_{\mathrm{m}}^{\prime \prime \prime} \mathrm{A}_{\mathrm{m}} \Delta \mathrm{z}-\mathrm{Q}_{\mathrm{mp}}-\mathrm{Q}_{\mathrm{mq}}-Q_{\mathrm{m} \ell}+\rho \overline{\mathrm{v}}_{\theta} \mathrm{g} \Delta \mathbf{z}\left(\mathrm{H}_{\mathrm{P}}-\mathrm{H}_{\mathrm{m}}\right)
$$

$\mathrm{H}_{\mathrm{P}}$ is the average enthalpy in the wall subchannel preceding (m), the direction of the swirl flow being taken as a reference.

The last term represents the energy carried by the directional swirl flow. It has been written the same way as in the program itself; in fact this expression is the result of the following approximation: 


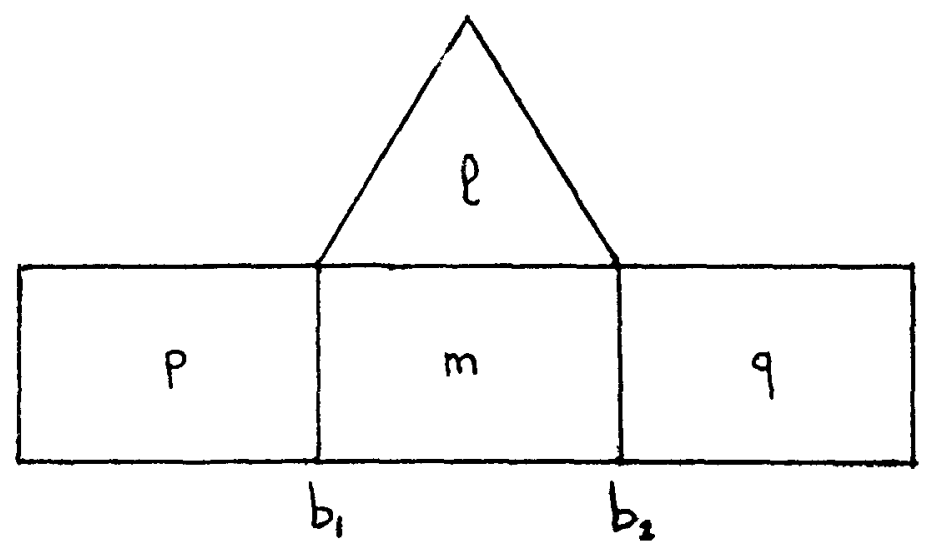

\section{SWIRL FLOW DIRECTION}

The balance of energy carried by the swirl flow can be written as :

$$
Q_{\text {sf }}=\rho \bar{v}_{\theta} g \Delta z\left(\mathrm{H}_{b_{1}}-\mathrm{H}_{\mathrm{b}_{2}}\right)
$$

where $\mathrm{H}_{\mathrm{b}_{1}}$ and $\mathrm{H}_{\mathrm{b}_{2}}$ are the enthalpies at the boundaries $\mathrm{b}_{1}$ and $\mathrm{b}_{2}$. These can be reasonably taken equal to

$$
\mathrm{H}_{\mathrm{b}_{1}}=\frac{\mathrm{H}_{\mathrm{p}}+\mathrm{H}_{\mathrm{m}}}{2} \quad \mathrm{H}_{\mathrm{b}_{2}}=\frac{\mathrm{H}_{\mathrm{m}}+\mathrm{H}_{\mathrm{q}}}{2}
$$

$Q_{\text {sf }}$ takes the form:

$$
Q_{s f}=\rho \bar{V}_{\theta} g \Delta z \frac{\left(H_{p}-H_{q}\right)}{2}
$$

Under the assumption that the gradient of enthalpy is uniform along the wall, it is possible to derive the final form: 


$$
\begin{aligned}
& \mathrm{H}_{\mathrm{m}}=\frac{\mathrm{H}_{\mathrm{p}}+\mathrm{H}_{\mathrm{q}}}{2} \\
& \frac{\mathrm{H}_{\mathrm{p}}-\mathrm{H}_{\mathrm{q}}}{2}=\mathrm{H}_{\mathrm{p}}-\mathrm{H}_{\mathrm{m}}
\end{aligned}
$$

Replacing $(\mathrm{Cp} \Delta \mathrm{T})$ by $\Delta \mathrm{H},\left(\frac{\mathrm{k}}{\rho \mathrm{Cp}}\right)$ by $\alpha$ and $\mathrm{Q}_{\mathrm{m} \gamma}$ by its expression Equation (4al), yielàs.

$$
\begin{aligned}
\left(\frac{\Delta \mathrm{H}_{\mathrm{m}}}{\Delta \mathrm{z}}\right)= & \frac{\mathrm{Q}_{\mathrm{m}}^{\prime \prime \prime} \mathrm{A}_{\mathrm{m}}}{\dot{\mathrm{M}}_{\mathrm{m}}}-\frac{1}{\dot{\mathrm{M}}_{\mathrm{m}}}\left[\rho(\mathrm{P}-\mathrm{D}) \frac{\left(\mathrm{H}_{\mathrm{m}}-\mathrm{H}_{\ell}\right)}{\eta_{\mathrm{m} \ell}}\left(\varepsilon_{\mathrm{ml}}+\mathrm{K} \alpha\right)+\rho g \frac{\left(\mathrm{H}_{\mathrm{m}}-\mathrm{H}_{\mathrm{q}}\right)}{\eta_{\mathrm{m}_{\mathrm{g}}}}\left(\varepsilon_{\mathrm{mq}}+\mathrm{K} \alpha\right)\right. \\
& \left.+\rho \mathrm{g} \frac{\left(\mathrm{H}_{\mathrm{m}}-\mathrm{H}_{\mathrm{p}}\right)}{\eta_{\mathrm{mq}}}\left(\varepsilon_{\mathrm{mp}}+\mathrm{K} \alpha+\eta_{\mathrm{mp}} \bar{v}_{\theta}\right)\right] \\
\text { Region II } & \text { (4a4) }
\end{aligned}
$$

$$
\begin{aligned}
& \text { In Region II: } \varepsilon_{\mathrm{m} \gamma}=\varepsilon_{2} \text { if } \mathrm{m} \text { and } \gamma \text { are respectively } \\
& \text { rectangular and triangular sub- } \\
& \text { channels } \\
& \varepsilon_{\mathrm{m} \gamma}=\varepsilon_{3} \text { if both } \mathrm{m} \text { and } \gamma \text { are rectangular } \\
& \text { subchannels } \\
& \varepsilon_{\mathrm{m} \gamma}=\varepsilon_{4} \text { if } \mathrm{m} \text { and } \gamma \text { are rectangular and } \\
& \text { corner subchannels }
\end{aligned}
$$

Equation (4a4) represents a fully explicit forward difference scheme. The enthalpy of each subchannel at the elevation $(z+\Delta z)$ can be independently calculated in terms of the enthalpies of the adjacent channels at the former level $(z)$. 
The input parameters which must be adjusted are $\left(K, \varepsilon, \bar{V}_{\theta}\right)$ In the program ENERGY $I$, the numerical value of $K$ is fixed: $K=1$ In fact $\varepsilon$ and $\bar{v}_{\theta}$ are adjusted through the dimensionless parameter $\varepsilon^{*}$ and $C$, which will be expressed later in terms of $\varepsilon$ and $\bar{V}_{\theta} \cdot \quad \varepsilon^{*}$ and $C$ are determined empirically for each bundle.

\subsubsection{MISTRAL II}

\subsubsection{Simplified Model of Flow}

The cross section of the LMFBR fuel assembly is also divided into two predominant regions: the central and the wall regions.

The inner region is essentially similar to the ENERGY I inner region; the axial flow has a uniform eddy diffusivity which is characterized by the parameter $\mu$.

The wall region has a completely different model of swirl flow. The directional effect of the swirl flow, is obtained by introducing an asymmetry in the exchange taking place at two boundaries of a wall subchannel.

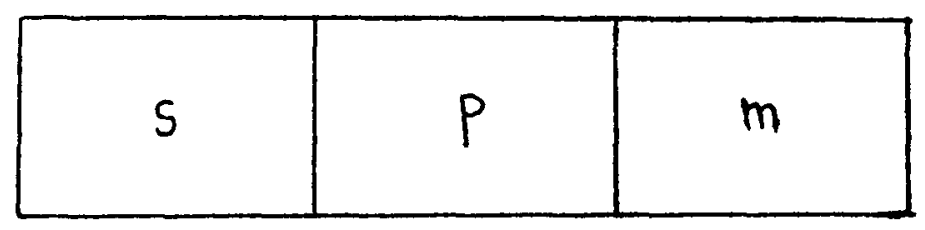

\section{SWIRL FLOW DIRECTION}

For example, to calculate the enthalpy rise of the coolant inside the subchannel $p$, one takes the mixing into account at the boundary $(p, m)$ and neglects it at the boundary $(s, p)$. 
The mixing rate in the gap region is fixed by the parameter $\mu_{w}$ (and $\mu_{e}$ for the corners), which depends on a parameter of efficiency EF. The higher is EF, the stronger is the effect of the swirl flow.

1.2.2.2 Formulation of the Finite Difference Equations for Both Regions

These equations represent the energy balance of a subchannel $i$ and its three neighbors $(j, k, l)$ [fig. 1-4] written in a finite difference form.

\section{2 .2 .2 .1 Region I}

Using the notation defined in the nomenclature, the expression for $Q_{i j}$ has the following form.

$$
Q_{i j}=\Delta x\left(\mu_{i j} \dot{M} C p\left(T_{i}-T_{j}\right)+\lambda\left(T_{i}-T_{j}\right) \frac{S_{i j}}{\Delta y_{i j}} f * g(z)\right)
$$

The first term of the sum accounts for the energy transferred by exchange of flow; the second term accounts for the energy transferred by conduction.

$\mu_{i j}$ (dimension $8 / \mathrm{cm}$ ) represents the percentage of flow streaming through the subchannel $i$ and deviated per unit of length towards the subchannel $j$.

The factor $f^{\star}$ is an efficiency factor for heat conduction and is analogous to $\mathrm{K}$.

$g(z)$ is a function of correction, modifying slightly the value of $\lambda$, as a function of $z$. 
The range of values taken by $g(z)$ is very close to 1 , and the average value over the heated length can be taken equal to 1 . (Its true value, in the cases examined below is $\bar{g}=0.96$ ). To simplify the study, $g(z)$ has been always replaced by 1, so that the expressions for $Q_{i j}$ be similar. Another argument in favor of this simplification could be that, in forced convection, the energy transfer due to flow exchange is always at least one order of magnitude greater than the energy transfer due to conduction. Thus, a slight change of this conduction term should not affect significantly the results.

The heat balance of the subchannel $i$, can be written as:

$$
\dot{\mathrm{M}}_{i} \operatorname{Cp} \Delta \mathrm{T}_{i}=\psi_{i} \Delta \mathrm{x}-Q_{i j}-Q_{i k}-Q_{i \ell}
$$

where $\psi_{i}$ is the linear power provided inside the subchannel $i$. Replacing $(\mathrm{Cp} \Delta \mathrm{T})$ by $\Delta \mathrm{H}$ and $\left(\frac{\mathrm{k}}{\rho \mathrm{Cp}}\right)$ by $\alpha$ and combining Equations ( $1 \mathrm{~b})$ and $(2 \mathrm{~b})$ yields:

$$
\begin{array}{r}
\left(\frac{\Delta \mathrm{H}_{i}}{\Delta \mathrm{x}}\right)=\frac{\psi_{i}}{\dot{\mathrm{M}}_{i}}-\frac{1}{\dot{\mathrm{M}}_{i}} \sum_{\gamma=j, k, l} \rho s_{i \gamma} \frac{\left(\mathrm{H}_{i}-\mathrm{H}_{\gamma}\right)}{\Delta \mathrm{y}_{i \gamma}}\left(\dot{\mathrm{M}}_{i} \frac{\mu_{i \gamma}}{\mathbf{s}_{i \gamma}} \frac{\Delta \mathrm{y}_{i \gamma}}{\rho}+f^{*} \alpha\right) \\
\text { Region } I
\end{array}
$$

In region $I$, the mixing parameter $\mu_{i \gamma}$ is uniform and has the following value.

$$
\mu_{i \gamma}=\frac{1}{3} \mu
$$

Where $\mu$ represents the exchange parameter of a triangular subchannel (percentage of flow streaming through the subchannel $i$ 
and deviated towards its neighbors). Under the assumption that the eddy diffusivity is the same at each of the three boundaries of the inner channels, the meaning of the coefficient (1/3) is evident.

\subsection{Region II}

For MISTRAL II, the treatment of the wall channels is very similar to the treatment of the inner channels. Only the term expressing the heat transfer (by exchange of flow or conduction) at the first boundary traversed by the swirl flow, vanishes. In this case the sum of Equation $(3 b)$ is reduced to two terms.

The final expression for subchannel m yields.

$$
\left(\frac{\Delta \mathrm{H}_{m}}{\Delta z}\right)=\frac{\psi_{m}}{\dot{M}_{m}}-\frac{1}{\dot{M}_{m}} \sum_{\gamma=\ell, q} \rho s_{m \gamma} \frac{\left(H_{m}-H_{\gamma}\right)}{\Delta y_{m \gamma}}\left(\dot{M}_{m} \frac{\mu_{m \gamma}}{s_{m \gamma}} \frac{\Delta y_{m \gamma}}{\rho}+f * \alpha\right)
$$

Region II

$$
\text { In region II: } \begin{aligned}
& \mu_{m \gamma}=\mu_{w} \equiv \pi \frac{D W}{F_{I I}} \mathrm{EF} \\
& \text { if both } m \text { and } \gamma \text { are rectangular subchannels } \\
& \mu_{m \gamma}=\mu_{e} \equiv \pi \frac{D W}{F_{I I I^{H}}} \mathrm{EF} \\
& \text { if } m \text { and } \gamma \text { are rectangular and corner sub- } \\
& \text { channels }
\end{aligned}
$$

The scheme chosen to solve the finite difference Equations (3b) and (4b) is not fully explicit.

Instead of evaluating the transferred heat $Q_{i j}$ at the level $(x)$ and solving directly Equation (3b) for $H_{i}(x+\Delta x)$ in 
terms of $\mathrm{H}_{\gamma}(\mathrm{x})$, the heat transfer $Q_{i j}$ is assumed to take place at the intermediate level $\left(x+\frac{\Delta x}{2}\right)$ between to successive steps. This approach seems to be more rigorous but leads to an implicit scheme; the enthalpy of each subchannel $i$ at the elevation $(x+\Delta x)$ cannot be found independently in terms of the enthalpies at the elevation $(x)$.

$$
Q_{i j}\left(x+\frac{\Delta x}{2}\right)=\frac{1}{2}\left(Q_{i j}(x)+Q_{i j}(x+\Delta x)\right)
$$

Equation (3b) has the following form:

$$
\dot{M}_{i} \operatorname{Cp}\left(T_{i}(x+\Delta x)-T_{i}(x)\right)=\psi_{i} \Delta x-\frac{1}{2} \sum_{\gamma=j, k, l}\left(Q_{i \gamma}(x)+Q_{i \gamma}(x+\Delta x)\right)
$$

or

$$
\begin{aligned}
\dot{\mathrm{M}}_{i} \operatorname{Cp}\left(\mathrm{T}_{i}(\mathrm{x}+\Delta \mathrm{x})\right) & +\frac{1}{2} \sum_{\gamma=j, k, l} Q_{i \gamma}(\mathrm{x}+\Delta \mathrm{x})=\dot{\mathrm{M}}_{i} \mathrm{Cp}\left(\mathrm{T}_{i}(\mathrm{x})\right) \\
& +\psi_{i} \Delta \mathrm{x}-\frac{1}{2} \sum_{\gamma=j, k, l} Q_{i \gamma}(\mathrm{x})
\end{aligned}
$$

Since the $Q_{i \gamma}(x)$ 's are linear functions of temperature $\left(T_{i}(x)\right.$ and $\left.T_{\gamma}(x)\right)$, both sides of Equation $\left(5 b_{3}\right)$ are linear expressions of the temperatures, respectively at the elevation $(x+\Delta x)$ for the left and $(x)$ for the right hand side.

If the temperature distribution is known at the elevation $(x)$, the right hand side can be evaluated and Equations (5b 3 ) form a system of equations which can be solved for the temperature distribution at the following step $(x+\Delta x)$. 
This scheme is used by MISTRAL II. The system of equations (one equation per subchannel) is solved by the GAUSSSEIDEL iterative procedure.

The first guess of the solution is taken equal to the temperature distribution at the former level. Since the new temperature distribution is very close to this first guess when the axial step size is small, the procedure converges quite well and never requires more than 30 iterations. (Reference [1], subroutine GAUDEL).

\subsubsection{Comparison of the Schemes Used for Solving the Equations}

In order to be able to compare analytically the finite difference equations and derive some relations between the input parameters $\left(\varepsilon^{\star}, C\right)$ and $(\mu, E F)$, it is necessary that both schemes of solving the balance equations be the same.

It is assumed that the conversion of the actual scheme of MISTRAL II into a fully explicit scheme, would not significantly change the numerical results. Equations (3b) and (4b) remain valid but the sum of three or two terms is evaluated at the level (x) instead of being split and being evaluated at the level $\left(x+\frac{\Delta x}{2}\right)$.

Under this assumption, Equations (3a), (4a4) and (3b), (4b) have a very similar form; they express the enthalpy rate of variation in terms of the enthalpy differences between the neighboring subchannels at the former level. 
A sufficient condition for both programs to have the same results is that they use the same equations to calculate the enthalpy rate of variation. This requires the coefficients corresponding to the same enthalpy difference to be equal and yields a set of relations between the desired input parameters.

It is foreseeable that some of these relations will be incompatible since both codes are not based on the same model of flow (in the gap region). Nevertheless, even if it is impossible to make the two sets of equations exactly the same for all the subchannels, it should be possible to succeed for the majority of the inner and outer subchannels and then derive a set of correlations between input parameters:

- one involving $\varepsilon_{1}$ and $\mu$ (given by the inner region)

- one involving $\varepsilon_{3}, C l$ and $\mathrm{EF}$ (given by the outer region).

1.3 Comparison of the Finite Difference Equations Applied to al1 Types of Subchannels

In the following discussion,

- Subchannels of type I, correspond to subchannels only connected with triangular subchannels

- Subchannels of type II, correspond to triangular subchannels having a wall subchannel as a neighbor

- Subchannels of type III, correspond to rectangular subchannels

- Subchannels of type IV, correspond to corner subchannels 
The fact that, the theoretical flow split calculation treats uniformly the subchannels having the same geometry has been taken advantage of. The subscripts I, II, III refer respectively to the triangular, rectangular and corner subchannel geometry. These subscripts characterize the axial velocity $V$, the area $A$ and the mass flow rate $M$ in these subchannels. They also characterize the distance between the centroids of two adjacent subchannels $n$, the hydraulic diameter and the axial velocity ratio: $\mathrm{x}=\mathrm{V} / \overrightarrow{\mathrm{V}}$.

The notations of each code have been kept and the correspondence is shown in the nomenclature.

\subsubsection{Subchannels of Type I}

Equations (3a) and (3b), valid for region I and applied to such a subchannel $i$ shown on figure 1-3 or 1-4 take the following form:

MISTRAL II

$$
\left(\frac{\Delta \mathrm{H}_{i}}{\Delta \mathrm{x}}\right)=\frac{\psi_{i}}{\dot{\mathrm{M}}_{I}}-\frac{I}{\dot{\mathrm{M}}_{I}} \sum_{\gamma=j, k, l} \rho \mathrm{s}_{I} \frac{\left(\mathrm{H}_{i}-\mathrm{H}_{Y}\right)}{\Delta \mathrm{y}_{I}}\left[\left(\frac{1}{3} \mu \frac{\dot{\mathrm{M}}_{I} \Delta_{\mathrm{Y}}}{\mathrm{s}_{I} \rho}+f * \alpha\right)\right]\left(6_{I}\right)
$$

\section{ENERGY I}

$$
\left(\frac{\Delta H_{i}}{\Delta z}\right)=\frac{Q_{i}^{\prime \prime} A_{I}}{\dot{M}_{I}}-\frac{1}{\dot{M}_{I}} \sum_{\gamma=j, k, l} \rho(P-D) \frac{\left(H_{i}-H_{\gamma}\right)}{\eta_{I}}\left[\left(\varepsilon_{I}+K \alpha\right)\right]\left(\sigma_{I I}\right)
$$

The enthalpy rate of variation will be calculated the same way by both codes if the terms in brackets are equivalent: 
$\left(\frac{1}{3} \mu \frac{\dot{\mathrm{M}}_{I} \Delta \mathrm{y}_{I}}{\mathrm{~s}_{I} \rho}+\mathrm{f}^{*} \alpha\right)=\left(\varepsilon_{1}+\mathrm{K} \alpha\right)$

It is easy to express $\varepsilon_{1}$ in terms of $\varepsilon^{*}$, dimensionless input parameter of ENERGY I by definition:

$\varepsilon^{*}=\frac{\lambda_{L I}}{\lambda \bar{a}} \varepsilon^{1 *} \quad$ and $\quad \varepsilon^{1 *}=\frac{\varepsilon_{1}}{\bar{v} D_{e I}}$

where

$\lambda_{L I}$ is the lateral porosity in region $I$ and $\lambda_{L l}=\frac{P-D}{P}$

$\lambda_{\bar{a}}$ is the average axial porosity of the bundle and

$\bar{\lambda}_{\mathrm{a}}=\frac{\text { void area }}{\text { total area }}=\frac{\mathrm{V}}{\mathrm{T}}$

$T=\frac{\sqrt{3}}{2}\left[P\left(N_{r} \sqrt{3}+2\right)-D\right]^{2}$

$V=T-\frac{\pi}{4}\left(D^{2}+D_{w}^{2}\right) N p$

$\mathrm{N}_{r}$ is the number of rings of triangular subchannels.

$\mathrm{N}_{\mathrm{p}}$ is the number of pins.

$D_{W}$ is the diameter of the wire wrap

$\bar{V}$ is the average axial velocity in the bundle.

$D_{e I}$ is the hydraulic diameter of a triangular subchannel.

$\varepsilon^{1 *}$ is the dimensionless eddy diffusivity used in subchannel anaiysis.

The subscript 1 has been converted into a superscript to avoid confusion with $\varepsilon_{1}^{*}$, the value of $\varepsilon^{*} \operatorname{defined}$ from $\varepsilon_{1}$. We 
shall define the same way $\varepsilon_{2}^{*}, \varepsilon_{3}^{*}$, and $\varepsilon_{4}^{*}$ as the values of $\varepsilon^{*}$ calculated from the values of the eddy diffusivity at the different boundaries between adjacent subchannels.

Equation (7) becomes:

$$
\varepsilon_{1}^{*}=\frac{\lambda_{L I}}{\lambda_{a}} \frac{1}{\bar{V} e_{I}}\left(\frac{I}{3} \mu \frac{\dot{M}_{I} \Delta y_{I}}{s_{I} \rho}+\left(f^{*}-K\right) \alpha\right)
$$

Introducing the dimensionless conductivity $\alpha^{*}=\frac{\alpha}{\mathrm{D}_{\mathrm{eI}} \overline{\mathrm{V}}}$, the velocity ratio $x_{I}=V_{I} / V$ and the wetted parameter ${ }^{\mathrm{w}} \mathrm{pI}$

Equation (7) takes the final form:

$$
\varepsilon_{1}^{*}=\frac{\lambda_{L 1}}{\lambda_{a}}\left(\frac{1}{12} \mu \frac{\Delta y_{I}{ }^{w p_{I}}}{s_{I}} x_{I}+(f *-K) \alpha^{*}\right)
$$

If the relation (8) is satisfied, the calculation of the axial increment of enthalpy for each subchannel of type I, will be analogous in both codes.

If $\mathrm{N}$ is the number of rings of triangular subchannels in the hexagonal bundle, there are $6 \mathrm{~N}(\mathrm{~N}-)$ subchannels of type $I$.

\subsubsection{Subchannels of type II}

Equations (3a) and (3b) valid for region $I$ and applied to such a subchannel $l$, shown on figure $1-3$ or $1-4$ take the following form: 
MISTRAL II

$$
\begin{aligned}
& \left(\frac{\Delta \mathrm{H}_{\ell}}{\Delta \mathrm{x}}\right)=\frac{\psi_{\ell}}{\dot{\mathrm{M}}_{I}}-\frac{1}{\dot{\mathrm{M}}_{I}}\left[\sum_{\gamma=i, \mathrm{~m}} \rho \mathrm{s}_{I} \frac{\left(\mathrm{H}_{\ell}{ }^{\left.-\mathrm{H}_{\gamma}\right)}\right.}{\Delta \mathrm{Y}_{I}}\left(\frac{1}{3} \mu \frac{\dot{\mathrm{M}}_{I} \Delta \mathrm{Y}_{I}}{\mathrm{~s}_{I} \rho}+\mathrm{f}^{*} \alpha\right)\right. \\
& \left.+\rho s_{I} \frac{\left(H_{P}-H_{m}\right)}{\Delta Y_{I I}}\left(\frac{1}{3} \mu \frac{\dot{M}_{I} \Delta Y_{I I}}{s_{I} \rho}+f * \alpha\right)\right]
\end{aligned}
$$

ENERGY I

$$
\begin{aligned}
\left(\frac{\Delta \mathrm{H}_{\ell}}{\Delta \mathrm{z}}\right)= & \frac{Q_{\ell}^{\prime \prime \prime} \mathrm{A}_{I}}{\dot{\mathrm{M}}_{I}}-\frac{I}{\dot{\mathrm{M}}_{I}}\left[\sum_{\gamma=i, \mathrm{~m}} \rho(P-D) \frac{\left(\mathrm{H}_{\ell}-\mathrm{H}_{\gamma}\right)}{n_{I}}\left[\varepsilon_{I}+K \alpha\right]\right. \\
& \left.+\rho(P-D) \frac{\left(\mathrm{H}_{\ell}-\mathrm{H}_{\mathrm{m}}\right)}{{ }^{\eta_{I I}}}\left[\varepsilon_{2}+K \alpha\right]\right]
\end{aligned}
$$

The enthalpy rate of variation will be calculated the same way by both codes if the terms in the brackets, coefficients of the same enthalpy differences are equivalent.

$$
\begin{aligned}
& \left(\frac{1}{3} \mu \frac{\dot{\mathrm{M}}_{I} \Delta \mathrm{y}_{I}}{\rho \mathrm{s}_{I}}+f^{*} \alpha\right)=\left(\varepsilon_{1}+\mathrm{K} \alpha\right) \text { (Similar to Equation } \\
& \left(\frac{1}{3} \mu \frac{\dot{\mathrm{M}}_{I} \Delta \mathrm{y}_{I I}}{\rho \mathrm{S}_{I}}+f^{*} \alpha\right)=\left(\varepsilon_{2}+\mathrm{K} \alpha\right)
\end{aligned}
$$

Introducing the dimensionless parameters $\varepsilon_{1}^{*}$ and $\varepsilon_{2}^{*}$ in these equations yields as final result:

$$
\varepsilon_{I}^{*}=\frac{\lambda_{L I}}{\bar{\lambda}_{a}}\left(\frac{1}{12} \mu \frac{\Delta y_{I} w_{I}}{s_{I}} x_{I}+\left(f^{*}-K\right) \alpha^{*}\right)
$$

and 


$$
\varepsilon_{2}^{\star}=\frac{\lambda_{I I}}{\bar{\lambda}_{a}}\left(\frac{1}{12} \mu \frac{\Delta y_{I I} w_{I}}{s_{I}} x_{I}+\left(E^{\star}-K\right) \alpha^{*}\right)
$$

If both relations (I1) and (12) are simultaneously satisfied, the calculation of the axial increment of enthalpy for each subchannel of type II, will be analogous in both codes.

There are $6 \mathrm{~N}$ subchannels of type II.

\section{3 .3 Subchannels of Type III}

\subsubsection{Subchannel not Adjacent to a Corner}

Equations (4a4) and (4b) valid for region II and applied to such a subchannel $p$, shown on figure $1-3$ or $1-4$ take the following form:

$$
\begin{aligned}
& \text { MISTRAL II } \\
& \begin{aligned}
\left(\frac{\Delta \mathrm{H}_{\mathrm{P}}}{\Delta \mathrm{x}}\right)= & \frac{\psi_{\mathrm{P}}}{\dot{\mathrm{M}}_{I I}}-\frac{1}{\dot{\mathrm{M}}_{I I}}\left[\rho \mathrm{s}_{I I} \frac{\left(\mathrm{H}_{\mathrm{P}}-\mathrm{H}_{\mathrm{S}}\right)}{\Delta \mathrm{y}_{I I I}}\left(\mu_{\mathrm{w}} \frac{\dot{\mathrm{M}}_{I I}}{\mathrm{~s}_{I I}} \frac{\Delta \mathrm{y}_{I I I}}{\rho}+\mathrm{f} \alpha^{*}\right)\right. \\
& \left.+\rho \mathrm{s}_{I} \frac{\left(\mathrm{H}_{\mathrm{P}}-\mathrm{H}_{j}\right)}{\Delta \mathrm{Y}_{I I}}\left(\frac{1}{3} \mu \frac{\dot{\mathrm{M}}_{I I} \Delta \mathrm{y}_{I I}}{\mathrm{~s}_{I} \rho}+\mathrm{f} * \alpha\right)\right]
\end{aligned}
\end{aligned}
$$

\section{ENERGY I}

$$
\begin{aligned}
\left(\frac{\Delta H_{p}}{\Delta z}\right)= & \frac{Q_{p}^{\prime \prime \prime} A_{I I}}{\dot{M}_{I I}}-\frac{I}{\dot{M}_{I I}}\left[\sum_{\gamma=m, s} \rho g \frac{\left(H_{p}-H_{\gamma}\right)}{n_{I I I}}\left[\varepsilon_{3}+K \alpha\right]\right. \\
& \left.+\rho(P-D) \frac{\left(H_{P}-H_{j}\right)}{n_{I I}}\left[\varepsilon_{2}+K \alpha\right]+\rho \bar{v}_{\theta} g\left(H_{p}-H_{s}\right)\right]
\end{aligned}
$$


The enthalpy rate of variation will be calculated the same way by both codes if the terms in brackets, coefficients of the same enthalpy difference are equivalent.

The fact that the first equation contains only two differences poses a slight problem. Equating directly the terms in brackets would yield a set of two incompatible equations.

$$
\varepsilon_{3}+K \alpha=0
$$

and

$$
\varepsilon_{3}+K \alpha+\Delta y_{I I I} \bar{V}_{\theta}=\mu_{W} A_{I I} V_{I I} \frac{\Delta y_{I I I}}{s_{I I}}+f^{*} \alpha
$$

It is preferable to use the assumption already made in ENERGY I [Cf 1.2.1.2.2] of a constant gradient of enthalpy along the wall, in the swirl direction, and reduce this set of equations into one relation. Using the approximation

$$
\mathrm{H}_{\mathrm{P}}=\frac{\mathrm{H}_{\mathrm{s}}+\mathrm{H}_{\mathrm{m}}}{2} \text { or } \quad\left(\mathrm{H}_{\mathrm{p}}-\mathrm{H}_{\mathrm{m}}\right)=-\left(\mathrm{H}_{\mathrm{p}}-\mathrm{H}_{\mathrm{s}}\right)
$$

The sum of two terms in the second equation, vanishes.

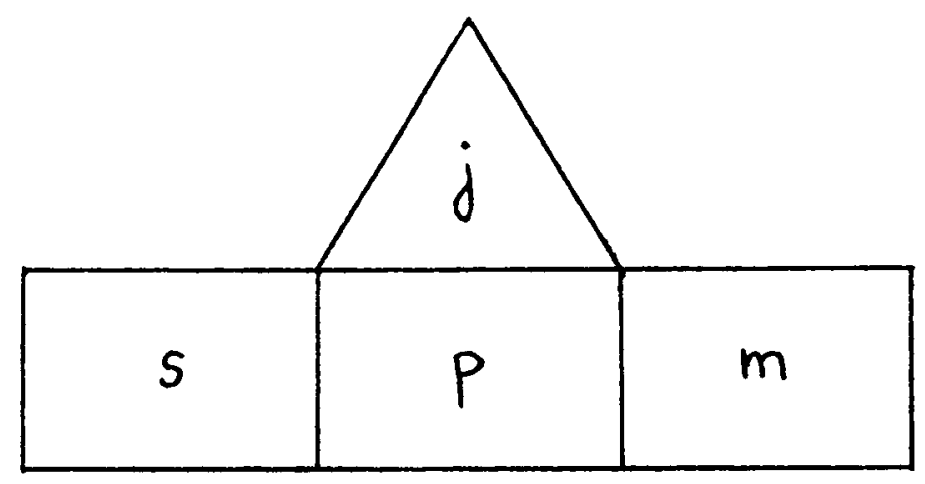

SWIRL FLOW DIRECTION 
The final set of relations is:

$$
\left(\dot{\bar{M}}_{I I} \mu_{W}+E^{*} \alpha \frac{\rho s_{I I}}{\Delta y_{I I I}}\right)=\rho w \bar{v}_{\theta}
$$

and

$$
\left(\frac{1}{3} \mu \frac{\dot{\mathrm{M}}_{I I} \Delta \mathrm{Y}_{I I}}{\mathrm{~s}_{I} \rho}+\mathrm{I} * \alpha\right)=\left(\varepsilon_{2}+\mathrm{K} \alpha\right)
$$

$\overline{\mathrm{V}}_{\theta}$ must now be expressed in terms of $\mathrm{C}$, dimensionless input parameter of ENERGY $I$ and $\mu_{w}$ has to be replaced by its expression in terms of a function of EF.

By definition:
$c \equiv c_{1} \frac{\lambda_{s}}{\bar{\lambda}_{a}}$
and
$c_{1} \equiv \frac{\bar{v}_{\theta}}{\bar{v}}$

where

$\lambda_{\mathbf{s}}$ is the lateral porosity in region II $\lambda_{\mathbf{s}}=\frac{g}{g+D / 2}$

$g$ is the width of the gap between the rod and wall

$C_{1}$ is the parameter used in subchannel analysis.

$\mu_{W} \equiv \frac{D W}{A_{I I}{ }^{H}} E F \quad$ and $\quad \dot{M}_{I I}=\rho A_{I I} V_{I I} \quad x_{I I}=\frac{V_{I I}}{\bar{V}}$

Equations (15) and (16) take the following final form:

$c=\frac{\lambda_{s}}{\bar{\lambda}_{a}}\left(\pi x_{I I} \frac{D}{H} E F+f * \alpha * \frac{D_{e I}}{\Delta y_{I I I}}\right)$ 
and

$$
\varepsilon_{2}^{*}=\frac{\lambda_{L I}}{\bar{\lambda}_{a}}\left(\frac{1}{12} \mu \frac{\Delta y_{I I} w_{I}}{s_{I}} \frac{A_{I I}}{A_{I}} x_{I I}+\left(f^{*}-K\right) \alpha^{*}\right)
$$

If both relations (17) and (18) are simultaneously satisfied, the calculation of the axial increment of enthalpy for each subchannel of type III not adjacent to a corner subchannel, will be analogous in both codes. There are $6(\mathrm{~N}-2)$ such subchannels.

\subsubsection{Subchannel Adjacent to a Corner}

In this case it is necessary to treat separately the case of a rectangular subchannel preceding or following a corner subchannel (the direction of the swirl flow being taken as a reference).

One of the two terms of the sum, in the second Equation $\left(13_{I I}\right)$ is replaced by:

$$
\rho g \frac{\left(H_{p}-H_{\gamma}\right)}{{ }^{\eta_{I V}}}\left(\varepsilon_{4}+K \alpha\right)
$$

The equivalence of the terms in brackets requires that Equation (18) be satisfied simultaneously with two other complicated relations involving $\left(\varepsilon_{3}^{*}, \varepsilon_{4}^{*}\right.$, and $\left.C\right)$.

These equations are of minor interest since for medium sized bundles, these subchannels only represent a small fraction of the total subchannel number; they will not be of any use in the following and then will not be derived here. 


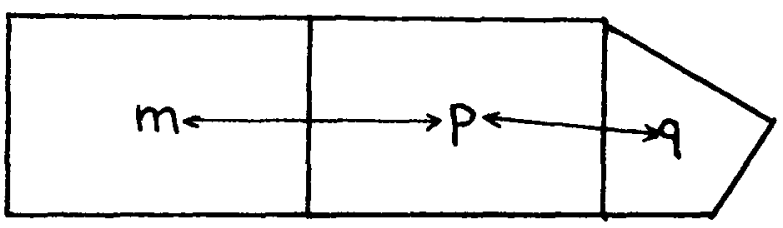

Since the distances between the centroids of the subchannels adjacent to $\mathrm{p}$ are different, the preceding approximation of a constant gradient of enthalpy is not of use here with respect to canceling the $\varepsilon$.

There are 12 such subchannels.

\subsubsection{Subchannels of Type IV}

Equations (4a4) and (4b) valid for region II and applied to such a subchannel $q$ shown on figure 1-3 or 1-4 take the following form:

\section{MISTRAL II}

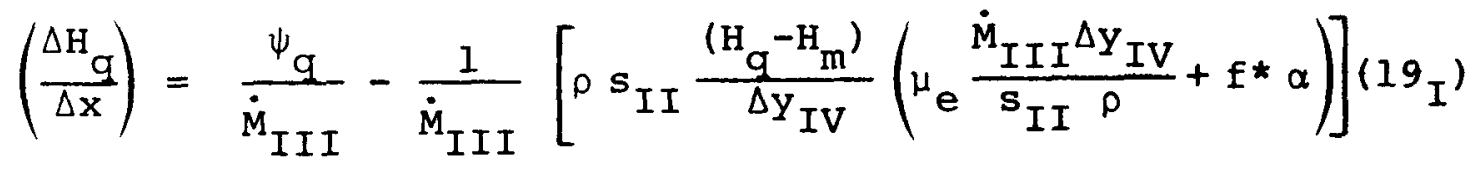

\section{ENERGY I}

$$
\begin{aligned}
\left(\frac{\Delta H_{g}}{\Delta z}\right)= & \frac{Q_{g}^{\prime \prime \prime} A_{I I I}}{\dot{M}_{I I I}}-\frac{I}{\dot{M}_{I I I}}\left(\rho g \frac{\left(H_{g}-H_{m}\right)}{n_{I V}}\left(\varepsilon_{4}+n_{I V} \bar{v}_{\theta}+f^{*} \alpha\right)\right. \\
& \left.+\rho g \frac{\left(H_{g}-H_{r}\right)}{n_{I V}}\left(\varepsilon_{4}+f^{*} \alpha\right)\right)
\end{aligned}
$$


Equating the terms in brackets, and using the approximation of a constant gradient of enthalpy in the swirl direction that is, $\left(\mathrm{H}_{\mathrm{q}}-\mathrm{H}_{\mathrm{m}}\right)=-\left(\mathrm{H}_{\mathrm{q}}-\mathrm{H}_{\mathrm{r}}\right)$, yields the following relation:

$$
\left(\dot{\mathrm{M}}_{I I I} \mu_{e}+\frac{f^{\star} \alpha \rho s_{I I}}{\Delta y_{I V}}\right)=\rho g \bar{v}_{\theta}
$$

Introducing the dimensionless parameter $\mathrm{C}$ and replacing $\mu_{e}$ in terms of $\mathrm{EF}, \mathrm{yields:}$

$$
\begin{aligned}
& \mu_{e} \equiv \pi \frac{D W E F}{A_{I I I}{ }^{H}} \quad \dot{M}_{I I I}=\rho A_{I I I} V_{I I I} \quad x_{I I I}=\frac{V_{I I I}}{\bar{v}} \\
& C=\frac{\lambda_{S}}{\bar{\lambda}_{a}}\left(\pi \frac{D}{\bar{H}} E F x_{I I I}+f * \alpha * \frac{D e_{I}}{\Delta Y_{I V}}\right)
\end{aligned}
$$

If this relation is satisfied, the calculation of the enthalpy rate of variation for the corner subchannels will be analogous for both codes. There are 6 corner subchannels.

\section{3 .5 Summary}

If all the precedent relations were simultaneously satisfied the two programs MISTRAL II and ENERGY I would be equivalent, since the enthalpy rate of variation would everywhere be calculated by the same equations.

In fact, several relations are incompatible and cannot be satisfied simultaneously. (Equations (12) and (18) for example). This is a proof that the two codes, based on different models of flow are not absolutely equivalent. 
The following table (Taile l-I) summarizes all the previous derived equations and indicates the frequency with which they have been encountered.

The next step of the reasoning will consist of choosing the most important relations, making both codes equivalent for the greatest number of subchannels; then these relations will be simplified by further approximations and then validity will be checked against the very few data available.

1.4 Relationship Between the Two Sets of Input Parameters $(\varepsilon *, C)$ and $(\mu, E F)$

In this paragraph MISTRAL II notation will be converted into ENERGY I parameters, to facilitate the comparison.

\section{4 .1 Relation $\varepsilon^{*}=\mathrm{f}(\mathrm{P}, \mathrm{D}, \mu)$}

\subsubsection{Derivation}

In spite of its capability to accomodate four different parameters $\varepsilon_{1}^{*}, \varepsilon_{2}^{*}, \varepsilon_{3}^{*}, \varepsilon_{4}^{*}$, the ENERGY I code is generally used with a single value of $\varepsilon^{*}$. The four parameters takes this uniform value.

Equations (11), (12) and (18) present these different expressions for $\varepsilon^{*}$. Since all three cannot be simultaneously satisfied, we shall choose one of them and ignore the other two. Equation (11) is the most interesting since it matches the equations for the greatest number of subchannels (6N ${ }^{2}$ against $6 \mathrm{~N}$ ). 


\begin{tabular}{|c|c|c|c|c|c|}
\hline & & Relation & $\begin{array}{l}\text { Number } \\
\text { of Rings } \\
N=1\end{array}$ & $\begin{array}{l}\text { Number } \\
\text { of Rings } \\
\text { N } 2\end{array}$ & $\begin{array}{l}\text { Type of } \\
\text { Subchannel } \\
\text { Giving the } \\
\text { Relation }\end{array}$ \\
\hline$\varepsilon_{1}^{*}$ & (11) & $\varepsilon_{1}^{*}=\frac{\lambda_{L I}}{\bar{\lambda}_{a}}\left(\frac{1}{12} \mu \frac{\Delta y_{I} w_{I}}{s_{I}} x_{I}+(f *-K) \alpha *\right)$ & $\begin{array}{l}0 \\
6\end{array}$ & $\begin{array}{l}6 \mathrm{~N}(\mathrm{~N}-1) \\
6 \mathrm{~N}\end{array}$ & $\begin{array}{l}\text { Type I } \\
\text { Type II }\end{array}$ \\
\hline \multirow{2}{*}{$\varepsilon_{2}^{\star}$} & $(12)$ & $\varepsilon_{2}^{\star}=\frac{\lambda_{\mathrm{Ll}}}{\bar{\lambda}_{\mathrm{a}}}\left(\frac{1}{12} \mu \frac{{ }_{\mathrm{y}} \mathrm{II}_{\mathrm{wp}} \mathrm{P}_{\mathrm{I}}}{\mathrm{s}_{\mathrm{I}}} \mathrm{x}_{\mathrm{I}}+\left(\mathrm{f}^{*}-\mathrm{K}\right) \alpha^{*}\right)$ & 6 & $6 \mathrm{~N}$ & Type II \\
\hline & $(18)$ & $\varepsilon_{2}^{\star}=\frac{\lambda_{L I}}{\bar{\lambda}_{a}}\left(\frac{1}{12} \mu \frac{\Delta_{I I}{ }^{W p}}{s_{I}} \frac{A_{I I}}{A_{I}} x_{I I}+(f *-K) \alpha *\right)$ & $\begin{array}{l}0 \\
6\end{array}$ & $\begin{array}{l}6(N-2) \\
6 \\
6\end{array}$ & $\begin{array}{l}\text { Type III } \\
\text { (Adjacent } \\
\text { or not to } \\
\text { corner sub- } \\
\text { channel }\end{array}$ \\
\hline \multirow{2}{*}{ C } & (17) & $C=\frac{\lambda_{s}}{\bar{\lambda}_{a}}\left(\pi x_{I I} \frac{D}{H} E F+f * \alpha * \frac{D_{I}}{\Delta y_{I I I}}\right)$ & 0 & $6(N-2)$ & Type III \\
\hline & $(21)$ & $c=\frac{\lambda_{s}}{\bar{\lambda}_{a}}\left(\pi x_{I I I} \frac{D}{H} E F+f * \alpha * \frac{D e_{I}}{\Delta y_{I V}}\right)$ & 6 & 6 & Type IV \\
\hline
\end{tabular}

Two relations involving $\varepsilon_{3}^{*}, \varepsilon_{4}^{\star}$ and $C$ have not been reported here. These relations correspond to subchannels of Type III adjacent to corner subchannels. Six such subchannels exist in any hexagonal bundle. 


$$
\varepsilon^{*}=\frac{\lambda_{I I}}{\bar{\lambda}_{a}}\left(\frac{1}{12} \mu \frac{\Delta y_{I} w_{I}}{s_{I}} x_{I}+(f *-K) \alpha^{*}\right)
$$

The value of $K$ is fixed to $I$ in ENERGY $I$. In most of the cases the value of $f^{*}$ is set equal to 1 . Even when the second term does not vanish, it is legitimate to neglect it in forced convection, since the conduction term is then always at least an order of magnitude smaller than the transport term. Under these considerations, Equation (11) reduces to:

$$
\varepsilon^{*}=\frac{\lambda_{L I}}{\bar{\lambda}_{a}}\left(\frac{1}{I 2} \mu \frac{\Delta Y_{I} w_{I}}{s_{I}} x_{I}\right)
$$

Using the notations of ENERGY I and expressing the factors in terms of $P$ and $D$ yields:

$$
\begin{aligned}
& \Delta y_{I}=\eta_{I}=\frac{P}{\sqrt{3}} \\
& w p_{I}=\frac{\pi}{2} D+\frac{\pi}{2}(P-D)=\frac{\pi}{2} P \quad \begin{array}{l}
\text { if } D_{\text {wire }}=P-D \text { as is usually } \\
\text { the case }
\end{array} \\
& s_{I}=(P-D) \\
& \varepsilon^{*}=\frac{\lambda_{L I}}{\bar{\lambda}_{a}}\left(\frac{\pi}{24 \sqrt{3}} \mu D \frac{(P / D)^{2}}{(P / D-1)} x_{I}\right)
\end{aligned}
$$

D should be expressed in $\mathrm{cm}$ if $\mu$ is expressed in $\mathrm{cm}^{-1}$.

\subsubsection{Application of the Correlation (23)}

The purpose of this paragraph is to check the validity of this correlation, with the data of the Karlsruhle 61 pins bundle, reported in reports [2] and [4]. 
This bundle has the following geometrical parameters:
$D=0.6 \mathrm{~cm}$
$\lambda_{L I}=0.2405$
$P / D=1.3167$
$\lambda_{\mathrm{a}}=0.4738$

The conduction has been fully taken into account by both codes: $\quad K=E^{*}=1$ the flow split calculation yields $x_{I}=0.9509$.

Numerical Application

$$
\begin{aligned}
& \frac{\varepsilon^{*}}{\mu}=\frac{{ }_{\mathrm{L} l}}{\bar{\lambda}_{\mathrm{a}}} \frac{\pi}{24 \sqrt{3}} \mathrm{D} \frac{(\mathrm{P} / \mathrm{D})^{2}}{(\mathrm{P} / \mathrm{D}-1)} \mathrm{x}_{\mathrm{I}} \\
& \frac{\varepsilon^{*}}{\mu}=\underline{0.1198}
\end{aligned}
$$

This 61 pin bundle has been studied for three values of the helical pitch $H$; recommended values of $\mu$ and $\varepsilon^{*}$ and their range of uncertainty have been determined separately by both codes. The results are summarized in Table 1-II.

\begin{tabular}{|c|c|c|c|c|c|c|c|}
\hline \multirow{2}{*}{$\frac{\begin{array}{c}\mathrm{H} \\
(\mathrm{mm})\end{array}}{100}$} & \multirow{2}{*}{$\frac{H / D}{16.67}$} & \multicolumn{2}{|c|}{$\begin{array}{l}\text { Range of } \mu\left(\mathrm{cm}^{-1}\right) \\
\text { (Experimentally } \\
\text { Determined) }\end{array}$} & \multirow{2}{*}{ 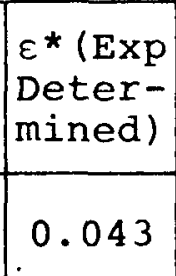 } & \multirow{2}{*}{$\frac{\begin{array}{c}\varepsilon^{\star} \\
\text { Recom- } \\
\text { mended }\end{array}}{0.035}$} & \multicolumn{2}{|c|}{$\begin{array}{l}\text { Range of } \\
\text { Uncertainty } \\
\quad+208\end{array}$} \\
\hline & & $0.300 \leq$ & $\leq 0.350$ & & & $0.028 \leq$ & $\leq 0.042$ \\
\hline 200 & 33.33 & $0.148 \leq$ & $\leq 0.174$ & 0.021 & 0.017 & $0.014 \leq$ & $\leq 0.021$ \\
\hline 300 & 50.0 & $0.084 \leq$ & $\leq 0.110$ & 0.014 & 0.012 & $0.010 \leq$ & $\leq 0.014$ \\
\hline
\end{tabular}

TABLE 1-II 
The values $\mu$ reported in this table have been taken from (report [2], (fig. 17)) and reproduced as (fig. 1-5).

The values of $\varepsilon^{*}$ experimentally determined have been calculated from the value of $\varepsilon^{1^{\star}}$ (parameter used in subchannel analysis) taken from report ([4], (fig. 16)) and reproduced as (fig. $1-6)$.

$$
\begin{aligned}
\varepsilon^{\star}=\varepsilon^{1 *} \frac{\lambda_{\mathrm{Ll}}}{\bar{\lambda}_{\mathrm{a}}} & \varepsilon_{1}^{\star}=0.086 \\
& \varepsilon_{1}^{\star}=0.044 \\
\varepsilon_{1}^{\star} & =0.028
\end{aligned}
$$

The values of $\varepsilon^{*}$ recommended by $\mathrm{E}$. KHAN have been directly calculated utilizing the correlation derived in his thesis. ([5], page 68) and reproduced as (fig. 1-7).

Using Equation (24) and the values of $\mu$ reported in Table I-II, allows calculation of the range of $\varepsilon^{*}$ predicted by the correlation (23). The results are shown on Table 1-III.

TABLE 1-III

\begin{tabular}{|c|c|l|l|l|l|}
\hline & & \multicolumn{2}{|c|}{$\begin{array}{l}\text { Range of } \mu\left(\mathrm{cm}^{-1}\right) \\
\text { Experimentally } \\
\text { Determined }\end{array}$} & \multicolumn{2}{|c|}{$\begin{array}{c}\varepsilon^{*}(\mu) \\
\text { Calculated with } \\
\text { Correlation (23) }\end{array}$} \\
\hline 100 & 16.67 & $0.300 \leq$ & $\leq 0.350$ & $0.036 \leq$ & $\leq 0.042$ \\
\hline 200 & 33.33 & $0.148 \leq$ & $\leq 0.174$ & $0.018 \leq$ & $\leq 0.021$ \\
\hline 300 & 50.00 & $0.084 \leq$ & $\leq 0.110$ & $0.010 \leq$ & $\leq 0.013$ \\
\hline
\end{tabular}




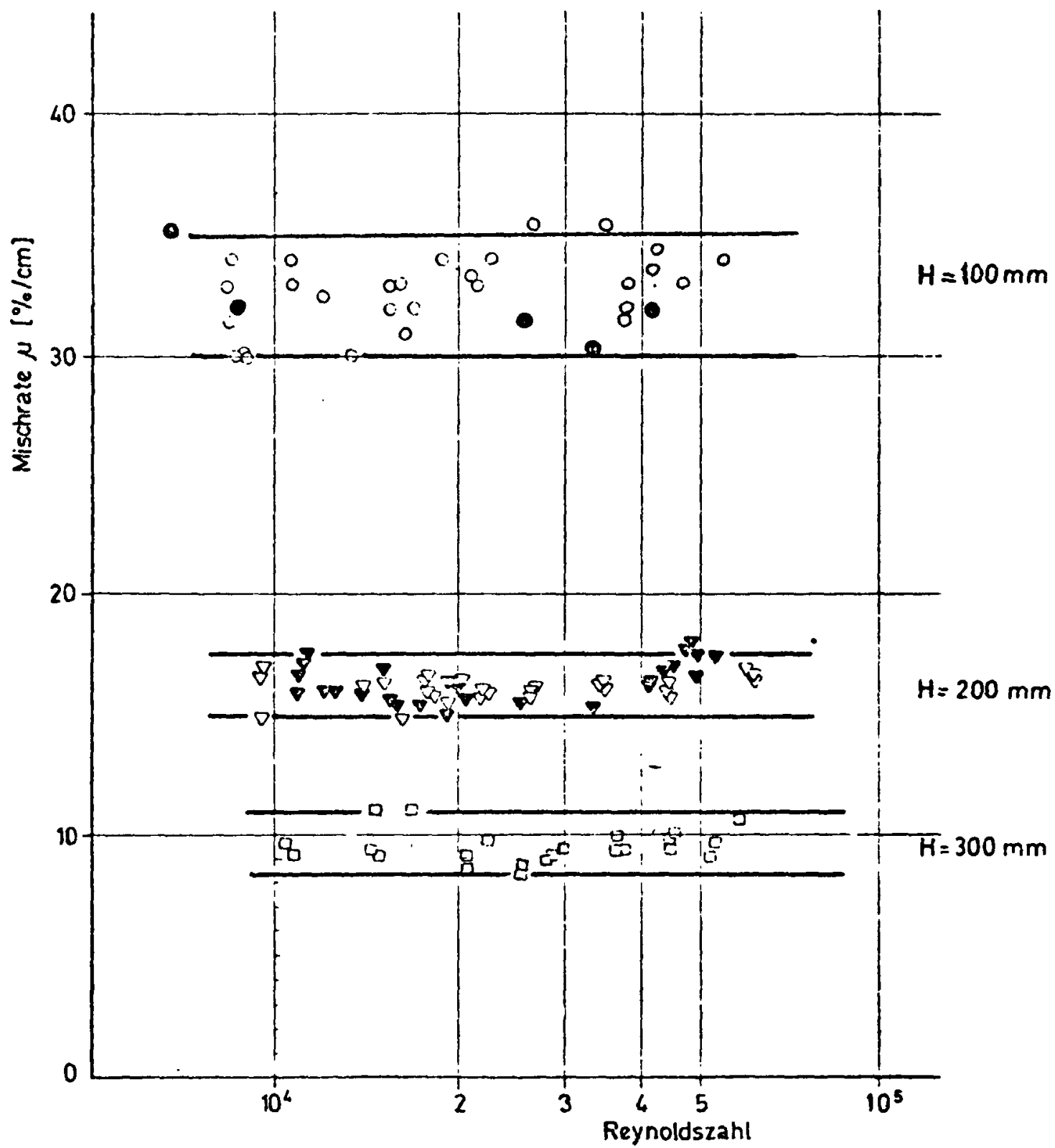

MIXING PARAMETER $\mu$ VERSUS THE REYNOLDS NUMBER

FOR DIFFERENI VALLES OF THE HELICAI PITCH $H$

IN A 61 PINS WIRE WRAPPED BUNDLE $(P / D=1 \cdot 32)$

\section{PIGURE 1-5}




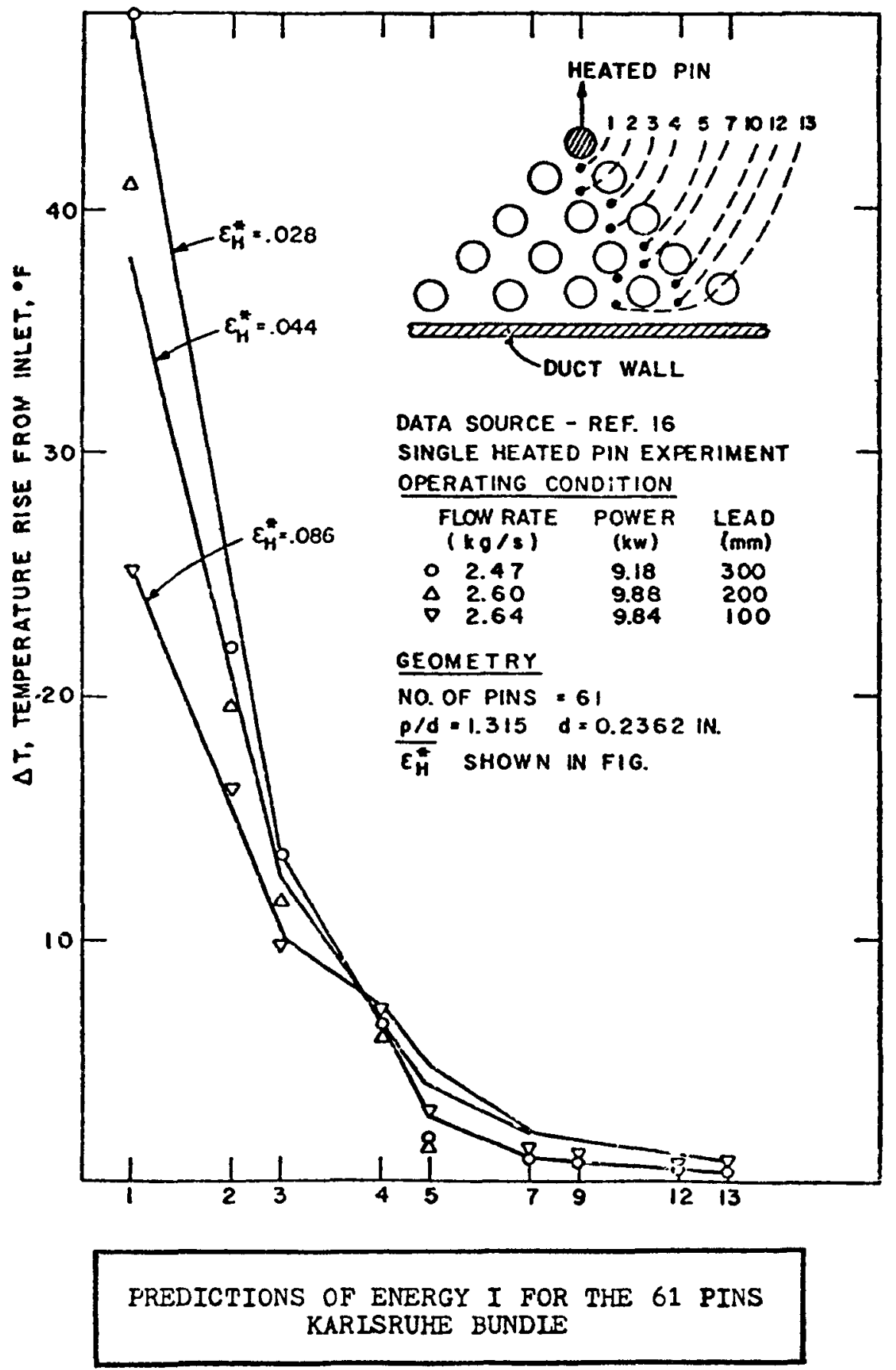

FIGURE 1-6 
(a) all wire-wraps of the same diameter wrapped in the same serse from tre same start position.

(b) $11 \leq \mathrm{h} / \mathrm{d} \leq 52$

(c) $\quad 1.14 \leq \mathrm{p} / \mathrm{d} \leq 1.32$

The correlations for $\varepsilon^{*}$ and $C$ are as follows:

$$
\varepsilon^{\star}=\left[0.85-12.8\{|\mathrm{p} / \mathrm{d}-1.25|\}^{1.424}\right\}(\mathrm{d} / \mathrm{h})
$$

Data corrclated within \pm 208 at a 958 confidence level.

$$
c=0.09+2(d / h-0.03)
$$

Data correlated within \pm 359 at a 953 confidence level.

CORRELATIONS EXPRESSING $\epsilon^{*}$ AND $C$ IN TERISS OF THE GEONETRICAL PARALETERS

FIGURE 1-7 
The comparison of Table 1-II and Table 1-III presented on fig. 1-8 show that the three ranges of $\varepsilon^{\star}$ calculated from $\mu$ per the correlation of Equation (15) are all included in the range of uncertainties of KHAN's predictions.

NOTE: It can be noticed that for the usual values of $P$ and $D$, the values of $\Delta Y_{I}=$ and $\Delta Y_{I I}$ are very close (their value is respectively 0.460 $\mathrm{cm}$ and $0.476 \mathrm{~cm}$ in the preceding example). Therefore, Equations (11) and (12) are about numerically equivalent. Relation (18) would yield a significantly different result since the value of $\left(A_{I I} / A_{I}\right)$ is about 0.5 in the usual cases, (0.496 for the precedent example).

\section{4 .2 Relation $C=g(P, D, H, E F)$}

\subsubsection{Derivation}

Equations (17) and (21) propose two different expressions for $\mathrm{C}$. Using the same approach as before, we keep the first relation which matches the equation for the greatest number of subchannels $(6(\mathrm{~N}-2)$ against 6$)$.

$$
C=\frac{\lambda_{s}}{\lambda_{a}}\left(\pi x_{I I} \frac{D}{H} E F+f * \alpha * \frac{D e_{I}}{\Delta y_{I I I}}\right)
$$

First we will get an estimation of the factor $f=\frac{D e_{I}}{\Delta y_{I I I}}$ since

$$
\begin{aligned}
& D e_{I}=\frac{4 A_{I}}{w p_{I}}, A_{I}=\frac{\sqrt{3}}{4} P^{2}-\frac{\pi}{8}\left(D^{2}+(P-D)^{2}\right), \quad w p_{I}=\frac{\pi}{2} P, \\
& \Delta y_{I I I}=\eta_{I I I}=P
\end{aligned}
$$




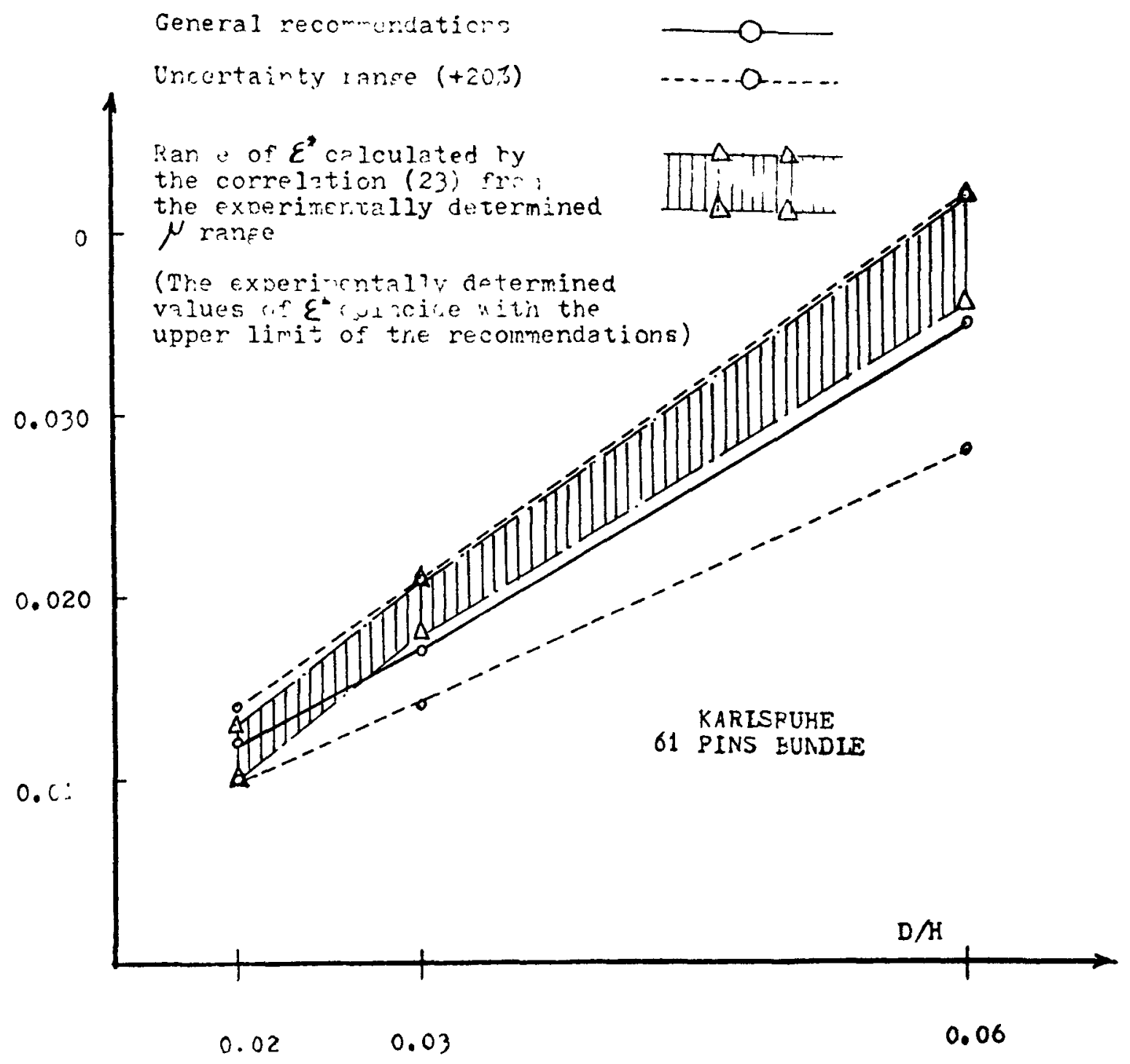

COMPARISON OF $\varepsilon^{*}(\mu)$ GIVEN BY THE CORRELATION (23) WITH THE GENERAL RECOMMENDATIONS FOR THIS PARAMETER.

FIGURE $1-8$ 
we obtain

$$
f=\frac{2 \sqrt{3}}{\pi}-\left[\left(\frac{D}{P}\right)^{2}+\left(1-\frac{D}{P}\right)^{2}\right]
$$

The values of interest for this function (Parabola, minimum for $\mathrm{P}=1 / 2)$ is the range $[0.1 ; 0.6]$. The extremes are obtained for $P / D=1$ and $P / D=2$.

Since the factor $f$ is less than 1 , the approximation made in the preceding paragraph (cf 1.4.1.1) is still valid; in forced convection, the second term of the sum can be neglected yielding

$$
c=\frac{\lambda_{s}}{\bar{\lambda}_{a}}\left(\pi x_{I I} \frac{D}{H} E F\right)
$$

\subsubsection{Application of the Correlation (25)}

The purpose of this paragraph is to check the validity of this correlation, using the results reported for the Karlsruhe 61 pins.

This bundle has the following geometrical parameters:

$$
\begin{array}{ll}
\mathrm{D}=0.6 \mathrm{~cm} & \lambda_{s}=0.3878 \\
\mathrm{H}=10 \mathrm{~cm} & \bar{\lambda}_{\mathrm{a}}=0.4738
\end{array}
$$

The flow split calculation yields $x_{I I}=1.105$

Numerical Application

Rearranging Equation (25) we obtain

$$
\frac{\mathrm{C}}{\mathrm{EF}}=\frac{\lambda_{s}}{\bar{\lambda}_{a}}\left(\begin{array}{lll}
\pi & x_{\text {II }} & \frac{D}{\mathrm{H}}
\end{array}\right)
$$


which upon substitution of the above geometric parameter yields

$$
\frac{\mathrm{C}}{\mathrm{EF}}=\underline{0.170}
$$

Two heated pin experiments, reported in report [2], (fig. 28 and 29)) and reproduced as (fig. 1-9) show that the best fit with experimental data is obtained for a value of $\mathrm{EF}$ taken in the range $[0.8 ; 1.0]$.

Using 0.9 as a value for $\mathrm{EF}$, the corresponding value of $\mathrm{C}$, predicted by the correlation (25) via Equation (26) yields:

$$
\underline{C p}=0.153
$$

This predicted value is very close to the recommended value of $c(0.15 \pm 0.05)$ calculated by the correlation reported in KHAN's thesis ([5], (page 68)) and reproduced as (fig. 1-7).

For this set of data at least, the correlation (25) correctly relates the values of $\mathrm{C}$ and $\mu$ corresponding to the best fit with the experimental data.

NOTE: $X_{I I}$ and $X_{I I I}$ are always very close to $I$ for the usual cases. (Their value is respectively 1.105 and 0.9226 in the precedent example). Therefore, Equations (17) and (21) are about numerically equivalent when the conduction term is neglected.

According to the results of the two preceding paragraphs, the correlations (23) and (25) are able to relate well the sets of input data needed by MISTRAL II and ENERGY I, when these data correspond to the best fit with the experimental results. 


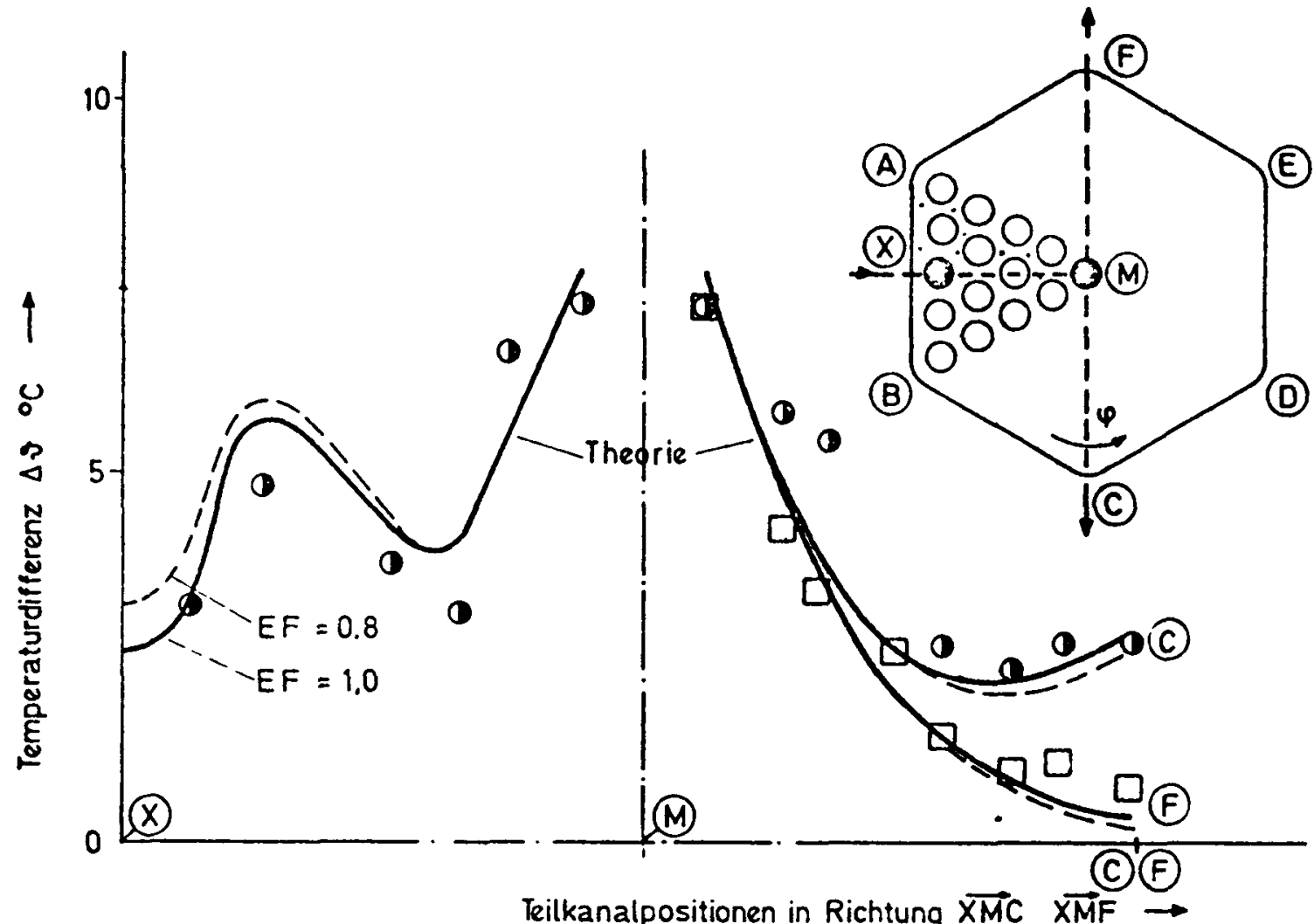

Teilkanalpositionen in Richtung $\overrightarrow{X M C} \quad \overrightarrow{X M F} \rightarrow$

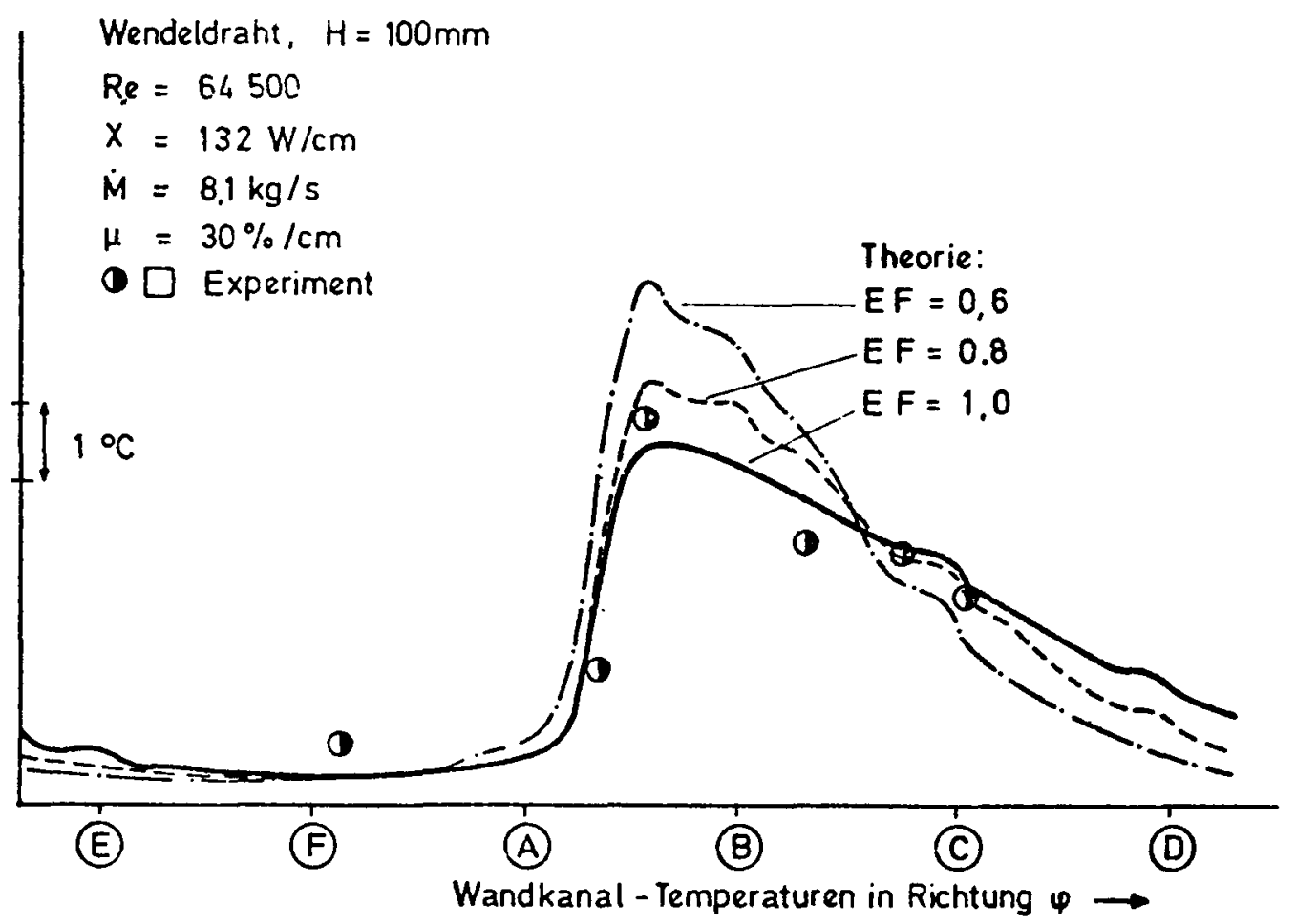

TEMPERATURE PROFIIE ACROSS THE BUNDLE COMPARISON MISTRAL II-EXPERIMENT 
The purpose of the following paragraph is to check the validity of these correlations when one set of parameters has been arbitrarily chosen and when the output is not supposed to match any experimental data.

\subsubsection{Validity of the Two Correlations for an Arbitrary Set of Input Data}

Two available runs of MISTRAL II are being utilized.

- The first run calculates the temperature distribution in a 37 pin bundle having the same geometrical parameters as the real Karlsruhe 61 pin bundle. The axial power distribution has a cosine shape. The parameters $\mu$ and EF are respectively taken equal to $308 / \mathrm{cm}$ and 0.6. Reference [6].

- The second rur calculates the temperature distribution in a 217 pin bundle having the same geometrical parameters as the real Karlsruhe 61 pin bundle. The axial power distribution has also a cosine shape and the parameters $\mu$ and $E F$ are respectively taken equal to $30 \% / \mathrm{cm}$ and 0.5 . This run is given as a example at the end of the report [1] which is the user manual for MISTRAL II. The 37 rods of the preceding bundle have an identical linear power as the 37 rods of the first three rings of this bundle.

We have run ENERGY I for the same cases and tried to match the two temperature predictions by adjusting the parameters $\varepsilon$ * and $\mathrm{C}$. 
$1.4 .3 .1 \quad 37$ Pin Bundle

Geometrical Parameters:

$$
\begin{array}{ll}
\mathrm{D}=0.6 \mathrm{~cm} & \lambda_{\mathrm{Ll}}=0.2405 \\
\mathrm{H}=10 \mathrm{~cm} & \bar{\lambda}_{\mathrm{a}}=0.4860 \\
\mathrm{P} / \mathrm{D}=1.3167 & \lambda_{\mathrm{s}}=0.3878
\end{array}
$$

The flow split calculation yields $X_{I}=0.9429$ and $X_{I I}=$ 1.095 .

1.4.3.1.1 Correlations (15) and (18)

The application of the relations (15) and (18) leads to the following values of $\varepsilon^{*}$ and $C$, corresponding to $\mu=0.30 \mathrm{~cm}^{-1}$ and $\mathrm{EF}=0.6$.

$$
\underline{\varepsilon^{*}=0.035} \quad \underline{C=0.099}
$$

1.4.3.1.2 KHAN's Predictions

The application of the correlations from fig. 1-7 proposes the following values of $\varepsilon^{*}$ and $C$ :

$$
\underline{\varepsilon^{*}=0.035} \quad \underline{C=0.150}
$$

and the range of uncertainly

$$
[0.028 ; 0.042] \quad[0.10 ; 0.20]
$$

\subsection{Experimental Adjustment}

The results are presented on fig. 1-10 and 1-11. Figure 1-10 shows the comparison of MISTRAL II's output with KHAN's best fit prediction and the corresponding range of uncertainty. 


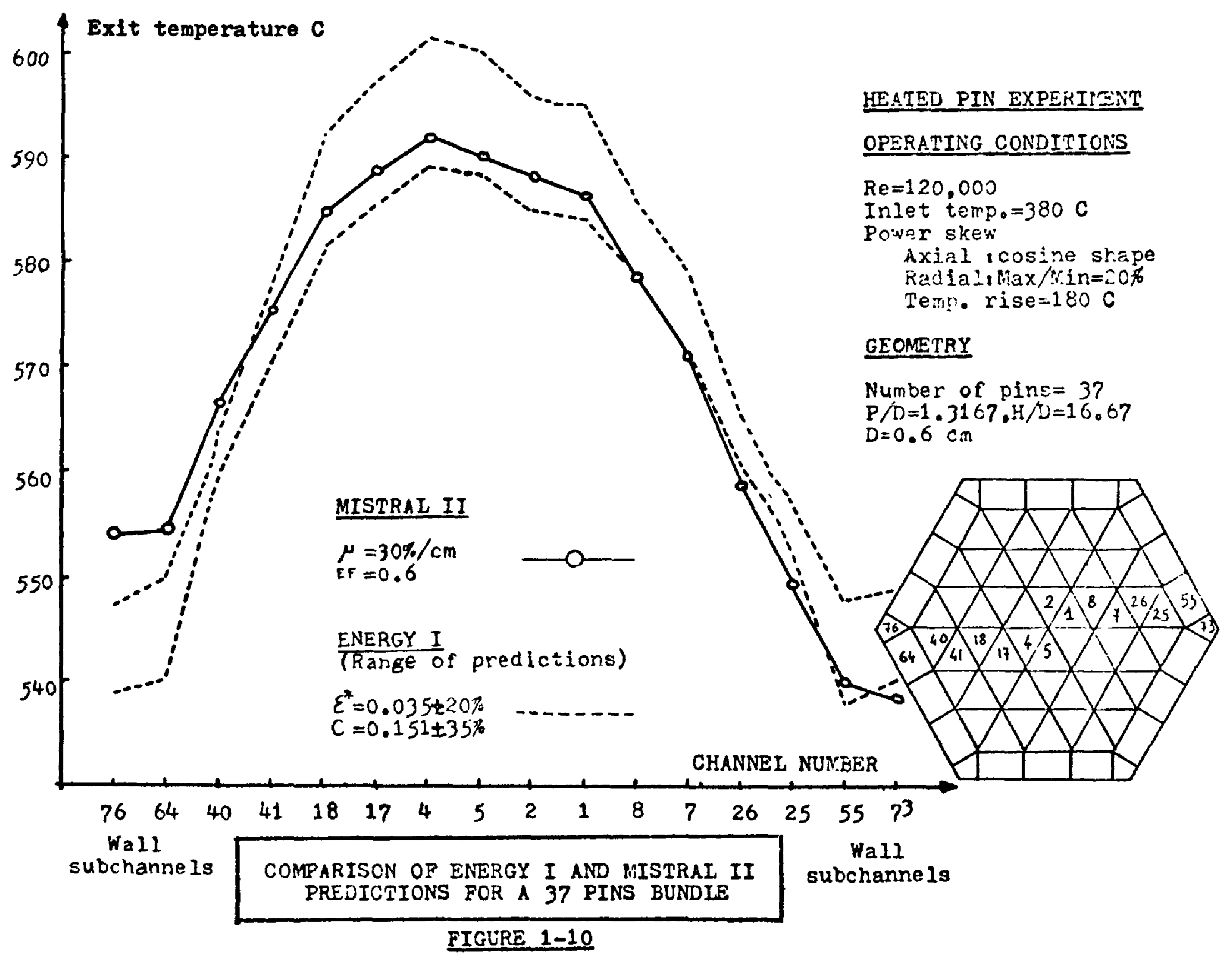




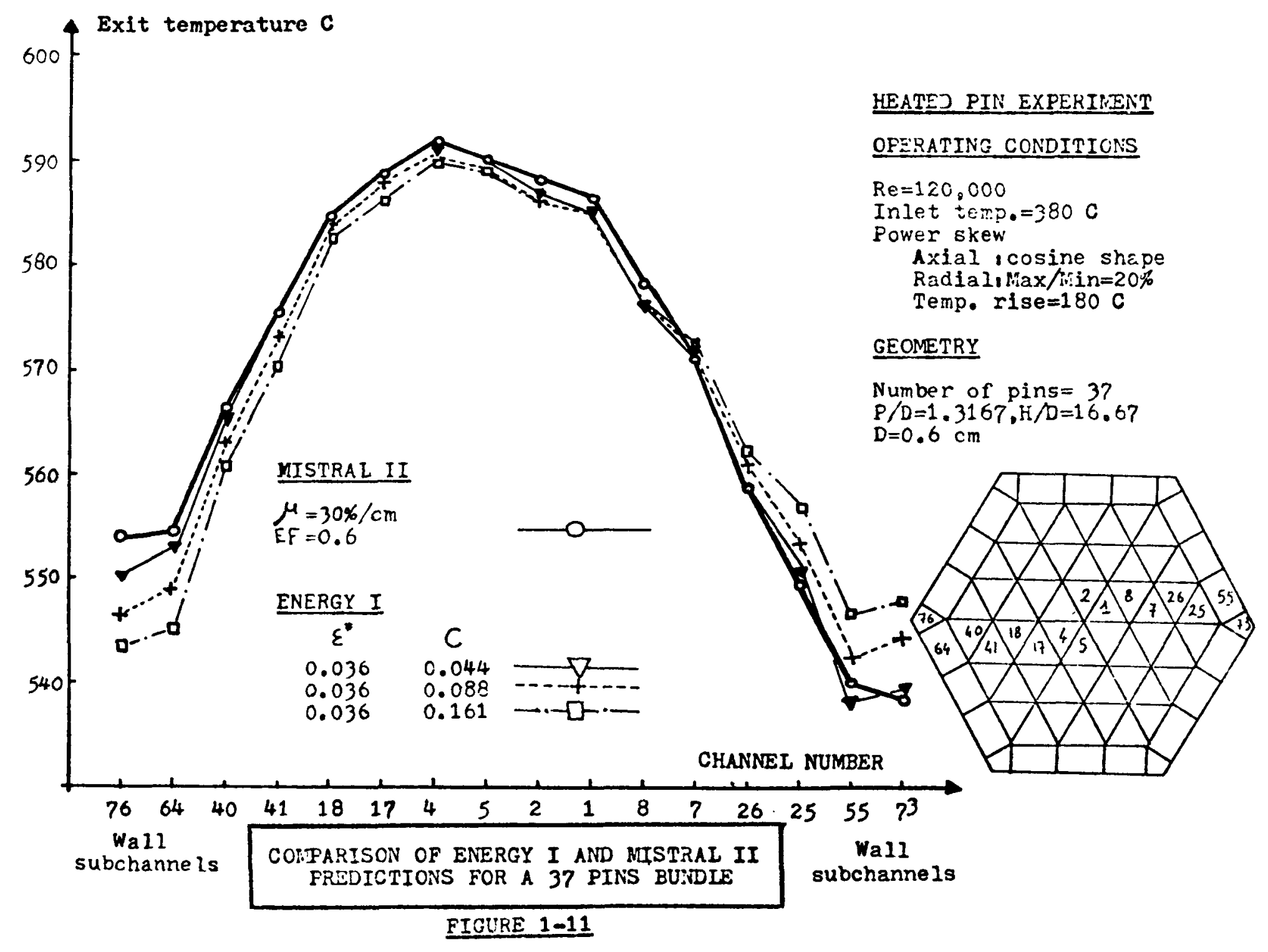


The results match well for the central region of the bundle, but important discrepancies are observed at the outer boundary •

Figure 1-11 shows several runs attempting to get a better fit with the results of the Karlsruhe code. The set of parameters leading to the best fit seems to be

$$
\underline{\varepsilon^{*}=0.036} \quad \underline{\mathrm{C}=0.044}
$$

The average difference between the two curves is about $1^{\circ} \mathrm{C}$.

\subsection{Discussion}

We can here take advantage of the results obtained for the Karlsruhe 61 pin bundle, having the same geometrical parameters as the 37 pin bundle.

The value of $\mu$ used by MISTRAL II has been chosen within the range supposed to give the best fit with experimental data (Table $1-I I)$.

The value of EF is significantly different (about one half) of the value leading to the best fit with experimental data (if 1.4.2.2) .

The correlation (23) is able to predict well the experimentally determined $\varepsilon^{*}$.

The correlation (25) has not been able to predict the right value of $C$. The predicted value is better than KHAN's prediction but about twice to big. 
1.4.3.2 217 Pin Bundle

Geometrical Parameters
$D=0.6 \mathrm{~cm}$
$\lambda_{\mathrm{LI}}=0.2405$
$\mathrm{H}=10 \mathrm{~cm}$
$\bar{\lambda}_{a}=0.4608$
$P / D=1.3167$
$\lambda_{\mathbf{S}}=0.3878$

The flow split calculation yields

$X_{I}=0.9690 \quad X_{I I}=1.126$

1.4.3.2.1 Correlations (23) and (25)

The values of $\varepsilon^{*}$ and $C$ corresponding to $\mu=0.30 \mathrm{~cm}^{-1}$ and $E F=0.5$ are:
$\underline{\varepsilon^{*}=0.035}$
$\underline{C}=0.095$

1.4.3.2.2 KHAN's Predictions

Correlations from fig. $1-7$ propose the following values.

$\underline{\varepsilon^{*}=0.035} \quad \underline{C=0.150}$

and the range of uncertainty
$[0.028 ; 0.042]$
$[0.10 ; 0.20]$

\subsection{Experimental Adjustment}

The results are presented on fig. $1-12$ and $1-13$.

- Figure 1-12 shows the comparison of MISTRAL II results with KHAN's best fit prediction and the corresponding range of uncertainty. 
Exit temperature C

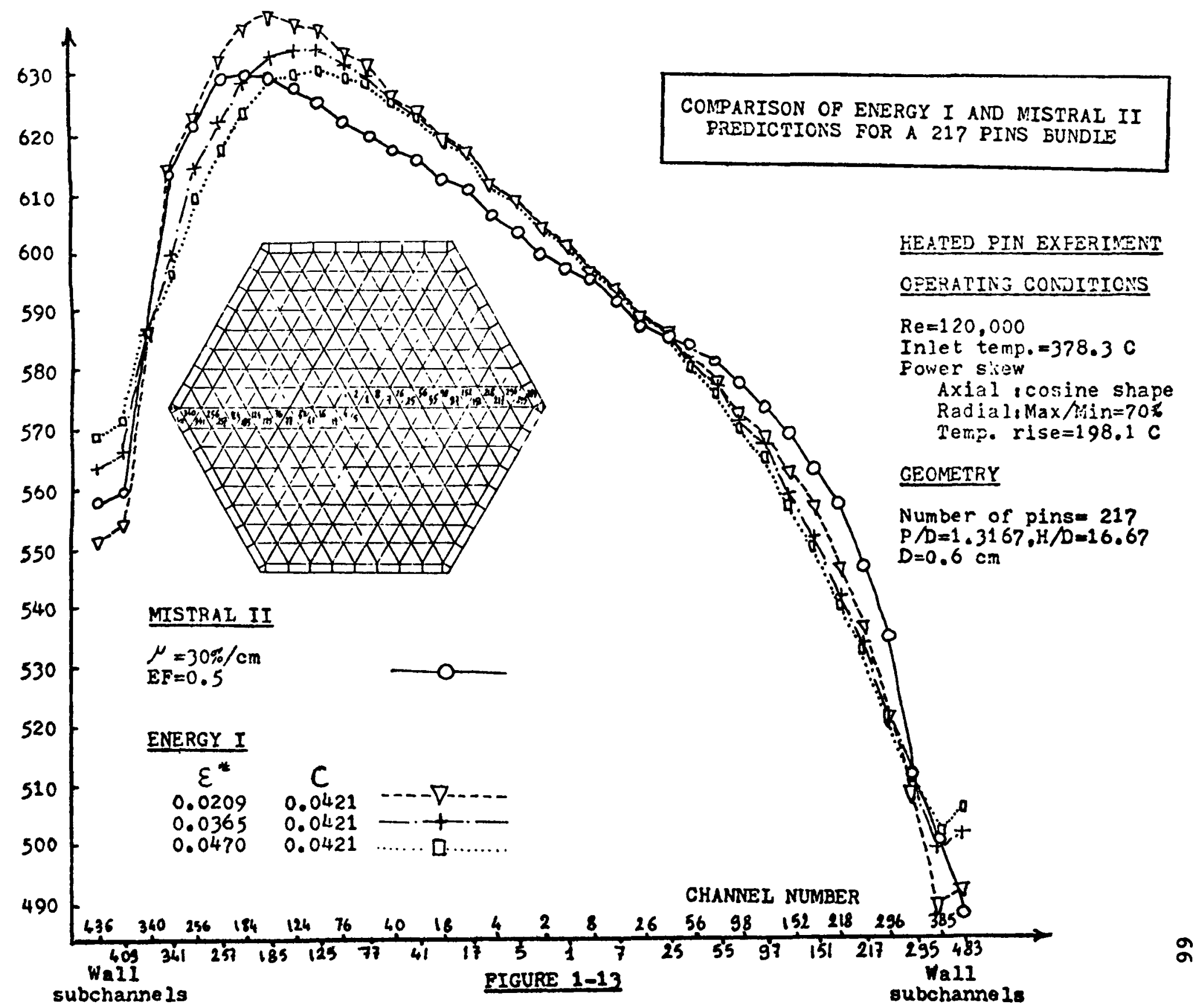


- Figure 1-13 shows several runs attempting to get a better fit with the results of the Karlsruhe code.

It has been impossible to adjust the temperature predictions of both codes, within a reasonable range of uncertainty. The central region of the bundle seems to remain unaffected by a change of $\varepsilon^{*}$ or $C$. When $\varepsilon^{*}$ decreases from 0.09 to 0.04 the maximum predicted by ENERGY I moves towards the place where MISTRAL II predicts its maximum, but the value of this maximum increases up to $12^{\circ} \mathrm{C}$ above the value calculated by the Karlsruhe code.

All the curves of fig. 1-12, have an average difference of about $7^{\circ} \mathrm{C}$ with MISTRAL II results. Speaking of a "best fit" is questionable in this case. 


\subsection{Conclusion}

As it is proven by the last analyzed case, MISTRAL II and ENERGY I are two codes of different conceptions and their predictions are not equivalent in all the cases. Since the model of flow assumed by both codes is different, this conclusion was foreseeable. The size of the bundle seems to emphasize the discrepancy of che results.

However, when the set of input parameters is not arbitrarily chosen and corresponds to the best fit observed with experimental data, the two correlations (23) and (25) derived in the preceding chapter seem to relate well the two pairs of parameters $(\varepsilon *, C)$ and $(\mu, E F)$.

Thus, these correlations seem to be valid about the peculiar point corresponding to the best fit (the interesting range) but do not seem to be reliable outside this range.

Only very few data for MISTRAL runs are available, and they all have been used for this study. If more data were available, it would perhaps be interesting to pursue the analysis with different cases and define out of curiosity the amplitude of the range within which the correlations are reliable. 
CHAPTER 2

GRIDDED BUNDLES

For the case of wire wrapped bundles, the ENERGY I computer program models the periodic sweep flow through rod gaps as an enhanced effective eddy diffusivity, uniform over the length. The purpose of this section is to find an approximate expression of this eddy diffusivity when the wire wrap is replaced by grid spacers.

\subsection{Model of Flow}

The rods are maintained by equidistant grids. Right behind a grid, the enhanced eddy diffusivity is important because of the turbulence induced by the grid. However, experiments show that after a short distance (a few inches). This turbulence dies very fast and is almost zero when the flow traverses the following grid (fig. 2-1).

This problem has already been approached in two different ways

- A sophisticated approach is reported in Reference [7]

- A simplified approach is treated in section 7 of Reference [8]

Only the second approach has been studied here.

The fluctuation of $\varepsilon^{*}$ can roughly be approximated by an exponential term taking its maximum at the downstream end of a grid and decreasing almost to zero after a few inches. 


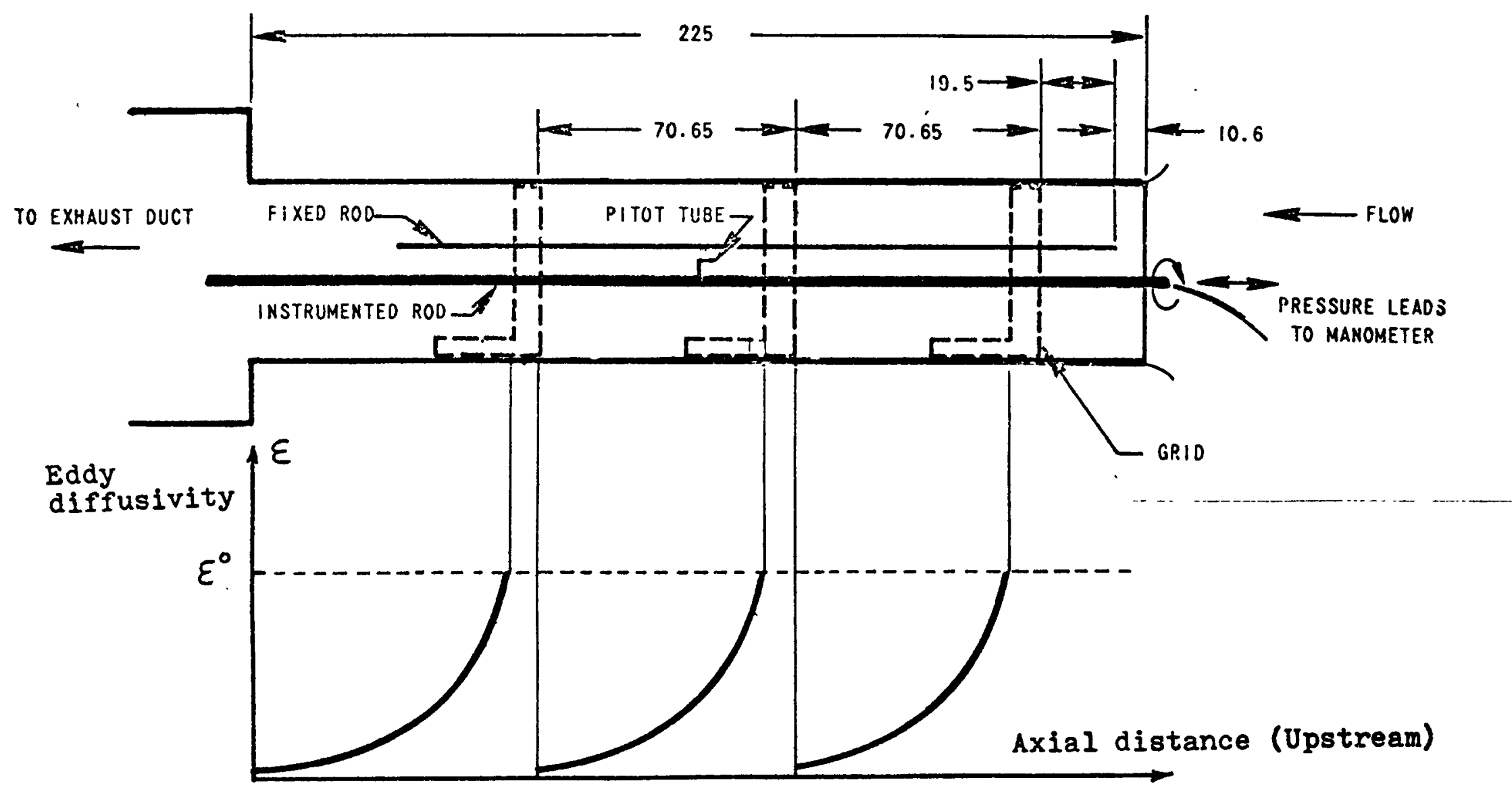

Typical assumed exponential decrease of the eddy diffusivity behind a grid. 
The proposed model is then

$$
\varepsilon^{*}=\varepsilon_{0}^{*} e^{-\mu x}
$$

where $\mathrm{x}$ is the distance measured from the downstream end of the grid.

The new set of input parameters $\left(\varepsilon_{0}^{*}\right.$ and $\left.\mu\right)$ will have to be adjusted the same way as done before with ( $\varepsilon$ * and $c$ ) to obtain the best fit with experimental data.

\section{2 Predictions of ENERGY I}

The computer program ENERGY I has been modified for the present purpose, and the axial variation of $\varepsilon$ * has been taken into account, (Appendix B).

only very few data have been published on this subject; the two analyzed cases are reported below.

\subsubsection{Karlsruhe Data (Honeycomb Grids)}

The experiment described in the Reference [9] is a single heated pin test. In the $100 \mathrm{~cm}$ long test section, the space between to consecutive grids is $10 \mathrm{~cm}$. By heating the central rod, temperature profiles have been generated for different Reynolds numbers, over the bundle cross section. These temperatures have been increased at the exit of the test section.

The results are shown on fig. (2-2) and (2-3). The experimental temperatures can be very well predicted by the code by adjusting $\varepsilon^{*}$ and $\mu$. Moreover, it has been found, that any 


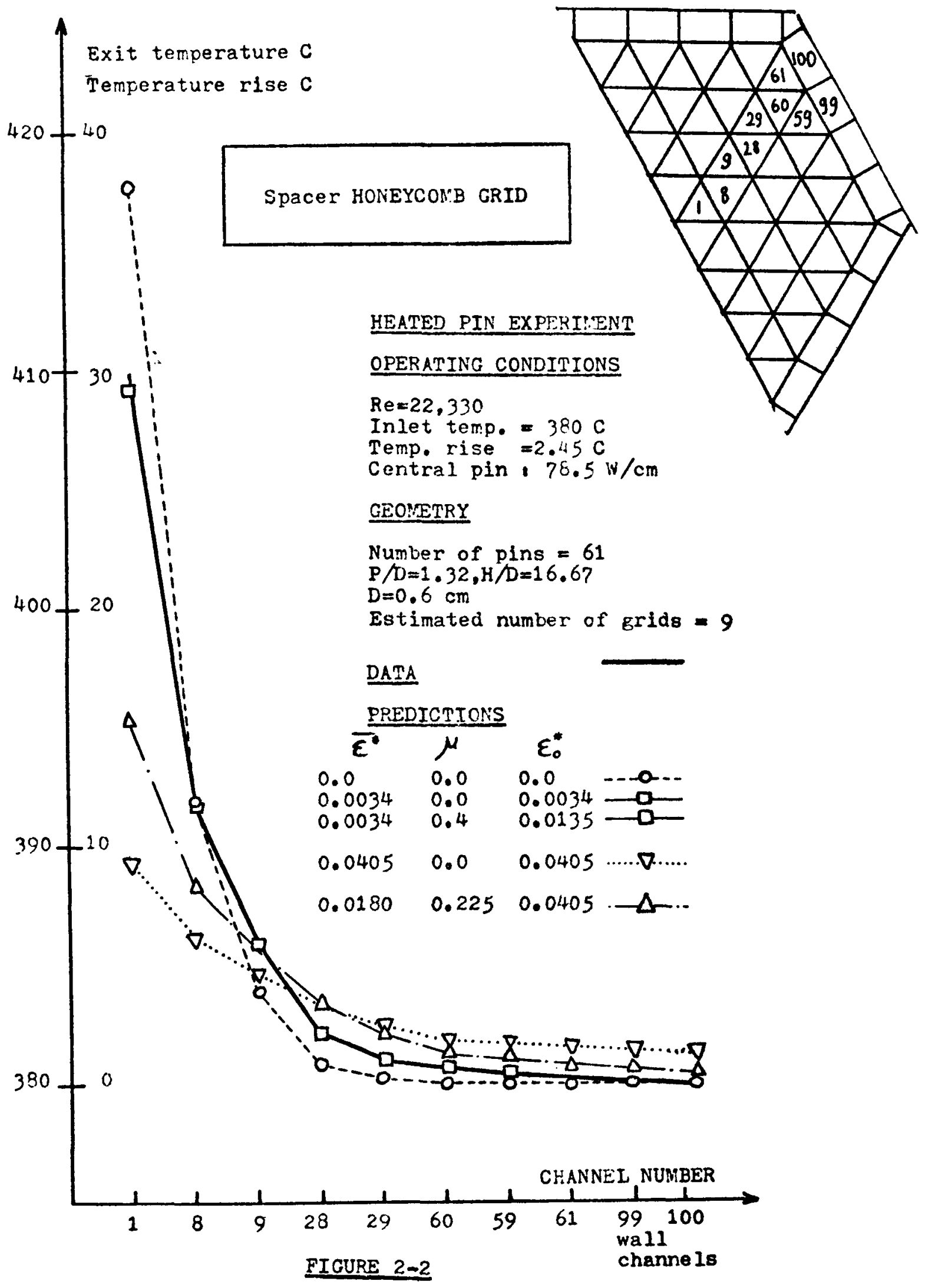




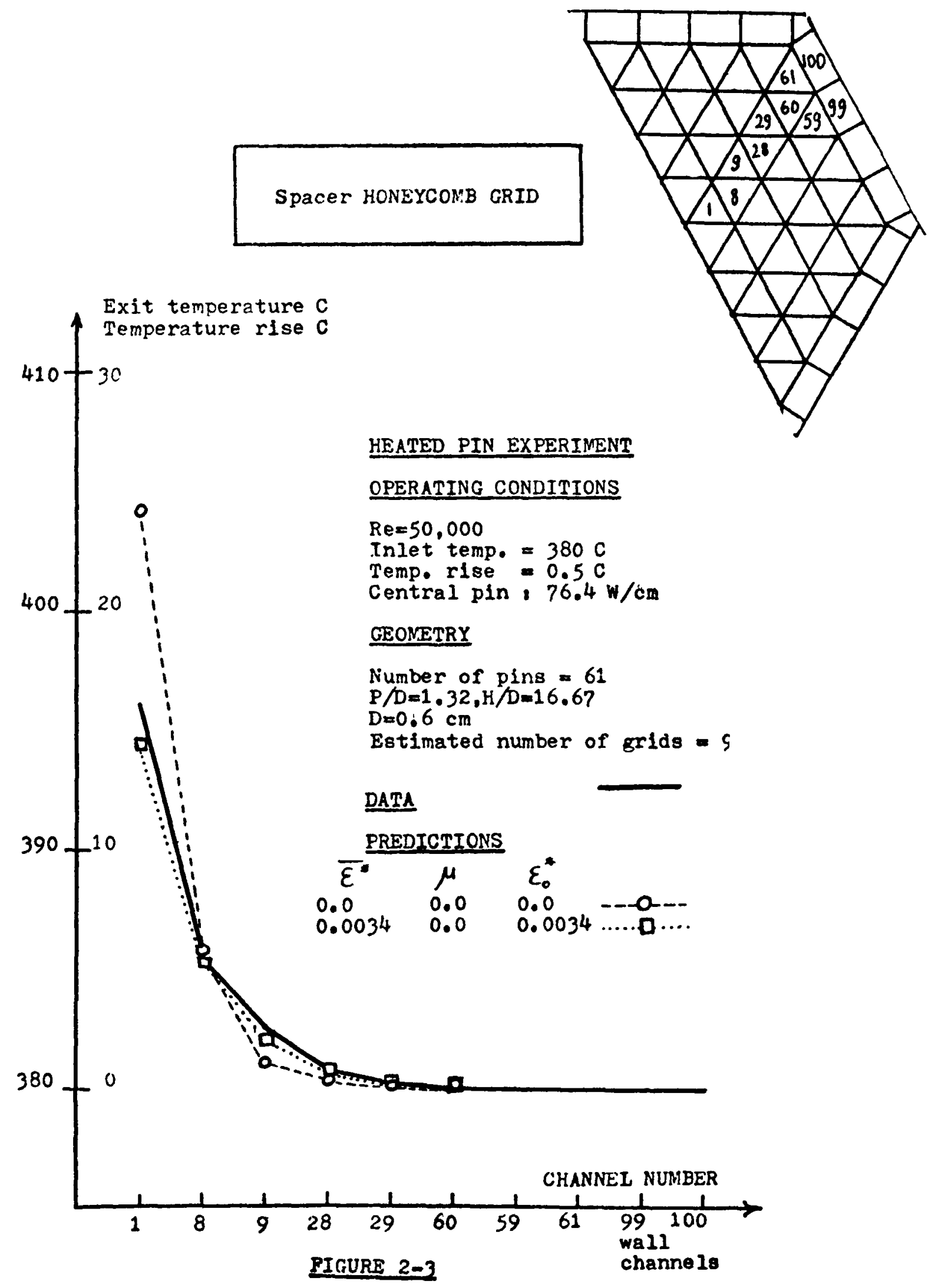


set of parameters corresponding to the same average value of $\varepsilon^{*}$ led to the same prediction.

If $\mathrm{H}$ is the distance between two grid spacers, the average is given by:

$$
\bar{E}^{\star}=\frac{1}{\mathrm{H}} \int_{0}^{\mathrm{H}} \varepsilon_{0}^{*} e^{-\mu x} d x=\varepsilon_{0}^{*}\left(\frac{1-e^{-\mu H}}{\mu H}\right)
$$

When $R_{e} \simeq 22,330$ (fig. 2-2) the best fit is obtained for $\bar{\varepsilon}^{\star}=0.0034$. This prediction can be obtained either with the couple of parameters $\left(\varepsilon_{0}^{*}=0.0135 ; \mu=0.4\right)$ or with $\left(\varepsilon_{0}^{*}=0.0034\right.$; $\mu=0$ ), which yield the same average: $\bar{\varepsilon}^{\star}=0.0034$.

Figure 2.3 shows the prediction for $R_{e} \simeq 50.000$. The best fit is again obtained for an average value of $\varepsilon^{*}$ equal to about 0.0034 .

These two experiments represent the two limits of the range of Reynolds number investigated by HOFFMANN and BAUMGARTNER.

Our results show that in this range $\bar{\varepsilon}^{*}$ is not sensitive to the Reynolds number.

Since these heated pin experiments only yield the temperature profile at one axial level (the exit), we have not been able to solve the ambiguity of our parametric representation. In this case $\bar{\varepsilon}^{\star}$, rather than $\left(\varepsilon^{*}\right.$ and $\left.\mu\right)$ is the significant parameter to be adjusted. If we had had at least the temperature profiles measured at two different axial level we could have solved separately for $\varepsilon$ * and $\mu$. 


\subsubsection{1:1 Scale Rod Bundle Flow Test}

An experiment was performed in the 11:1 scale grid-type rod bundle flow test to measure the scaler eddy diffusivity by a tracer injection and sampling technique. Samples of the tracer fluxes (ethane) are taken at two positions downstream of the injector to obtain axial variations of the fluxes in both the injection subchannel and those adjacent to it, fig. 2-4 and $2-5$.

The experimentally measured concentrations are shown in Table 2-I.

TABLE 2-I

\begin{tabular}{|c|c|c|c|c|}
\hline $\begin{array}{l}\text { Distance } \\
\text { Downstream } \\
\text { from } \\
\text { Injection }\end{array}$ & $\begin{array}{c}\text { Subchannel } \\
(0)\end{array}$ & $\begin{array}{c}\text { Subchannel } \\
(1)\end{array}$ & $\begin{array}{c}\text { Subchannel } \\
(2)\end{array}$ & $\begin{array}{c}\text { Subchannel } \\
(3)\end{array}$ \\
\hline $29.73^{\prime \prime}$ & $717.8 \mathrm{ppm}$ & $59.7 \mathrm{ppm}$ & $1.2 \mathrm{ppm}$ & $0.0 \mathrm{ppm}$ \\
\hline $35.73^{\prime \prime}$ & $707.9 \mathrm{ppm}$ & $176.7 \mathrm{ppm}$ & $3.3 \mathrm{ppm}$ & $1.5 \mathrm{ppm}$ \\
\hline
\end{tabular}

Using these data, the eddy diffusivity and cross flows have been calculated (Reference [8], p. 7-4)) for the axial position between the two measurement positions.

$$
\begin{aligned}
& \varepsilon_{m}^{\theta}=0.073 \mathrm{ft}^{2} / \mathrm{sec} \\
& v_{1-0}=3.395 \mathrm{ft} / \mathrm{sec} \\
& v_{2-0}=-2.235 \mathrm{ft} / \mathrm{sec} \\
& v_{3-0}=1.072 \mathrm{ft} / \mathrm{sec}
\end{aligned}
$$




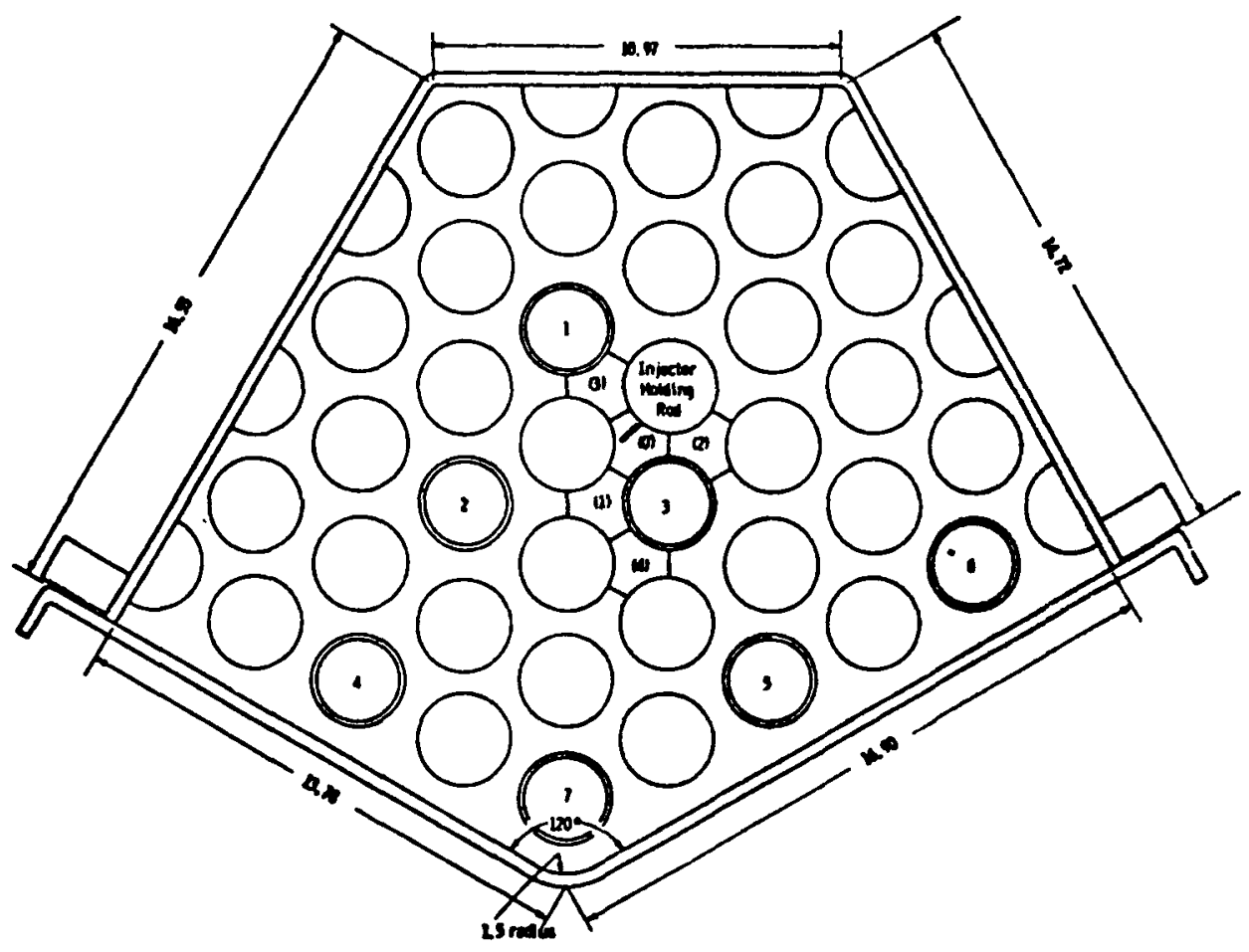

CROSS -SECTION OF TEST SECTION (DIMENSIONS IN INCHES)

\section{PIGURE 2-4}




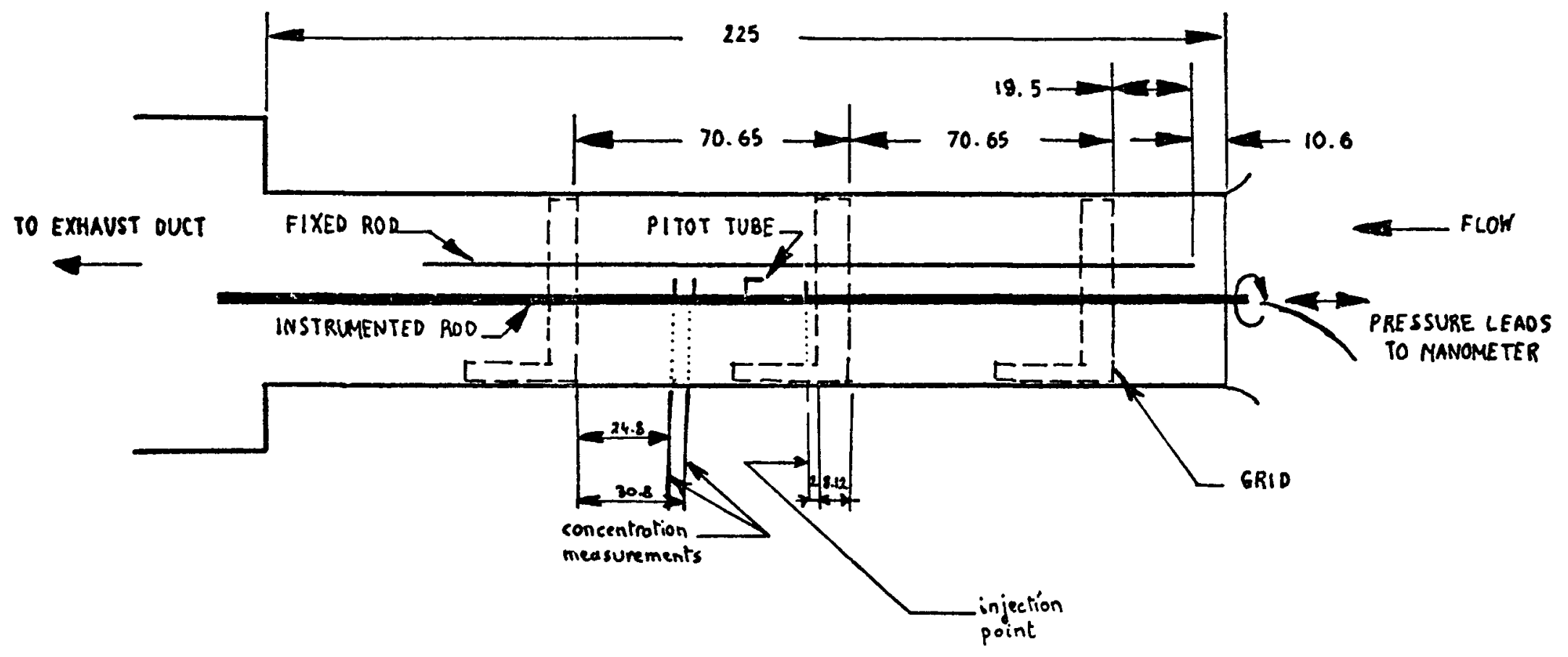

All aimensions are in inches.

Axial location of the injection and measurement points.

11,1 SCALE ROD BUNDIE FIOW TEST 
The negative sign on $V_{2-0}$ and $V_{3-0}$ indicates the flow is going from the injected subchannel to the adjacent subchannel.

It is obvious in these conditions that ENERGY I will never be able to predict these concentrations. The three cross flows in the region of measurement positions are very different (in value and sign) and hence, the exchange phenomenon at each of the three gaps of the subchannel (0) are not similar at all.

The assumption of an isotropic exchange at the boundaries of each subchannel of the inner region, is made in ENERGY I; the exchange at each boundary between two adjacent subchannel is assumed to be only due to the eddy diffusivity, adjusted by a single parameter $\varepsilon^{\star}$.

No directional cross flow effect is taken into account in this inner region. Assuming an axial eddy diffusivity profile of the form $\varepsilon_{m \theta}=\varepsilon_{\theta} e^{-x / l}$, using the expression for $\varepsilon_{m \theta}$ given in Reference [8] p. 7-8, and calculating the concentration profiles with ENERGY I yields the following results:

$$
\begin{aligned}
& \varepsilon_{0}=0.138 \mathrm{ft}^{2} / \mathrm{sec} \\
& \varepsilon_{O}^{*}=\frac{\varepsilon_{0}}{\bar{V} D_{e}} \frac{\lambda_{L I}}{\bar{\lambda}_{a}}=0.0047 \\
& \mu=0.014 \mathrm{in.}_{.}^{-1}
\end{aligned}
$$

where $\bar{V}$ is the average velocity across the bundle $(92 \mathrm{ft} / \mathrm{sec})$ $D_{e}$ is the hydraulic diameter of a triangular subchannel (1.851") 
$\lambda_{a}$ and $\lambda_{L 1}$ are the two coefficients used in the porous body model and presented in the nomenclature of Chapter $I$.

$$
\begin{aligned}
& \lambda_{\mathrm{Ll}}=0.1958, \bar{\lambda}_{\mathrm{a}}=0.4050 \\
& \text { Relative Concentration Profiles, } \frac{\mathrm{C}(\mathrm{z})}{\mathrm{C}_{\mathrm{o}}}
\end{aligned}
$$

TABLE 2-II

\begin{tabular}{|l|c|c|c|}
\hline $\begin{array}{l}\text { Distance } \\
\text { Downstream } \\
\text { from } \\
\text { Injection }\end{array}$ & $\begin{array}{c}\text { Subchannel } \\
(0)\end{array}$ & $\begin{array}{c}\text { Subchannel } \\
(1),(2),(3)\end{array}$ & $\begin{array}{l}\text { Subchannels } \\
\text { Adjacent to } \\
(1),(2),(3)\end{array}$ \\
\hline $29.73 \mathrm{in.}$ & 0.755 & 0.074 & 0.003 \\
\hline $35.73 \mathrm{in.}$ & 0.725 & 0.082 & 0.004 \\
\hline
\end{tabular}

where $C(z)$ is the concentration at the elevation $z$ and $C_{0}$ is the concentration at the injection.

It is unfortunately impossible to compare these results based on a uniform exchange through the gaps, with the experimental data because the experimental bundle appeared to have directional cross flows present. 


\subsection{Conclusion}

The two experimental data analyzed in the preceding paragraphs, dit not completely accomplish the purpose of this section. The validity of our simplified model for the eddy diffusivity axial variations, could not be checked thoroughly and it would be interesting to pursue this study with other sets of data, having at least two axial measurements.

If the parameters ( $\varepsilon_{0}^{*}$ and $\mu$ ) can independently be adjusted and if ENERGY I's predictions match satisfactorily the experimental measurements, it would be then interesting to find a correlation expressing $\varepsilon_{0}^{*}$ and $\mu$ in terms of the geometrical parameters of the bundle (geometry of the grids, space between them ...).

However, this study has proved that this simplified model can predict the temperature profile at one axial level, by adjusting an average value of the eddy diffusivity $\bar{\varepsilon}^{\star}$, (lumping together the effect of the two parameters $\varepsilon_{0}^{*}$ and $\left.\mu\right)$. 
CHAPTER 3

OAK RIDGE NATIONAL LABORATORY 5C BUNDLE

\section{$3.1 \quad$ Introduction}

No data from wire wrapped bundle with a half sized gap has been analyzed so far and all the correlations expressing $\left(\varepsilon^{*}\right.$ and $\left.C\right)$ in terms of the geometrical parameters are based on the results obtained with bundles having a full sized gap. The ORNL 5C Bundle will be analyzed here and the results will be compared to the set of parameters given by the usual correlations and supposed to give the best fit if the gap had a full size.

This bundle possesses the same geometrical characteristics as bundle $2 \mathrm{~A}$ analyzed in Reference [10], but the diameter of the helical wire in the gap region has been reduced to half its size.

These parameters are:

Pitch $\mathrm{P}=0.286$ inches

Rod diameter $D=0.230$ inches

Helical pitch $\mathrm{H}=12$ inches

19 heated pins

Gap: $g=0.028$ inches

Wire diameter: $d=0.056$ inches

Liquid sodium was used to cool the electrically heated pins. The heated length of the rods is 18 inches. The coolant 


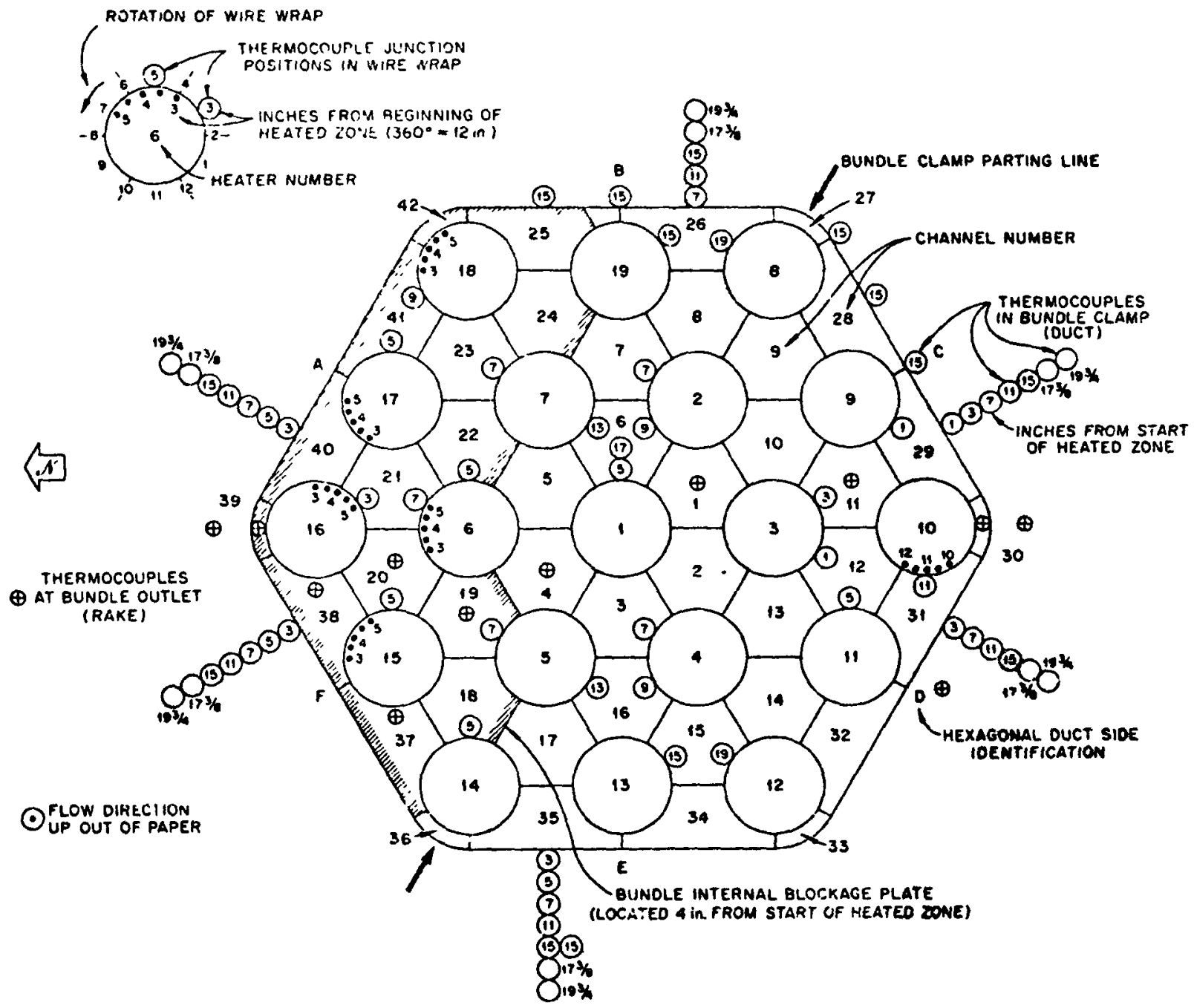

IMPBR-FFM BUNDIE 5B INSTRULISNATION 
enters the bundle approximately 6 inches below the plane where the rods are heated in order to provide a fully developed flow field at the entrance to the heated section. Thermocouples are located in the rod walls and also in the wire wraps. An exit rake is located 3 inches above the exit of heated bundle and is instrumented with thermocouples which directly measure coolant at the center of various subchannels. The axial power profile is uniform. The hexagonal duct wall is surrounded by guard heaters to minimize heat losses.

\subsection{Analysis of the Data}

\subsubsection{Procedure Adopted}

This procedure is described by KHAN in Reference [4]; it is based on the fact that the two parameters are independent and have separate effects:

- $\varepsilon^{*}$ affects mostly the inner region and does not greatly influence the temperature distribution in the gap.

- C affects essentially the wall region.

A third parameter to be adjusted is the flow split in the bundle. Experiments show indeed that for turbulent flow, the measured flow split is not very satisfactorily represented by NOVENDSTERN theoretical flow split, even for bundles with half size edge wires and would be closer to a uniform velocity profile (see Table prepared by A.A. Bishop and reproduced as fig. $(3-2)$. 


\section{RATIO OF SIDE SUBCHANNEL AXIAL AVERAGE VELOCITY TO BUNDLE AXIAL AVERAGE VELOCITY}

\begin{tabular}{|c|c|c|c|c|c|}
\hline Rods-In-Bundle & Experimenter & $\left(U_{S} / U\right)_{\text {Noninal }}$ & Reynolds Number & Method & $\begin{array}{c}\text { Possible } \\
\text { Range }\end{array}$ \\
\hline 7 & Ginsberg-Lorenz & $\begin{array}{l}1.00(3)(2) \\
1.00(3)(2)\end{array}$ & $\begin{array}{l}17,000 \\
13,000\end{array}$ & Isokinetic & \\
\hline 19 & Graves \& Catton & 1.00 & $10,000-90,000$ & Salt Tracer & $\pm 5 \%$ \\
\hline 19 & Graves \& Catton (1) & 1.00 & $10,000-90,000$ & Salt Trácer & $\pm 5 \%$ \\
\hline 61 & Chen-Todreas & 1.19 & 640 & Laser Beam & $\pm 4 \%$ \\
\hline 61 & Chen-Toulreas & 1.04 & 4500 & Laser Beam & $\pm 4 \%$ \\
\hline 91 & Pedersen et. al. (4) & 1.17 & $5,000-20,000$ & Dye Tracer & $\pm 4 \%$ \\
\hline 91 & Pedlersen et. al. & 1.03 & $5,000-20,000$ & Thermal Tracer & $\pm 4 \%$ \\
\hline 91 & Lorenz et. al. & 0.99 & $9,000-20,000$ & Isokinetic & \\
\hline 217 & Graves \& Catton & 1.00 & $10,000-90,000$ & Salt Tracer & $\pm 5 \%$ \\
\hline 217 & Graves \& Catton $(1)$ & 1.00 & $10,000-90,000$ & Salt Tracer & $\pm 5 \%$ \\
\hline
\end{tabular}

(1) Side Channel Area Decreased By Reducing Wire Wrap Diameter -

(2) Calculated By A. A. Bishiop

(3) All 12 Subchannels Sampled

(4) Refer To Paragraph 7 Under Conclusions 
The following table shows the difference in the theoretical flow split for bundles $2 \mathrm{~A}$ a normal geometry fuel array and 5C. The first set of values reported for $5 \mathrm{C}$ is yielded by an exact flow split calculation, taking the half size of the wire in the gap, into account. The second set of values reported for 5C are yielded by the usual version of ENERGY I, for half sized gap and a wire diameter supposed uniform (since there is no special input for the edge wire). The slight inconsistancy introduced here changes the preceding values by about 48 . The exact flow split calculation has been used for the following study.

TABLE 3-I

\begin{tabular}{|cc|c|c|c|}
\hline \multirow{2}{*}{ Bundle 2A } & $X_{I}$ & $X_{I I}$ & $X_{I I I}$ \\
\cline { 3 - 5 } & & 0.936 & 1.083 & 0.884 \\
\hline Bundle 5C & $(1)$ & 1.030 & 1.001 & 0.658 \\
& $(2)$ & 1.063 & 0.956 & 0.626 \\
\hline
\end{tabular}

The adopted procedure consists then of the three following steps:

- Choosing a flow split

- Adjusting the parameter $\varepsilon^{*}$ to obtain the best fit of the prediction for the inner subchannels with the data

- Adjusting the parameter $c$ to obtain the best fit in the wall region. Since this last adjustment does not greatly affect the results of the inner region, it is 
unnecessary to iterate these two adjustments. The prediction thus obtained is the best one for the initially assumed flow split.

\subsubsection{Description of the Data (Reference [11])}

The temperature profile measurement has been performed at the exit of the test section, for three different cases.

- Bundle 5C with a 7.58 power skew and a 508 over powered corner pin

- Bundle 5C with a 15\% power skew and a 508 over powered corner pin

- Bundle 5C with a 258 power skew and a 508 over powered corner pin.

For each of these cases, a range of Reynolds number from $(4,000$ to 65,000$)$ has been investigated.

The test-section housing is covered with 1.5 inch Kaowool insulation enclosed in a $1 / 16$ inch thick stainless steel sheath wrapped with electrical guard heaters.

However, for low Reynolds number, the average velocity is so low (up to $2 \mathrm{gpm}$ ) and the temperature rise so large that the effectiveness of the insulation becomes questionable.

Therefore, the heat loss occuring through this insulation ranges from 2.248 to more than 208 for low flow cases.

Since ENERGY I treats the bundle as though it was insulated at its outer boundary, we have been obliged at this point to 
eliminate from our analysis the cases corresponding to too large heat loss (more than $5 \%$ ).

The analyzed ranged of Reynolds number is $[27,200$ to $65,200]$.

\subsubsection{Analysis of the Results}

For each of the four studied cases, runs have been made with several versions of ENERGY I.

First $\varepsilon^{*}$ and $C$ have been adjusted to give the best fit with the adiabatic version of ENERGY I. The outer boundary (wal1) is supposed to be insulated. When the heat loss is important, this program overpredicts the average exit temperature by up to $6.7^{\circ} \mathrm{F}$ (for 58 heat loss).

With this first program two models of flow split are studied, the theoretical flow split and the uniform flow split. Results using these flow splits are very similar, except for the case of the corner subchannels. Indeed, we get about equivalent predictions in both cases, using the same value for $\varepsilon^{*}$ and slightly different values for $C$.

Secondly, a new version of ENERGY I, recently written has been used to allow some heat loss through the housing, (Reference [12]). This version, called SUPERENERGY, is an extension of the initial program; it is able to calculate the temperature profile across a whole assembly of fuel and blanket bundles, separated by a gap of sodium. SUPERENERGY can simulate the heat loss in several ways. 
The most direct way is to consider a fuel bundle, with an outer gap in which the coolant is allowed to flow. One can assume a constant flow rate for the coolant in the gap and then try to adjust the conductivity in the wall, to predict exactly the average exit temperature.

Another way consists of using the same whole bundle-gap as before, but trying to adjust the flow rate in the gap with a constant wall conductivity.

These two procedures assume that the whole bundle-gap is insulated at the outer boundary.

The last way consists of adding six adjacent bundles at the periphery of the bundle of interest. This ensemble of 7 bundles is assumed to be insulated at its outer boundary but heat exchange is allowed through the gaps between these bundles. The inlet temperature is uniform; there is no heat generation in the peripheral bundles which act like heat sinks. The exit temperature is adjusted as before by varying the flow rate of the coolant in the gaps.

These three types of calculation procedures have been tested within SUPERENERGY.

It turns out that the corresponding temperature profile in the analyzed bundle is not very sensitive to the way the heat loss is taken into account. The two first procedures appear to be about equivalent; with the third one the 
temperature profile predicted by the two others flattens slightly in the overpowered region.

For the runs made with SUPERENERGY, only the theoretical flow split has been considered. Trial runs have shown that the overall fit to data cannot be improved using a uniform flow split. Specifically by substituting a uniform flow split, the temperatures in the interior and edge subchannels would rise slightly while those in the corner subchannels would drop. These changes are accomodated by increasing $\varepsilon^{*}$ slightly and dropping $C$. However as noted above, even with such changes, the fit of predictions with data for all subchannels across the bundle is not improved.

\subsubsection{Test $46-101$}

The experimental data are the following:

Heat balance $97.76 \%$

$\operatorname{Re} \simeq 65,200$

Temperature rise: $63.3^{\circ} \mathrm{F}$

Power skew: 158

One 508 overpowered rod in the corner 37.

\subsubsection{I ENERGY I with Theoretical Flow Split}

Good predictions of the temperature profile in the inner region have been obtained for several values of $\varepsilon^{\star}$ ranging from 0.0045 to 0.0178 . The parameter $\varepsilon^{\star}$ does influence the profile but the predictions are about equally good. The average exit temperature is $699.8^{\circ} \mathrm{F}$ and the actual temperature is overpredicted by $0.9^{\circ} \mathrm{F}$. 
The set of parameters

$$
\varepsilon^{*}=0.089 \text { and } \quad C=0.0268
$$

predicts well the temperature in the overpowered region. Figure 3-3 shows predictions corresponding to different values of $\varepsilon^{*}$.

It has been impossible to obtain a simultaneous fit for the three wall channels $(40,31,32)$, by adjusting the value of $c$.

\subsection{ENERGY I with Uniform Velocity}

Since the theoretical flow split is very close to the uniform velocity profile, for a bundle having a half sized gap, the predictions are very similar to the preceding, except for the corner channels. The same predictions as above are obtained, when the value of $C$ is adjusted to yield the best fit with the data. This value of $C$ leading to the same fit in the corner regions, is lower than the preceding since the velocity ratio $\mathrm{x}_{\text {III }}$ is lower also $(0.058<1)$

The set

$$
E^{*}=0.089 \text { and } \quad C=0.0178
$$

predicts well the temperature in the overpowered region. Figure 3-4 shows the results.

\subsection{SUPERENERGY with Theoretical Flow Split}

Figure 3-5 shows the different curves obtained with this computer program. Taking the heat loss into account drops the 


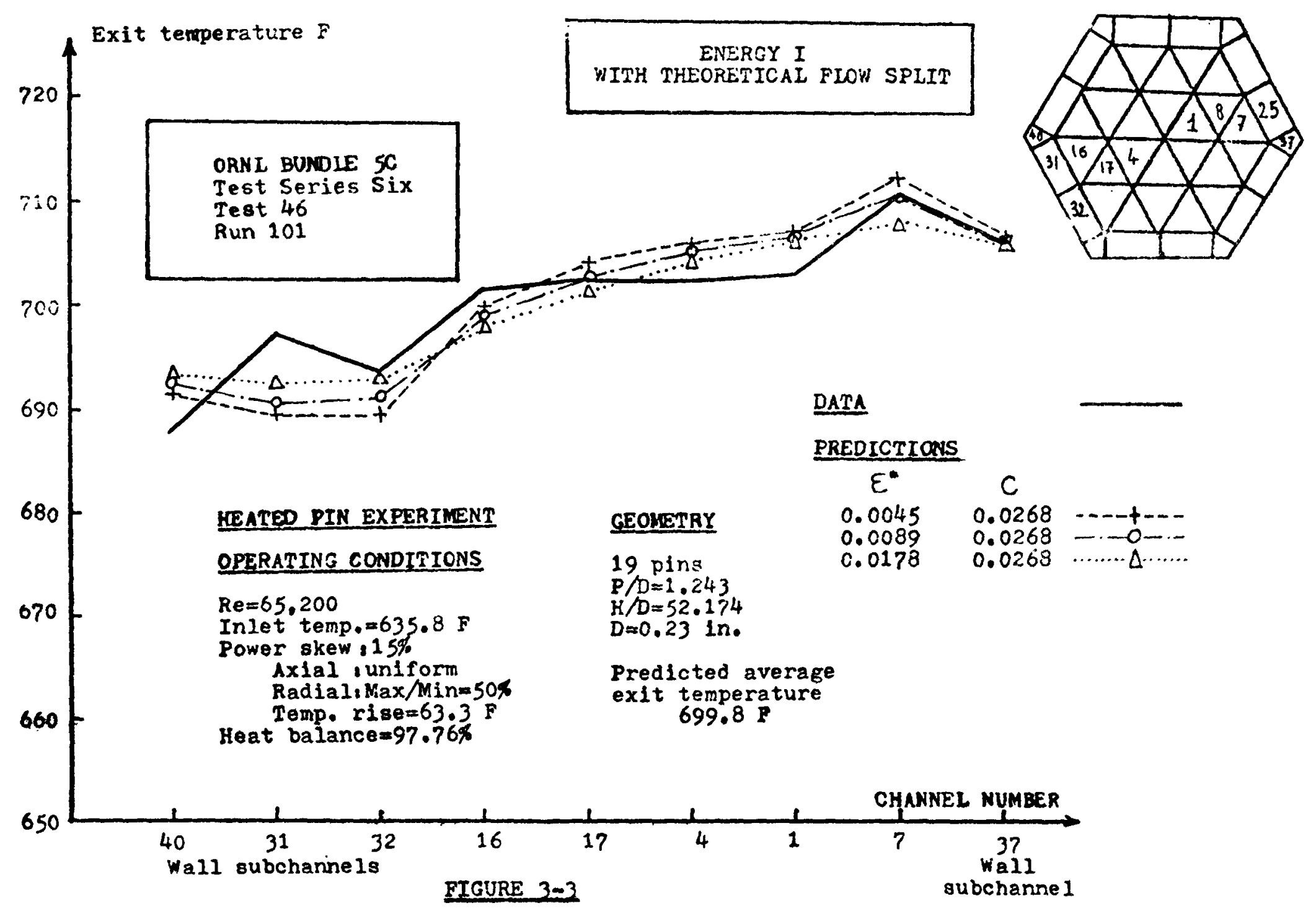




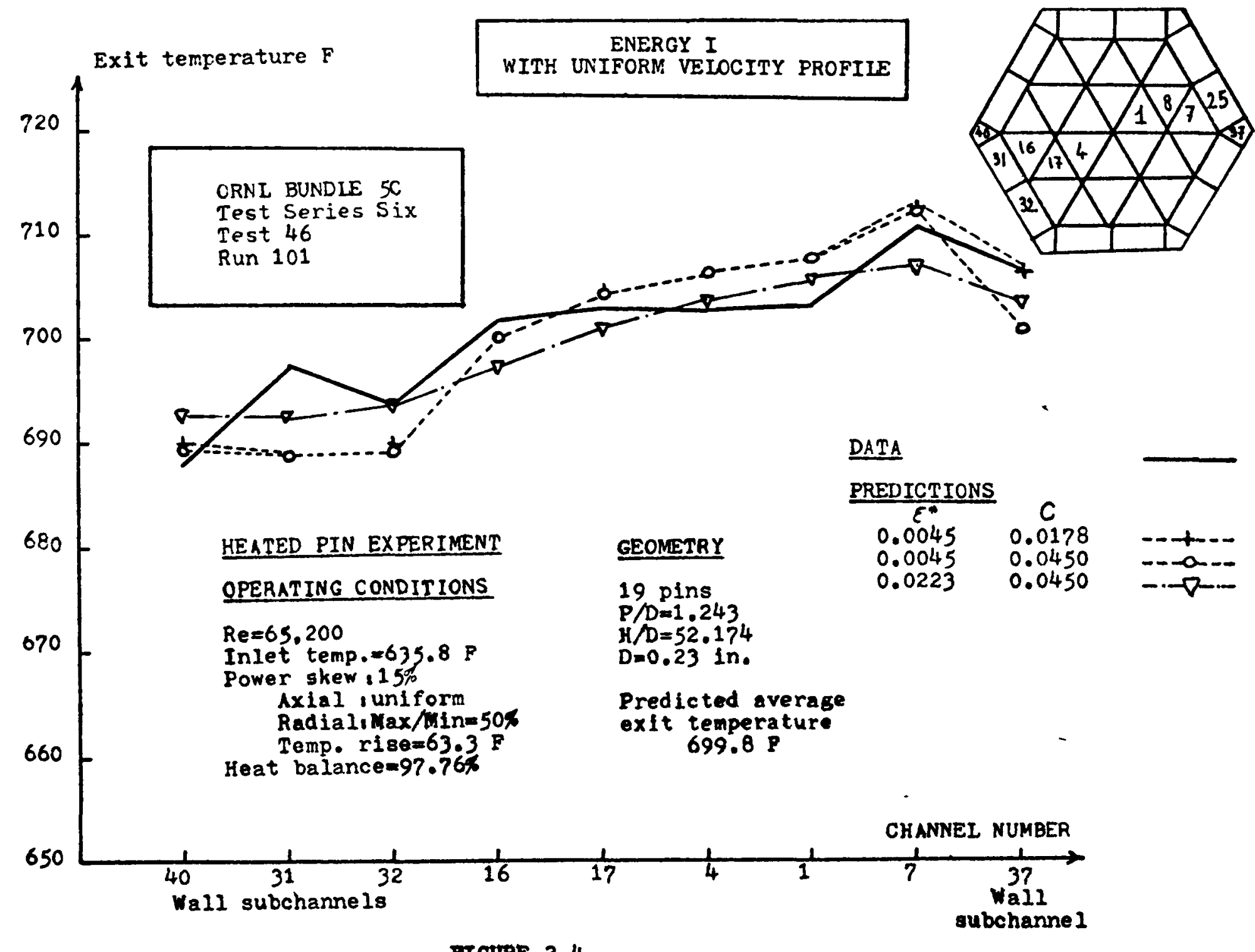




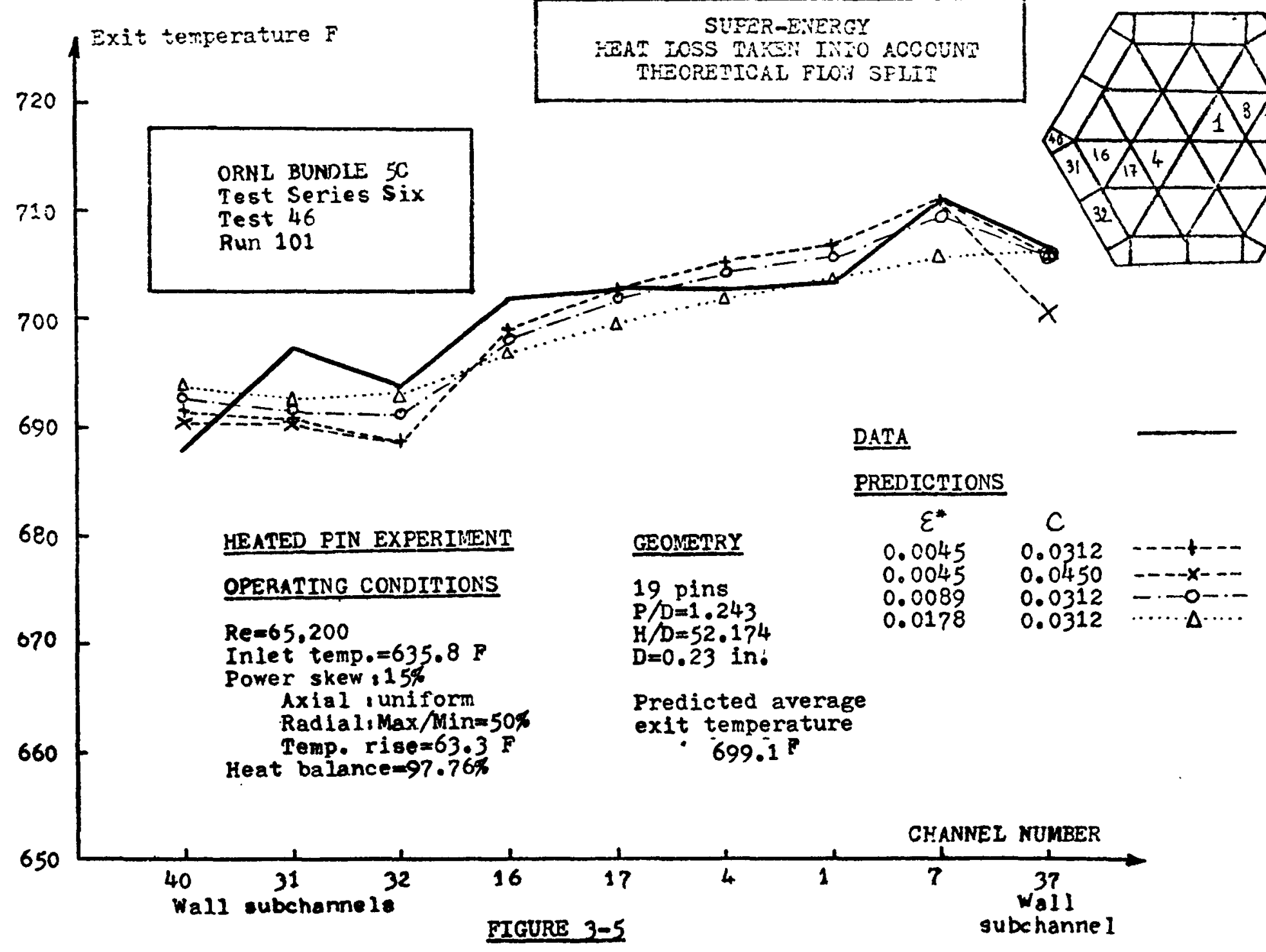


temperature prediction in the wall region since this boundary is no longer insulated. The inner region is not significantly affected by this heat loss.

When the average exit temperature is adjusted to its experimental value $699.1^{\circ} \mathrm{F}$ by dropping the wall conductivity to $1.2 \mathrm{BTU} / \mathrm{ft} \mathrm{hr}{ }^{\circ} \mathrm{F}$, for a flow rate in the gap of $500 \mathrm{lb} / \mathrm{hr}$, several values of $\varepsilon^{*}$, in the range $(0.045$ to 0.0178$)$ yield about equally good predictions.

The set

$$
\varepsilon^{*}=0.045 \text { and } C=0.0312
$$

predicts well the temperature in the overpowered region.

In fact, in this paragraph as well as in the two preceding ones, the predictions are so equivalent that it is questionable to speak about a particular best fit.

Figure 3-6 shows that the three ways of taking the heat loss into account are about equivalent. The three curves corresponding to

$$
\varepsilon^{\star}=0.0045 \text { and } \mathrm{C}=0.0450
$$

are obtained with the flow split (2) of Table 3-I, they coincide approximately for the inner subchannels.

There are only very few degrees of discrepancy in the region of the overpowered rod. Since the exit temperature of the coolant in the gap is lower when the six bundles are added, 


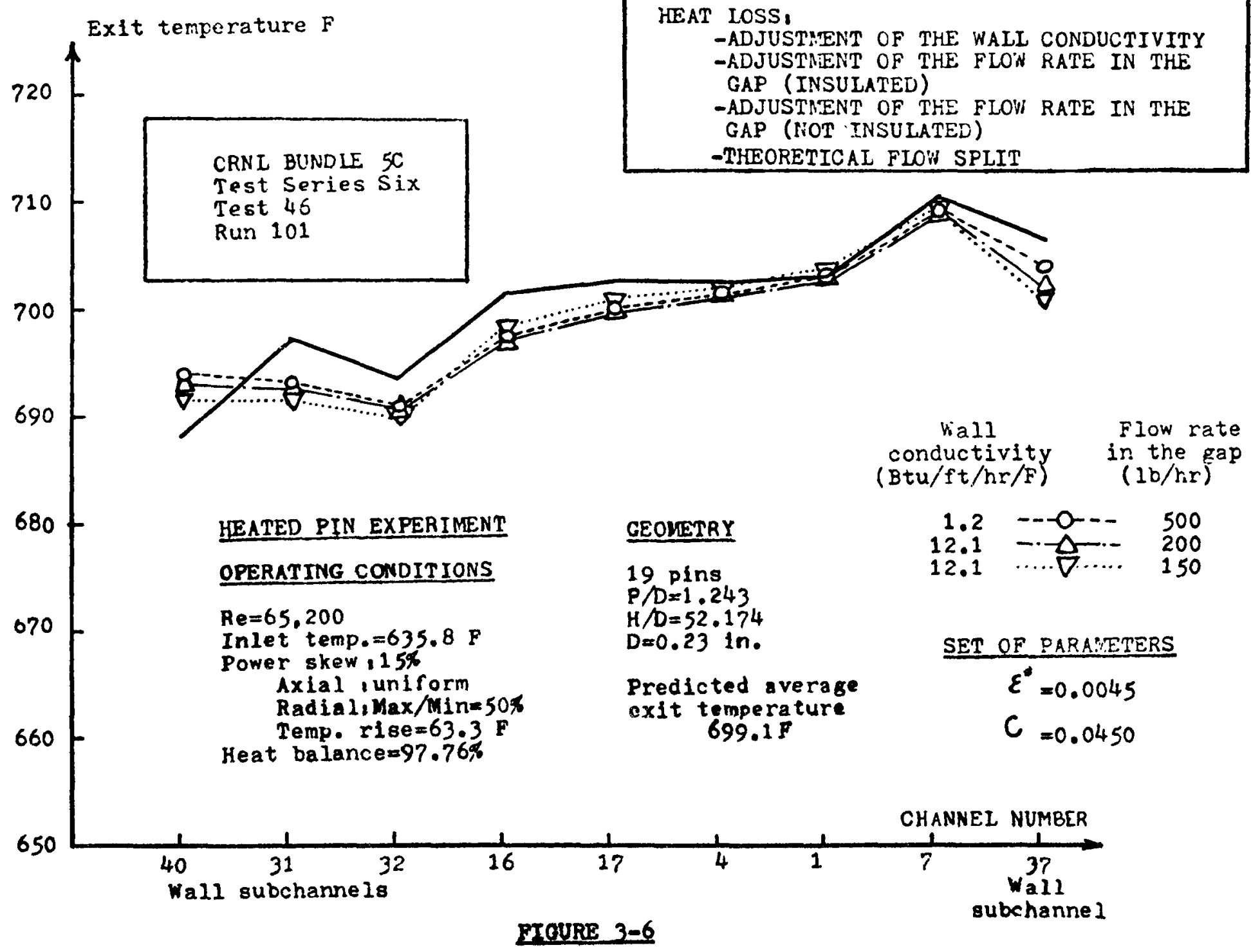


the heat transfer through the wall is more important and the temperature drops slightly in the corner subchannel 37.

The same results would probably be found with the flow split (1) of Table 3-I.

For the 46-101 test the best fit is then obtained for

$$
\varepsilon^{*}=0.0045 \text { and } \quad \mathrm{C}=0.0268
$$

with ENERGY I (theoretical flow split).

Comparable predictions are made when a uniform velocity profile is assumed.

However numerous predictions by ENERGY I with uniform flow split are good but show little sensitivity of results to input parameters with respect to improving the prediction.

\section{2 .3 .2 Test $46-104$}

The experimental data are the following:

Heat balance: $95.26 \%$

$\operatorname{Re} \simeq 27,200$

Temperature rise: $154,53^{\circ} \mathrm{F}$

Power skew: 158

One $50 \%$ overpowered rod in the corner 37 .

\subsection{ENERGY I with Theoretical Flow Split}

The heat loss is important in this case and the program overpredicts the average exit temperature by $6.7^{\circ} \mathrm{F}\left(791.7^{\circ} \mathrm{F}\right.$ instead of $785.0^{\circ} \mathrm{F}$ ). 
Good predictions have been obtained with small values of $\varepsilon^{*}$. The best agreement with the peak in the overpowered region has been obtained for the set:

$$
\varepsilon^{*}=0.0022 \text { and } C=0.0238
$$

The corresponding prediction shows a maximum discrepancy of $5^{\circ} \mathrm{F}$ in the inner region. The temperature distribution flattens significantly when $\varepsilon^{\star}$ increases. For a value of $\varepsilon^{*}$ equal to 0.0045 the prediction is still good, but the peak is underpredicted by $4^{\circ} \mathrm{F}$.

The adopted value of $C$ matches the temperature in the corner 37 , but is not able to represent correctly the profile in the wall subchannels $(40,31,32)$.

The results are shown on fig. 3-7.

\subsection{ENERGY I with Uniform Velocity}

An about equivalent fit has been obtained with this velocity profile, when the value of $C$ is dropped to 0.0178 and the value of $\varepsilon^{*}$ taken equal to 0.0045 the effect of increasing the flow rate in the corner subchannels, drops the temperature in these regions, and keeping the same prediction for subchannel 37 requires that $\mathrm{C}$ decreases. This is what is effectively observed. Only the wall subchannels 31 and 32 are not correctly predicted. The results are shown on fig. 3-8. 


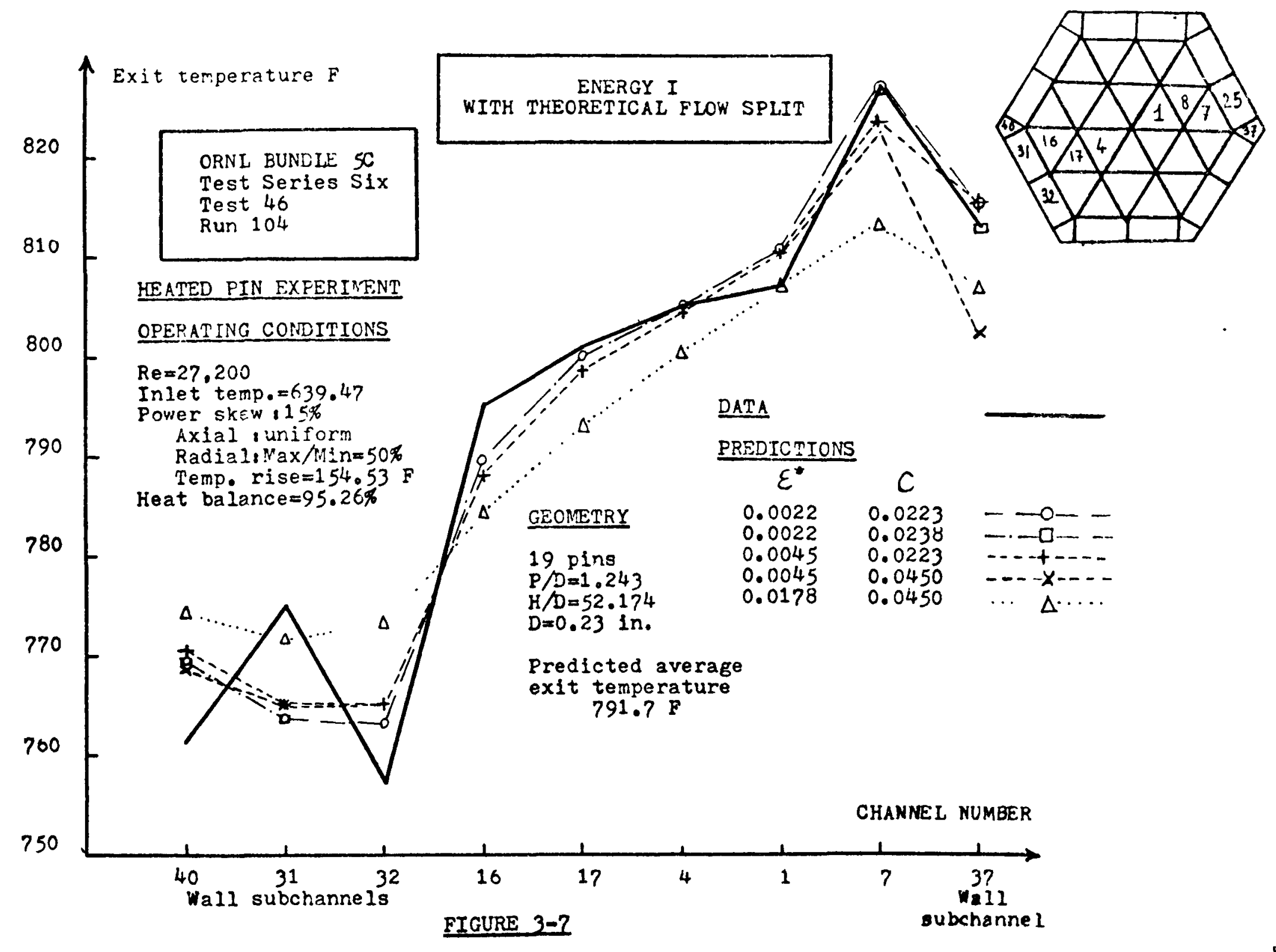




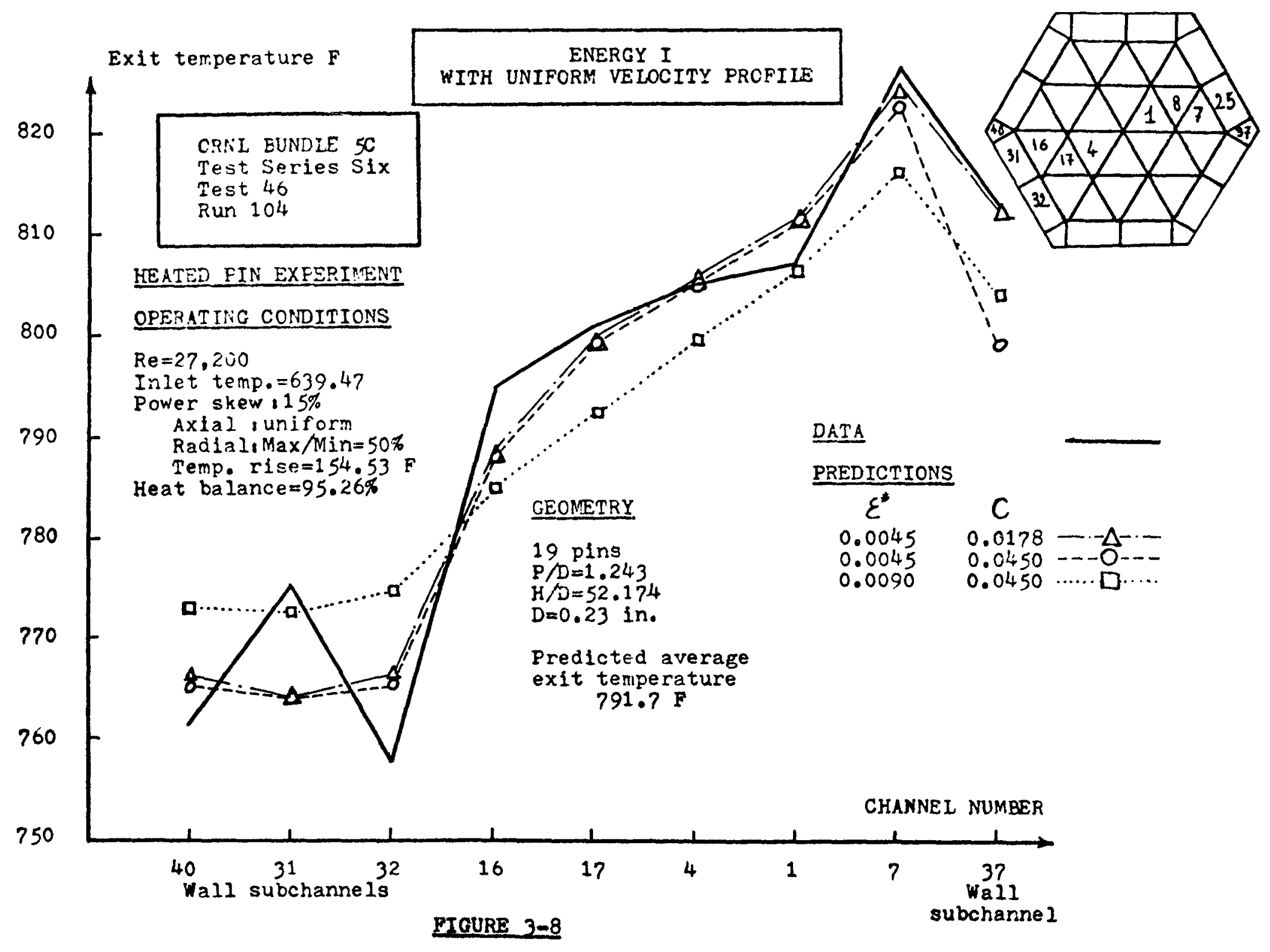




\subsection{SUPERENERGY with Theoretical Flow split}

The average exit temperature has been adjusted to $785^{\circ} \mathrm{F}$ by dropping the wall conductivity to $2.15 \mathrm{BTU} / \mathrm{ft} \mathrm{hr}{ }^{\circ} \mathrm{F}$ for a flow rate in the gap of $500 \mathrm{lb} / \mathrm{hr}$.

Taking the heat loss into account decreases the temperature profile everywhere and especially in the wall channels, where the heat transfer occurs.

No set of parameters could yield a better prediction than the preceding two. The best fit corresponds to about

$$
\varepsilon^{*}=0.0022 \text { and } \quad \mathrm{C}=0.0178
$$

The results are shown on fig. 3-9 and the fit with the value $\mathrm{C}=0.0178$ can be seen by interpolation.

When $\varepsilon *$ further decreases (up to 0.0004 ) the peak becomes very well predicted, but the calculated exit temperatures of the subchannels 40,31 , and 32 decrease drastically, so that this solution does not improve the preceding fit.

For the 46-104 test, the best fit is obtained for

$$
\varepsilon^{*}=0.0022 \text { and } \mathrm{C}=0.0268
$$

with ENERGY I (theoretical flow split) comparable predictions are made when a uniform velocity profile is assumed.

\subsubsection{Test $47-101$}

The experimental data are the following: 


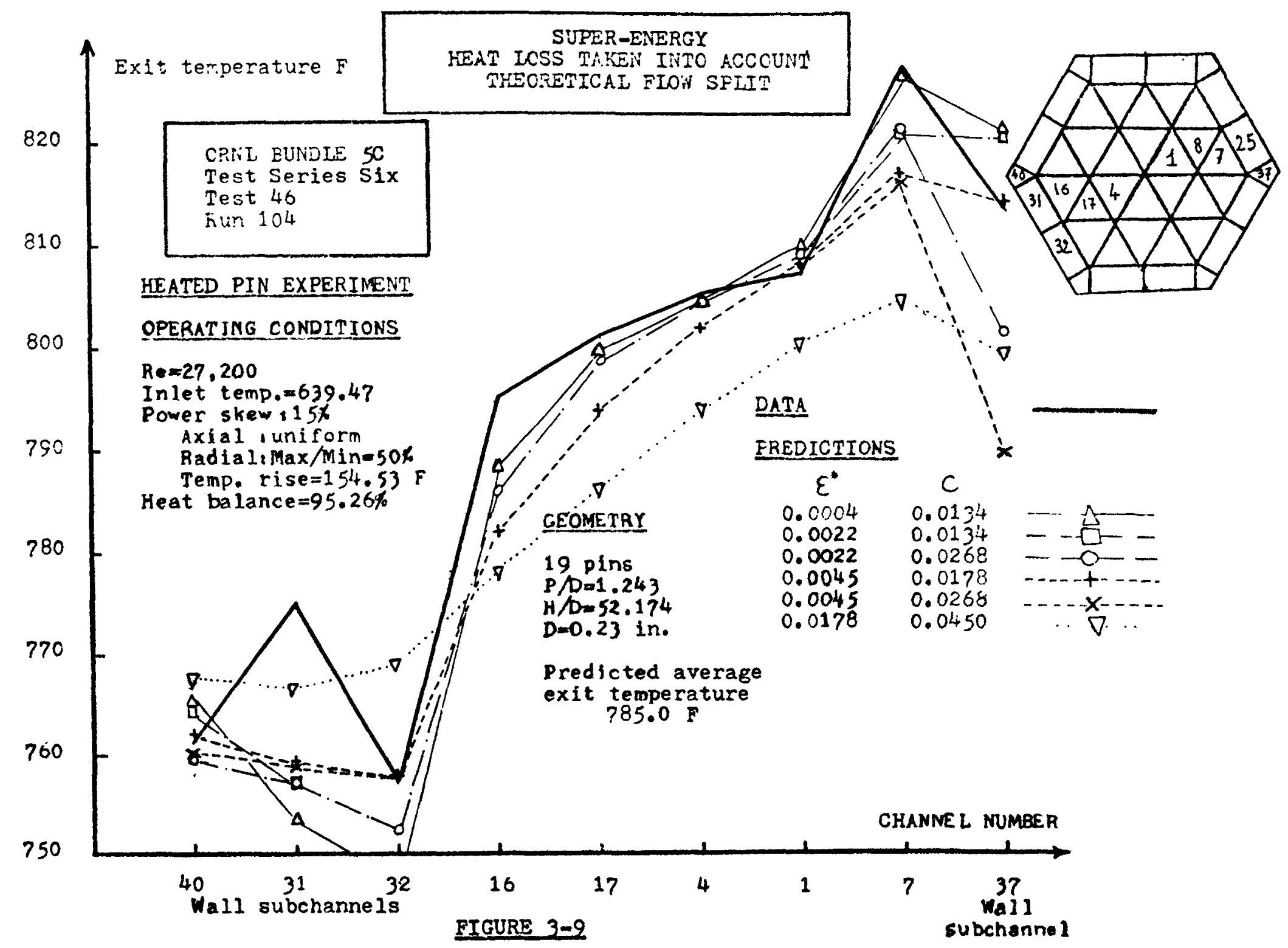


Heat balance: $96.90 \%$

$\operatorname{Re}=64,460$

Temperature rise: $62^{\circ} \mathrm{F}$

Power skew: 25\%

One $50 \%$ overpowered rod in the corner 37.

3.2.3.3.1 ENERGY I with Theoretical Flow Split

The program overpredicts the average exit temperature $\left(687.5^{\circ} \mathrm{F}\right)$ by $1.7^{\circ} \mathrm{F}$

About equivalent predictions have been obtained when $\varepsilon^{*}$ varies within the range $(0.0022$ to 0.0178$)$.

The set of parameters

$$
\varepsilon^{*}=0.0022 \text { and } \mathrm{C}=0.0535
$$

leads to a good prediction of the peak in the overpowered region. However, whatever, parameters are assumed, it has been impossible to reduce the discrepaicy in the corner 40 , further than $12^{\circ} \mathrm{F}$.

The results are shown on fig. 3-10.

\subsection{ENERGY I with Uniform Velocity}

An about equivalent fit has been obtained with this velocity profile, when the value of $C$ is slightly decreased to 0.0450 .

The value of the parameter $\varepsilon^{*}$ has been investigated in the range $(0.0045$ to 0.0223$)$. About equally good predictions have been obtained for several values of $\varepsilon^{*}$, and speaking of a particular best fit might be questionable. 


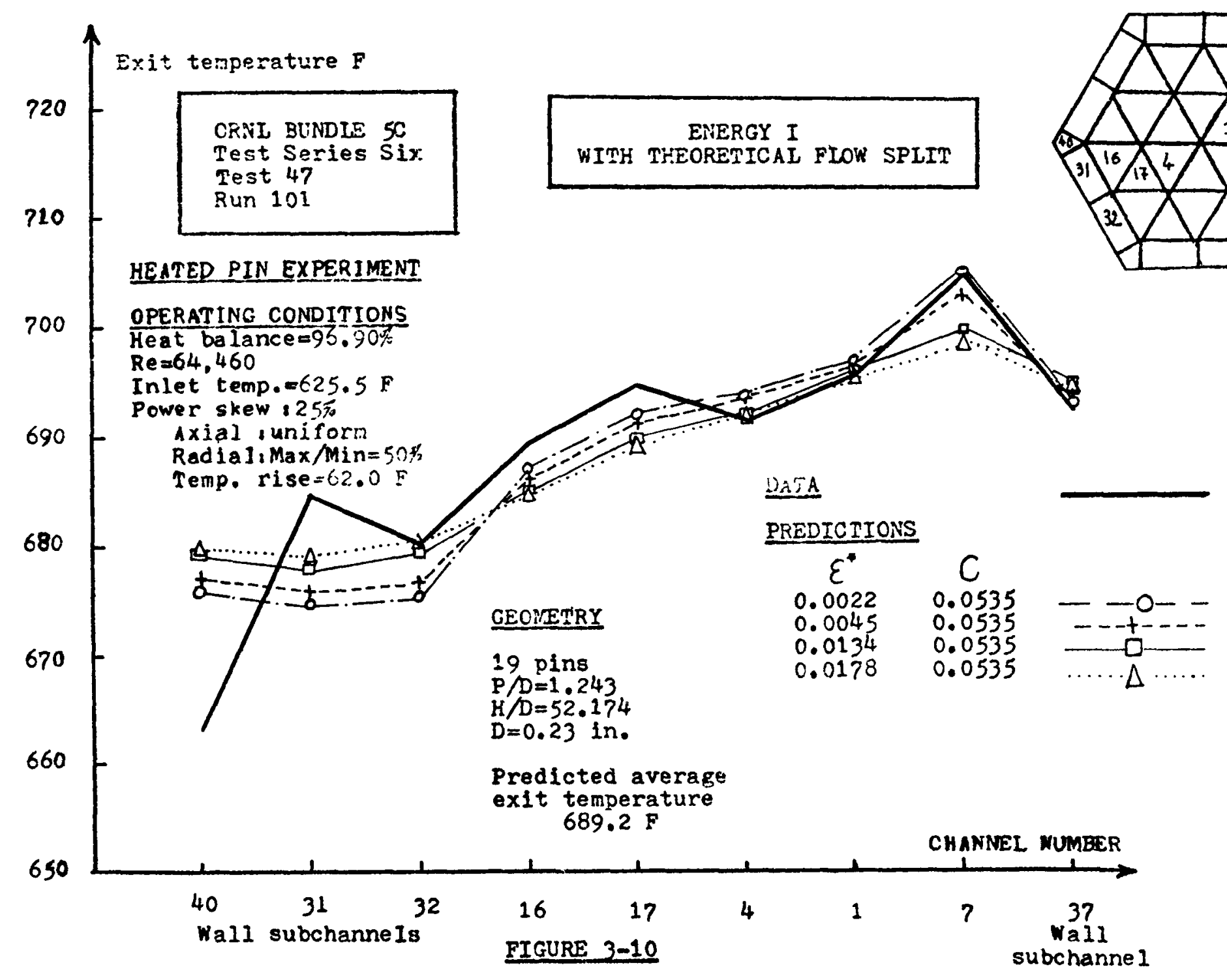


However, the two extreme wall subchannels (31 and 40) remain poorly predicted, whatever set of parameters is assumed.

The results are shown on fig. 3-11.

The range of $\varepsilon^{*}$ investigated $(0.0045$ to 0.0223$)$ gives about equivalent predictions.

\subsection{SUPERENERGY with Theoretical Flow Split}

The average exit temperature has been adjusted to $678.5^{\circ} \mathrm{F}$ by dropping the wall conductivity to $2.97 \mathrm{BTU} / \mathrm{ft} \mathrm{hr}{ }^{\circ} \mathrm{F}$ for a flow rate in the gap of $500 \mathrm{lb} / \mathrm{hr}$.

Taking the heat loss into account does not affect significantly the inner region; only the temperature distribution in the wall region decreases importantly.

No set of parameters could give a better prediction than the preceding two.

The best fit corresponds to:

$E^{*}=0.0022$ and $\quad C=0.0312$

The results are shown on fig. 3-12.

Figure 3-13 shows the temperature profile when the heat loss is successively adjusted by, acting on the wall conductivity, acting on the velocity of the coolant in the gap with and without 6 adjacent bundles acting as a heat sink. 


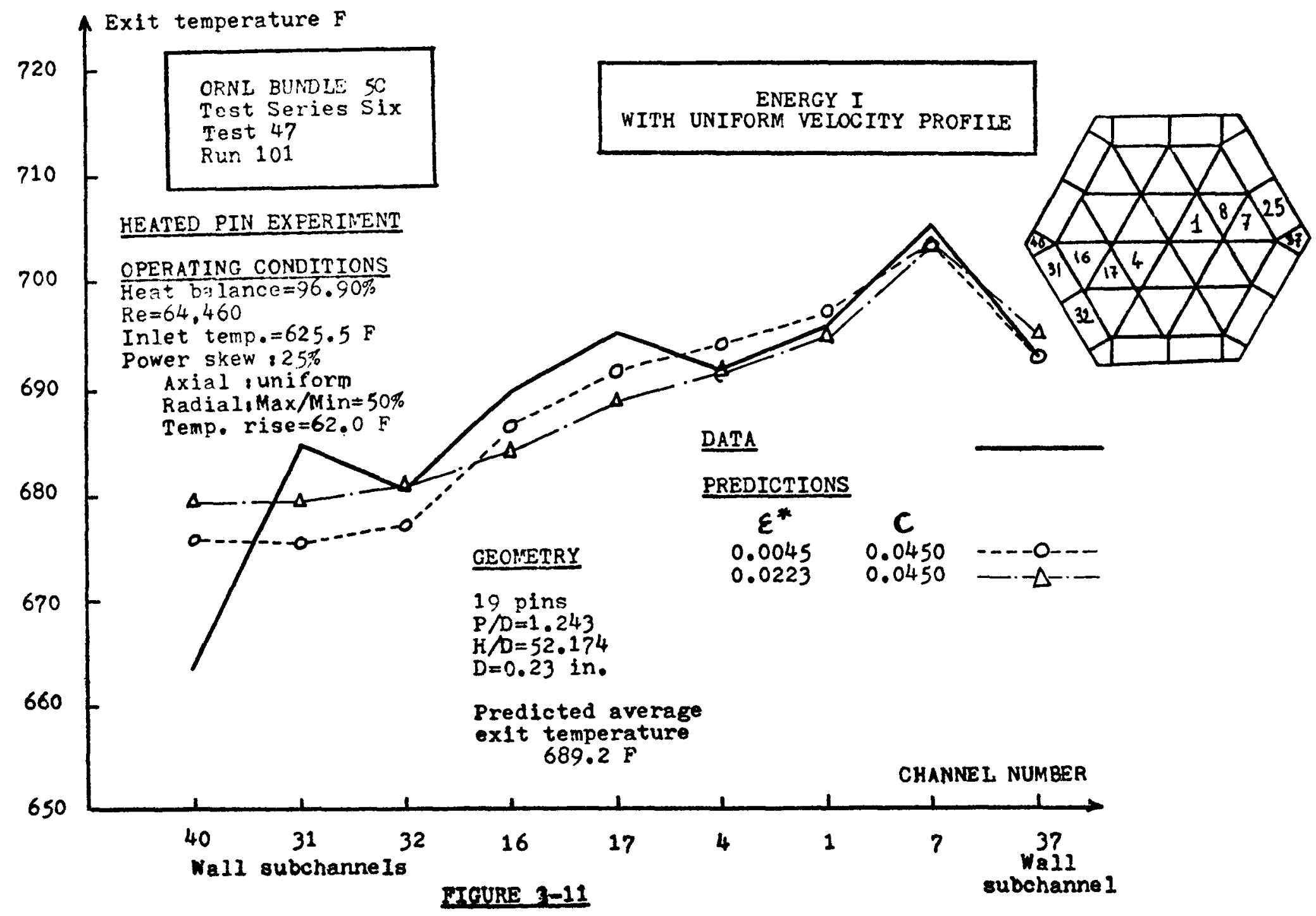




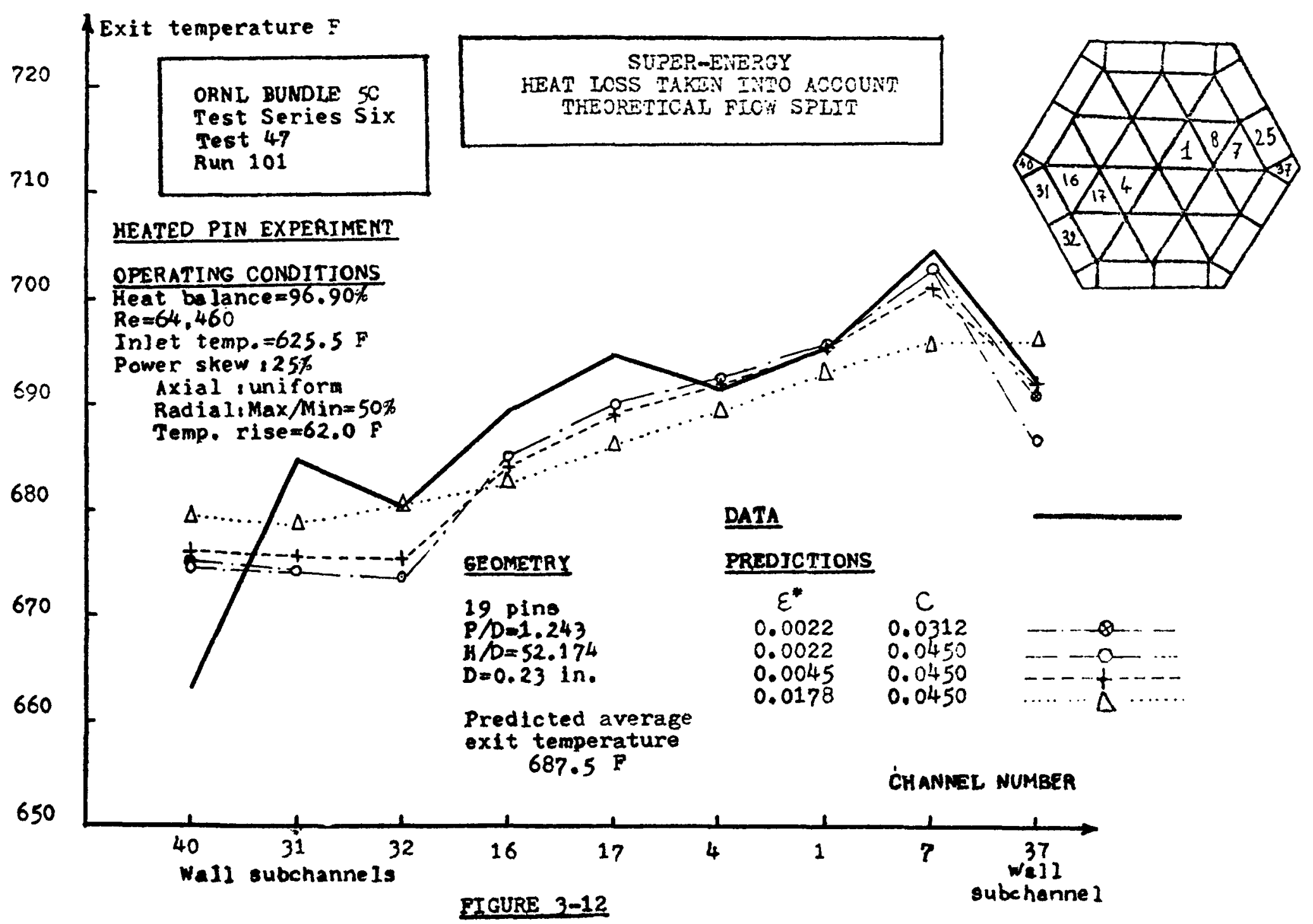




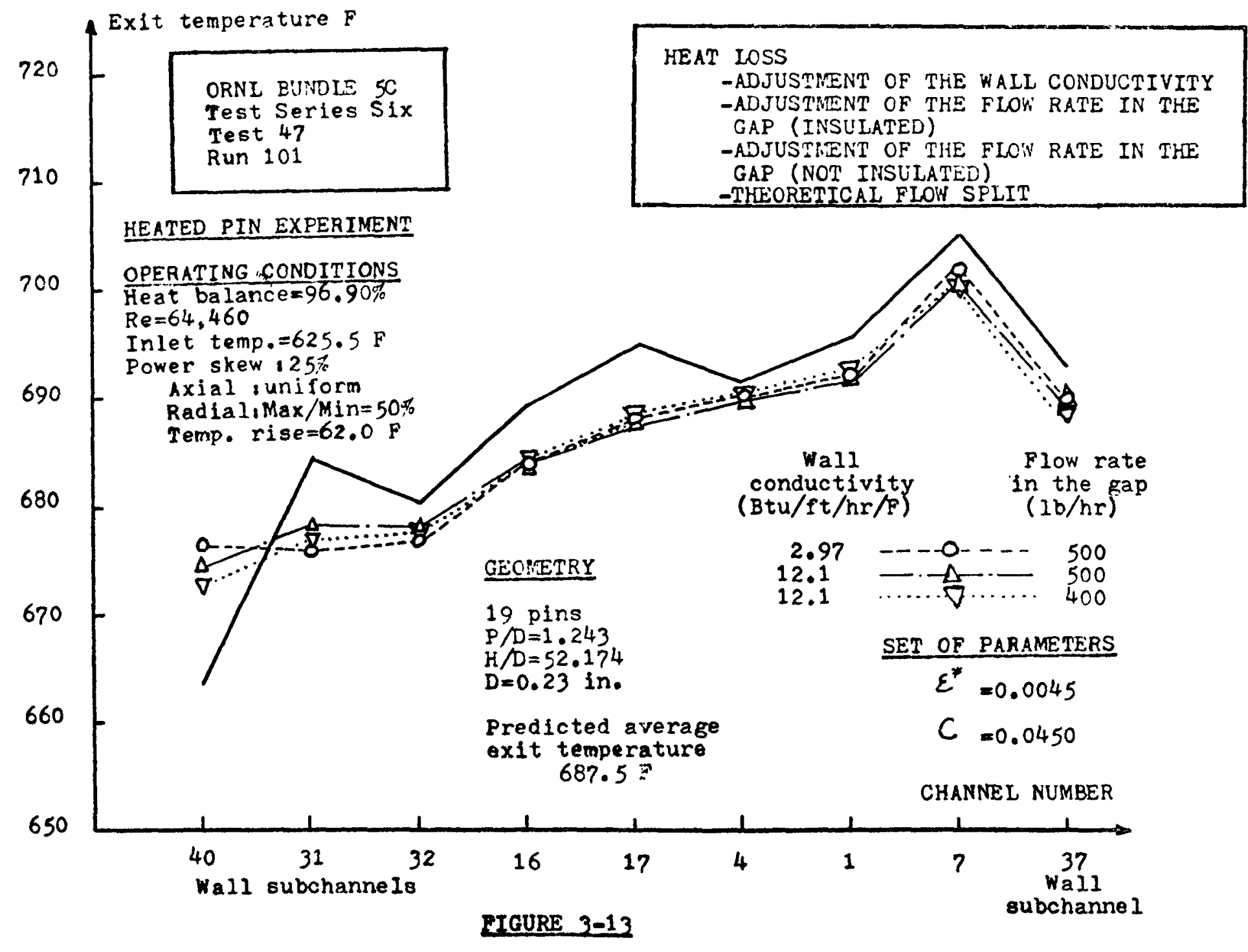


They have been obtained by assuming the flow split (2) of Table 3-I. The conclusions are the same as in the paragraph (3.2.3.1.3) and they probably would remain unchanged if the flow split (1) was assumed.

For the 47-101 test, the best fit is then obtained for $\varepsilon^{*}=0.0022$ and $\mathrm{C}=0.0535$

with ENERGY I (theoretical flow split).

However, assuming a uniform velocity profile leads to comparable results and several equivalent predictions are obtained for different values of $\varepsilon^{*}$.

3.2 .3 .4 Test $47-103$

The experimental data are the following:

Heat balance: 95.328

$\operatorname{Re}=40,850$

Temperature rise: $99.8^{\circ} \mathrm{F}$

Power skew: $25 \%$

One $50 \%$ overpowered rod in the corner 37 .

\subsection{ENERGY I with Theoretical Flow Split}

The program overpredicts the average exit temperature $\left(729.8^{\circ} \mathrm{F}\right)$ by $4^{\circ} \mathrm{F}$.

No set of parameters could give an excellent fit with the experimental measurements. 
The best agreement has been obtained for:

$\varepsilon^{*}=0.0045$ and $C=0.0357$

When $\varepsilon^{*}$ is increased (up to 0.0112), the overpowered

peak becomes better predicted but the calculated exit temperature drops in the inner region, so that this solution does not improve the preceding fit. The discrepancy attains $10^{\circ} \mathrm{F}$ in the corner 40 .

The results are shown on fig. 3-14.

\subsection{ENERGY I with Uniform Velocity}

An about equivalent fit is obtained for the following set of parameters:

$\varepsilon^{*}=0.0045$ and $C=0.0178$

Here again, the temperature in the subchannel 7 , adjacent to the overpowered rod, is overpredicted by $3^{\circ} \mathrm{F}$, but an increase in $\varepsilon^{*}$ would lead to a significant underprediction of the exit temperature in the inner region. The difference of flow rate in the corner subchannel explains the slight decrease of $\mathrm{C}$.

The results are shown on fig. 3-15.

The whole range of $\varepsilon^{*}(0.0045$ to 0.223$)$ gives about equivalent predictions.

\subsection{SUPERENERGY with Theoretical Flow Split}

The average exit temperature has been adjusted to $729.8^{\circ} \mathrm{F}$ by dropping the wall conductivity to $3.03 \mathrm{BTU} / \mathrm{ft} \mathrm{hr}{ }^{\circ} \mathrm{F}$ for a flow rate in the gap of $500 \mathrm{lb} / \mathrm{hr}$. 


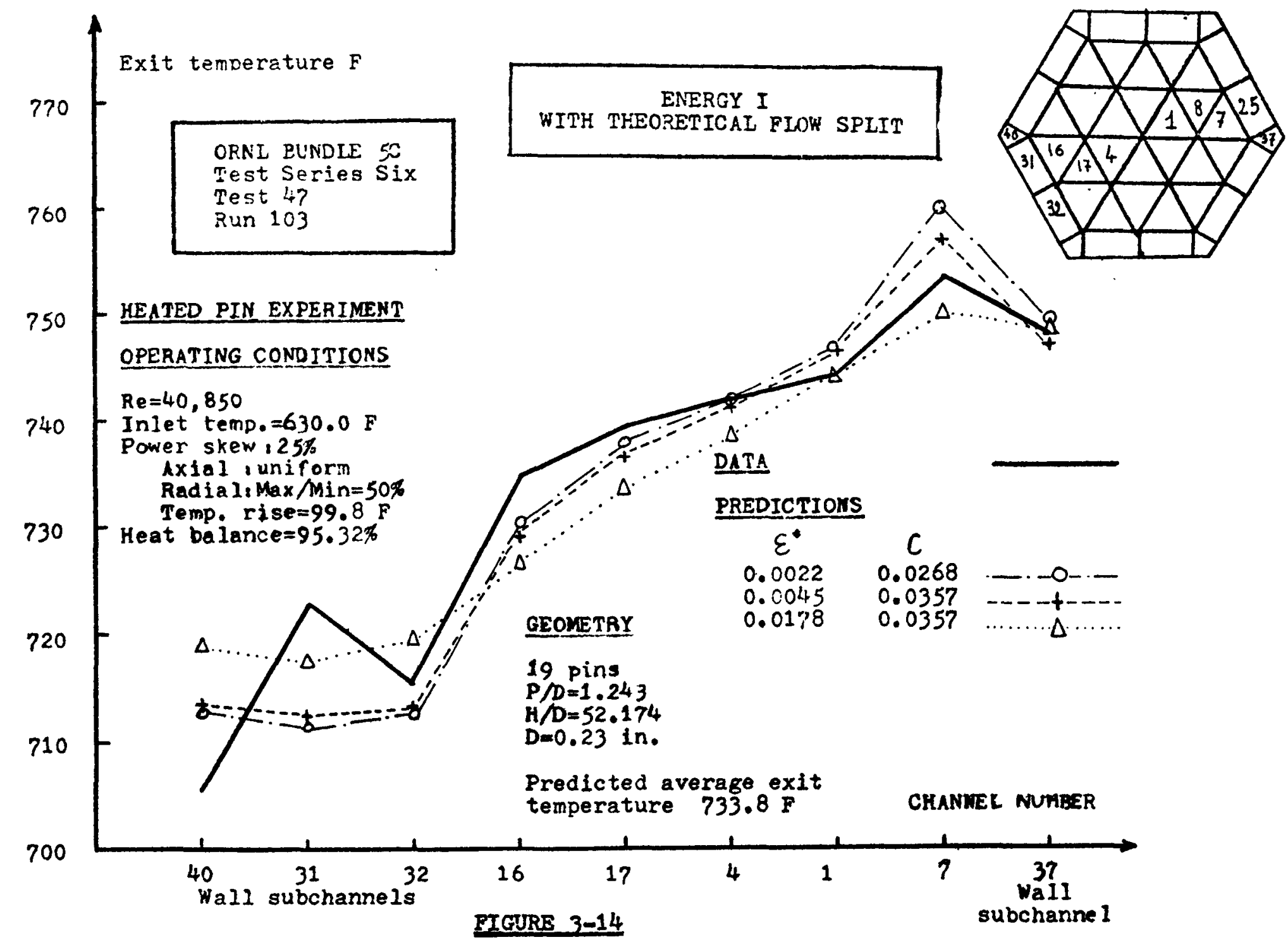




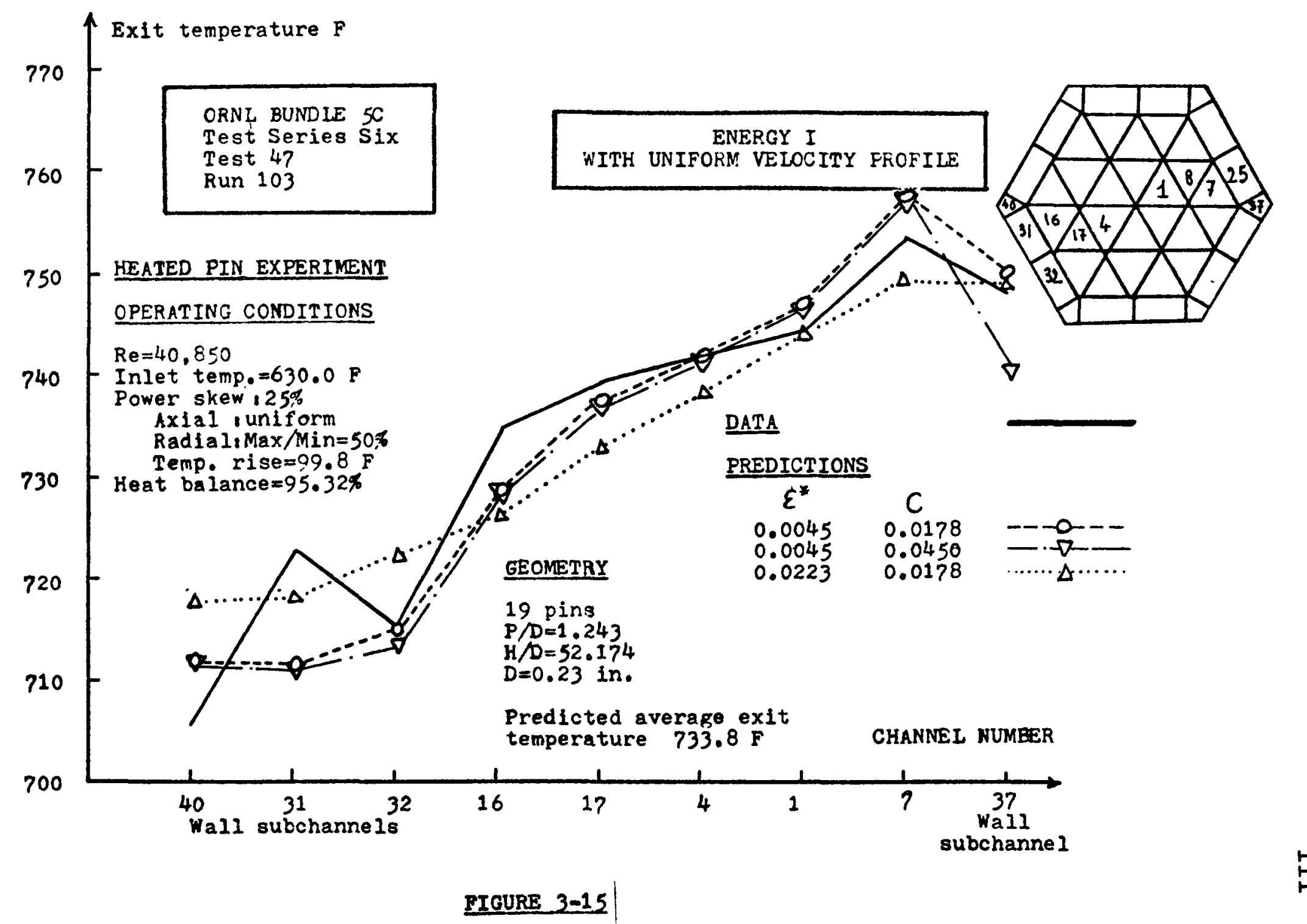


Taking the heat loss into account significantly decreases the temperature prediction, especially in the wall subchannels. No set of parameters could yield a better prediction than the preceding two.

The best fit corresponds to:

$$
\varepsilon^{*}=0.0045 \text { and } C=0.0268
$$

The results are shown on fig. 3-16.

For the 47-103 test, the best fit is then obtained for $\varepsilon^{*}=0.0045$ and $\mathrm{C}=0.0357$

with ENERGY I (theoretical velocity). Comparable results are obtained when a uniform velocity profile is assumed.

\section{3 Conclusion}

The prediction made by SUPERENERGY with theoretical flow split is systematically lower (and therefore worse) than the best prediction of ENERGY I, whatever flow split model is assumed. One reason for that could be that the heat loss is assumed to be linear in this program and therefore may not correspond exactly to the reality.

Using a uniform velocity profile in SUPERENERGY would keep about the same temperature prediction both in the inner or outer regions and therefore cannot improve the fit in this region. This is why it has not been tried. 


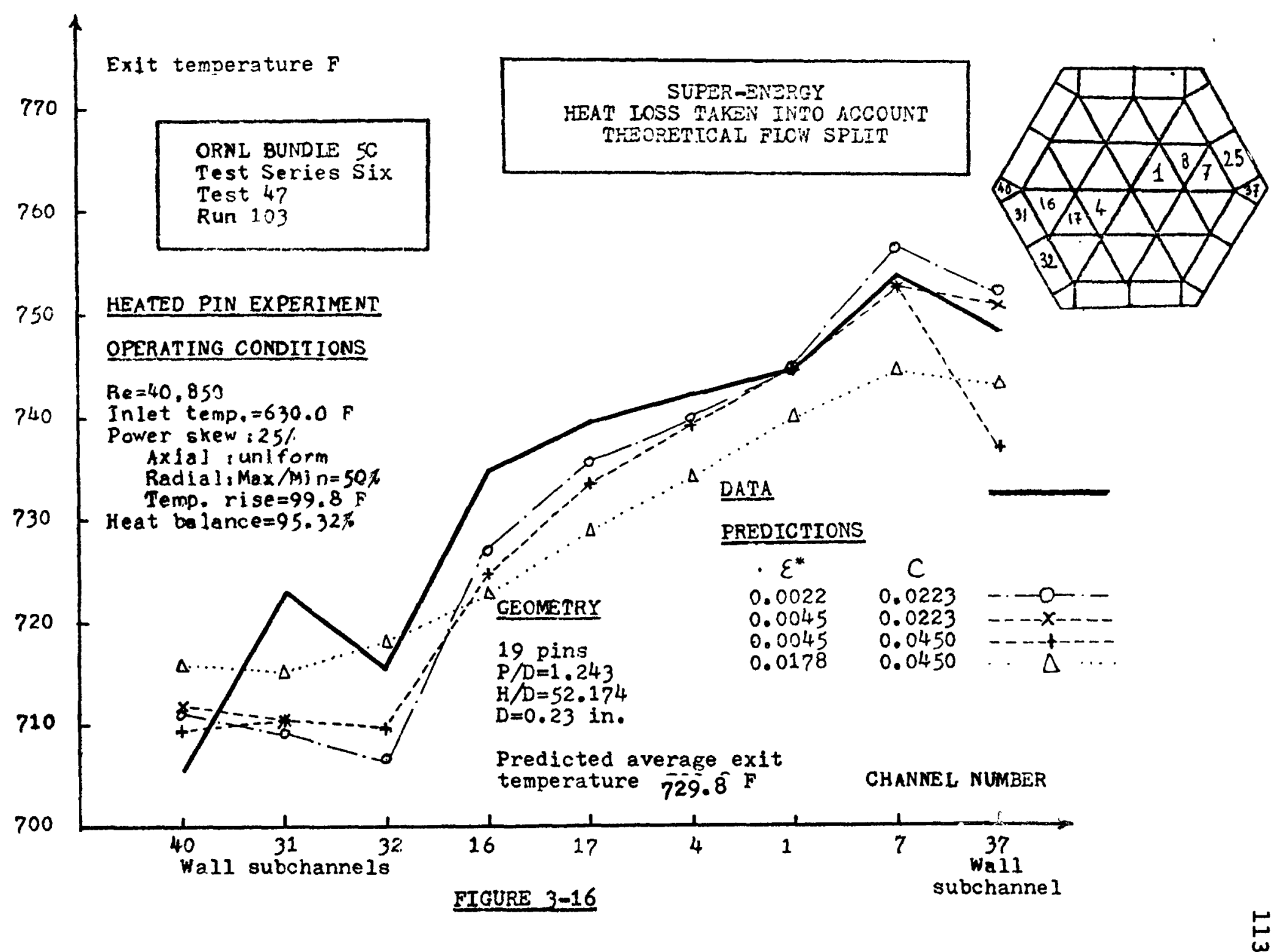


However, the program ENERGY I yields the best results in the four analyzed cases, whatever flow split is assumed (theoretical or uniform) profile. It has been impossible to make the temperatures measured in the three wall subchannels $(40,31$ and 32$)$ coincide simultaneously with the predictions. ENERGY I is not the only code to face this problem. The three figures, page 7.31 of Reference [13] (reproduced as fig. 3-17) show some discrepancies in this region. The predictions based on Henry's (ANL-RDP-4 April 1972, p. 8.1) forced mixing model remain very flat in this region. We found the same trend in our own predictions. The point corresponding to the subchannel 32 was omitted in this ANL publication. It should also be noted that thermocouple readings for channel 25 were not made. In view of the unusual behavior of the data for subchannel 31 compared to 40 , and the symmetry of channels 37 and 25 with respect to 31 and 40 , data for 25 would be valuable.

The resolution of observed differences in corners and edge subchannels is important since the setting of a $\mathrm{C}$ value presently requires that a choice be made as to whether an edge or corner channel is to be used as the basis for setting the $\mathrm{C}$ value.

Since the use of a uniform velocity profile does not lead to any improvement of the prediction obtained with the theoretical flow split, it is not useful to run ENERGY I with this modification. 


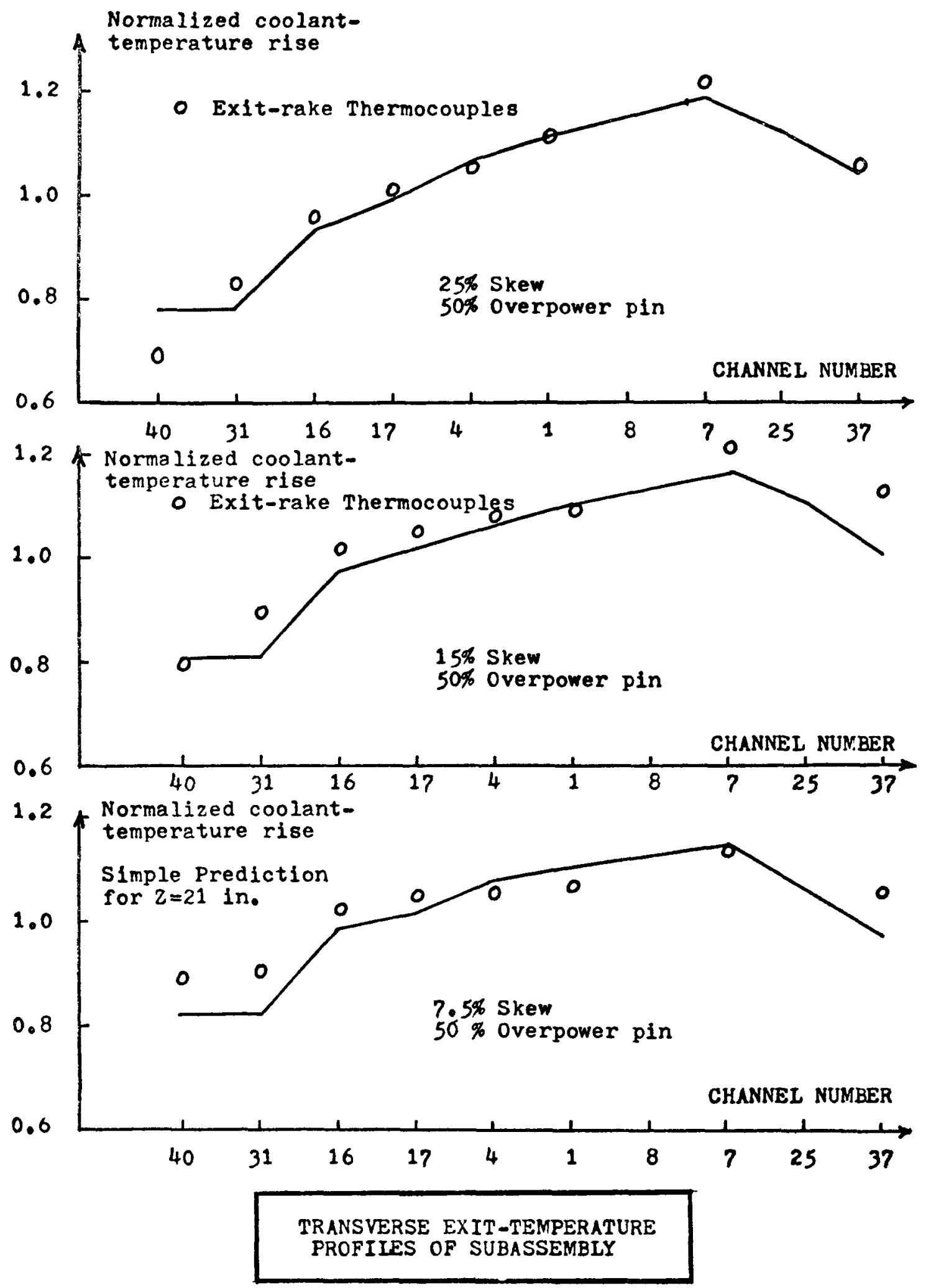

FIGURE 3-17 
The following advised set of parameters for use with ENERGY I in its initial version (NOVENDSTERN flow split model), results from an assessment of all the here studies cases:

$$
\begin{aligned}
& \varepsilon=0.0045 \\
& c=0.0357 \\
& \text { with the theoretical flow split. }
\end{aligned}
$$

The values recommended by the correlations of KHAN's thesis [5] are largely different from the range corresponding to our best fit

$$
\varepsilon *(0.0128 \text { to } 0.0200) \quad C(0.0442 \text { to } 0.1045)
$$

The value of $\varepsilon^{*}$ for the half wire bundle determined in this study is about four times smaller than the previously recommended value and $\mathrm{C}$ is at the lower limit of the prediction.

The low value of $C$ can perhaps be explained by the friction in the half sized gap, preventing the flow from getting the same average velocity as in a full sized gap.

The low value of $\varepsilon^{*}$ still remains to be explained.

A principal characteristic of the analyzed data is that, about equivalent predictions could be made with largely different values of $\varepsilon^{*}$. The predictions are not very sensitive to this parameter except for the peak in the overpowered corner. The best value of $\varepsilon^{*}$ has been chosen to give the best fit with this particular point; it is not surprising that the peak is better predicted by low values of $\varepsilon^{*}$. 
For practical use, ENERGY I gives the best results, for small and average values of the heat loss (from 28 to about 58). In the previously examined cases, the prediction is fairly good, except for the wall subchannels in the opposite face to the overpowered corner. Even when this region is taken into account, the uncertainty never exceeds $10 \%$ of the average temperature rise. 
CHAPTER 4

11:1 SCALE MODEL CLINCH RIVER BREEDER REACTOR SUBASSEMBLY

\subsection{Introduction}

In the case of tracer injection, ENERGY I is not able to predict correctly everywhere the concentration profile. This is inherent to its assumed flow model which is valid only after some distance downstream of the injector. The predictions of the code will be here compared to the measurements in this entry region.

\subsection{Analysis of the Data}

Westinghouse Research Laboratories ran this test to study the interchannel flow distribution. Figure (4-1) shows a layout of the test bundle cross section and the subchannel divisions. There are 35 full rods and 8 half rods in the duct. Their diameter is nominally 2.50 inches and the nominal pitch is 3.141 inches. The length of the fixed rods is 197 inches. The wire pitch is 124.4 inches.

This experiment consists of an injection of gaseous tracer (ethane) in the flow of air streaming through the bundle. The injection is made in the subchannel number 39, (called subchannel (0)), the three adjacent subchannels are, 33, 40 and 45, (respectively called subchannels (1), (2) and (3). The injector can take several positions on the surface of the instrumented rod shown on fig. (4-1). 


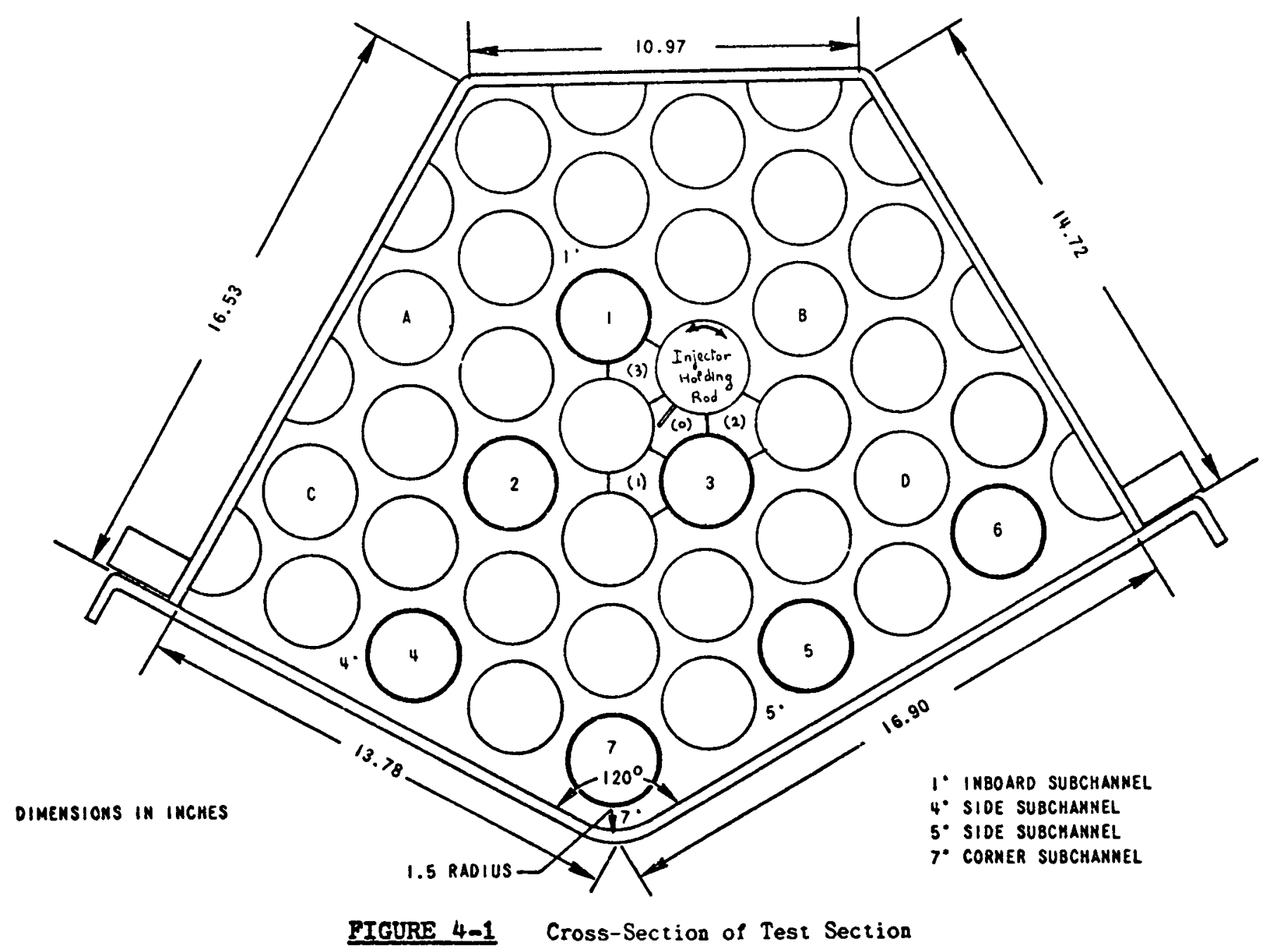


Westinghouse ran 6 experiments with different injector locations ( $A$ through $F$ ). The data of two experiments $A$ and $E$ has been analyzed below; they both correspond to an injector location at the boundary between subchannels (0) and (1).

Each test is a set of 5 concentration measurements in the three subchannels (0), (1) and (2) made at different distances downstream from the injection point: 8", 14", 20", and $32 "$, to the limit possible due to the sensitivity of the concentration measuring instrumentation. These lengths represent only a fraction of the helical pitch (129.4 inches) and the mixing in this region, essentially due to the directional cross flow is very anisotropic. (These experiments have been run precisely to determine the magnitude of the cross flows in the subchannel (0)).

A simplified flow model adopted by the code ENERGY I to calculate the exchange between adjacent subchannels, assumes that the mixing is not directional; this mixing is adjusted by the dimensionless parameter $\varepsilon^{*}$. ENERGY I assumes then an isotropic exchange through the three boundaries of the subchannel (0). This simplified model, leads to good predictions at axial distances exceeding a helical pitch, when the concentration gradients are made lower; the threshold length for validity of ENERGY I results is called the mixing length.

The purpose of this section is to compare ENERGY I's predictions with the measured concentrations and decide whether or not the mixing length is smaller than 32 " or of a $1 / 4$ axial pitch. 
The favorable case, where ENERGY I can predict well the concentrations in this region, would be a very interesting result; it would prove that ENERGY I's simplified model is valid after a distance equal to only one fourth of the helical pitch, downstream of the injector.

\subsubsection{Method Adopted for the Comparison}

The results of the test are presented in the form of ethane tracer concentrations as shown in fig. (4-2). The lines of constant tracer gas concentrations are readings from the infrared analysis on which a reading of 100 corresponds to about $2000 \mathrm{ppm}$ ethane (the scale is approximately proportional).

Since ENERGY I treats the subchannel analysis in a lumped parameter approach, these concentrations have to be integrated over each subchannel, to yield the corresponding average concentration.

\subsubsection{Integration Procedure}

A uniform velocity profile has been assumed across the subchannel since velocity data is not yet available. Under this condition, the integration is simply represented by the sum:

$$
\sum_{i} A_{i} C_{i}
$$

where $A_{i}$ and $C_{i}$ are respectively the area and the concentration of regions $i$. 


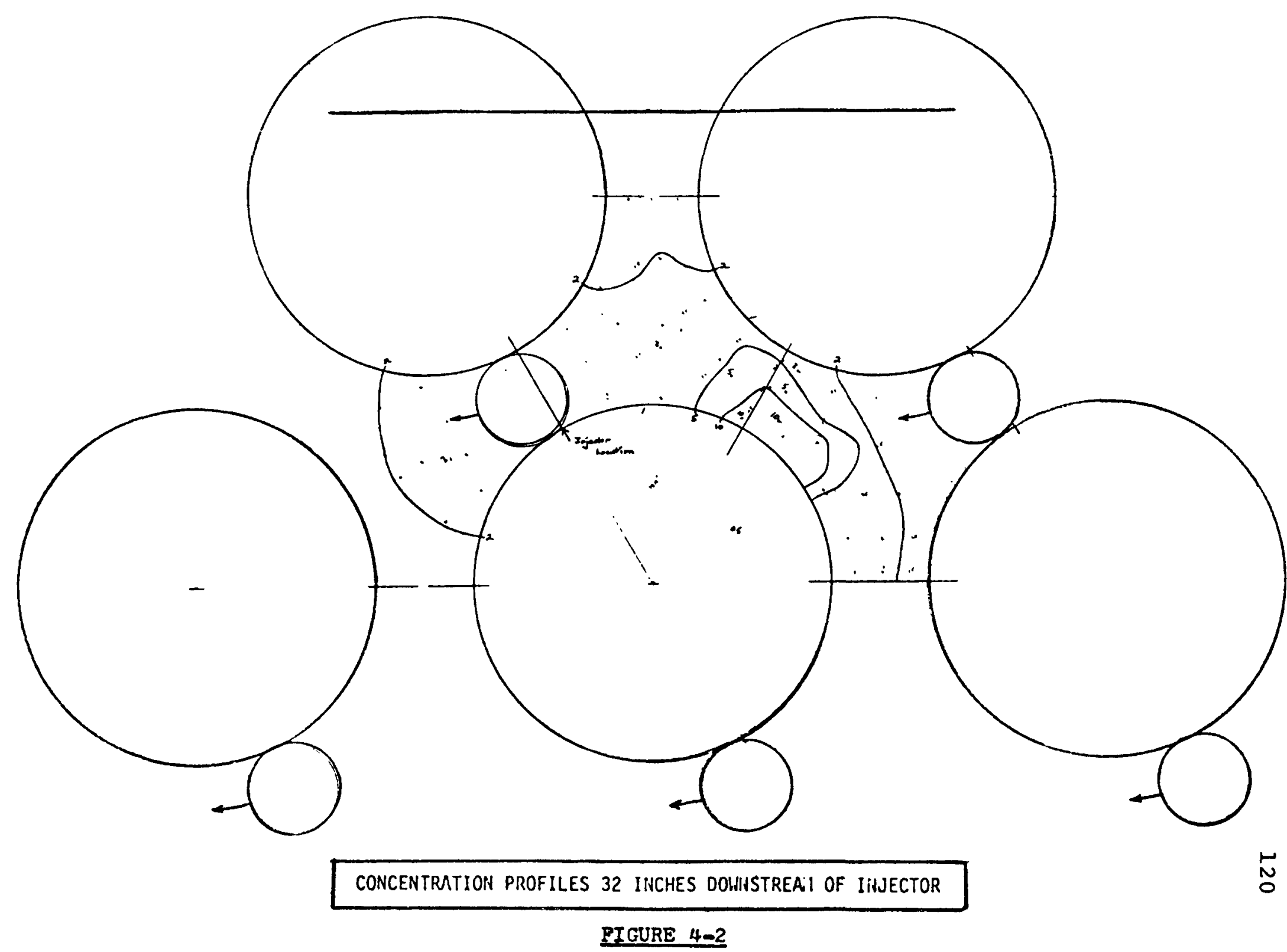


The values of $\sum_{i} A_{i} C_{i}$ were obtained by tracing the contours onto heavy paper and cutting them out (a cut was also made along the line at the gap). These profiles were drawn to 5.0 times experimental scale.

Following the procedure reported in Reference [14], the contour cutout were weighted and this weight was multiplied by the concentration corresponding to each contour. Summing these for a given subchannel and dividing this sum by the weight corresponding to the whole subchannel area yields the average concentrations.

The results for experiment $A$ are shown on fig. (4-3). The injection point is located at the limit between subchannels (0) and (1); the tracer flow rate is $0.236 \mathrm{lb} / \mathrm{hr}$.

\subsubsection{Analysis of the integration results}

The total flux in a subchannel is given by

$$
F=\int_{A} C U d A
$$

where $A$ is the area of the subchannel, $C$ and $U$ respectively the local concentration and the local velocity.

The mass balance requires that the sum of the flux over all the subchannels is a constant. This condition is equivalent to:

$$
s=\sum_{k} \sum_{i} A_{i} v_{i} c_{i}=\text { constant }
$$




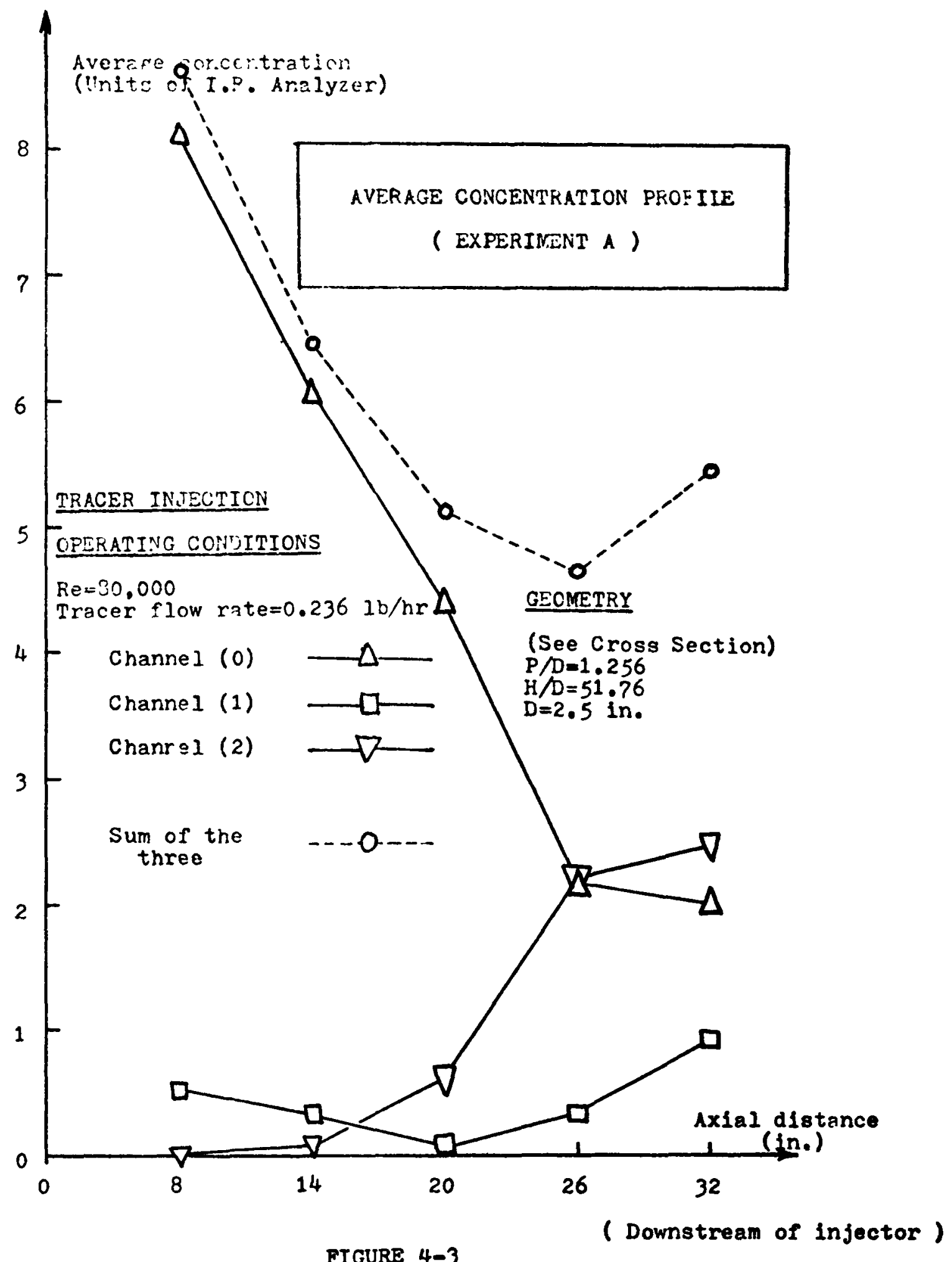


$k$ refers to the subchannels

$i$ refers to the region inside a subchannel

$v_{i}$ is the average velocity in the region $i$

If the velocity profile across a subchannel was really constant, the calculated sums $\sum_{i} A_{i} C_{i}$ should be independent of the axial level. In fact, fig. (4-3) shows important variations of concentration.

For the values obtained with the first set of data (Experiment A) the sum of the calculated average concentrations in the subchannels (0), (1) and (3) drops from 8 to 5 (in analyzer units. This situation is partially due to the fact that the velocity profile is not a constant across the subchannels. The velocity is low in the neighborhood of the rods and attains a maximum at the center of the subchannel.

When the injection is made near a rod, the concentration profiles expand progressively towards the center of the subchannel, and the products $A_{i} C_{i}$ have to be multiplied by a factor $v_{i}$ which increases with the expansion (and therefore the axial distance downstream from the injection point). Since $\sum_{k} \sum_{i} A_{i} C_{i} V_{i}$ remains constant, and $v_{i}$ increases, the products $A_{i} C_{i}$ and their sum $\sum_{k} \sum_{i} A_{i} C_{i}$ decrease. This is, what is observed in some of the examined cases (Experiment A).

However, for the case of experiment $\mathrm{E}$, the sum $\mathrm{S}$ remains approximately constant $(S=4.10 \pm 108)$ over the axial distance. The same remark is also applicable to the results of 
experiment $C$, where the injector location makes an angle of $15^{\circ}$ with the boundary between the subchannels (0) and (1) $(S=3.50 \pm 15 \%)$.

The authors of Reference [14] say that they have normalized the results to yield a constant value of $S$ from one axial location to the next.

4.2.1.3 Special Version of ENERGY I Used for this Study

Once the average concentrations at the 5 axial levels have been determinated for the three subchannels of interest (0), (1) and (2), a special version of ENERGY I (presented in Appendix A) is used to predict the calculated concentrations of one of these subchannels.

The mesh used is represented on fig. (4-4). Each of the subchannels (0), (1), (2) and (3) is described by 280 mesh points. The approximate shape of the rods is shown; the surface of each rod is treated as an insulated boundary. The elementary cell is a triangle. The exchange taking place at the boundary between two adjacent triangles is assumed to be uniform and modelled by a constant value of the eddy diffusivity. This value is the only parameter to be adjusted.

The injection is represented by two adjacent mesh points. When the injection is done in the gap separating two adjacent subchannels $((0)$ and (1) for example), only one mesh point is used and its initial concentration is taken equal to the half of the actual injection concentration. The corresponding gap 


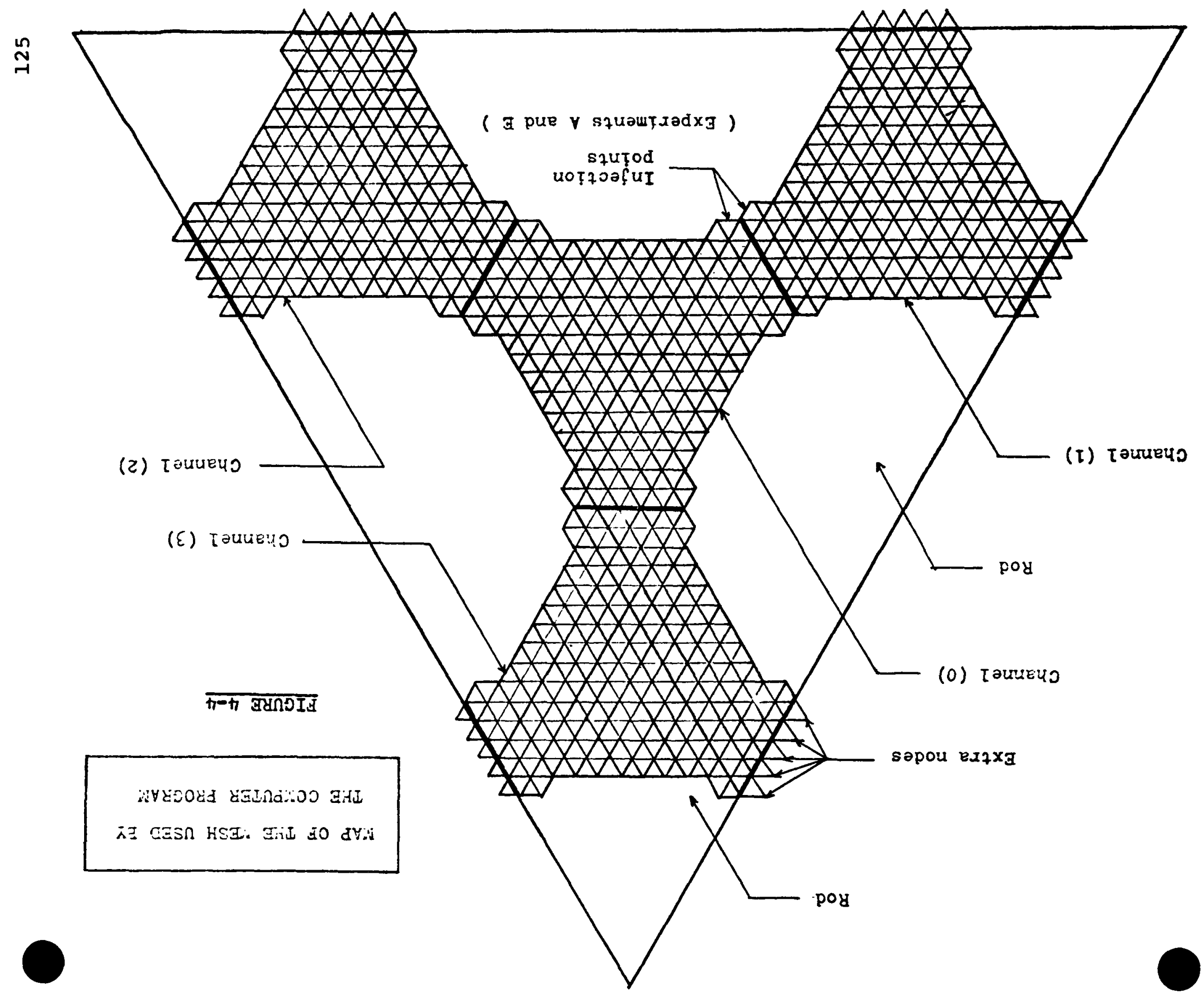


is also treated as an insulated boundary. This procedure is justified by the symmetry due to the isotropy of ENERGY I predictions, and permits considerable reduction in the computation time.

Some leakage is allowed outside the described mesh through the gap of subchannels (1), (2) and (3) at the limit of the mesh. At these points, an extra node is calculated. The value of the concentration is extrapolated by the exponential which fits to the values of the two closest points inside the mesh.

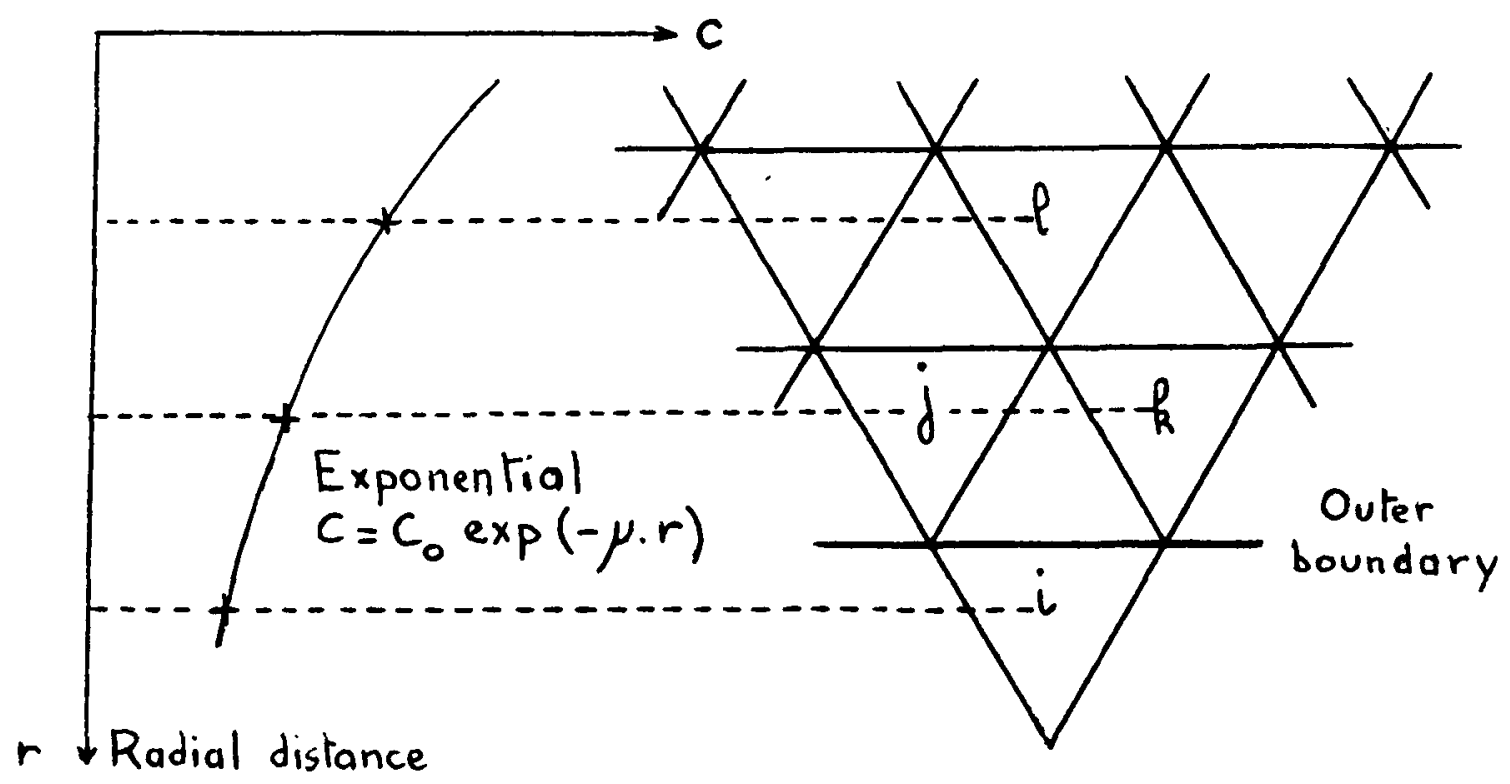

The concentration at $C_{i}$ is calculated by:

$$
\frac{c_{i}}{\left(c_{j}+c_{k}\right) / 2}=\frac{\left(c_{i}+c_{k}\right) / 2}{c_{\ell}}
$$

or

$$
c_{i}=\frac{\left[\left(c_{i}+c_{k}\right) / 2\right]^{2}}{c_{\ell}}
$$


For each analyzed case, this computer program has been run, and its predictions have been adjusted by changing the value of $\varepsilon^{*}$, to fit the experimental data.

\subsubsection{Results of the Comparison}

\subsubsection{Resu1ts}

Two cases ( $A$ and $E$ ) have been analyzed. Both have an injection point at the interface between the subchannels (0) and (1); the injected concentration is respectively $0.236 \mathrm{lb} / \mathrm{hr}$ and $0.2141 \mathrm{~b} / \mathrm{hr}$.

The computer program has been run for five values of $\varepsilon$ * ranging from $(0.01$ to 0.16$)$.

The predicted concentration for the subchannels (0) and (1) are the same since ENERGY's prediction is symmetric; they are shown on fig. $(4-5)$ and $(4-6)$.

The predicted concentrations for the subchannel (2) are shown on fig. (4-7). For experiment E, concentration measurements in subchannel (2) have not been made.

The measured concentration are shown on the same figure. For experiment $A$, the average concentration in the subchannel (0) drops, when the concentration rises suddenly in the subchannel (2), 18 inches behind the injector.

It is now possible to interpolate at each elevation the actual value of $\varepsilon^{*}$ which would yield the experimentally observed concentration. The results of these extrapolations and interpolations are shown on fig. (4-8). 


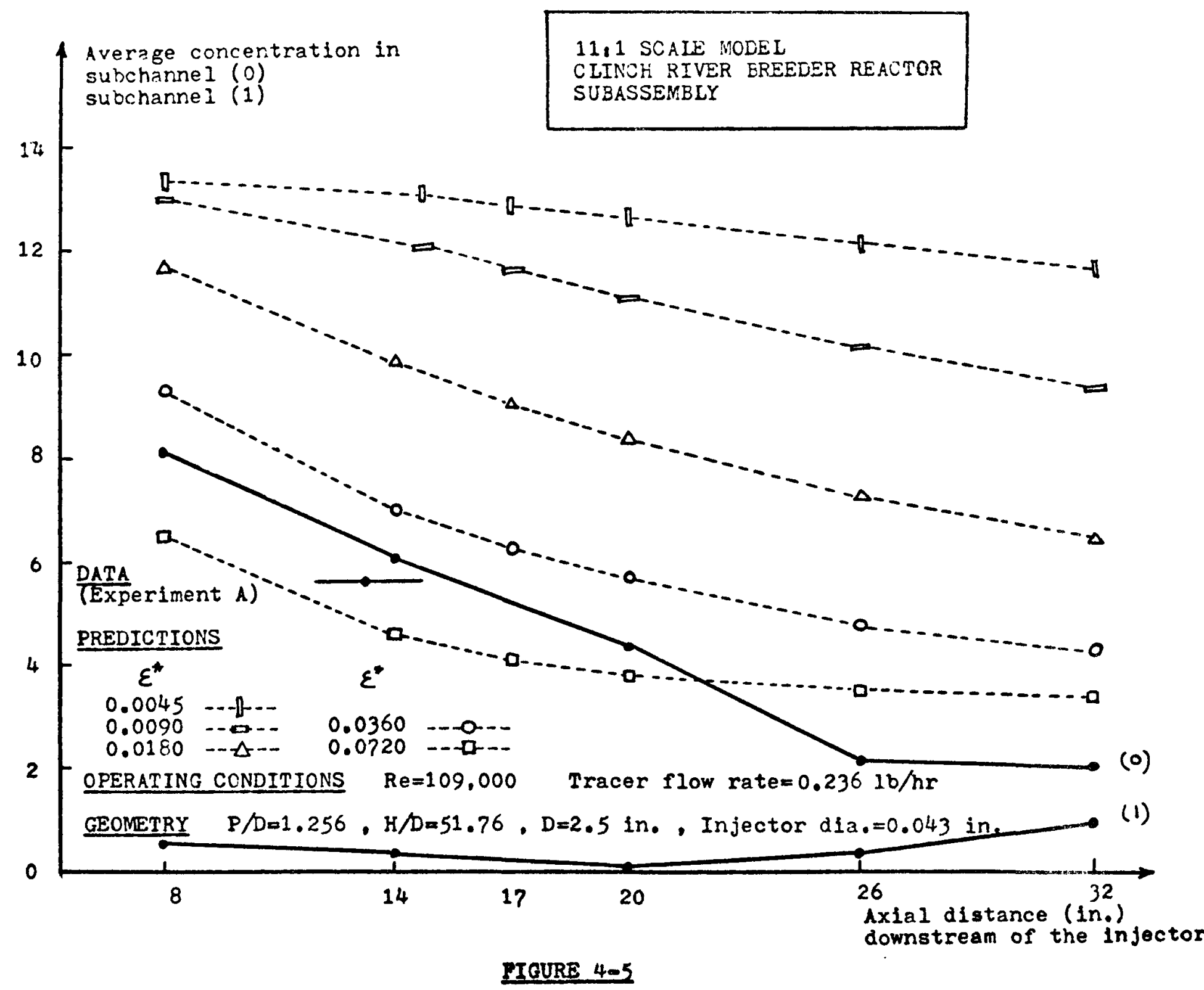




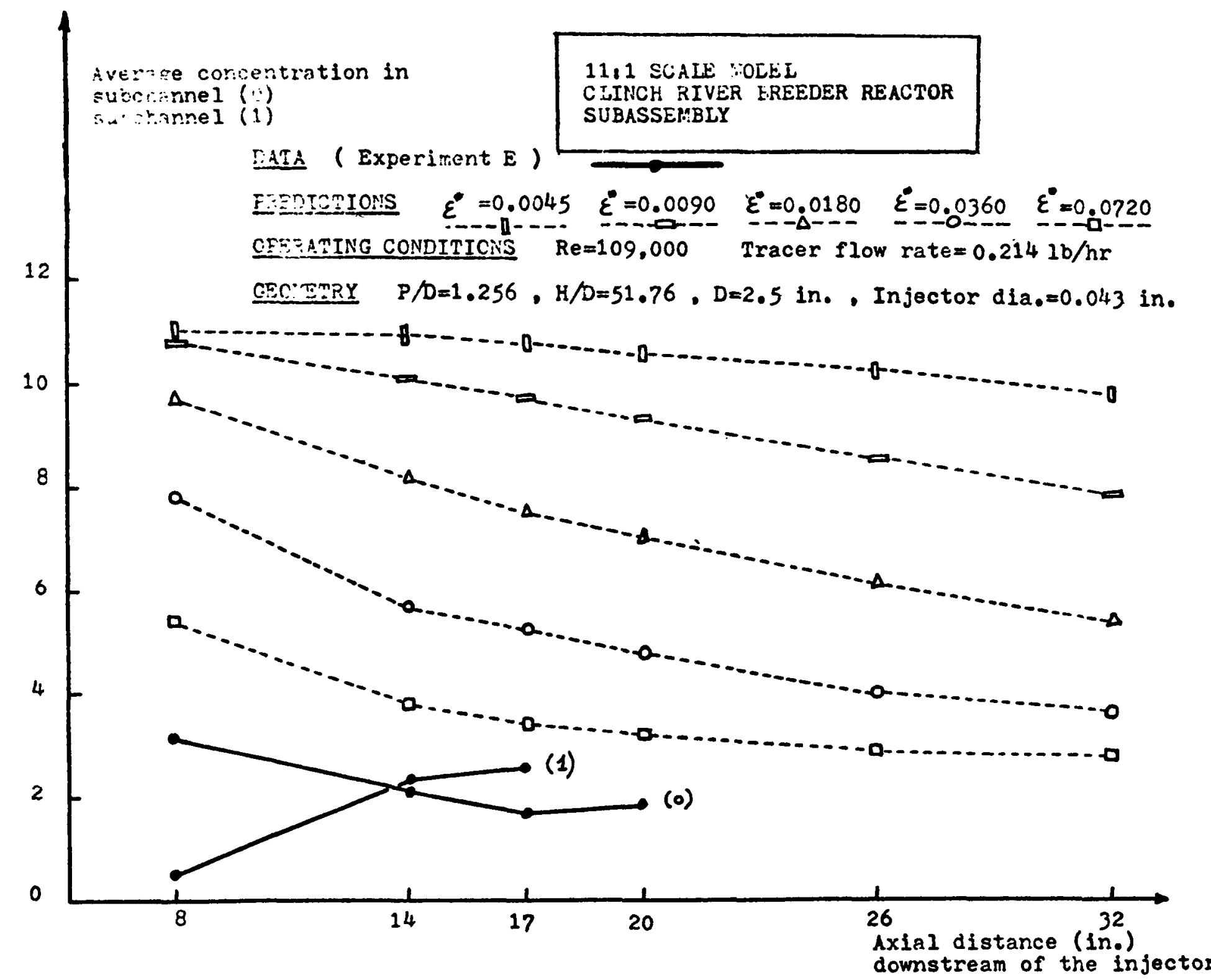




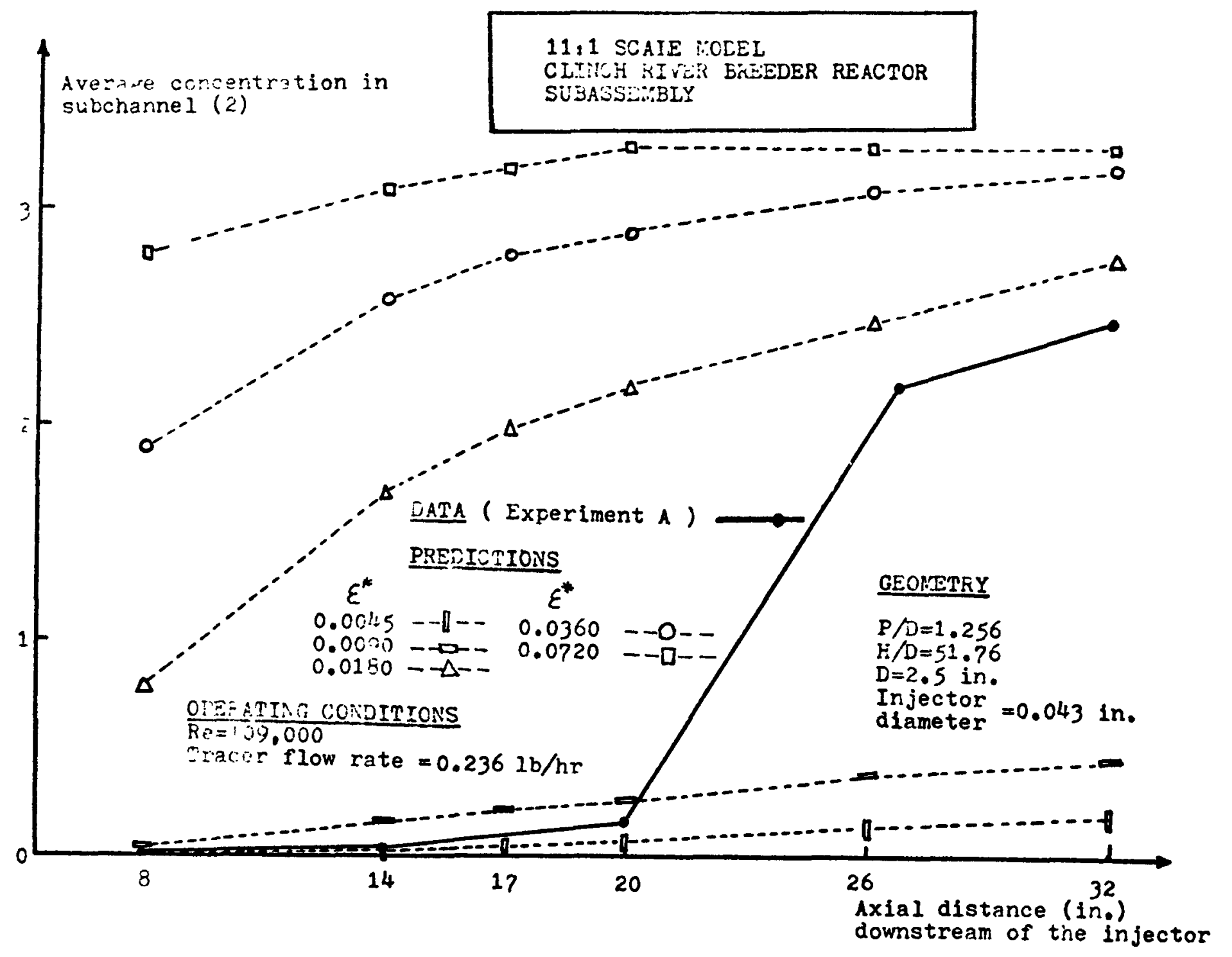

EGURE 4-7 


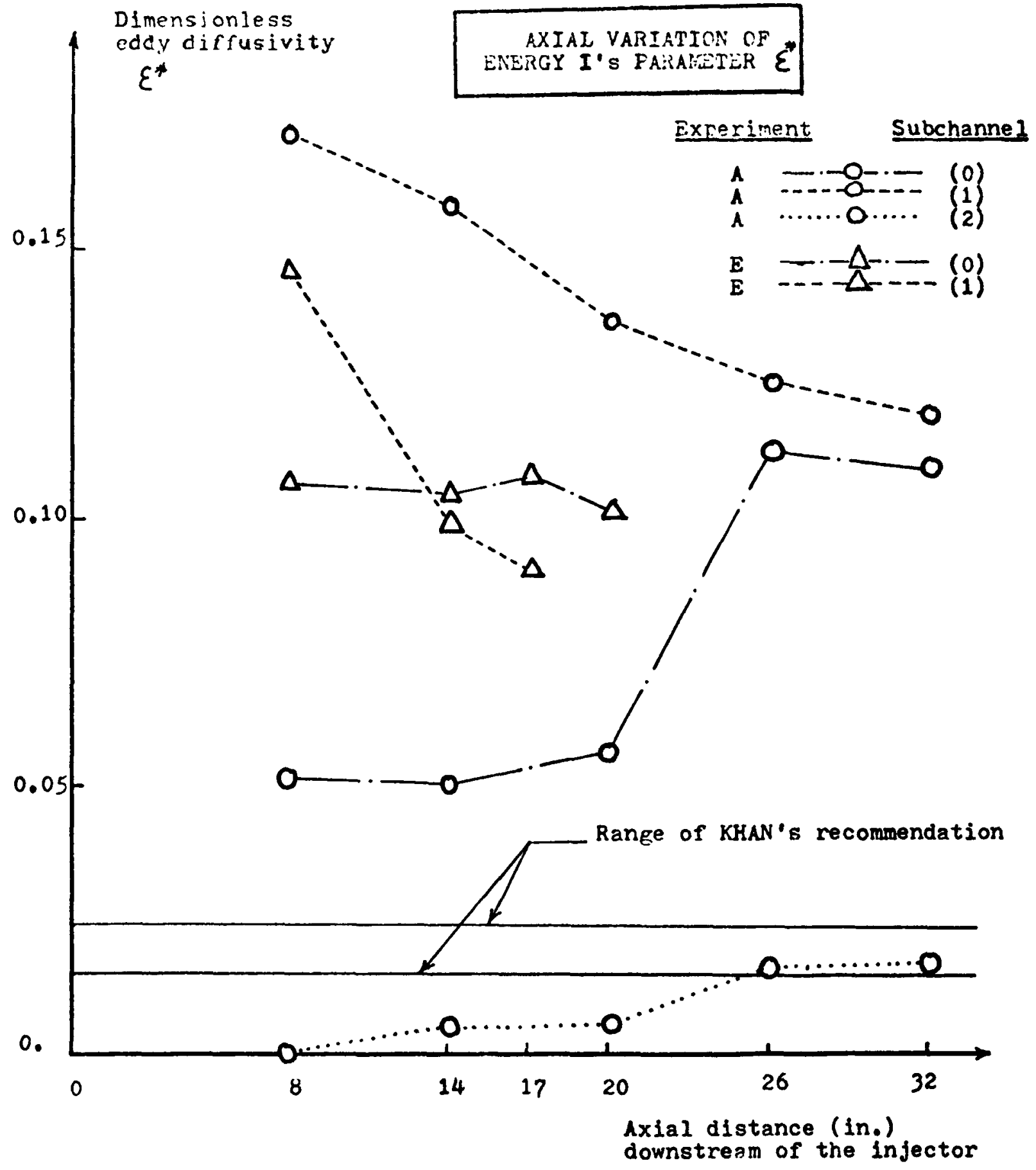

FIGURE 4-8 
The range of $\varepsilon^{*}$ recommended by KHAN's correlation is:

$\varepsilon *(0.0130 ; 0.0204)$

This prediction is far below the values yielded by both subchannels (0) and (1). However, one can notice that for both experiments $A$ and $E$, the curves obtained have approximately the same shape (but with different amplitudes); the slope of the last portion shows that the values of $\varepsilon^{*}$ will drop further with higher axial distances and therefore become closer to the recommendation.

The results obtained with the subchannel (2) show that the value of $\varepsilon^{*}$ giving a good fit, increases gradually and seems to remain in the range of recommendation beyond 26 inches. The distance where the measurements have been done is too short to calculate the further variations of $\varepsilon^{*}$

It is probable that the concentration profile is a strongly dependent on the direction of the sweep cross flow. Since 32 inches represent only a rotation of about $90^{\circ}$, the value of $\varepsilon^{*}$ will likely further oscillate, until it reaches its equilibrium value, expected to be the same for all three analyzed subchannels.

\subsubsection{Discussion of the Results}

The evaluation of the concentration profiles is due to two different effects, in reality and in ENERGY I's calculation. 
In reality, the process described in 4.2 .1 .2 , is superimposed on the turbulent mixing, acting radially. The radially non-uniform velocity profile affects the concentrations regions by varying $\mathrm{V}_{i}$. Since these parameters increase from one axial elevation to the next one, the "static concentration" $\sum_{i} A_{i} C_{i}$ seems to decrease. This happens during the first phase of the profile expansion. This process acts like an axial leakage of "static concentration" (measured at one fixed axial level).

In ENERGY I, the model assumes a uniform velocity profile over each subchannel; there is consequently no way to represent this axial leakage. The only way to decrease the concentration in a given subchannel $(0)$ is to increase the eddy diffusivity and therefore to allow more radial leakage, first toward the adjacent subchannels (1), (2) and (3) and then outside the mesh.

These two processes are physically different and hardly comparable. However, in order to investigate the limits of the assumptions on which ENERGY I is based, we had to use it without any modification trying to simulate the real physical process.

The preceding argument explains why the values of $\varepsilon$ * giving the best fit are very high compared to the value of KHAN's prediction, yielded by the correlation reported fig. 1-7. The smaller is the average concentration in the subchannel where the injection has taken place $((0))$, the higher has to be the leakage outside this subchannel and hence the higher has to be the eddy diffusivity. 
4.3 Conclusion

It is unfortunate that measurements beyond 32 inches are not possible to make.

The only definitive conclusion is that the mixing length is larger than this distance, since, for two of the three studied subchannels, the equilibrium value of $\varepsilon^{*}$ has not been reached.

It is probable, that one exponential extrapolation outside the mesh allows less leakage than it is observed in reality, and therefore, the values of $\varepsilon^{*}$ can be slightly over estimated, especially in the range of high values of $\varepsilon^{*}$, where the leakage occurs after a short distance downstream of the injector. However, this extrapolation seems to match better the actual shape of the concentration profile; the simple linear extrapolation, allows more leakage but seems to be a grosser approximation since it leads to negative values of the concentration in some extra nodes. Another point is that, this difference of leakage outside the mesh does not affect significantly the values of $\varepsilon^{*}$ in the range of interest (about 0.0162 ), since for this small value, the mass of tracer going out of the mesh does not exceed 108 of the injected quantity, 32 inches behind the injector.

Since direct concentration measurements cannot be made beyond 32 inches, it is necessary to calculate these unknowns from another directly measurable quantity: the velocity profile, for example. 
It would then be interesting to pursue the preceding study by studying the velocity field beyond a distance equivalent to a fourth of the axial pitch and by using these data to predict a value of the local concentration in the subchannels of interest. Then, the procedure developed above would permit us to find the corresponding values of $\varepsilon^{*}$ and to verify whether or not this parameter attains its predicted limit. 
General Conclusion

The partial conclusions have been already presented at the end of each corresponding section, and our present purpose is to summarize the principal results.

The comparison of ENERGY I and MISTRAL II shows that their predictions are fairly comparable, except for the case of large bundles (217 pins). This result is advantageous for ENERGY I, which is a much smaller and simpler program than MISTRAL II and can therefore be run at much lower cost. The analyzed 217 pins case probably does not correspond to any real set of experimental data and therefore its results should perhaps not be taken into account, however, the noticed discrepancy can perhaps be explained by a bundle size effect. Two simple relationships have been derived, relating the sets of input parameters needed by the two codes.

If further investigations confirm their reliability, it will be possible to take advantage of all the results obtained with the bundles previously analyzed by MISTRAL II and get directly ENERGY I's best prediction by simply converting the set of parameters.

The analysis of Karlsruhe data for gridded bundles, proves that the temperature profile can be accurately predicted at one axial level by adjusting a single parameter. The validity of the exponential decrease behind a grid could not be checked, so that investigation is still required to determine whether or 
not the temperature profile can be predicted everywhere by this model.

The results obtained within ORNL 5C Bundle show a strong independence of a variation of $\varepsilon^{*}$, especially in the inner region; very different values of $E^{*}$ can yield about equivalent predictions and speaking of a real best fit is sometimes questionable. The criterion chosen to determine this best fit has been the ability to predict well the $50 \%$ overpowered corner (this is the most sensitive region to a change of $\varepsilon^{*}$ ). This choice leads to very small values of $\varepsilon^{\star}$ and $c$, far below the range of recommendation for bundles having a full sized gap.

With these parameters, ENERGY I is able to predict fairly well the temperature distribution, when a uniform velocity profile is assumed across the bundle. These results are very comparable to the predictions given by other methods; in addition, these methods show the same unaccuracy as ENERGY I, in predicting the temperature in the gap region.

The 1l:l Scale Model Clinch River Subassembly experiment shows that the values of $\varepsilon^{*}$ which should be used to match the local concentrations immediately downstream of the injector oscillate strongly before attaining their equilibrium value.

This equilibrium value is reached first in the region where the sweep cross flow directs the injected tracer; in addition, attainment of this equilibrium value requires at least a fourth of helical pitch, in the subchannels adjacent 
to the injection point. Assuming that the mixing process is nut directional requires implicitly that the flow is deviated in all directions; therefore it is possible that the mixing length may not be smaller than a full heical pitch.

The preceding conclusions are largely favorable to the simple code ENERGY I, since, beyond a mixing length at least equal to the helical pitch, its predictions are reliable and comparable with the results of a much more complicated code, MISTRAL II. It can be easily adjusted to predict the temperature distribution in bundles having a half sized gap as well as other codes and will probably be able to treat satisfactorily gridded bundles as soon as further sets of data will be available to pursue the study. 
Recommendations for Future Work

The following specific investigations should be performed to extend the results of this study:

- MISTRAL II - ENERGY I:

- Run several cases corresponding to real experimental data, obtain the best fit for each of them and check the domain of reliability of the derived correlations.

- GRIDDED BUNDLES :

- Analyze data with at least two axial measurement locations and determine whether or not $\varepsilon_{0}^{*}$ and $\mu$ can be satisfactorily adjusted separately.

- Known data sources include:

- Experimental determination of the turbulent diffusivity coefficient in a bundle of rods with and without spacer grids $25=28819 \quad(E U R=4552)$

- Decay of weak turbulence generated by various grids, spectra of grid turbulence, The Physics of Fluids Vol. 13 Number 12, Vol. Number 17

- ORNL 5C BUNDLE:

- Analyze some experiments belonging to the test Series 6 , Tests $31,32,33,34$, showing a more important heat loss (up to $20 \%$ ).

- Run a test with the Laser Doppler Anemometer and check the value of the peripheral velocity in the gap; this should verify the value of $c$. 
- 11:1 SCALE BUNDLE:

- Step 1: Use Westinghouse data (for interior subchannel) or MIT Laser Doppler Anemometer (for exterior subchannel) to obtain a flow model.

- Step 2: Then, two approaches can be undertaken

- Use of tracer:

- Heated pin experiment (beyond 1/4 pitch)

- Concentration (analytically extrapolated beyond $1 / 4$ pitch by use of the flow model).

- Direct comparison of the velocity profile, with the assumptions made in ENERGY I. 
REFERENCES

[1] W. Baumann, "MISTRAL II Thermohydraulischer Mischtromungsalgorithmus for Stabbundel", KFK-1605, Juni 1972.

[2] H. Hoffmann, "Experimentelle Untersuchung zur Kuhlmittelquervermisching and zum Druckabfeil im stabbundel mit Wendelformigen Abstandhaltern, Einfluss der Ergebnisse auf die Auslegung von Brennelementen Schneller Natriumgekuhlter Reaktoren", KFK-1843, Dezember 1973.

[3] E. Novendstern, "Turbulent Flow Pressure Drop Model for Fuel Rod Assemblies, Utilizing a Helical Wire-Wrip spacer System", Nuclear Engineering and Design, Vol. 22, No. 1, August 1972 .

[4] E. Khan, N.E. Todreas, W. Rohsenow, A.A. Sonin, "Analysis of Mixing Data Relevant to Wire Wrapped Fuel Assembly Thermal-Hydraulic Design", C00-2245-12, MITNE-165.

[5] E. Khan, "A Porous Body Model for Predicting Temperature Distribution in Wire Wrapped Fuel and Blanket Assemblies of a Liquid Metal Fast Breeder Reactor", SCD Thesis, MIT January 1975. Also appears as Report C00-2245-16TR.

[6] Listing of a 37 pin bundle case calculated by MISTRAL II, transmitted by Dr. L. Wolf.

[7] R. Byron Bird, Warren E. Stewart, Edwin N. Lightfoot, Transport Phenomena.

[8] 11:1 Scale Rod Bundle Flow Tests Grid-Type Rod Bundle Mixing Studies, (WARD-OX-3045-6).

[9] H. Hoffmann, E. Baumgartner, "Experimental Investigations of the Thermodynamic Behavior of Fast Breeder Reactor Fuel Elements with Different Spacer Types, IAEA-SM-173/20.

[10] M.H. Fontana, P.E. MacPherson, P.A. Gnadt, L.F. Parsly, J.L. Wantland, Temperature Distribution in a 19-Rod Simulated LMFBR Fuel Assembly. In a Hexagonal Duct - (Fuel Failure Mockup Bundle 2A). Record of Experimental Data.

[11] Oak Ridge National Laboratory, Out of Pile Test for FEFP In-Pile Experiment PI (Bundle 5C). Test Series Six, Tests $45,46,47$ provided by M.H. Fontana.

[12] Brian C. J. Chen., Prediction of Coolant Temperature Field in a Breeder Reactor Including Inter-Assembly Heat Transfer MS Thesis MIT, 1975. 


\section{REFERENCES (Cont.)}

[13] Analysis of Skewed Power Tests on FFM Bundle 5C G.L. Bordner (ANL-RDP-31, August 1974).

[14] Clinch River Breeder Reactor Plant: 11:I Scale Wire Wrap Bundle Air Flow Test, Pre-Test Predictions. WR40860. Personal Communication, M. Roidt. 
APPENDIX A

\subsection{General Description}

For analyzing the tracer injection experiment made in the 11:1 Scale Clinch River Subassembly, it has been useful to write a smali code very similar to ENERGY I in principle; however its smaller mesh size allows a more accurate definition of the concentration profile, in four adjacent subchannels, close to the injection point.

The total mesh, shown on fig. A-l, has the general form of a triangle and the actual mesh size can be adjusted to the need of the user.

The turbulent exchange between one node and its three neighbors is calculated by the same finite difference equation as ENERGY I (Reference [5], Appendix B), and therefore, the same conditions of stability, relative to the axial increment size are directly applicable.

The calculation is not carried over the whole mesh; the surfaces of the rods are treated like insulated boundaries and only the nodes inside the subchannels are calculated.

The outer boundary of this mesh must not be a physical barrier to the diffusion of the tracer; it is then necessary to allow some leakage outside this mesh. For this purpose 6 sets of extranodes are calculated, outside the mesh itself. 
At each axial step, when all the concentrations have been calculated, inside the mesh, an assumed continuity condition assigns the values of the extra-nodes.

Different schemes can be chosen and the present version of the program extrapolates the concentration profile by the decreasing exponential determined by the values associated to the closest points inside the mesh.

\subsection{Numbering Scheme}

The algorithm used by the program utilizes two different numbering schemes for the mesh points and the adjacent boundaries. The SUBROUTINE NUMB treats this numbering automatically.

\section{$2.1 \quad$ Mesh Points}

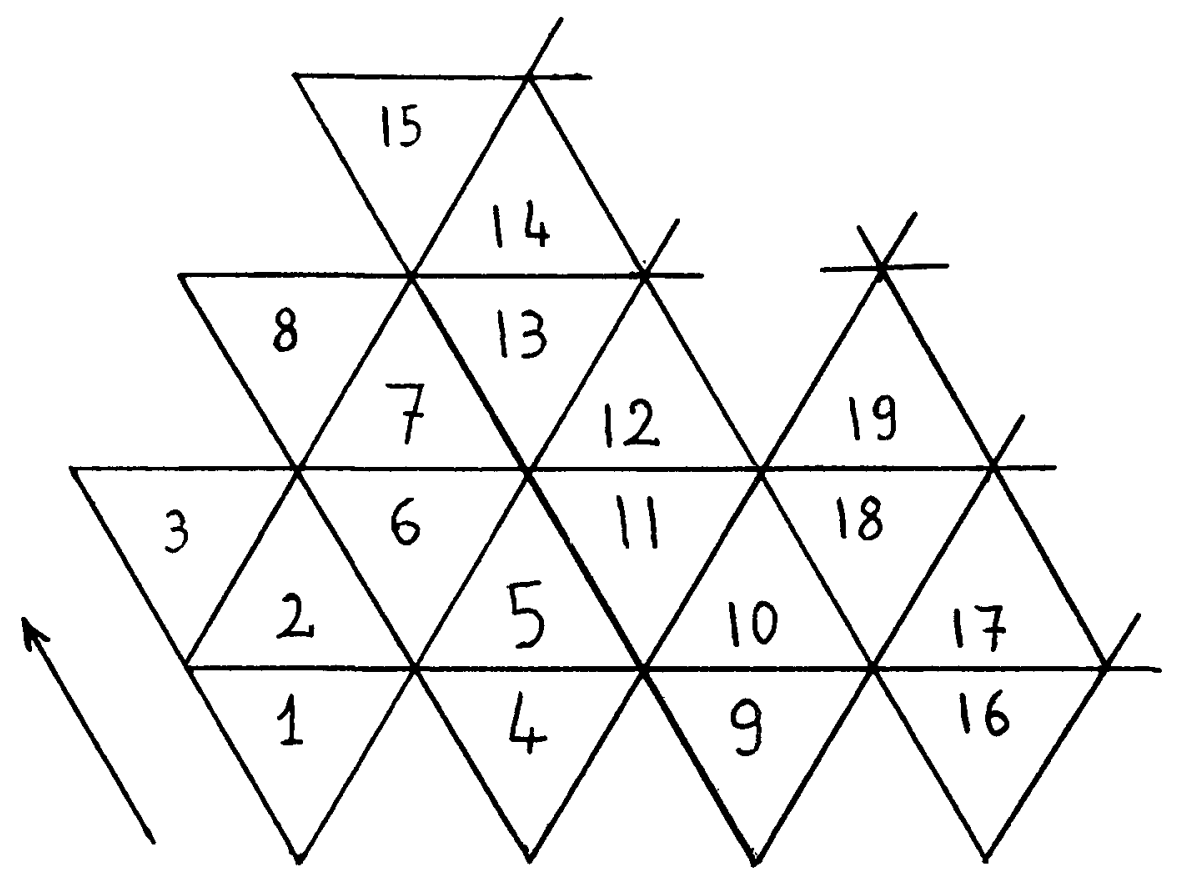

The rows are numbered in sequence and one extranode is added at the two ends of each row. 


\subsection{Boundaries}

The boundaries are also numbered in sequence from one row to another.

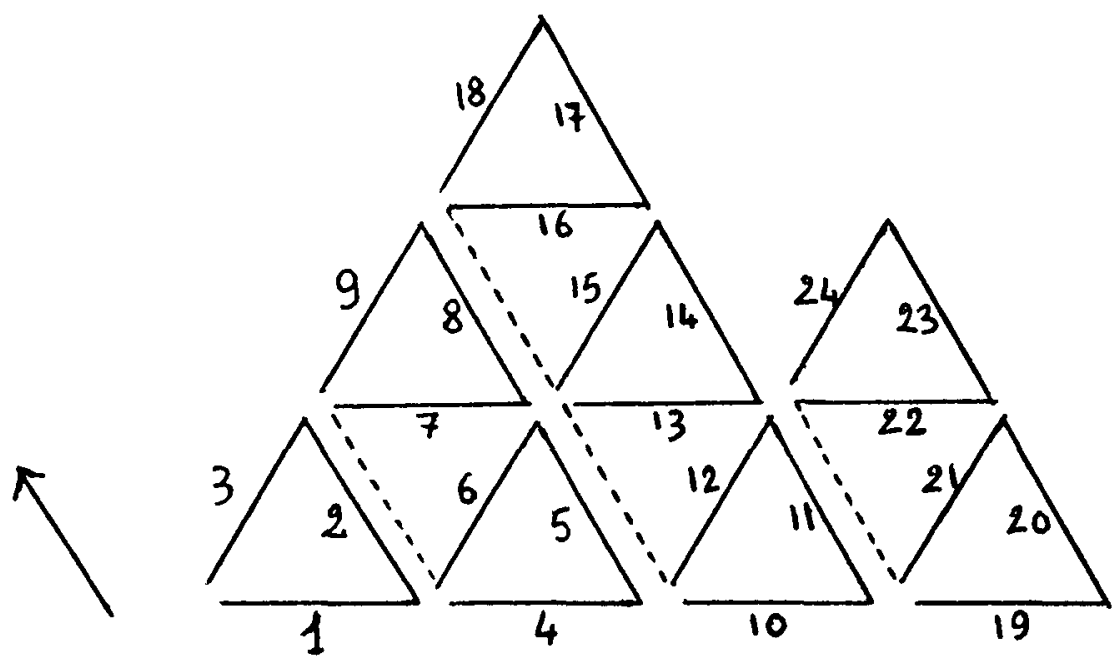

The surface of one rod is represented by an approximative contour defined by a sequence of boundaries assumed to be insulated. This contour is chosen to give the best fit with the real shape of the rods.

\subsection{Input Data}

\section{Description of the Mesh}

NORING

(I5)

$((\operatorname{NINTEX}(K, L), L=1,2), K=1,2)$ (16I5)
Total number of rows used to describe the total mesh (minimum 2)

The mesh has two sets of rows where extranodes have to be calculated at each end. For each set $(L), \operatorname{NINTEX}(K, L)$ represents the numbers of the first and last row. 
( ( ( $\mathrm{LCH}(I, K, L), L=1,2)$, $K=1,16), I=1,4)$

(I6I5)

NOBNDZ

(I5)

(NBDZ (I) , I = I, NOBNDZ)

(16I5)

Description of the Bundle

DROD , LENGTH , POD

(3F11.4)

DEUNIT

(F11.4)
For each row (K) of each subchannel (I), LCH $(I, K, L)$ describes the extreme nodes limiting the range within which the calculation has to be carried out.

Total number of insulated boundaries (surface of the rods)

Each insulated boundary is described by its number on the mesh

Rod diameter (inch)

Axial length over which the calculation has to be carried out

Pitch over diameter

Hydraulic diameter of an inner subchannel (in inches)

Description of the Operating Conditions

GBAR, HIN , QTOTAL, VELI

(4FI1.4)
IOPT

(I5)
$\overline{\mathrm{G}}=\rho \overline{\mathrm{V}}$

Inlet enthalpy (always 0 for tracer injection)

QTOTAL equals 1

Ratio of the average velocity in a triangular subchannel to the average velocity in the bundle

IOPT $=2$ tracer injection calculation

IOPT $=3$ this option pursues a calculation abandoned to an axial elevation $\mathbf{z}$

The ratio of the concentrations at this level $z$ to the injected concentration is read for each node (CRAT (J))

For our purpose IOPT $=2$ 
$\mathrm{NINJCH}$

(I5)

Only if IOPT is greater than 2)

(CRAT (I), I=I, NCHANL)

(6F11.4)

INJ , RHAVG

(I5,E11.4)

(Only if NINJCH is greater than 1) INJ2, INJ 3, INJ4, INJ 5 , INJ 6

(5I5)

CONVUN

(F4.11)

NORUNS

(I5)

OPTION, EHSTA

(2FII.4)

CFRONT

(F11.4)
Number of channels where the tracer is injected (maximum 6)

Here, the ratios $\mathrm{C}(\mathrm{z}) / \mathrm{CO}$ are read for all the nodes (NCHANL is the total number of nodes)

Number of the subchannel where the injection is made

Average density of the fluid flowing through the bundle

Numbers of all the other subchannels where the tracer is injected

Value of the inlet concentration for the nodes where the tracer is injected. The units of the output will be the same as the units used here

Number of separate runs having the same above set of parameters

OPTION, determines the size of the axial increment. Higher it is, smaller is the increment. The stability requires OPTION $\geq 1 / 2$ VELI

EHSTA is the dimensionless eddy diffusivity, normalized with the hydraulic diameter (different from the $\varepsilon^{*}$ of the porous body model, used in KHAN's thesis).

The output results give the number of nodes per subchannel, having a concentration above CFRONT; this measures the expansion of the front concentration CFRONT. (Same units as CONVUN)

Number of axial levels at which the concentrations profile will be printed.

Axial levels in inches where the results will be printed out.
(ZPRINT (I) , I=1, NPRINT)

(6F11.4)
NPRINT

(I5) 
4.0 Output Description

NO OF DIVISIONS

QINT

ZSTART, ETAST, DZSTAR, GBAR

AX INCREM, OPTION, EHSTA

NB OF ITERATIONS

AXIAL DIST (IN)

AVERAGE CONCENTRATION

IN ALL THE SUBCHANNELS
Number of rows in the mesh (NORING)

The parameter printed should be lower than 0.25 to prevent the instability

ZSTART total length divided by the rod diameter

ETAST distance between the centroids of two adjacent cells of the mesh, divided by the rod diameter

DZSTAR axial increment divided by the rod diameter

GBAR $\bar{G}=\rho \bar{V}$

Minimum distance between two adjacent locations where the results are printed (inch)

OPTION and EHSTA are input parameters

Axial distance since the beginning of the calculation

The concentration at each node is printed. One line counts $10 \mathrm{fig}-$ ures and the first number indicates the number of previous lines. (For example node 2275 is the fifth of the line preceded by 227,2280 is the tenth of the same line).

Then for each subchannel, the number of concentrations above CFRONT and the average concentration is indicated.

Example: SUBCHANNEL 0

144 CONCENTRATIONS ABOVE 5.0

AVERAGE CONCENTRATION 6.9 
The listing is presented below.

An example of run with its partial output follows the listing.

The storage capacity required by this program is $120 \mathrm{~K}$ for a mesh size corresponding to 280 nodes per subchannel (NORING-50).

If the four subchannels are calculated with the previous mesh size, 1000 iterations require 33 seconds on the IBM $370-168$ or 130 seconds on the IBM 360-65. With the largest possible axial increment 1000 iterations represent about 16 inches, in the case shown below. (This in fact depends on the geometrical parameters, on the eddy diffusivity and on OPTION). 


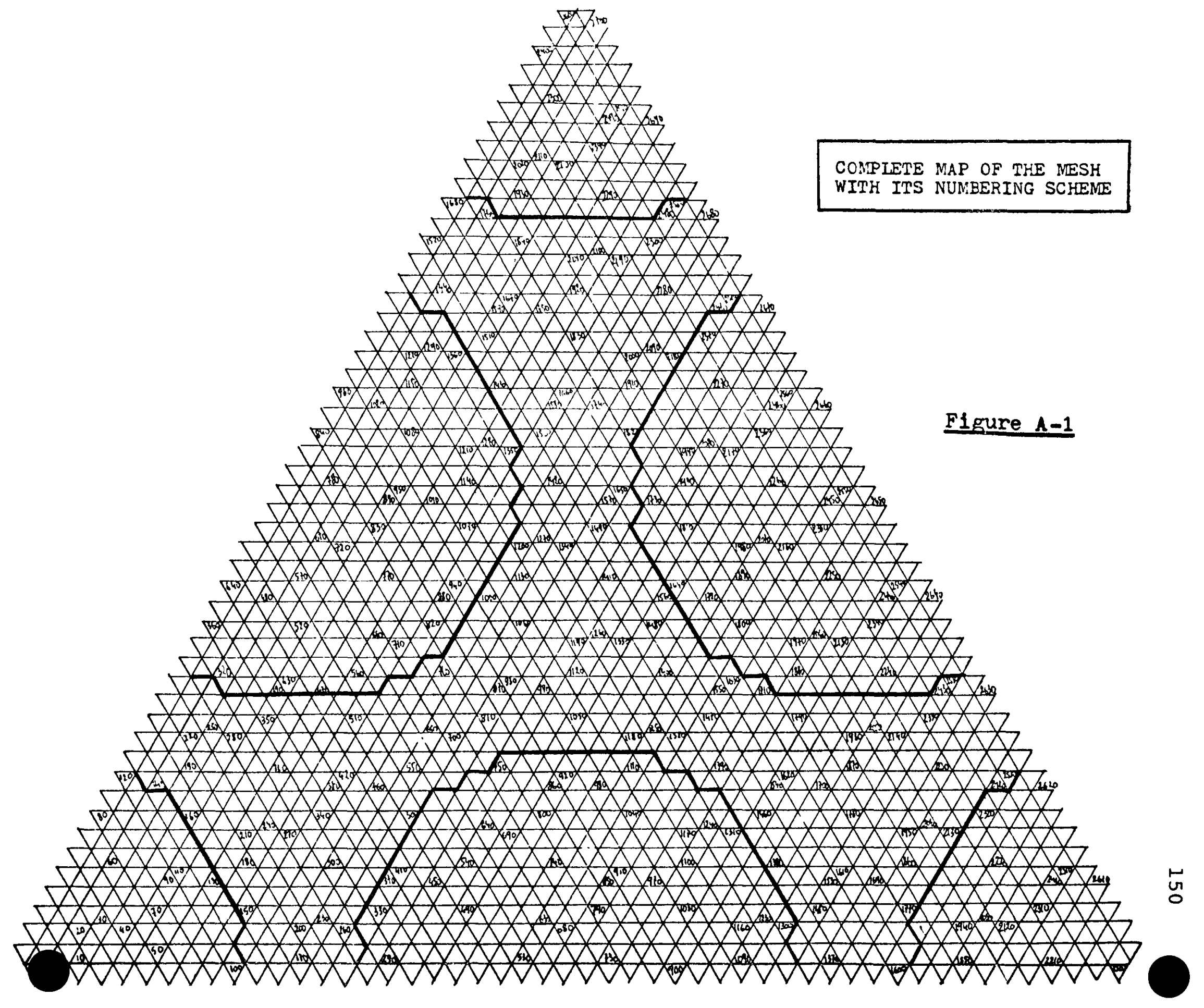




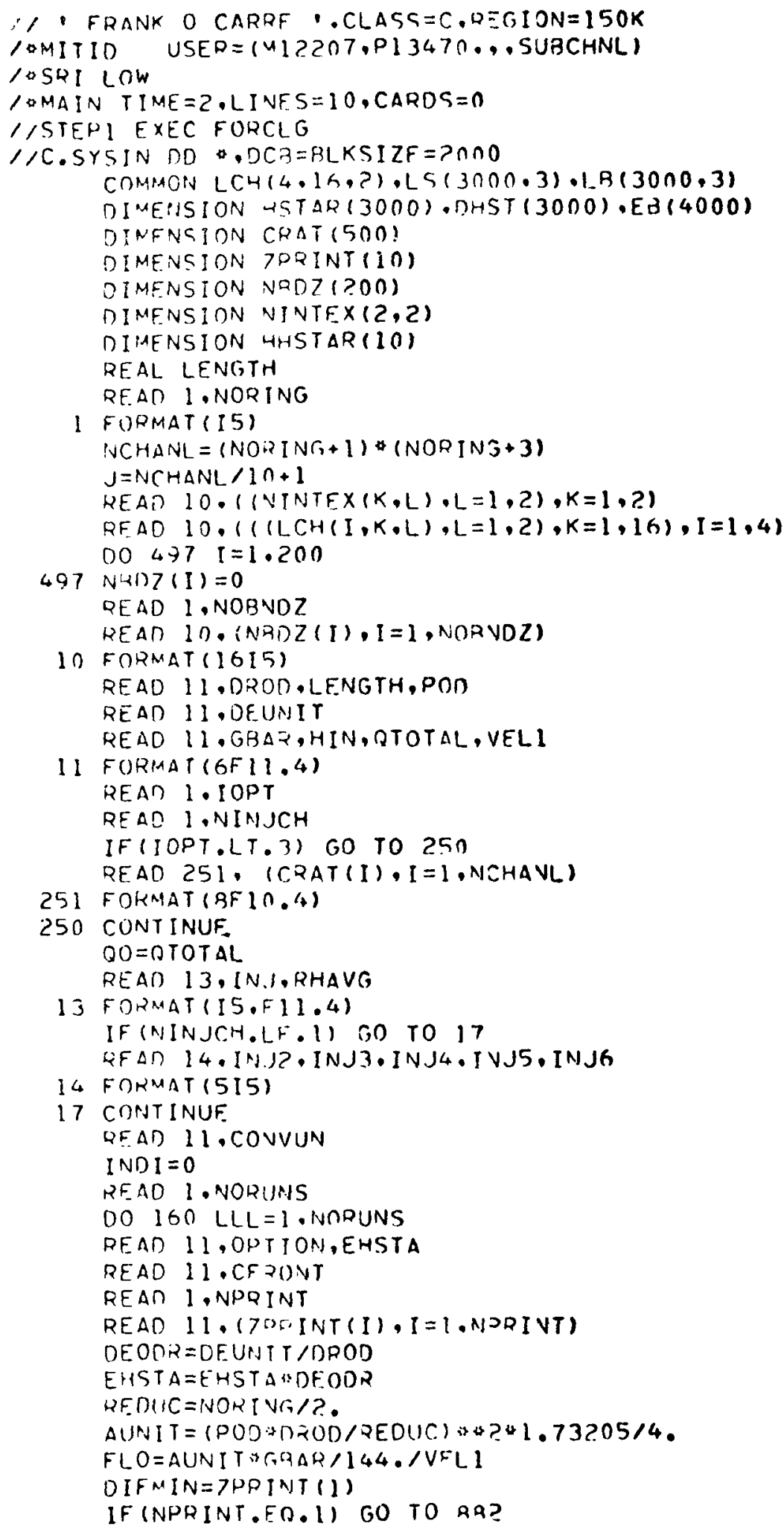


DO 883 IZP=2,NPRINT

$1 Z P M=I Z P-1$

DIF $=2 P R I N T(I Z P)-7 P R I N T$ (IZPM)

IF (DIF.GT.DIFMIN) GO TO AR3

883 CONT INUE

$D I F N I N=D I F$

BR2 XPRINT $=$ DIFMIN/DROD

NOVER $=$ NORING $I$

ATOTAL $=\triangle U N I T * N O R I N G * 2$

ZST $A R T=L E N G T H / D R O O$

$Z S T A R=0$.

BNOYST $=$ PON/PEDUC

ETAST $=P O D / 1.73205 / R E D U C$

ASTAR=AUNIT $/ D Q O D / O R O D$

DST AKM = ASTAL FF.TAST/2, /F.HSTA/OPT ION/ANOYST

NNN $=X P R[N T / D S T A R Y$

IF (NNN.LT.1) NNN=I

DZSTAR $=$ XPRTNT/ (4. NNNN)

QTPRAR $=00 / L F V G T H / A T O T A L \$ 12 . \$ 144$.

CON:VER=OTPAAR

CCRONT =CFRONT /CONVER

Dก $49 \quad I=1$, NCHANL

$49 \operatorname{HSTAR}(I)=0$.

$00499 \quad I=1.4000$

$E B(I)=1$.

499 CONTINUE

DO $498 \quad I=1$, NOANDZ

$M=N P O Z(I)$

$498 E R(M)=0$.

IF (IOPT.GT.P) 60 TO 255

HSTAK (INJ) = GBAR 20012 . INTPBAR/OROD/FLO

IF (NINJCH.LF. I) GO TO 400

HSTAR (INJZ) =GA

HSTAK $(1 N J 3)=G A A R * Q 0 * 12$. I TTPQAR/DRDO/FLO

HSTAR $(I N J 4)=G R A R \backsim O O N 1$. / JTPBAR/DROD/FLO

HSTAR (INJ5) = GRAR $\triangle O O * 1$ ? / TTPHAR/DROO/FLO

HSTAR $(I N J G)=G H A R * O O * 1 ? . / 2 T P 3 A R / D Q O D / F L O$

GO TO 400

255 CONTINUE.

DO $256 \quad I=1$. NCHANL

HSTAR (I) = GBAR*CRAT II) \$DO I ? IOTPHAK/DROO/FLO

256 CONTINUE

400 CONTINUE

OINT $=1$. /ASTAR \#HNTYST/ETAST \#EHSTA VVLL IDZSTAR

IF(INOI.GT.0) GO TO 97

PRINT $3 O$, NORING

30 FORMAT (IHI. 'NO OF DIVISIONSI/5X, I5)

PRINT 131.OINT

PRINT 130

130 FORMAT $(1 X / 1$ TSTART ETAST DZSTAR

PRINT 131.7START.ETAST.N7STAR,GRAR

131 FORMAT $(1 X .4 F 11.4 /)$

97 CONTINUE

PRINT 122

122 FORMATIIHI. AX INCHFM OJTION EHSTAM)

PRINT 123, DIFMIN,OPTION, EHSTA

123 FOPHAT $(1 X, 3 F 11.4 /)$

INDI $=$ INDI +$]$

I $2 P=1$ 
XPRINT $=Z P R I N T(I) / D R O 0$

I COMPT $=0$

CALL NUMB

26 ZBAR =DZSTAR/2 + ZSTAR

$Z B A R=\angle B A R \approx D P O D / L E N G T H$

I COMPT $=$ ICOMPT +1

DO 500 IP $=1.4$

DO $500 \quad L M=1 \cdot 16$

$M L I=L C H(I P, L M, 1)$

$M L 2=L C H(1 D, L M, ?)$

DO $500 \quad M=M L I \cdot M L 2$

$M M l=L S(M, 1)$

$M M 2=L S(M \cdot 2)$

$M M 3=L S(M, 3)$

$I B I=L B(M, I)$

$I B Z=L B(M, 2)$

$I B 3=L B(M, 3)$

DHST $(M)=$ OINT*(EA(IAI)*(HSTAR(MMI)-HSTAR(M)) +FR (IBP)* (HSTAR (MMZ)

1-HSTAR (M)) +FB(IB3) * (HSTAP(M43)-HSTAR (M)))

500 CONTINUE

DO 501 IP $=1.4$

DO $501 L M=1 \cdot 16$

$M L I=L C H(I P, L M, I)$

$M L Z=L C H(I D, L M, 2)$

DO $501 M=M L 1$, ALL

HSTAR $(M)=H S T A R(M)+$ DHST $(M)$

501 CONTINUE

DO $506 I I=1 \cdot 2$

IL I =NINTEX $(I I, 1)$

$I L ?=N I N T E \times(I I, 2)$

DO $504 \quad I=I L I \cdot I L 2$

$M=1 * 2$

$M M I=M+1$

$M M 2=M+2$

$M M 3=M+2 * I+3$

$M M 4=M+3$

$M M 5=M M 3+2$

$M M 6=M M 3+1$

$H I=(H S T A R(M \because 2)+H S T A R(M M 3)) / 2$.

$H 2=H S T A R(M M 5)$

HSTAR $(M)=H 1 * 2 /(4)+1 . F-10)$

$M=I *(I+2)$

$M M I=M-2$

$M M 2=M-1$

$M M 3=M+2+1+1$

$M M 4=M-3$

$M M 5=M M 3-2$

$M M 6=M M 3-1$

$H I=(H S T A R(M M 1)+H S T A H(M M))) / ?$. $H 2=H S T A R(M M 5)$

$H S T A R(M)=H 1 * 2 /(H 2 \cdot 1 . F-10)$

504 CONTINUE

ILI $=2$ \& ILI

IL $=2 * I L 2$

DO $505 K=I L I \cdot I L 2 \cdot 2$

$M=N O V E R \otimes 2+K$

$M M]=M-2 \$ N O R[N G-3$

$M M 2=M M 1+1$

$M M 3=M M 1+2$ 
$M M 4=M-4 * N O R$ I NG -3

$M M 5=M M 4+1$

$M M 6=M M 4+2$

$H 1=(H S T A R(M M 1)+H S T A R(M M 3)) / 2$.

$H Z=H S T A R(M M 5)$

HSTAR $(M)=H 1: 2 /(H 2+1 . F-10)$

505 CONTINUF

506 CONTINUE

ZST $\triangle R=Z S T A R+D Z S T A R$

7TSTAR=7STAR DROD

DIFF $=A B S(7 S T A R-X P R$ INT)

IF (DIFF-07STAF/2.) 92.92 .100

$92 \quad I 7 P=I Z P+1$

XPPINT $=7 P R I N T(I 7 P) / R R O D$

PRINT 91 ICOMPT

91 FORMAT(IH, NNB OF ITERATIONS / $/ 6 X \cdot I 5 /)$

PDINT 93

93 FORMATIHH // AXIAL DIST (IN) $)$

PRINT 94.775TAR

94 FORMAT $(4 X, E 11.4 /)$

PRINT 96

96 FORMATIIX, A AVERAGE CONCEVTRATION IN ALL THE SUBCHANNELS / DO $496 \quad I=1 . J$

$I L I=I \$ 10-9$

$1 \mathrm{~L} 2=\mathrm{I} * 10$

$\mathrm{JJ}=\mathrm{I}-\mathrm{I}$

DO $98 K=I L 1 \cdot I L 2$

$K K=K-I L I+1$

98 HHSTAR $(K K)=H S T A R(K)$ *CNVER

PRINT 95, JJ, (HHSTAR (KK), KK $=1,10$ )

95 FOOMAT $(1 X, 15,5 X, 10(F \mid 1.4) / 1)$

496 CDNTINUE

DO 502 IP $=1.4$

I $S S=I P-1$

NFRONT $=0$

SUM $\doteq 0$.

DO $503 \quad L M=1.16$

$M L I=L C H(I D, L M, I)$

$M L Z=L C H(I P \cdot L M \cdot 2)$

กO $503 M=M L 1, M L 2$

$S U M=S U M+H S T A R(M)$

IF (HSTAR(4)-CCRONT) 503.507 .507

507 NFRONT $=$ NFRONT +1

503 CDNTINUE

SUM $=$ SUM $/ 280 . *$ CONVER

PRINT $99, I C \angle, N F R O N T, C F R O V T$, SUM

99 FORMAT(IX.' SIJRCHANNEL NJMJER ',I3/T5.' CONCENTRATIOVS ABOVE "

IF6.1/1 AVERAGE CONCENTOATIOV I.FB.1/1)

$50 ?$ CONTINUE

100 IF (ZZSTAR.LF.ZPRINT(NPRIVT)) GN TO $>6$

150 CONTINUF.

STOP

END

SUBROUT INF NUMA

COMMON LCH $(4,16.2), \operatorname{LS}(3 \cap 00,3) \cdot 1.9(3 \cap n 0,3)$

$00400 \quad T P=1.4$

DO $400 \quad L M=1,15$

$M L 1=L C H(i P, L M, 1)$

$M L 2=L C H(I P \cdot L M \cdot ?)$ 
$Z=M L I+0$.

$I=\operatorname{SORT}(Z)$

$N A P=3 * I *(I-1) / 2$

$I D=I * 2$

$K K=M L I-I D$

$K K Q=K K /$ ?

$K K R=K K-2 \forall K K n$

$M L 1=M L 1+1-K K R$

DO $401 \quad M=M L 1, M L 2,2$

$1 S(M, 1)=M-1$

LS $(M, 2)=M+1$

$L S(M, 3)=M+2+(I+1)$

$K=M-10$

$L R(M, 1)=N R D+3 *(K-1) / 2+1$

$\operatorname{LR}(M, ?)=\operatorname{LR}(M, 1)+2$

$\operatorname{LB}(M, 3)=\operatorname{LB}(M, 1)+1$

401 CONTINUE

$M L I=M L I-1+2 \$ K K Q$

DO $402 M=M L 1 \cdot M L 2 \cdot 2$

$\operatorname{LS}(M, 1)=M-2 \& I$

$\operatorname{LS}(M, 2)=M-1$

$L S(M \cdot 3)=M+1$

$K=M-10$

$\operatorname{LB}($ iA, 1$)=N R P-3 *(I-1 * 3 *(K-2) / 2+2$

$L B(M, 2)=N B D+3 *(K-2) / 7+3$

$L B(M, 3)=L R(M, 2)+1$

402 CONTINUE

400 CONTINUE

RE TURN

END. 
MG.SYSIN DO

50

$11 \quad 15 \quad 36 \quad 40$

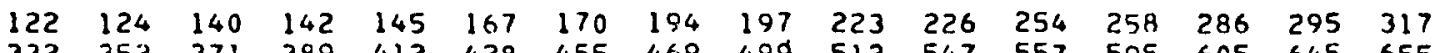

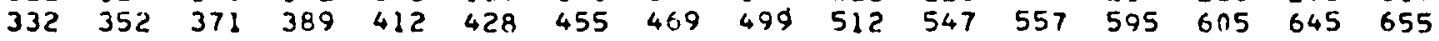

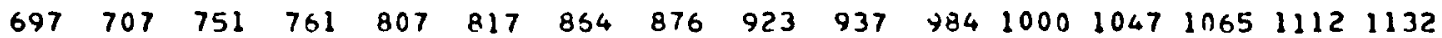
$\begin{array}{llllllllllllllll}1179 & 1201 & 1246 & 1274 & 1318 & 1346 & 1393 & 1419 & 1470 & 1494 & 1549 & 1571 & 1630 & 1632 & 1648 & 1650\end{array}$

$\begin{array}{llllllllllllllll}1297 & 1299 & 1315 & 1317 & 1370 & 1392 & 1445 \quad 1469 & 1522 & 1548 & 1601 & 1629 & 1683 & 1711 & 1770 & 1792\end{array}$

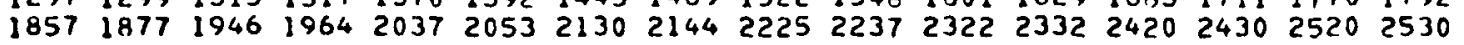

$\begin{array}{llllllllllllllll}1347 & 1349 & 1365 & 1367 & 1420 & 1442 & 1495 & 1519 & 1572 & 1598 & 1651 & 1679 & 1733 & 1761 & 1820 & 1842\end{array}$ $19071927199620142087210321802194227522872372 \quad 2382247024802570 \quad 2580$

132

$\begin{array}{llllllllllllllll}137 & 164 & 171 & 173 & 176 & 179 & 182 & 185 & 188 & 191 & 193 & 363 & 365 & 404 & 406 & 417\end{array}$ $\begin{array}{llllllllllllllll}451 & 471 & 502 & 528 & 556 & 599 & 613 & 651 & 673 & 717 & 736 & 786 & 802 & 856 & 873 & 930\end{array}$ $\begin{array}{lllllllllllllllll}940 & 1006 & 1023 & 1086 & 1102 & 1168 & 1185 & 1252 & 1272 & 1339 & 1362 & 1429 & 1455 & 1522 & 1551 & 1618\end{array}$ $\begin{array}{llllllllllllllll}1650 & 1715 & 1717 & 1752 & 1754 & 1787 & 1816 & 1860 & 1889 & 1896 & 1898 & 1901 & 1904 & 1907 & 1910 & 1913\end{array}$

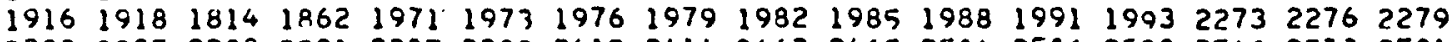
$\begin{array}{llllllllllllllllllll}2282 & 2285 & 2288 & 2291 & 2387 & 2389 & 2412 & 2414 & 2463 & 2465 & 2504 & 2506 & 2538 & 2540 & 2579 & 2581\end{array}$ $\begin{array}{lllllllllllllllllll}2592 & 2626 & 2667 & 2701 & 2721 & 2752 & 2796 & 2827 & 2853 & 2881 & 2928 & 2956 & 2988 & 3013 & 3063 & 3088\end{array}$

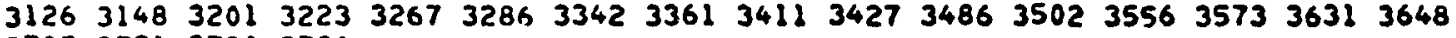
$\begin{array}{llll}3705 & 3721 & 3780 & 3796\end{array}$
2.5
32.
1.2564

1.343

32325.876

0.

1.

1.0307

2

1

$8650.7421 E-01$

7434.

1

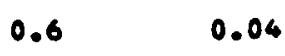

5.

6
14.

17.

20.

26.

32.
NORING

$\operatorname{NINTEX}(K, I)$

$\operatorname{LCH}(1, \mathrm{~K}, \mathrm{I})$

$\operatorname{ICH}(2, K, I)$

$\operatorname{ICH}(3, K, I)$

$\operatorname{ICH}(4, K, I)$

NOBNDZ

NBNDZ (I)

DROD . IENGTH,POD

DEUNIT

GBAR,HIN, QTOTAI, VEIL

IOPI

NINJCH

INJ, RHAVG

CONVUN

NORUNS

OPTION ,EHSTA

CFRONT

NPRINT

ZPRINT (I) 
AX INCREY CPTIEY EHSTA

$0.30005+01 \quad 0.60025+20 \quad 0.2149 \mathrm{z}-01$ NB OP ITERATIONS

PARTIAL OUTPUT
No OF DIVISIONS

50
$0.21485+00$

ZSTART ETAST DZSTAR GBA3

$0.1280 \mathrm{E}+02 \quad 0.29028-010.6122 \mathrm{E}-02 \quad 0.3233 \mathrm{E}+05$

- AXIAL DIST (IN)

$0.80 \mathrm{CHE}+09$

AVERAGE CONCENTEATION IN ALL THE SDFCHANNELS

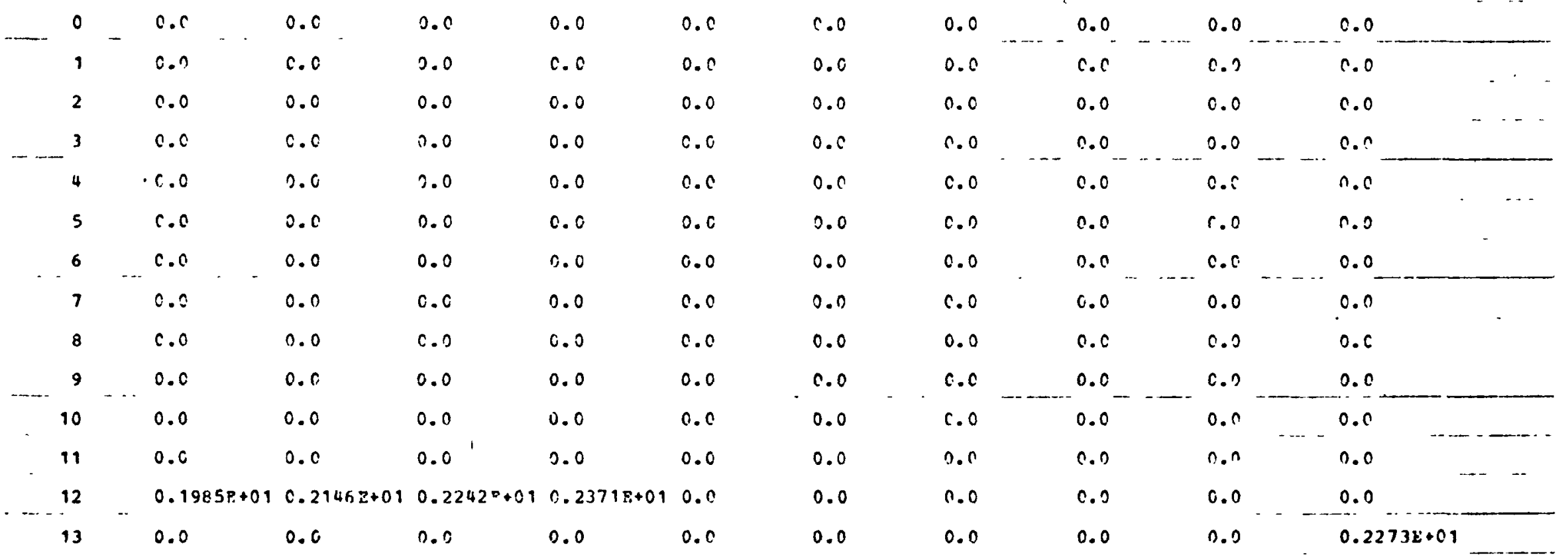

$0.2141 E+010.20435+010.18795+010.1965 E+010.21618+010.2245 L+010.245 C E+010.25358+010.2808 Z+010.2352 E+01$ $0.3133 E+010.3216 E+010.3336 E+010.3363 E+010.3429 E+010.3401 E+010.34152+010.3336 E+010.3295 R+010.3163 E+01$ $0.36695+010.28773+C 10.2723 z+010.24418+010.23625+010.2143 E+010.2057 E+010.1953 E+010.13965+010.22213+01$ $0.2305 P+310.2566 E+010.26 .35 E+010.2911 E+010.2971 E+010.3230 z+010.3268 E+010.3477 F+010.3467 E+010.3624 E+C 1$

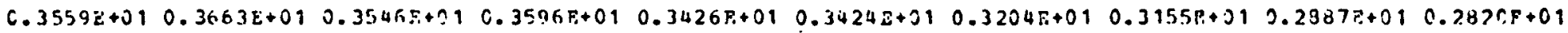

$190.2537 F+010.2465 E+010.2202 E+010.21175+010.1883 z+010.2025 E+010.23058+010.2404 F+010.2717 E+010.2771 E+01$ 


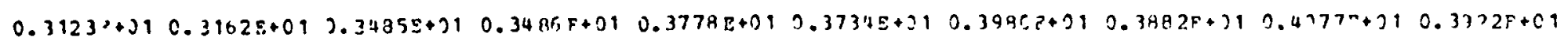

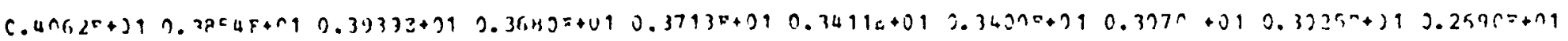

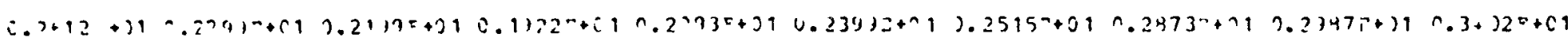

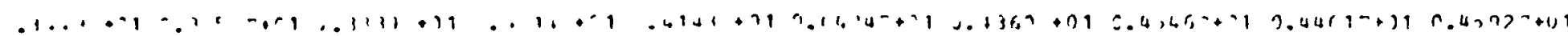

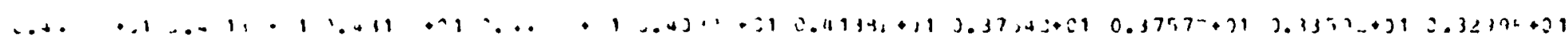

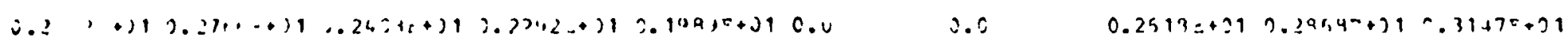

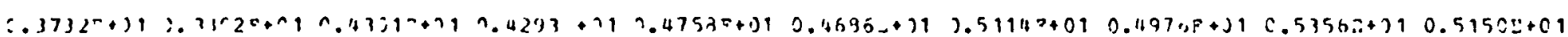

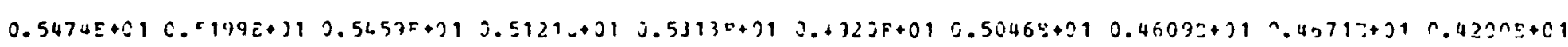

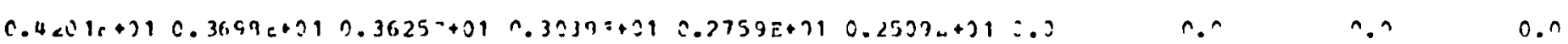

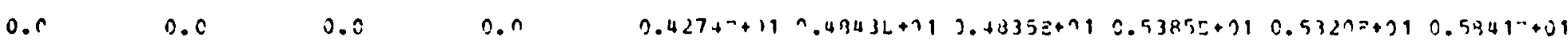
$0.5705=+? 10.61335+010.59 n 35+210.639 C 3+C 10.63982+010.64535+010.53839+010.63605+010.5926+3) 10.61262+01$ $0.5637 E+110.57628+010.5233 E+010.52312+010.4735 E+010.47402+010.41682+010.1 \quad 0.0$
0.0
0.0
0.0
2.0
$n .0$
0.0
0.1
0.0
0.0
0.0

$0.0 \quad 0.5444 \vec{g}+n 10.53555+010.6022 F+010.6633 E+010.6513 E+010.7094 E+010.6893 E+310.7415 \vec{r}+210.7121 F+21$ $0.75720+210.71995+010.7557 F+310.7091 \mathrm{E}+01 \quad 0.7370 \mathrm{E}+010.6836 \mathrm{E}+010.70263+01 \quad 0.5439 \mathrm{~F}+010.5547 F+310.59295+01$
$0.5969 F+C 10.5343 E+010.0$
0.0
0.0
0.0
0.0
0.0
0.2
$0 . n$
0.0
0.0
C. 0
$0.0 \quad 0.0$
0.0
0.0
0.0
0.2
0.0

$0.6750 z+21 \quad C .74465+01 \quad 0.7374 E+01 \quad 0.8350 E+01 \quad 0.7884 E+01 \quad 0.8511 E+01 \quad 0.8239 E+C 1 \quad 0.8793 E+21 \quad 0.8414 E+01 \quad 0.8879 E+01$ $0.8399 z+31 C .8763 g+010.9194 E+210.8454 E+01 \quad 0.7815 E+010.7972 E+010.728 B P+010.7356 E+010.66558+010.0$
0.0
0.2
0.0
0.0
0.0
0.3
$0.0 \ldots-0.3$ 0.0

$\begin{array}{llllll}C .0 & 0.0 & 0.0 & 0.0 & 0.0 & 0.0\end{array}$

$0.0 \quad 0.0$ 0.0

$0.82217+010.4997 ?+010.84958+010.9635 E+010.94118+010.1039 E+020.9725 P+010.1329 P+020.982 r=+C 1$

$0.10283+02 \quad C .46948+010.1033 \Xi+020.9353 E+010.95678+010.9213 z+010.8916 E+C 10.8134 E+C 10.0$

$\begin{array}{cccccc}0.46948+09 & 0.10038+02 & 0.9353 \Sigma+01 & 0.95678+01 & 0.92132+01 & 0.89 \\ 0.0 & 0.0 & 0.0 & 0.0 & 0.0 & 0.0\end{array}$

$0.0 \quad 0.0$

0.0

0.0

0.0

0.0

C. 0

C.o

0.0

$0.0 \quad 0.0 \quad 0.0$

$0.98698+010.1073 z+020.1059 E+02 \quad 0.11388+02 \quad 0.1108 E+020.1976 E+02$

$0.1132 F+020.1187 E+02 \quad 0.113) F+020.1173 E+02 \quad 0.1103 E+02 \quad 0.1132 z+020.13529+020.1 n 558+020.979 n E+010.0$

$\begin{array}{llllllllll}0.0 & 0.0 & 0.0 & 0.0 & 0.0 & 0.0 & 0.0 & 0.0 & 0.0 & 0.0 \\ 0.0 & 0.0 & 0.0 & 0.0 & 0.0 & 0.0 & 0.0 & 0.0 & 0.0\end{array}$




\begin{tabular}{|c|c|c|c|c|c|c|c|c|c|c|}
\hline 48 & 0.0 & 0.0 & 0.0 & 1.0 & 0.0 & 0.0 & 0.0 & $0 . n$ & $0 . ?$ & $n . n$ \\
\hline
\end{tabular}

$50 \quad 0.12655+020.12445+02 \quad 0.13257+02 \quad 1.12355+? 2 \quad 0.1349 z+02 \quad 0.1295 E+02 \quad 0.13478+02 \quad 0.12815+02 \quad 0.1320 E+02 \quad 0.12385+02$

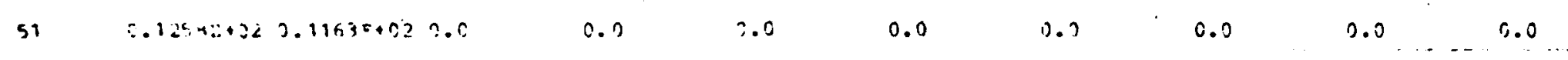

\begin{tabular}{|c|c|c|c|c|c|c|c|c|c|}
\hline 5 & $\therefore$. & $c . n$ & 2.0 & 3.0 & $3 . ?$ & 0.0 & $0.1)$ & 0.0 & 0.3 \\
\hline 53 & $\therefore$. & $\therefore 0$ & c.? & 0.3 & 0.0 & 0.0 & 0.0 & 0.0 & 0.0 \\
\hline
\end{tabular}

$\therefore \quad \therefore \quad \quad .0 \quad \therefore \quad 0.0 \quad 0.0 \quad 0 \quad 0.0 \quad 0.13765+020.1481 E+020.14415+220.1512 P+02$

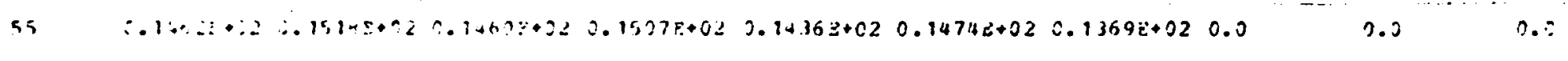

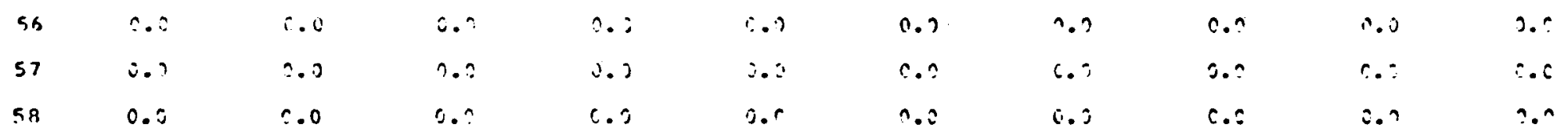

$590.0 \quad 0.0 \quad 0.0 \quad 0.0 \quad 0.16958+020.16203+02 \quad 0.16765+020.16258+020.15735+020.1527 \varepsilon+02$

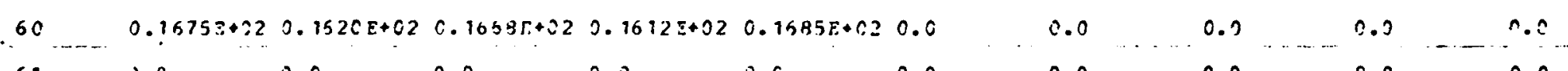

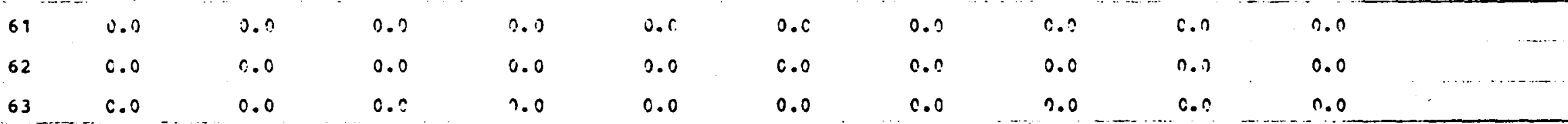

\begin{tabular}{|c|c|c|c|c|c|c|c|c|c|c|}
\hline 63 & c.o & 0.0 & 0.0 & 1.0 & 0.0 & 0.0 & $c .0$ & 2.0 & c.? & 0.0 \\
\hline 64 & 0.0 & 0.0 & 0.0 & 0.0 & $0.1761 E+02$ & $0.1917 \Sigma+J 2$ & $0.17745+02$ & $0.18198+02$ & $0.1774 E+02$ & $0.1916 \mathrm{P}+02$ \\
\hline 66 & $0 . c$ & 0.0 & 0.2 & 0.0 & 0.0 & 0.0 & c.o & 0.0 & 0.0 & 0.0 \\
\hline 67 & 0.0 & 0.0 & 0.0 & 0.0 & 0.0 & 0.0 & 0.0 & 0.0 & $0 . ?$ & 0.0 \\
\hline 68 & 0.0 & c.e & 0.2 & 0.0 & 0.0 & 0.0 & 0.0 & 0.0 & 0.0 & 0.0 \\
\hline 69 & 0.0 & 0.0 & 0.0 & $n .0$ & 0.0 & 0.0 & $0.1053 E+c 2$ & $0.19 c 58+n 2$ & $0.1935 z+02$ & $0.149 a z+C 2$ \\
\hline
\end{tabular}

$690.0 \quad 0.0 \quad 0.0 \quad 0.0 \quad 0.0 \quad 0.0 \quad 0.1053 E+C 2 \quad 0.19 c 58+020.1935 z+020.14998+C 2$

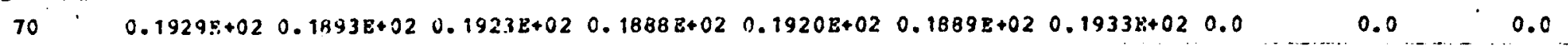

\begin{tabular}{|c|c|c|c|c|c|c|c|c|c|c|}
\hline 71 & 0.0 & 0.0 & 0.0 & 0.0 & 0.0 & 0.0 & 0.0 & 0.0 & 0.0 & 0.0 \\
\hline 72 & 0.0 & 0.0 & 0.0 & 0.0 & 0.0 & 0.0 & 0.0 & 0.0 & 0.0 & 0.0 \\
\hline
\end{tabular}

$\begin{array}{lllllllllll}72 & 0.0 & 0.0 & 0.0 & 0.0 & 0.0 & 0.0 & 0.0 & 0.0 & 0.0 \\ 73 & 0.0 & 0.0 & 0.0 & 0.0 & 0.0 & 0.0 & 0.0 & 0.0 & 0.0 & 0.0 \\ 74 & 0.0 & 0.0 & 0.0 & 0.0 & 0.0 & 0.0 & 0.0 & 0.0 & 0.0\end{array}$

$75 \quad 0.1989 E+02 \quad 0.2012 E+02 \quad 0.1989 E+02 \quad 0.20 .38 E+02 \quad 0.1983 E+02 \quad 0.20012+02 \quad 0.19763+02 \quad 0.1993 E+02 \quad 0.1970 E+02 \quad 0.1986 z+02$

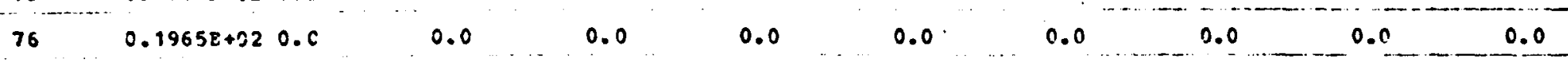

$0.0 \quad 0.0$

0.0

0.0

0.0

0.0

0.0

0.0 


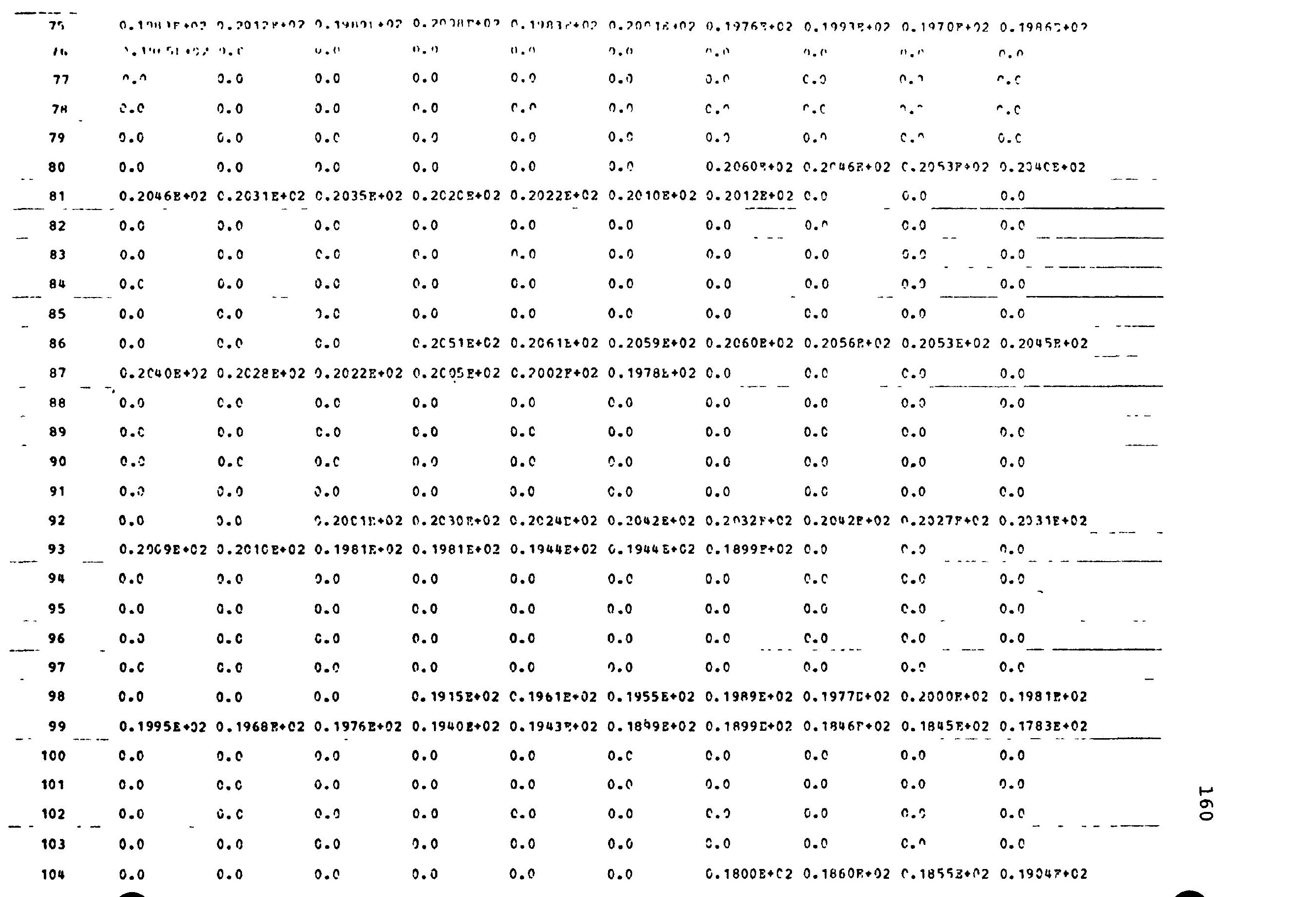




\begin{tabular}{|c|c|c|c|c|c|c|c|c|c|c|c|}
\hline 101 & $0 . " 1$ & 0.0 & 0.010 & 7.0 & $r . n$ & $n . c$ & $0 . n$ & 0.0 & $r . n$ & 0.0 & \\
\hline inis & 0.0 & $c 0$ & 1.1 & $" .1$ & $\because n$ & $" \cdot 1$ & $0.161+3)+n\rangle$ & $n \cdot \mid \cdots(n),(n)$ & n.nn?.,n,n) & 10.1001010018 & \\
\hline 105 & $c .19970+12$ & $0.193 r r+92$ & $0.19152+12$ & $\therefore .133^{5} E+n 2$ & J.19CGE+02 & $0.1922 E+02$ & $0.1883 E+02$ & $0.1991 \mathrm{E} \cdot 02$ & C. $1942 E+c 2$ & 0.18458 .02 & \\
\hline 106 & $\therefore .17, r=+22$ & $\therefore 1 / 45:+12$ & $3.171+\equiv+1$ & $\because 1714=02$ & $0.16338+02$ & $0.0^{\circ}$ & 0.0 & 0.0 & $n . n$ & 0.0 & \\
\hline 167 & $0 . c$ & 0.0 & 3.0 & 0.0 & c.r. & 0.0 & 0.0 & $c .0$ & $c .0$ & 0.0 & \\
\hline $1 C B$ & $0 . c$ & c.s & $c . c$ & 0.0 & 0.0 & 0.0 & 0.0 & 0.0 & 0.0 & 0.0 & \\
\hline 109 & 0.0 & 0.0 & 0.0 & 0.0 & 0.0 & 0.0 & 0.0 & 0.0 & 0.0 & 0.0 & \\
\hline 110 & $0 . c$ & 0.0 & 0.0 & 0.0 & 0.0 & $0 . c$ & 0.0 & 0.0 & 0.0 & 0.0 & \\
\hline 111 & 0.6 & C. $16568+02$ & 0.17311 .02 & C. $1736 E+02$ & $0.1793 E+C 2$ & $0.1785 E+02$ & $0.1835 E+C 2$ & $0.1818 \mathrm{P}+02$ & $0.17545+12$ & C. $1827 E+02$ & \\
\hline 112 & $C .1952 E+C 2$ & $0.9813 F+02$ & $0.18275+02$ & $0.1777 E+02$ & $0.1782 E+02$ & $0.1721 E+02$ & $C .1720 E+C 2$ & $0.16488+02$ & c. $1643 E+02$ & $0.1561 E+02$ & \\
\hline 113 & $0.15562+02$ & $0.1456 E+C 2$ & $0 . c$ & 0.0 & $c .0$ & 0.0 & 0.0 & 0.0 & 0.0 & 0.0 & \\
\hline 174 & 0.0 & 0.0 & 0.0 & 0.0 & c.o & 0.0 & 0.0 & 0.0 & 0.0 & 0.0 & \\
\hline 115 & 0.0 & 0.0 & 0.0 & 0.0 & 0.0 & 0.0 & 0.0 & 0.0 & $c .0$ & $0 . n$ & \\
\hline 116 & 0.0 & 0.0 & 0.0 & 0.0 & $c . c$ & 0.0 & $c .0$ & 0.0 & 0.0 & 0.0 & \\
\hline 117 & 0.0 & $c . c$ & 0.0 & 0.0 & 0.0 & 0.0 & 0.0 & 0.0 & C. $1481 E+02$ & $0.1574 E+02$ & \\
\hline 118 & C. $15492+02$ & $0.1658 E+C 2$ & $0.1657 \varepsilon+02$ & $0.1720 E+02$ & $0.1709 z+02$ & $0.1756 \varepsilon+02$ & $0.1735 E+02$ & $0.1768 E+02$ & $0.1734 E+22$ & c. $1753 P+02$ & \\
\hline 119 & $0.1707 E+32$ & $0.1715 E+02$ & $0.1656 \pm+02$ & $0.1655 z+02$ & $0.15838+02$ & $0.1575 z+02$ & $0.1492 E+C 2$ & $0.14 A G E+02$ & $C .1385 E+C 2$ & $0.1373 z+02$ & \\
\hline 120 & $0.1267 E+32$ & $0 . c$ & 0.0 & 0.0 & 0.0 & 0.0 & 0.0 & 0.0 & 0.0 & 0.0 & \\
\hline 121 & 0.0 & 0.0 & 0.0 & 0.0 & 0.0 & 0.0 & 0.0 & 0.0 & $? 0$ & $c .0$ & \\
\hline 122 & 0.0 & 0.0 & $n .0$ & 0.0 & 0.0 & 0.0 & 0.9 & 0.0 & $\therefore . n$ & $r .0$ & 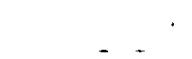 \\
\hline 123 & $0 . c$ & $0 . c$ & 0.0 & 0.0 & $c .0$ & 0.0 & 0.0 & 0.0 & 0.0 & 0.0 & \\
\hline 124 & 0.0 & 0.0 & 0.0 & c. 0 & 0.0 & $0.1120 \mathrm{E}+02$ & $0.1190 E+02$ & $0.1258 P+02$ & $0.1384 E+0 ?$ & $0.1409 E+02$ & \\
\hline 125 & $0.1502 R+02$ & $\therefore .15149+02$ & $O: 158 A E+02$ & $0.158 \partial z+02$ & $0.1646 \mathrm{P}+02$ & $3.1634 E+32$ & $0.1675 E+02$ & $0.1649 E+02$ & $0.1675 E+02$ & $0.1635 E+02$ & \\
\hline 126. & $0.1647 E+32$ & $0.1593 \bar{E}+C 2$ & $0.1593 P+J 2$ & $0.1525 E+02$ & $0.1515 E+C 2$ & $0.1434 z+02$ & $0.14178+02$ & $0.13238+02$ & $0.13008+02$ & $0.1192 E+02$ & \\
\hline 127 & $0.1167 E+02$ & $0.1023 z+C 2$ & $0.94932+01$ & $0.8778 \mathrm{~g}+01$ & 0.0 & 0.0 & 0.0 & 0.0 & 0.0 & 0.0 & \\
\hline 128 & 0.0 & 0.0 & 0.0 & 0.0 & 0.0 & 0.0 & 0.0 & 0.0 & 0.0 & 0.0 & -- \\
\hline 129 & $c .0$ & 0.0 & 0.0 & 2.0 & 0.0 & $0.3011 E+00$ & $0.3710 \Sigma+00$ & $0.4235 \mathrm{P}+00$ & $c .49648+c 0$. & $0 . c$ & \\
\hline 130 & 0.0 & 0.0 & 0.0 & 0.0 & 0.0 & 0.0 & 0.0 & 0.0 & 2.3 & 0.0 & \\
\hline 131 & 0.0 & 0.0 & 0.0 & 0.0 & $0.8328 E+01$ & $0.86882 \mathrm{E}+01$ & $0.93418+01$ & $0.105 c 8+92$ & $0.13948+? 2$ & $0.1197 E+02$ & . \\
\hline
\end{tabular}









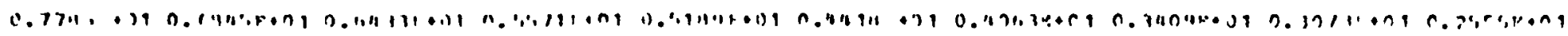

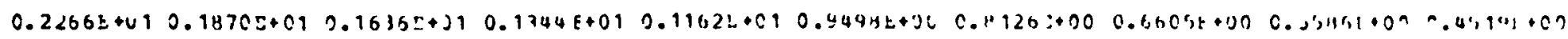

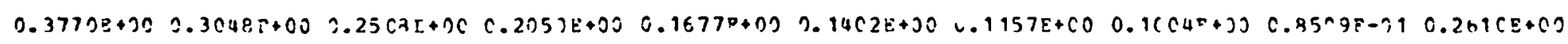

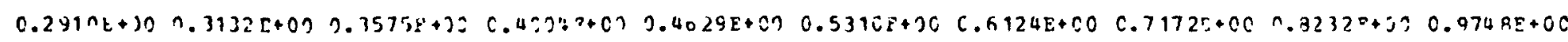
$0.1113 E+210.1319 E+010.14 B 9 L+) 10.1765 E+010.1374 E+210.2332 E+010.25833+01 \quad C .3 C 36 D+010.3326 F+31 C .3398=+01$

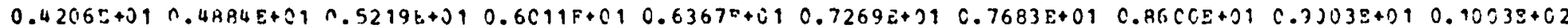

C.C

0.0

0.0

0.0

0.0

$0 . n$

0.0

0.0 - $-6746 F+012.6353 E+010.5505 E+010.512 H E+010.4347 E+010.4340 E+010.3392 E+010.3121 E+01 \quad C .2596 E+31 \quad 0.2354 E+01$

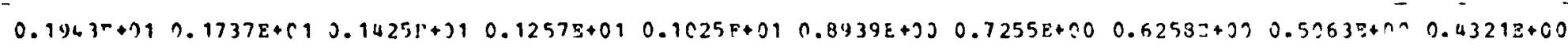
$0.3521 E+1) 0(.246 J E+00 \quad 0.2422 F+00 \quad 0.2 C 35 \Xi+00 \quad 0.1703 E+020.1427 E+00 \quad 0.1230 E+C 0 \quad 0.1046 E+20 \quad C .9497 E-010.8339 E-C 1$

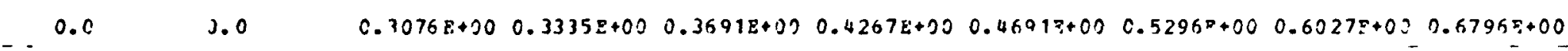
$0.7973 r+300.8325 E+00 \quad 0.1055 E+01 \quad C .1181 E+010.1403 E+010.1558 E+010.1848 E+C 10.2033 E+010.2403 E+010.2517 E+01$ $0.3 C 77 E+J 10.3312 E+010.3871 \Gamma+010.4119 E+010.4785 F+010.5040 E+01 \dot{0} .5839 E+010.6131 P+010+7193 E+310.7783 E+01$

$\begin{array}{ccccccccccc}0.83878+01 & 0.0 & 0.0 & 0.0 & 0.0 & 0.0 & 0.0 & 0.0 & 0.0 & 0.0 \\ 0.0 & 0.0 & 0.0 & 0.0 & 0.0 & 0.0 & 0.0 & 0.0 & 0.0 & 0.0\end{array}$
$0.2365=+010.1336 E+01 \quad C .1767 E+010.11449 E+01 \quad 0.1304 z+01 \quad 0.1063 E+010.9449 E+20 \quad 0.7662 E+00 \quad 0.67357+00 \quad 0.5447 E+00$ $0.4743 P+00 \quad 0.3845 E+00 \quad 0.3324 E+20 \quad 0.2728 E+C 0 \quad 0.2352 E+00 \quad 0.19872+00 \quad 0.17125+00 \quad 0.15125+0 C \quad 0.12695+00 \quad 0.1116 E+C 0$

\begin{abstract}
$0.10118+200.0$
\end{abstract}
0.0

0.0 .

0.0

0.0

0.0

0.0

0.0

$0.4534 E+00$

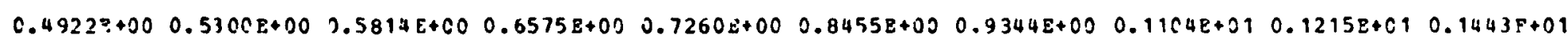

$0.15773+010.1871 E+C 10.2025 E+? 10.2304 E+010.2563 z+010.3012 E+210.1$

$$
179
$$

180

$0.4650 P+010.53798+010.0$

0.0

0.0

0.0

c. 0

0.0

0.0

0.0

0.0

\begin{abstract}
0.0
\end{abstract}
0.0

0.0

0.0

0.0

0.0

c. 0

$\begin{array}{cc}0.0 & 0.0 \\ 0.0 & 0.0 \\ 0.0 & 0.0\end{array}$

$98+01 \quad 0.4518 E+01$

\title{
182
}

$-183$

184

$0.29538+010.29508+010.23699+010$. $0.1781 E+000.1615 E++00.0$

$$
0.0
$$

0.0

\begin{abstract}
0.0
\end{abstract}
0.0

0.0

0.0

0.0

0.0

0.0
-0.0
0.35

$0.6903 E+00 \quad 0.7482 z+C C S .87 C 6 E+00 \quad 0.946 C E+00$

$0.5053 F+00 \quad 0.53278+00 \quad C .57075+02 \quad 0.61215+0 C$ 


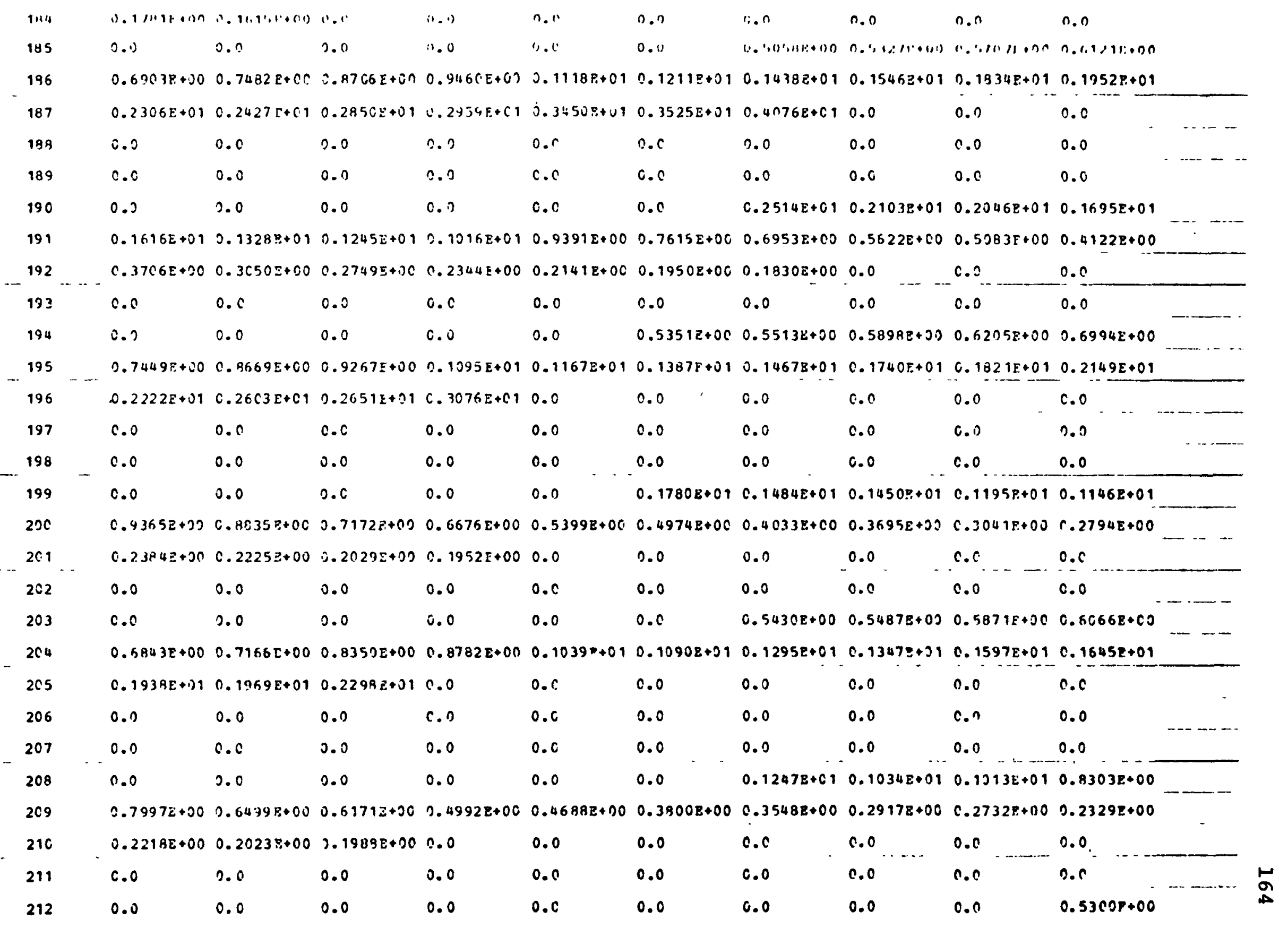



$0.1117 E+J$ $0.56208+C C \quad 0.57108+30$ C.6461L+00 $0.66535+30$

$.7772 \mathrm{E}+00 \quad 0.80$

$$
\text { c.u } 0.0
$$$$
0.0
$$

$$
0.0
$$

$0.0 \quad 0.0$

o.c

0.6

0.0

0.982 .0 .0

0.0

0.0

0.0

0.0

0.0

0.0

0.0

0.0

$$
\text { n.n }
$$

$0.1169 P+C 1$

218

$0.7094 E+00 \quad C .6962 E+C C \quad 0.5661 F+00 \quad 0.5485 E+00 \quad 0.4436 E+C 0 \quad 0.425$

0.0

0.0

0.0

0.0

$0 . n \ldots . . .0$.

$0.0-0.8619 E+C 0$

\section{0}

$$
0.9
$$

0.0

0.0
0.0

$$
0.0
$$

0.0

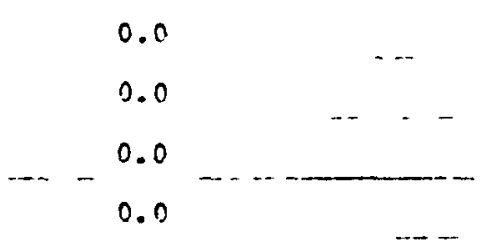

$0.5834 E+00 \quad 0.4728 E+00 \quad 0.467$

0.376

$$
0.0
$$

$0.44 n 68+00 \quad 0.4125 z+c 0 \quad 0.45$

0.0

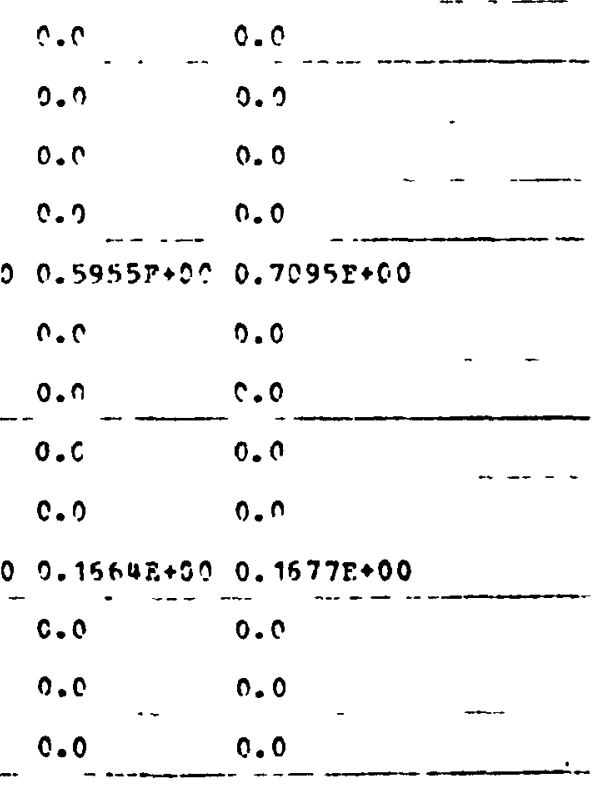




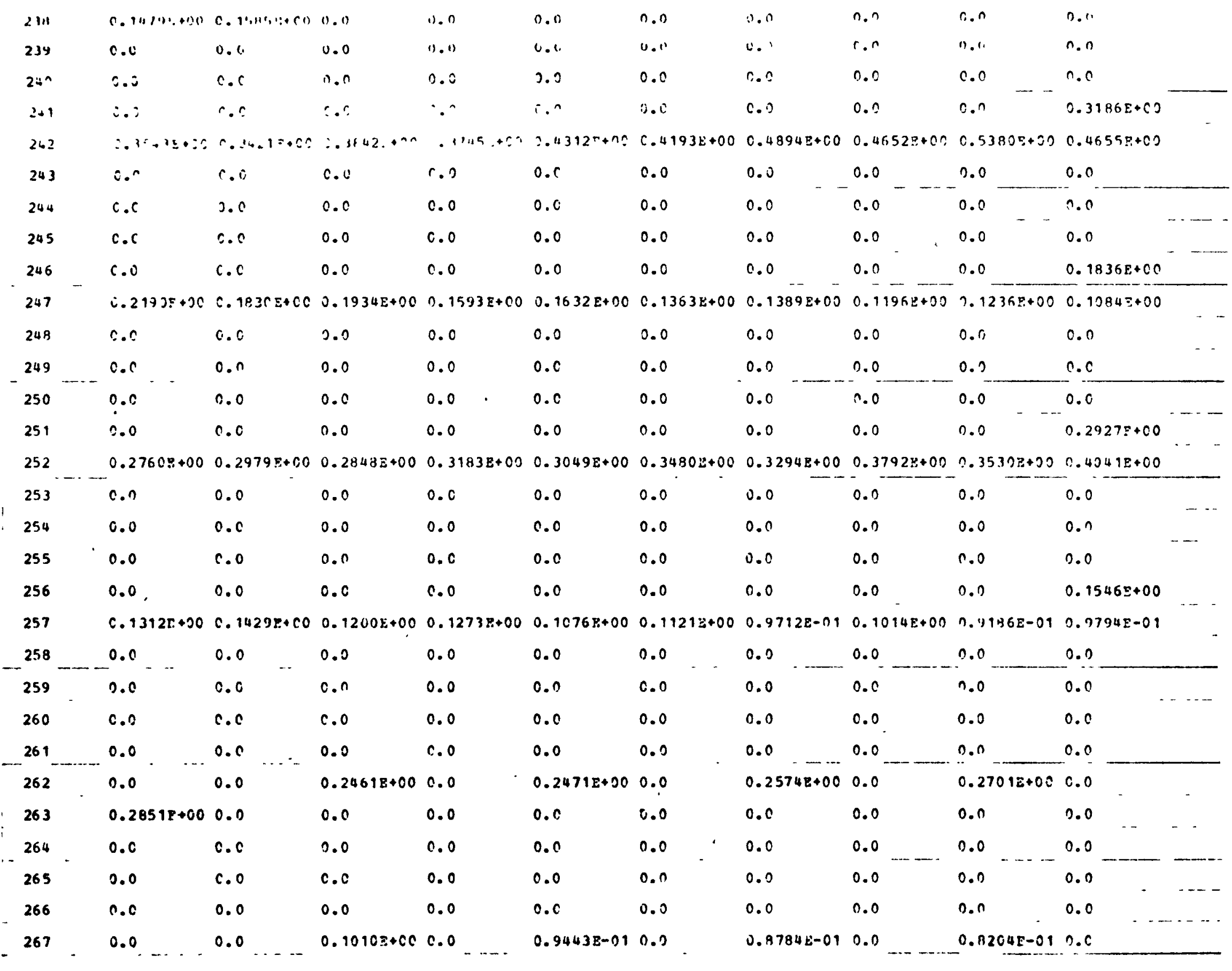




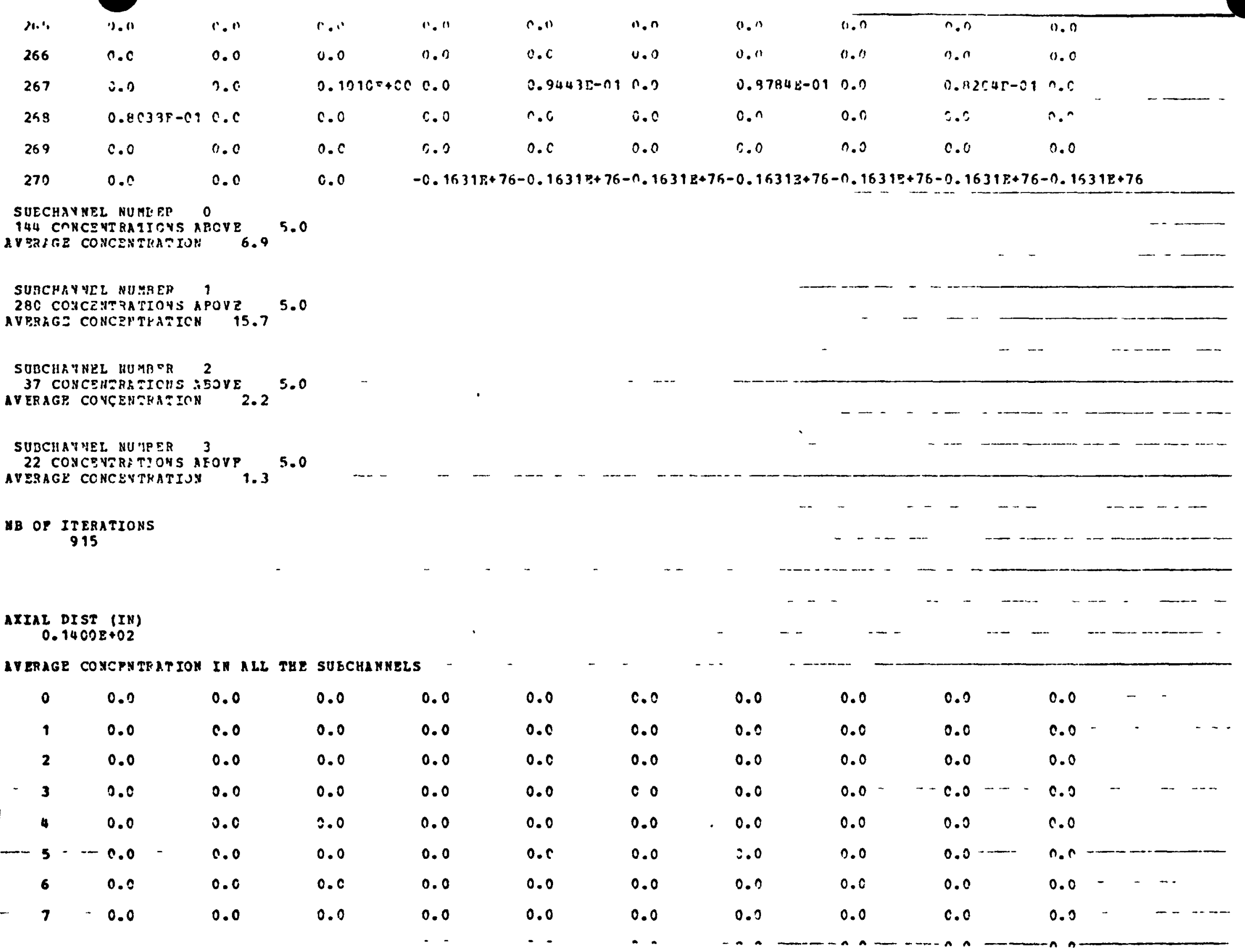


APPENDIX B

LISTING OF THE VERSION OF ENERGY I USED FOR THE

CALCULATION OF HEATED PIN EXPERIMENTS IN A GRIDDED BUNDLE 


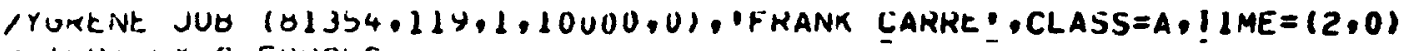

ISIEPI EXEC FURCLG

C.SYSIN DO *

VERSIUN UF ENERGY 1

FUK HLATEU PIN EXTERIMENT

IN A GRIUDEU BUNULE

CUMMUN MAIN PRUG.

COMMUN RP(SU), TI (SU), RHJFF (SO), KHUGG(SU), HAt $(S U)$, HHG (SU),

IUUR ( $2 U$ ), KKF (SU), SSIGMA (SU)

CUMMUIN NCHANL, REF NUUAIA, TSAI, HVSAI, MHSAT, RHVSAT, VISSAT, ISAT,

ICUNSAT, SIUSAI, IAVUL, CPAVJ, CUNAVG, RHAVU,NL, NZ,NS,N4, VELI, VELZ, VELJ

CUMPUN ENIMAL (

CUMMUN UKOU, UWIRE . LE AUUU, GAR, HUU, NURI VU, AUNI T, AWALL, ACORN, WPUNIT,

I WHWALL, WRCUKN, UEUNIT, DEWALL, UE CURN, HPUNII, APWALL, HPCURN

COMMUN FLUSOOO)

COMMUN LC'(SUU,3), MRUU(SOU,S)

LUMAUN EIAI,EIAC,EIAS,ETA4

DIMKNDIUN AXIAL $(\supset 0)$,FAX(SU)

OIMENSIUN H(SUO), WP $(S U U)$, UE $(S O U)$, HRERIM(SUO)

UIMENSIUIV ASTAK(SOO),UTOKI Y(SOO) ,USIARISUOI, HSTARISUO), UHUZST 1500

(1)

UIMENSION SUMM(SOU), RI (500), GOAKK(SOU), HINN(DOU)

DIMEINSION LPRINT (O)

PKUGKAM ENERGY PUK CALCULAIING IEMP. OF FLUIU IN WIRE WHAP.RODS

REAL LEAUUU.LENUIH,KKF

REAL MUS!

KEAU(b, I) NUUATA

1 PURMATIIS)

NUMBER UH DATA DESCHIBINS I t THEKMOUYNAMIC

PRPPERIIES OF THE. CUOLANI

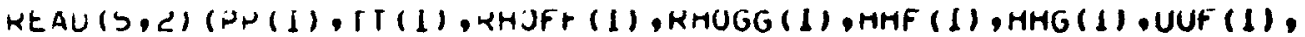

(KKr (1), SSIGNA $(1), 1=1$, NUUATÄ)

C FURIAT (Ytd.4)

SAIURAIIUN FKESSUKE (NSIA)

SAIUKAIIUN TEMHERATUKE (F)

UEIVSITY UF THE LIUUIO AT SAIURAIIUIV (LO/FI/FT/FT)

UENSIIY UR THE VAPUR AT SAIJKATIUN ILU/RI/FT/FT)

EIVIMALFY UF THE LIUUIU AI jaIUKAIIUN (BIU/LG)

ENIGALFY OF IHE VARUK at SAIUKAIIUN (BIUILB)

RLAU(b-1) NURUNC

NUMUEK OH CASES TAVING DIFEERENI GEOMEIKILAL CMARACIERISIICS

UO 100 LLLLL $=1$. NURUNE

REAU(b, I) VUUFAX

NUMOEK OF PUINTS UESLRIGING THE NORMALILEU FLUX SHAPE 
REAU $(5,4)(A X I A L(1), F A X(1), 1=1$, NUUF $A X)$.

- FUKMAI (HR IU.J)

UESCKIHTIUN JH ITE NURMALILEU FLUX SHAPE NUKMALILEU AXIAL UISIAIVC

- NUKMALILEO FluX

KeAU(b, I) VURUU

NUMUER UT IUEL PINS

ME AL Y.WWN LEAUUU,UWIRE, jaR

$\rightarrow$ HUMAI $(4+11.4)$

1 .

HELILAL NIILH UVER RUL DIAMEIER

UIAMETEK UF IHE WIKE (IN.)

UAR (IN.)

REAL IJ.URUU,LENGTH,POO

1) PURMAT (3R 11.4$)$

- TUU UIAIETER (IIN.)
HeATLU LENGTH (IV.)

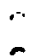

AXIAL FIICA UVEK KOU UIAMEIEK

$\angle=($ NUKUU-1) $/ 3$.

NURING SUKR $(\angle)$

iVI MN=6*INUKIIVO

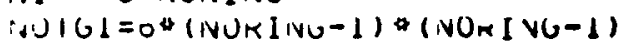

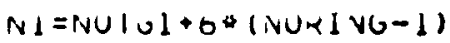

$\therefore . C=N I+N I .4 R$

in $J=N C+N I M R$

$N 4=N J+O$

NCMAINL $=! N 4$

. LMSU $=$ CHIVURI VU-I

I VRUI LALCULATIJUS BEGIN

$C: L L$ NUMS

CJLL UEUIA

nEAJ $(2,1)$ NUMJVI

f VIMELK UR LASE HAVIING T te same GEUMEIRY

UU 100 LLLL $=1 \cdot N U \checkmark U N 1$

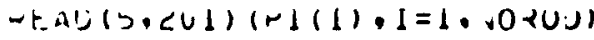

EUL F(jRAMIOH 10.4$)$

a

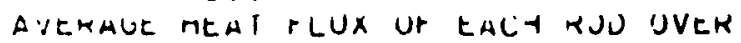

AVEKAUE mEAT PLUX UF THE NIJLE GUNULE (UUAK)

KE LU ICOUSAKOAIVORKER MUSAR PLUWW

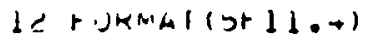

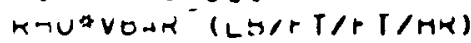

E IIHALRY AI ITE INLEI (NIU/LO)

RettKL..CE NKESDUKE (Nola)

AVEHAGE HEAI rLUX UF IHE WTJLE BUAULE (OIU/FI/FI/TA)

CUULAIVI rLUA KATE (LO/GK)

$I \sim \cup 1=0$ 
REAU(J.1) NURUNS

NUMBER OF RUVS FUK THE SAME URERAIING CONUITIONS

EUI UIFFEKEINI ROSLUN ANJ CI

DO LOU LLL $=1$, Vuruivs

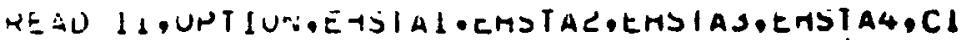

ONIUUV $F$ LXES IT AMIRLITUJE JF ITE AXIAL INCKEMENT

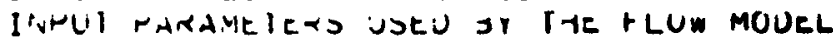

Li) 81 (y $1=1.0$

GIY ZPRINI I I) =0.

C

Lit $A O(2.1)$ intat.VT

NUMBEK OH AAIAL PUSIIIUNS NHERE IME KESUL!S

HAVE TU BE FNI.NTEU UUT

REAO (, 11$)(\angle P Q I N T(1), 1=1, N R K I N I)$

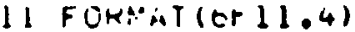

AXIAL RUSITIUVJ WHEKE THE KESULIS MAVE

TO ge pKIINIEU VUT (IN.)

$R \equiv A U(b, 1) \quad$ IURID

IERIUEU IF VU URIUS ARE PRESENI

IGKIU $=1$ IF UMIUS ARE FRESENI

$\therefore$ UルK $=1$.

Z.;iा $U=1$.

If (IUরIU.LI.1) نU IU YUI

c

$\therefore=+U 1=010)$ tSTCT

(U.LI \& IUMILI

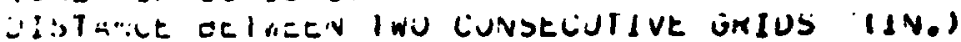

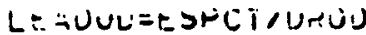

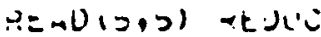

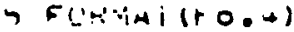

(oviti it lueloj=l)

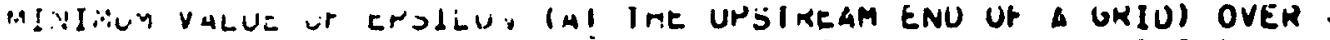

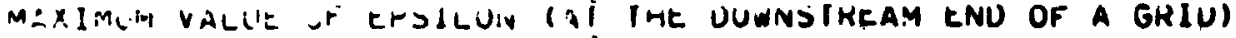

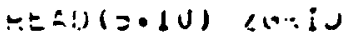

OISTALCE UH Irig r.IHSI ORIU PKUM IHE I.VLE! (IN.)

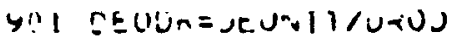

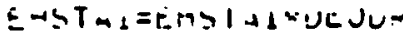

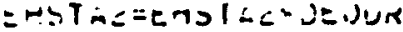

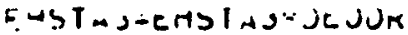

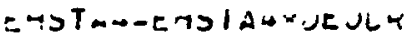

$\because \because$ ive

in) $1 ; 1=1$. ve

$\Delta(1)=-\Delta \vee 11$

D(I) =aru.VIT

$1 i=(1)=$ UeUVli 
I. HPCRDa. (I) =-ARUNII

$-i<1=\backslash v+1$

LU $\angle 1 \quad 1=N \times 1, N 3,1$

$A(1)=A \cdots A L L$

WP(I) = PPWALL

UE $(1)=U E M A L L$

CI $H D E R D M(j)=$ THMALL

$N K<=i v s+1$

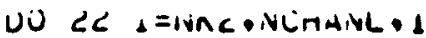

$Q(1)=$ nLUURV

$n d(I)=m p$ iund

$U E(I)=$ Lecluriv

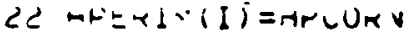

\& TUT $\triangle L=U .0$

MUIOTL $=0.0$

(II) $251=1 \cdot V L+A N L$

ATUTAL $=4(I)+\triangle T U T A L$

C) HPISIL

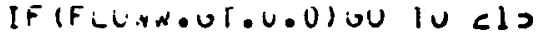

$(\because) T U=11$

CIS $G=A_{1}=($ L UWW/AIUTAL) $* 14+. U$

Cl/ (10 I/U $1=1$, N:C

1'l) F:U $(1)=(4(1) / 14+. U)$ GBAR/VEL 1

LC $1 /=1=N \cdot 1, N 3,1$

17n FLU $(1)=(.+(1), 1+\rightarrow \cdot U) \times U B d R / V=L C$

D) 1 le $I=N \cap C, N C H A I V L \cdot 1$

1/S $F L(1 / 1)=(m(1) / 14+0 U)$ \&usar/VELS

?HAVU=כOU

C

CHLCULATE MAIAL SIER SILE

ZSIMRT =LEVUIM/UKUU

ZSIM $=U .1$

ZIr:ifiv $=\langle k R \backslash$ LI $(1)$

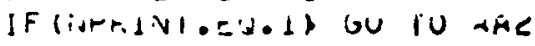

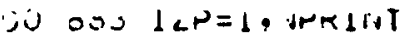

$i \angle R=\$ \angle N-1$

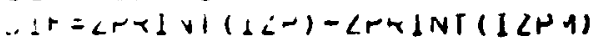

if (l.dr.úl.LIFindiv) uU tu 583

itr $+1 *=U_{1} r$

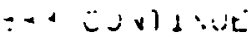

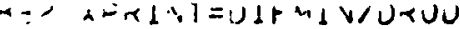

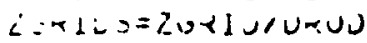

$\angle+t 1 .+1=-\angle U<1 u s$

$c T-1>1=2141 / J \cdots J]$

= T.C $=1=E \mid A C / U R U J$

tiajsi=einj/uruu

$\vec{E} T+4=1=$ LIA+/URU

$\therefore \rightarrow \sin =$ Uar/JaLU

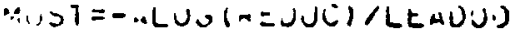

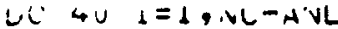

4" $=S \mid \mu R(1)=A(1) /($ URUUNURUU)

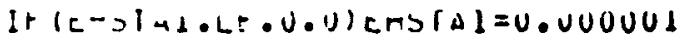

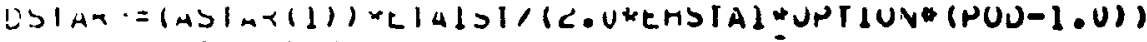

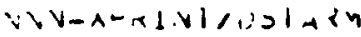

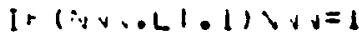

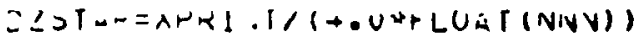

C

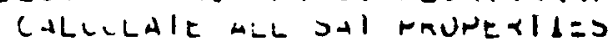

$1-. .4 \mid=1$

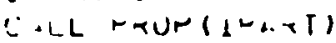

$c$

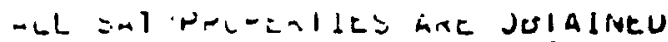




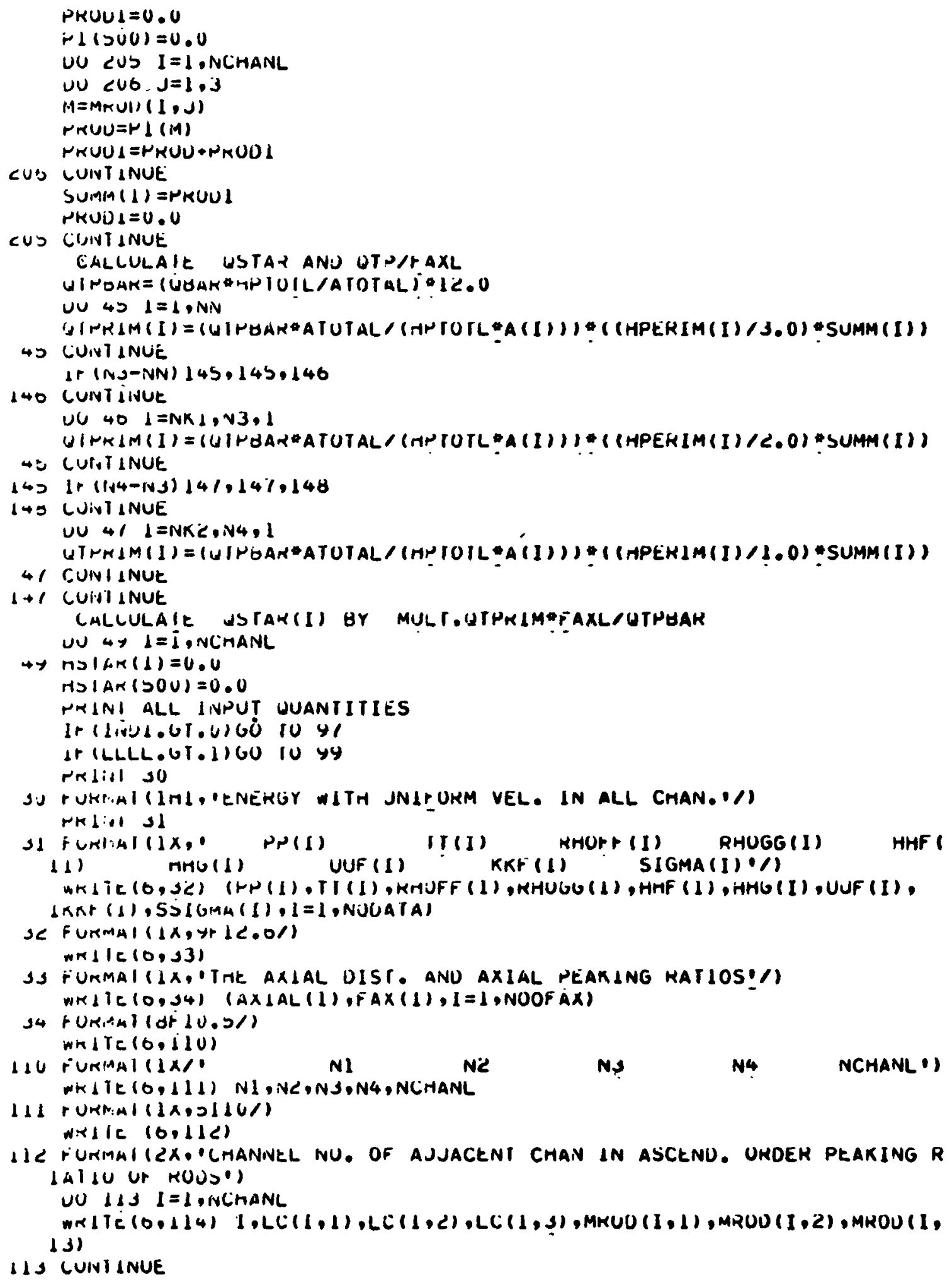


114 FURMAI $11 x, 1110,010,4 /$.

AKITE $(0,115)$

II r UMMAIIIHU, CENIRUIU SHACE dEIWEEN AUJ. IYPES OF CHANNEL'I NOIIE $(0, \$ 1 O)$ EIAI, TIAC,ETA3,EIA4

1 ID UKMAI $(1 X, 4 E 11.4 /)$ WHITE $(0,1) / 1$

II FURMAI(IA, W WWW SEAJUIA UIA UF WIRE GAPI) WRIE(O,11\&) WNALLAUOU, JWIRE,GAP

110 PUMMAT $(1 \times, 4 E 11.4 /)$ NQ⿻

ILU PURMAI(IX,P KUU UIA IIN) LENGIA (IIN) N/O NO UF RINGS I.)

WRITE $(0,121)$ URUU,LENG TH,PUS,NOKING

161 FURMAT $(1 \times, 3(F, 3,3,0 X), 15 /)$ relinI $1<1$

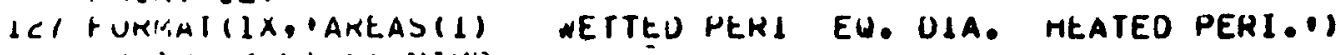
U'J 1 CO $K=N 1$, N4,NIMP $1=x+1$

1 CO NKITE $(0,129)$ A (I),WHII), JE (1), HPEKIM(1)

lCs rUKMAI $(1 x, 4611.4)$ NRITE $(0,1 J U)$ 
EMSTBC=EHSTAC\&EXH(-1GHIO\&LEAUUU MUST)

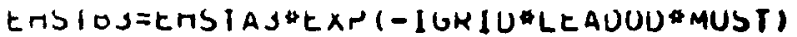

ERSIO4=EHSIA4*EXRI-IGKIO*LEAUUU*MUST)

EMSIIN =EMSIOI

$1 \angle H=1$

XHRINI $=\angle H K I N I(1) /$ URUO

EIVIEKING MALN LUOH

LALL AXIAL PEAXING FACTUNR

CO $\angle J A R=U \angle S \mid A K / \angle .0+\angle S T A R$

$\angle S A K=\angle U A K U U K J U / L E N G T H$

CMLL CURVE (F AXL, LOAK,FAX, AXIAL, NOOFAX, IEKKUE, I)

$A L+S \mid A=1<$. UQLUNAVG/ (OBAK \&CHAVG URUÜ)

IGRIUU $=\angle \$ 1 G K I D-\angle G K I U S /(Z S I A Y+0.000 !)$

Ir (IUKIUUं) OOJ, $803, d 84$

\&O4 Ir ( LKLLAI-LEAUOU) $887,887,886$

ONO $\angle K L L A I=\angle K L L A I-L E A U U U$

OJI CASIOL=EHSIAI*EXH (-MUST \& LRELAT)

EnSIDC=ERSIAC*EXR (-MUST \#RELAT)

EMSIOJ=E.HSIAS*EXN(-MUST * LRELAT)

EMSTO4=EHS IA $4 * E X P(-M U S T *$ LRELAT)

OOJ CUNIINUE

UU $10 \quad 1=1$, NCHAVL

IO USIAXं $(1)=U T P K I M(1)$ \&AXL/JTPJAK

UU dU $1=1, N O T G 1$

$M M 1=L(1,1)$

$M M C=L(1,2)$

$M M S=L(11,3)$

MSIAR $(\supset O U)=M S T A R(I)$

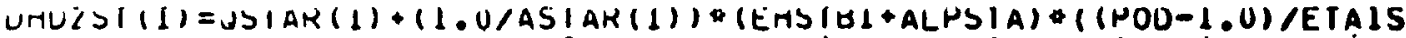

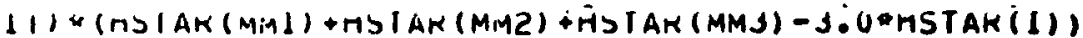

$U M U \angle S \mid I I)=U A U \angle S I(I) \otimes V E L I$

$=0$ CUNTINUE

Jus $n d n=1,6$

INUUM $=$ NUTUL $+(K-1) * N C H S O$

UU $I \supset G K K=\angle$, NCHSU,L

$1=N \cup U M+K K$

$\operatorname{IMI} 1=L(1,1,1)$

$M M C=L C(I, C)$

(MnS $=L(1, J)$

MSIAK(SOU) $=$ AST TAR (I)

URULSI I ) =USIAR $(1)+(1 . U / A S I A K(I)) *(E H S I B I+A L P S T A) *(1$ OOD- 1.0$) / E T A I S$

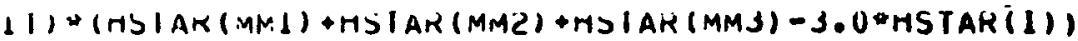

URU $\angle S I(1)=U M U \angle S T(1) \otimes V E L I$

L SU CUNI LIVUE

UU $1 \supset 1 K K=1, N C H S O, 2$

$1=N U \cup M+K K$

$M, M I=L C(I, 1)$

$A \cdot C=L C(1,2)$

$M \cdot A S=L C(1,3)$

MS $\mid A K(\supset O U)=H S I A K(1)$

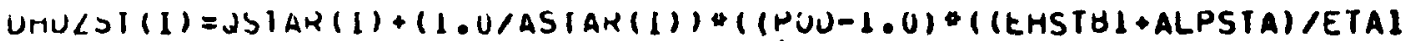

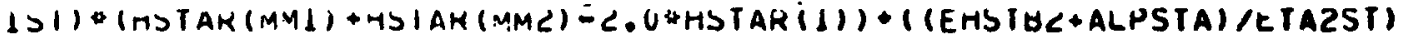

$2 *(H S I M K(M M S)-H S \mid A R(I))(H U U-1.0))$

URU $\angle S I(I)=U R U \angle S T(I)$ QVELI

IDI CUNTINUE

Cl CUNIINUE

UU ob $I=N \times I, N 3, I$

$M M I=L C(I, 1)$

$M M C=L C(1,2)$ 


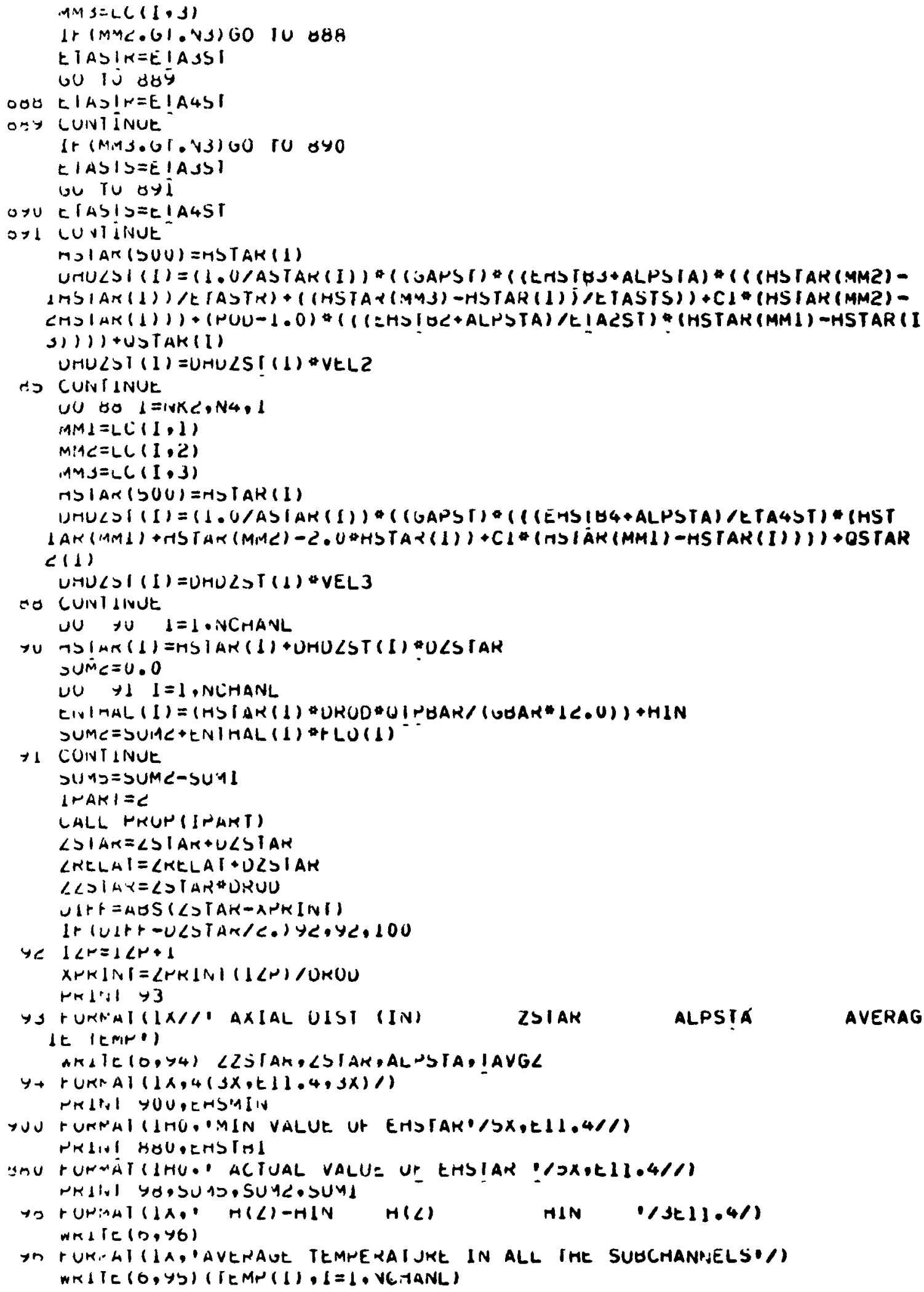


YD TUKMAI $(1 K, 16(+Y, 1,3 X) / 1$

IUU I+ ILLSIAK.LE. LPRINT (NPKIVT) 601026

loU LUNIINUE

Siur

tive

SUORUU! live NUMB

LUIFI:UN RP(SU), TI (SU), RHJFr (SO), KHUGG(SO), HHF $(50)$, HHG (5U),

luUt (bU), Rar $(5 U), 5 S 1 G M A(\zeta U)$

LUMNUI IVLMA.VL, RYET, NUUAIA, ASAI, HVSAI, RHSAT, KHVSAT, VISSAT, ISAT,

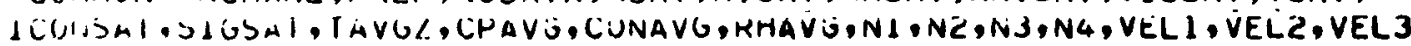

CUMAMUV ENITAL ( $20 U$ ), TEMN (

LUMRIUN URUU, UMIRE, LEAUUD, GAR, PUU, NURING, AUNIT, AWALL, ACORN, WPUNIT.

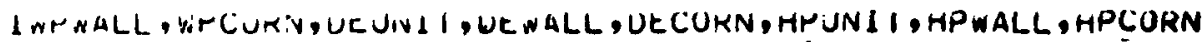

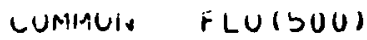

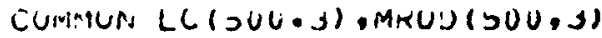

CUAAMUN $E I A 1, E I A C, E T A J, E T A 4$

INUIRU=U\#TURINU\#IYUKING

NVUIUI=D*(INURIING-1)*(NOKIVG-I)

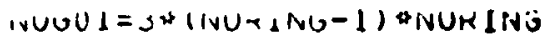

LSICM=IUIRU+UH (NUKING+1)

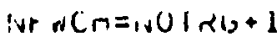

NLnCHELSICH-O

I,U $1=1$, inUting

$\angle=(1-1) / 0$.

$h=>\sin 1(L)+1.0001$

iNUIRU $=0$ Hiviniv

.hUIRT=0, $(i n-7)$ in $(n-1)$

IUI:C $=0 *(i n-C)=(i N-C)$

iNUIUI $=3$ Hid $(N-1)$

inUil $I C=j *(i n-i) *(n-c)$

$1 . \lambda=(1-v U \mid k 1-1) /\left(c^{2}+N-1\right)+0.0001$

$1 \alpha=I-1,1 k 1-1 \alpha *(\angle 4 N-1)+0.0001$

$1 \gamma=1 \cdot 0-1 /: v$

Ir $(1-i v u i r 1-1)$ y $1, y 02,901$

11) $1+(1.5, \cdot 101 \times 0) \mathrm{GU}$ lo yog

$J=1 \mathrm{a} / \mathrm{C}$

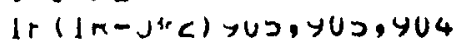

Y.Jy $1 /=1.0001 /$ (NUIRU-1)

L. $(1,1)=I V U \mid K C+I U *(C *, V-s)+I K-1$

LC $(1, C)=1-1$

$L C(1, s)=1+1$

MKUU $d, j)=1+$, NUT $1<+\{U *(i Y-1)+1 K / 2$

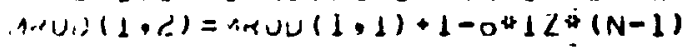

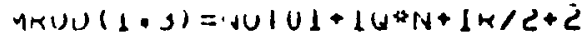

G) IU 1

$Y 04 L(1,1)=1-1$

$\operatorname{LC}(1,2)=1+1$

mipui) $(1,1)=1 Y+N U 11<+1 U *\left(n_{i}-1\right)+(I K+1) / 2$

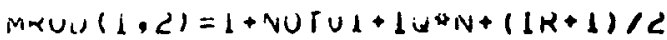

minu $(1,3)=$ Arun $(1,<)+1$

yod It linecueirurding) uU tu yug

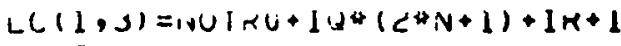

(o) 101

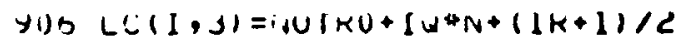

i, IU 1

yu.s $L((1,1)=1, J) \ln 1+1$

$L(1, C)=\operatorname{lv} \mid \times U-1$ 
muUU $(1,1)=1+1 r+1 N U 112$

AreUU $(1,2)=c+$ VUIU 1

Aruvil, 3$)=5+3 * 14 *(n+1)$

u. IU Yós

YJCLC(I, LI)=NUTRI+C

$L(1, \angle)=V U \mid<U$

inkui $(1,1)=1+1 t+i n j \mid l c$

PRUU $(1,2)=c+$ VUIU 1

ireu $(1,3)=$ vruu $(I, C)+1$

UU IU YUO

LURII INUJE

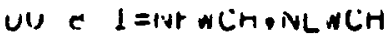

innuls $(1,3)=$ sUu

$1 \angle=1.0001 /(L S / C H-b-1)$

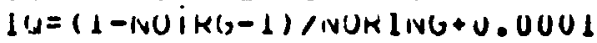

$1 k=1-1 N U 1 K G-12+40 R I N G+0.0001$

$L(1,1)=$ LVU $\mid U 1+1] *(\angle \otimes N R I V G-1)+C^{4} \mid K-1$

MRUU $(1,1)=1+$ NVUGU $1+1$ W $\$ N U R I N G+I K$

.MKUU $(1, C)=$ MKUU $(1,1)+1-6 * 1<* V U K I N G$

It $\left(1 K_{0}=U \cdot 1\right) \cup U$ IU YII

It (IK.EU.NUKIING)GU IO

L( $(1, C)=1-1$

LC $(1 \cdot 3)=1+1$

uU To is

$>1<\llcorner(1, C)=1-1$

$L(1, J)=(1-1<) *(L)(C H+1 U-4)+1 \angle *(1+1)$

uU iv 0

$+11 L C(1, C)=L S \mid C H+I U-b$

$L(1,3)=1+1$

\& Cuidlinue

U.J y $K=1,0$

$1=I V L N C H+K$

$1 v=R-1$

$L C(1, J)=$ JUU

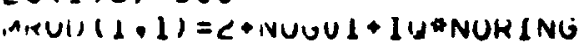

$\operatorname{lir} u(1, \cdot 2)=s U 0$

'nRUU $(1, J)=$ sUU

1+ $(1,1)>13,+14,+13$

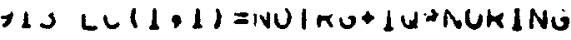

$\operatorname{Li}(1, \angle)=\operatorname{LC}(1,1)+1$

un iv $y$

$\rightarrow 1+L i(1,1)=1-i$

LC $(1, C)=i n \mid R+1$

- Cusid Inut

kcluniv

cind

sUsmuUlilit veUn

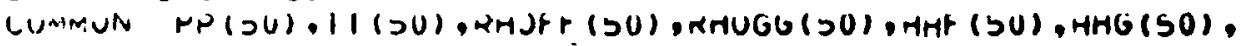

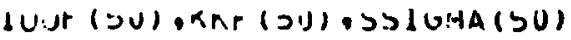

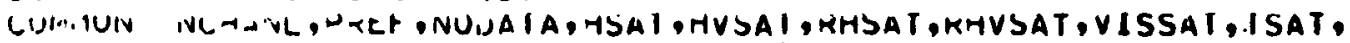

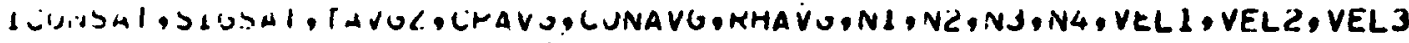

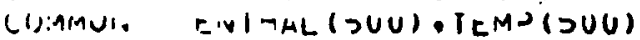

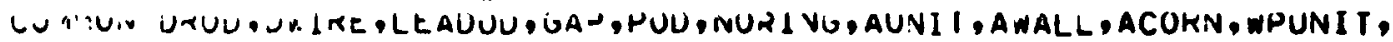

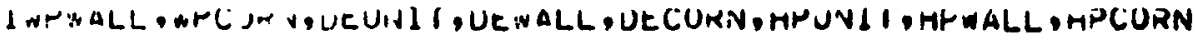

luinivid tlulsuU)

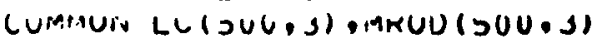

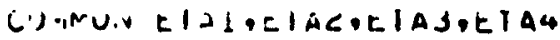

sUERUUIl.e LALCULAIES GEJMEIKY IOR 3 IYPES UF CHANNELS

KEML LEMUJU 
$111=$ ine

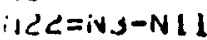

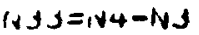

DHACE $=U A R$

iJR=UKUU

U.V $=U$ U I KE

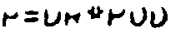

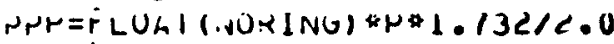

LI LAI $=\angle \cdot U *(H P P+U Q / C \cdot U+G A D)$

UT $A L E=J F L A I / 1.13 L$

$M 1=3.141$ DY

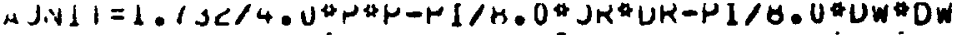

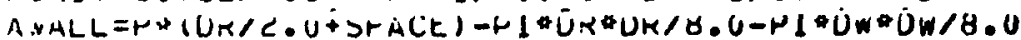

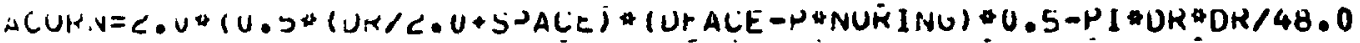

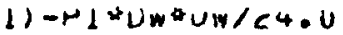

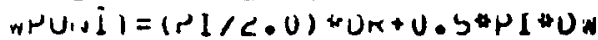

HTHLL $=4+W H U R T T$

WHCUKIN $=(1-1 / 0.0) * 3 K+(H I / 0.0) \geqslant U N+2.0 \geqslant(U F A C E-P \# N U K I N G) \geqslant 0.5$

UEUIVI $1=4$. U*AUNII/WHUNIT

JE MALI. $=\leadsto$.UWAWALL/WPWALL

UELUR:V $=4 \cdot U: \Delta C U R N / W P C U K N$

$\operatorname{mrUIV} 11=(1 / \mathrm{L} / \mathrm{L}, U) * U K$

MRWALL $=(r I / \angle \cdot U) * U R$

MrLURIV $=(1 / 1 / 0.0)$ \&

L. $1=V 11$ \#AUN $11+N C L \$ A W A L L+V 3 J \# A C U R N$

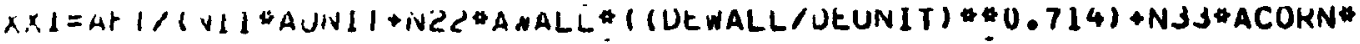

I (Ut (UU,UEUVI) $\$ 0 .(14))$

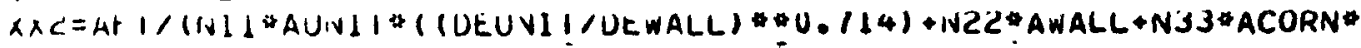

1 ( (UELURI/UENALL) \& $U .(14)$

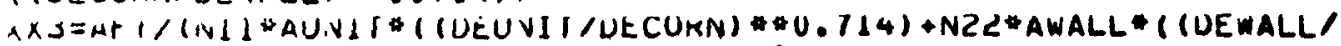

LUE $(U R T) * U \cdot(14)+N 3 j * A C U F V)$

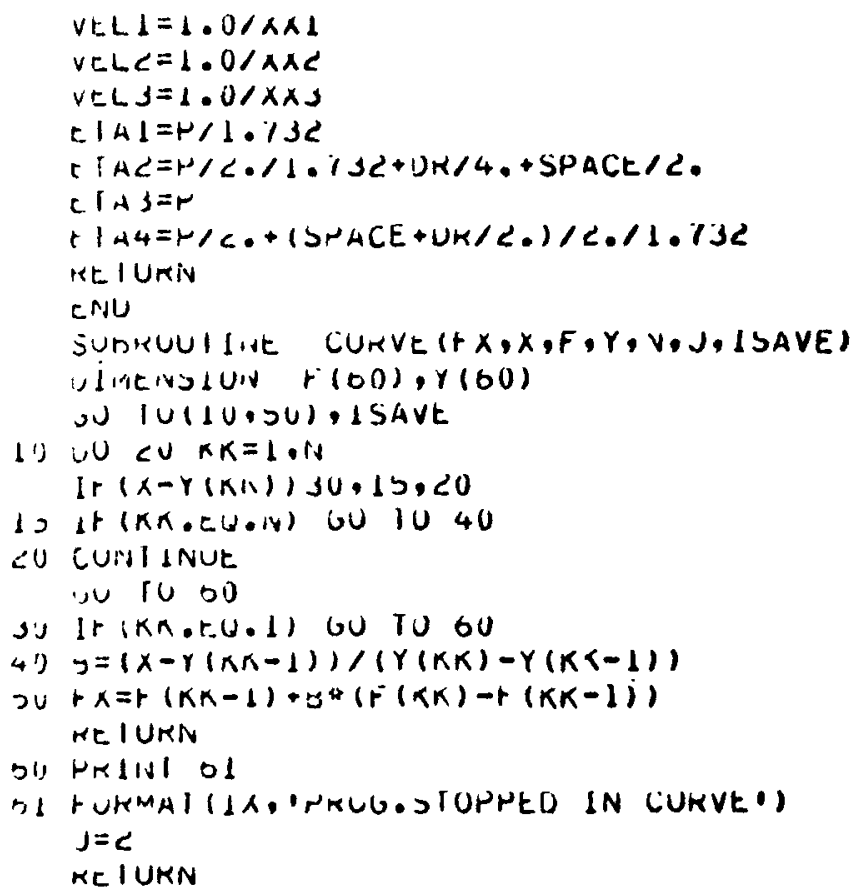


ENU

SUORUUT IIVE RhUP(IPAKT)

CUMMLN RP(SU), II (SU), KMJFF $(S U)$, KHUGG $(50)$, HHF $(S U), H H G(S O)$.

liJUr (SU) , RKK ( OU) , SDIGMA (SO)

CUAMUN INCHANL, RAL , NUIJATA, HSAT, HVSAI, RHSAT, RHVSAT , ISSAT, ISAT,

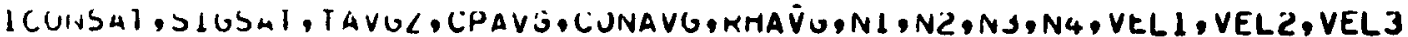

COIAIAUTN ENTHAL(SUU), ILMP(DUU)

CUMMUIV UKOU,UN IRE, LEAUUO, GAN, RUU, NURING, AUNI I, AWALL, ACORN, WPUNIT,

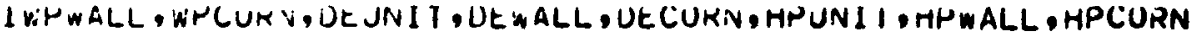

C'JMMUNA FLO(SOO)

CUMAUT. LC(DUU, 3), MKUO)(SOO, J)

CUMMUIV $t$ IAI,ETAC, TTAJ, ETA4

REAL KKr

UU IU (IU,IUU), INAKT

C

HAKI I CALCJUL, UP SATURATEU PKURERTIES

1.) U'J $111=1$, NUUATA

If (Pret ILI. HP(I)) 60 TJ 20

il CuIrT livUE

GU TU 300

cu If $(1.61 .1)$ GU TU 40

gu 10 SOU

$\rightarrow(1)$ VALUE $=($ HKL $-4 R(1-1)) /($ HP $(I)-H P(I-1))$

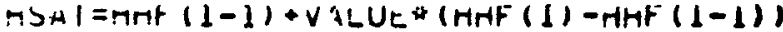

AVSAI = MAU $(1-1)+V A L U E *(M H J(1)-H H G(I-1))$

RHSWI = RMUPF $(1-1)+\operatorname{VALUE}($ RMUPF $(1)-$ KHOF $F(1-1))$

RMVSN $1=R H U G O(i-1)+V A L U E+(K M J G G(1)-K H U G G(1-1))$

$\checkmark I S S A 1=\operatorname{UUF}(1-1)+V A L U E *(U J F(1)-U U P(I-1))$

$\mid S A\}=\mid(1-1)+V A L U E *(1 T(1)-I T(1-1)\}$

CU.VSA $)=K K+(1-1)+V A L U E *(K<+(1)-K K r(1-1))$

SIUSAI = SSIGMA $(I-1)$ +VALUE (SSIGMA $(I)$ - SSIGMA $(I-1)$ )

REIURN

C RAKIL LALCULATE PRUREKIIES AT LUCAL CUNUIT.

li!) CINITINUE

UI) 1 \&U $I=1$, IVCHAIVL

|L:MH $11|=|$ SAT

If (E.YIRALI). (1) .HSATIGU TO 300

LALL CURVE (IEMH $(1)$, ENIHAL $(1)$, TT, HHF, NOUAIA, IERRUR, I)

IIU LUId divUt $s \cup 1,11=0.0$

UU $\perp 1 \perp 1=1$, VLHANL

SUIAM $1=$ SUMM $1+f L U(1)$ IEMP (I)/RHAVG

111 LUIVI livUt

SUMinc $=0 \cdot 0$

WU $11<1=1$, NCMANL

SUIAIC = SUMMC+ LU $(1) /$ KHAVS

lle CUNA LIVUE

TAVISL = SUMMI/SUMML

C

HUW LALCULCAIE CUIVUUCIIVIIY CN UENSITY

CFAVU $=U .3440<1-(1.0333 Y E-b) * 14 V G \angle+(2.681 J 1 E-8) *$ TAVGL TAVGZ

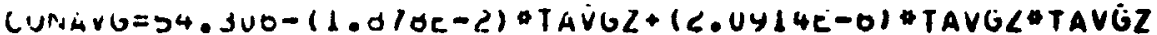

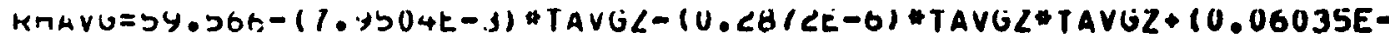

$(Y I * I A V U L \otimes J$

KE IUKN

SOU PKINI 501

JUL FUKMAI (1A, S IUPPEU IN PKJPO)

STUR

ENU 